\title{
Empirical studies on institutions, policies and economic development
}

\author{
Citation for published version (APA):
}

Farla, K. (2013). Empirical studies on institutions, policies and economic development. [Doctoral Thesis, Maastricht University]. Boekenplan. https://doi.org/10.26481/dis.20131216kf

Document status and date:

Published: 01/01/2013

DOI:

$10.26481 /$ dis.20131216kf

Document Version:

Publisher's PDF, also known as Version of record

\section{Please check the document version of this publication:}

- A submitted manuscript is the version of the article upon submission and before peer-review. There can be important differences between the submitted version and the official published version of record.

People interested in the research are advised to contact the author for the final version of the publication, or visit the DOI to the publisher's website.

- The final author version and the galley proof are versions of the publication after peer review.

- The final published version features the final layout of the paper including the volume, issue and page numbers.

Link to publication

\footnotetext{
General rights rights.

- You may freely distribute the URL identifying the publication in the public portal. please follow below link for the End User Agreement:

www.umlib.nl/taverne-license

Take down policy

If you believe that this document breaches copyright please contact us at:

repository@maastrichtuniversity.nl

providing details and we will investigate your claim.
}

Copyright and moral rights for the publications made accessible in the public portal are retained by the authors and/or other copyright owners and it is a condition of accessing publications that users recognise and abide by the legal requirements associated with these

- Users may download and print one copy of any publication from the public portal for the purpose of private study or research.

- You may not further distribute the material or use it for any profit-making activity or commercial gain

If the publication is distributed under the terms of Article $25 \mathrm{fa}$ of the Dutch Copyright Act, indicated by the "Taverne" license above, 
Empirical Studies on Institutions, Policies And ECONOMIC DEVELOPMENT

Kristine Farla 
(c) 2013 Kristine Farla

All rights reserved. No part of this publication may be reproduced, stored in a retrieval system, or transmitted in any form, or by any means, electronic, mechanical, photocopying, recording or otherwise, without the prior permission in writing, from the author.

ISBN 9789086663187

Publisher: Boekenplan, Maastricht 


\title{
Empirical Studies on Institutions, Policies and Economic Development
}

\author{
DiSSERTATION
}

to obtain the degree of Doctor at Maastricht University, on the authority of Rector Magnificus, Prof. dr. L.L.G. Soete in accordance with the decision of the Board of Deans, to be defended in public on Monday, 16 December 2013, at 10:00 hours

Kristine Farla 


\section{Supervisor:}

Prof. dr. B. Verspagen

\section{Co-supervisor:}

Dr. D. de Crombrugghe

\section{Asessement Committee:}

Prof. dr. A. Szirmai (Chair)

Prof. dr. M. Godinho (University of Lisbon)

Dr. T. Roca (Agence Française de Développement, Paris)

Prof. dr. T. van Veen (Maastricht University and Nyenrode Business Universiteit)

Dr. T. Ziesemer

Financial support for this dissertation has been provided by the Agence Française de Développement. 


\section{Acknowledgements}

A great team with special forces gave me the strength and perseverance needed to complete a PhD thesis. First and foremost, I thank my supervisors Bart Verspagen and Denis de Crombrugghe for their support. I have fully appreciated your patience and the freedom you have given me during the writing of this thesis. Denis de Crombrugghe, if it were not for your attention to detail I would have been bitten by many more bugs. Bart Verspagen, I could not have asked for a more brilliant and insightful supervisor.

This study benefits from collaboration with a Maastricht team of researchers interested in institutions and long-run growth. Along with Bart Verspagen and Denis de Crombrugghe, I thank Biniam Bedasso, Samyukta Bhupatiraju, Richard Bluhm, Luciana Cingolani, Chris de Neubourg, Kaj Thomsson, and Adam Szirmai. I wish to thank all of the above mentioned for wonderful discussions and for their critical opinions. In particular, I thank Chris de Neubourg for his generous support during the initial phases of my research project. Also, Adam Szirmai, thank you for your many suggestions and support for initiatives. Samyukta Bhupatiraju, it has been great fun discussing data cleaning and econometrics with you.

I am grateful for the guidance and financial assistance from the French Ministry and French Development Agency. I would like to thank Jacques Ould Aoudia, Virginie Diaz Pedregal, Anne-Sophie Dufernez, Nicolas Meisel, Robert Peccoud, Thomas Roca, and Veronique Sauvat for their contributions. In particular, Jacques Ould Aoudia for your kindness, Nicolas Meisel for your whit, and Thomas Roca for your persistence. Moreover, Chapter three benefits from the creative insight of Nicolas Meisel and especially Chapters four and five benefit from suggestions by Thomas Roca.

Dear Manuel Mira Godinho, Tom van Veen and Thomas Ziesemer, I am honored that you have taken the time and energy to scrutinize and evaluate this dissertation. Your comments have helped me revise but also remain valuable for the future development of my research.

I thank Luc Soete for welcoming me into the world of UNU-MERIT. I thank the Development Policy Centre of the Crawford School of Economics at Australia National University and Stephen Howes for hosting me as a research fellow for several months. Additionally, I thank Jesus Felipe and Francesca Guadagno for their collaboration in a related project. I extend my gratitude to Eveline in de Braek, Mieke Drossaert, Eric Engelen, Franziska Gassmann, Mindel van de Laar, Ad Notten, Herman Pijpers, Martin Rhem, Susan Roggen, and the other past and present staff of UNU-MERIT/MGSoG for reaching out and helping me coordinate my many activities.

A significant part of this thesis was written in trains, airplanes, hallways, and various homes. Nevertheless, I also had the luxury of sharing office space with numerous colleagues and friends: i.e. Ilire Agimi, Seda Arican, Bianca Buligescu, 
Fiona Dawns, Manoj Dora, Andrea Franco, Florian Henning, Katie Kuschminder, Gintare Mazeikaite, Undarga Sandagsuren, Esther Schüring, Oksana Slobozhan, Allan Tirivayi, and Nevena Zhelyakova. Moreover, I thank also thank Aziz Atamanov, Théophile Azomahou, Sachin Badkas, Danny Beckers, Özge Bilgili, Guney Celbis, Wilma Coenegrachts, Robin Cowan, Sonja Fransen, Bart Golsteyn, Howard Hudson, Hugo Hollanders, Michiko Iizuka, Jojo Jacob, Lutz Krebs, Mahmut Kobal, Alejandro Lavopa, François Lafond, Hibret Maemir, Dorcas Mbuvi, Pierre Mohnen, Paula Nagler, Zina Nimeh, Daniel Opolot, Jennifer Taborda, Giorgio Triulzi, Takevik Poghosyan, Iman Rajabzadeh, Shuan Sadre Ghazi, Melissa Siegel, Sonila Tomini, and others for their welcome distraction in and around the office. Some friends supported me whilst outside the Maastricht hub: Denisa Sologon and Victor Cebotari in Luxembourg and Jinjin Lee and Jasmin Kienzel in the ACT.

Some special friends have surprised me many times with their humour, generosity and kindness. I am appreciative of the friendship of Tia Ammerlaan, Irina Burlacu, Fabio Domanico, Xavier Janssen, Silena Joosten, Susanne Lein, Gladys Oh, Cheng Boon Ong, Claire and Pierre Pannaye, Rosa Pham, Leilah Thiart, Rina Tsubaki and Eliot Rolen. Alexandre Staff Varela, thank you for lending me your arm when mine was broken, sky views, believing in me, and so much more. Finally, I am grateful for the encouragement and guidance of my family: Carla Cremers, Els Cremers, Marijke Cremers, Ton Farla, Paul Farla, Robert Farla, and Linghui Wang. This thesis is dedicated to my parents. 


\section{Contents}

Acknowledgements $\quad$ v

List of Tables $\quad$ ix

List of Figures $\quad$ xi

Abbreviations xii

1 Introduction 1

1.1 Motivation .......................... 2

1.2 Measuring Institutions and Policy in Cross-Country Research . . . . . 10

1.3 Objectives and Outline . . . . . . . . . . . . . . . 12

2 Institutions and Credit $\quad \mathbf{1 5}$

2.1 Introduction . . . . . . . . . . . . . . . . . . 16

2.2 Empirical Approach . . . . . . . . . . . . . . . . . 18

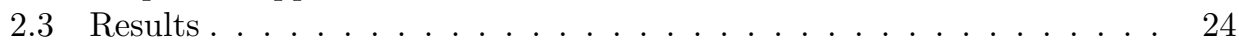

2.4 Conclusion . . . . . . . . . . . . . . . . . . . . . . . . . . . . . . . . . . .

2.5 Appendix $2 \mathrm{~A} \ldots \ldots \ldots \ldots \ldots \ldots \ldots$

3 Industrial Policy for Growth 41

3.1 Introduction . . . . . . . . . . . . . . . . . . . . . 42

3.2 Some Recent Trends in Industrial Policy . . . . . . . . . . . . . . . . . 43

3.3 Evidence and Theory on the Relation between Industrial Policy and Growth .................... . . 46

3.4 Industrial Policy Indicators . . . . . . . . . . . . . . . . . . . . . . . . . . . . . . . . . . .

3.5 Industrial Policy, Growth and Income . . . . . . . . . . . . . . . . . . 55

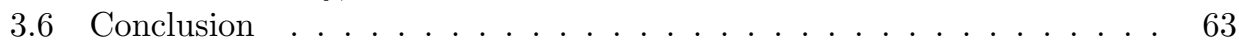

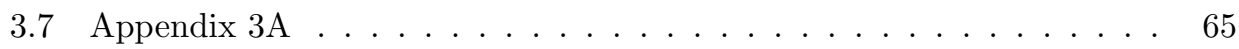

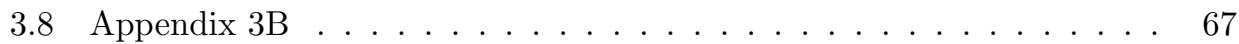

4 Institutions, Foreign Direct Investment, and Domestic Investment: crowding out or crowding in? $\quad 73$

4.1 Introduction . . . . . . . . . . . . . . . . . . 74

4.2 Institutions, FDI and Domestic Investment . . . . . . . . . . . . . 77

4.3 Macroeconomic Evidence on Crowding in and Crowding out . . . . . . 80

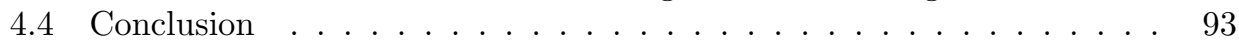

4.5 Appendix $4 \mathrm{~A} \ldots \ldots \ldots \ldots \ldots \ldots$ 
5 Determinants of Firms' Investment Behaviour: a multilevel approach

5.1 Introduction . . . . . . . . . . . . . . . . . . . . . . . 115

5.2 Literature Review . . . . . . . . . . . . . . . . 116

5.3 Data . . . . . . . . . . . . . . . . . . . . . . . 119

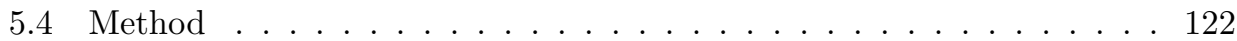

5.5 Results . . . . . . . . . . . . . . . . . . . . . 125

5.6 Conclusion . . . . . . . . . . . . . . . . . . . . 140

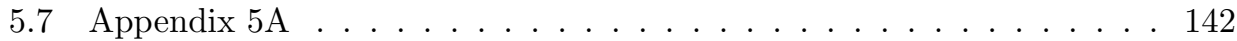

5.8 Appendix 5B . . . . . . . . . . . . . . . . . . . 148

6 Conclusion 155

6.1 Main Contributions . . . . . . . . . . . . . . . . . . 156

6.2 Discussion, Limitations and Future Research Directions . . . . . . . 160

$\begin{array}{ll}\text { Bibliography } & 163\end{array}$

$\begin{array}{ll}\text { Samenvatting } & 180\end{array}$

$\begin{array}{ll}\text { Biography } & 183\end{array}$

MGSoG Dissertation Series $\quad 184$ 


\section{List of Tables}

2.1 Regression Results: Dependent Variable Credit . . . . . . . . . . . . . 26

2.2 AM Regression Results: Dependent variable Credit . . . . . . . . . . . 28

2.3 AM Regression Results: Alternative Dependent Variables . . . . . . . 30

2.4 Robustness Tests. AM Regression Results: Dependent Variable Credit 32

2.5 Country List . . . . . . . . . . . . . . . . . . . . . . 34

2.6 Summary Statistics . . . . . . . . . . . . . . . . . . . . 36

2.7 Pairwise Cross-Correlations . . . . . . . . . . . . . . . . . . . . . . 37

2.8 Sources . . . . . . . . . . . . . . . . . . . . . . . . 39

3.1 WCY 1995-2011 . . . . . . . . . . . . . . . . . . 49

3.2 Summary Statistics . . . . . . . . . . . . . . . . . . . 57

3.3 Pairwise Cross-Correlations . . . . . . . . . . . . . . . 58

3.4 FE regression results: pro-market policy versus pro-business policy . . 60

3.5 FE regression results: pro-market policy versus pro-business policy . . 61

3.6 FE regression results: pro-market policy versus innovation/probusiness 2 policy . . . . . . . . . . . . . . . 62

3.7 FE regression results. Robustness check for delayed effects . . . . . . . 63

3.8 Country List . . . . . . . . . . . . . . . . . . . . . . 65

3.9 Sources . . . . . . . . . . . . . . . . . 66

3.10 Correlations between Policy Indicators (WCY 2007-2011 \& IPD 2009) 71

3.11 IPD $2009 \ldots \ldots \ldots$. . . . . . . . . . . . . . . . . . . . . . . . . .

4.1 Data . . . . . . . . . . . . . . . . . . . 85

4.2 Replicating M\&U (no interaction terms), dependent variable DPI . . . 94

4.3 Replicating M\&U (with interaction terms), dependent variable DPI . 95

4.4 Alternative estimation methods. Dependent variable: $D P I$. . . . . . 96

4.5 Dependent variable: $P I$, all estimation methods . . . . . . . . . . . . 97

4.6 Dependent variable: $G F C F$, all estimation methods . . . . . . . . . . 98

4.7 Dependent variable: $G F C F *$, all estimation methods . . . . . . . . . . 99

4.8 Dependent variable: $G C F$, all estimation methods . . . . . . . . . . . 100

4.9 Dependent variable: $D P I$, all estimation methods, stock FDI variables 101

4.10 Dependent variable: $P I$, all estimation methods, stock FDI variables . 102

4.11 Dependent variable: $G F C F$, all estimation methods, stock FDI variables 103

4.12 Dependent variable: $G F C F^{*}$, all estimation methods, stock FDI variables . . . . . . . . . . . . . . . . . . . . . . . . 104

4.13 Dependent variable: $G C F$, all estimation methods, stock FDI variables 105

4.14 Dependent variable: $G F C F^{*} \ldots \ldots$. . . . . . . . . . . 106

4.15 Dependent variable: $G F C F^{*} \ldots \ldots$. . . . . . . . . . . 107

4.16 Dependent variable: $G F C F^{*} \ldots \ldots$. . . . . . . . . . . . . 108 
4.17 Empirical macro studies on the effect of FDI on domestic private investment . . . . . . . . . . . . . . . . 109

5.1 Multilevel models with and without 'Mundlak' covariates . . . . . . . 127

5.2 Pairwise Correlations between Countries . . . . . . . . . . . . . . . . . 129

5.3 Multilevel Probit selection equations with macro-level covariates and with and without interaction terms . . . . . . . . . . . . . . 130

5.4 Multilevel RE and outcome models with macro-level covariates . . . . 132

5.5 Multilevel RE and outcome models with macro-level covariates and interaction terms . . . . . . . . . . . . . . . 135

5.6 RE and outcome random-coefficient models models with macro-level covariates and interaction terms . . . . . . . . . . . . . 136

5.7 Countries and Number of Firms . . . . . . . . . . . . . . . . . . . . . . 142

5.8 Definition of firm-level variables . . . . . . . . . . . . . . . . . . . 144

5.9 Probit and outcome random-intercept models models using alternative dependent variables . . . . . . . . . . . . . . . . . 149

5.10 Probit and outcome random-intercept models models using an alternative measure for partial foreign ownership . . . . . . . . . . . . 150

5.11 Probit and outcome random-intercept models models by sector . . . . 152

5.12 Probit and outcome random-intercept models models (pre-crisis \&

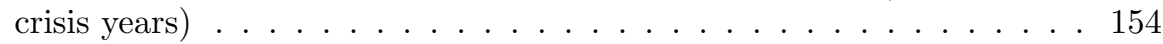




\section{List of Figures}

2.1 Construction of Orthogonal Institutional Measurements . . . . . . . . 21

2.2 Credit to the Private Sector: by country . . . . . . . . . . . . . . 35

2.3 Credit to the Private Sector: by region . . . . . . . . . . . . . 36

2.4 Scatter Plots: Credit and Institutional indicators . . . . . . . . . . . . 38

2.5 Scatter Plots: Credit and Composite . . . . . . . . . . . . . . . . . 39

3.1 Analysis of Policy Indicators: loadings of PCA . . . . . . . . . . . 50

3.2 Analysis of Varimax Rotated Policy Indicators . . . . . . . . . . . . . . 51

3.3 Analysis of Non-rotated Policy Indicators . . . . . . . . . . . . . . . 53

3.4 Analysis of Policy Indicators over Time . . . . . . . . . . . . . . . . . 54

3.5 Institutions and Policy . . . . . . . . . . . . . . . . . 59

3.6 Raw Coefficients . . . . . . . . . . . . . . . . . . . 69

3.7 Canonical Loadings . . . . . . . . . . . . . . . . . . . . . . 70

3.8 Analysis of Policy Indicators using IPD data . . . . . . . . . . . . 72

5.1 Conditional marginal effects of P_Foreign on investment . . . . . . . 138

5.2 Conditional marginal effects of Foreign100 on investment . . . . . . . 139

5.3 Histograms of the Distribution of Investment to Sales . . . . . . . . . 145

5.4 Histogram of the Distribution of Foreign Ownership . . . . . . . . . . 146

5.5 Histograms of the Distribution of $\widehat{\delta}_{1 j}, \widehat{\delta}_{2 j}$, and $\widehat{v}_{j} \ldots \ldots \ldots \ldots$ 


\section{Abbreviations}

AM Hausman-Taylor with Amemiya-MaCurdy specification

AR Autoregressive

CCA Canonical Correlation Analysis

CI Crowding-in

CO Crowding-out

CPI Corruption Perception Index

DPI Domestic private investment

EC European Commission

ES Enterprise Surveys

EU European Union

FE Fixed effect

FDI Foreign direct investment

FEVD Fixed effects vector decomposition

GCF Gross capital formation

GDP Gross domestic product

GMM General method of moments

GFCF Gross fixed capital formation

GCI Global Competitiveness Index

IMF International Monetary Fund

IPD Institutional Profiles Database

LAO Limited Access Order

LR Log restricted-likelihood ratio

NIE New Institutional Economics

NSE New Structural Economics

PCA Principal Component Analysis

PC Principal component

PCSE Panel corrected standard errors

PI Private investment

POLS Pooled ordinary least squares

PWT Penn World Tables

R\&D Research and Development

RE Random effect

TI Time-invariant

TI Transparency International

TV Time-varying

WCY World Competitiveness Yearbook

WDI World Development Indicators

WGI WorldWide Governance Indicators 
Chapter 1

Introduction 


\subsection{Motivation}

Why is per capita income in Congo merely a fraction of what it is in Luxembourg? Why do economic opportunities vastly differ between countries? What type of economic growth model has been conducive to stimulating growth in Brazil, Chile, China, India, South Korea, and Singapore and why has GDP growth failed to materialize in most of Sub-Saharan Africa? What concrete policy advice can be given to developing countries and to developed countries? These questions have spurred the research agenda of scholars from various disciplines including political economy, economic history, social policy, microeconomics, and economic growth and development. Following some of the more recent advances in the field of economic growth and development, this thesis aims to make its own unique contribution towards increasing the understanding of some of the determinants of long-term economic performance. In this section, we will motivate our analyses by discussing the wider context and overall relevance of the thesis. In this section, we will make a distinction between the neoliberal policy approach and the structuralist policy approach. We will specifically introduce the Washington consensus policy package and briefly outline its influence on policy making in various countries, its overall effect on countries' economic development and its relation to the increased recognition of the importance of institutions. Finally, we will provide a brief overview of the results of some analyses of the relation between institutions, policy and economic development and we will discuss some shortcomings in this field.

One way to distinguish economic growth models is by studying the type and degree of government intervention. We choose to contrast the neoliberal model with the structuralist model for development. The term neoliberal is used to describe a type of policy orientation that emphasizes the importance of the free market. Proponents of a neoliberal approach to development argue that in order for markets to function well there is relatively limited space for the state to intervene and to correct for market failures. The neoliberal approach emphasizes the importance of market competition and of policies that stimulate market competition such as free-trade polices, financial liberalization, deregulation, and privatization. For example, financial flows from capital-rich to capital-poor countries are relatively low (as noted in the seminal paper by Lucas (1990) this contradicts basic neoclassical growth models) and therefore policies that stimulate FDI inflow and competition may have a positive impact on growth. Additionally associated with neoliberalism is the role of the government in the enforcement of property rights and law and order. Here, the main objective is to address aspects of the public sector, including for example corruption, that constrain the development of the free market. The neoliberal approach to development is followed by several middle and upper-income economies and this approach was explicitly advocated by international organizations such as the World Bank in the 1980's and 1990's.

However, several scholars argue against the neoliberal model. In 1987 UNICEF (1987) published a report under the initiative titled 'Adjustment with a Human Face' which outlines the negative effect of the policies advocated by the World Bank and IMF at the time on health and education. Following the report, financial constraints- 
which were partly determined by the World Bank and IMF Structural Adjustment Programmes - had resulted in substantial budget cuts in the social sector. In a later study about Latin American countries, Ocampo (2004) argues that, to some degree, the lack of economic development is a result of market-based reforms. Additionally, opponents of neoliberal policy argue that several economies, e.g. the USA and Chile, are increasingly unequal as a result of the lack of government intervention to correct for market failures.

The structuralist approach to economic development is characterized as relatively more interventionist. According to this approach, structural heterogeneity within the economy generates unequal opportunities and hence strong government intervention is necessary to overcome externalities and coordination issues. One of the means of encouraging domestic industry development is import substitution, which was implemented in the 1960's and 1970's in several developing countries (e.g. Brazil and Argentina). Import substitution was criticized for having protected failing and uncompetitive industries for long periods of time and import substitution was largely abandoned in the 1980's as the main focus of countries' growth strategy. However, the structuralist approach towards development remains embedded in the industrial policy mix of several (mostly developing) countries.

There is a large amount of literature that emphasizes the role of industrial policy in stimulating growth and enhancing technological capabilities (e.g. Criscualo et al., 2012; Buigues and Sekkat, 2011; Rodrik, 2009; Peres, 2009; Gerschenkron, 1962). According to some of this literature, there should be a more pro-active approach in development policy. For example, Greenwald and Stiglitz (2006) are in favour of a return towards more interventionist policies and Wade (2009) argues that developing countries in particular should enhance the role of (protectionist) industrial policy to support industrial development. Even though, in the 1990's, India achieved rapid economic growth at the same time that markets were being liberalized, Rodrik and Subramanian (2005) argue that the economy already started to growth in the 1980's as a result of industrial support.

The degree to which structuralist policy supporting private sector development is compatible with a neoliberal approach towards development is not evident. One perspective is that a government cannot advocate both policy approaches at the same time. This view suggests a contradiction between structuralist policy and neoliberal policy and this contradiction fuels policy debate. However, when coming to terms with policy choices, governments have usually followed a more pragmatic approach. We will address this reality in the conclusion of the dissertation in an attempt to reconcile the two approaches to development.

The neoliberal approach to development, and much of modern economic thinking, is based on the foundation of neoclassical economic theory. The neoclassical growth literature provides some important building blocks that help understand why some countries have achieved higher long-run economic growth rates than other countries. One of the predictions of the neoclassical growth literature is that growth rates are higher in economies where the capital to labour ratio is relatively low because, in these economies the return on capital investment is relatively high. When countries 'catch-up' they will cease to have relatively higher rates of return on investment and 
the high-growth rate advantage erodes. This growth literature additionally predicts that improvements in technology can have a positive exogenous effect on long-run growth rates. Neoclassical growth models implicitly predict conditional convergence of income levels in the long-run. Even though the rapid growth and development in some parts of the world may be considered as evidence supporting neoclassical growth theory, in other parts of the world growth has failed to materialize. Hence, economists and policy makers became focused on identifying the determinants of growth that constrain the convergence of economies.

Building on the models of neoclassical growth theory, several scholars developed endogenous growth models in the 1980's. In these models, technological progress is considered an endogenous factor that can influence the long-run growth rate. The endogenous growth models also stress the importance of human capital development as a key growth determinant. And, on the basis of cross-country data, Barro (1991) confirms this relation. One implication of endogenous growth theory is that by means of policy (e.g. investment in education, R\&D subsidies and stimulating FDI spillovers) the government can influence long-run growth rates.

Also in the 1980's, the focus of development economics was on promoting the adoption of more neoliberal policies as outlined in the Washington consensus. Williamson (2004) formulated the Washington consensus, a list of ten policies, with the idea to establish a broad consensus on desirable macroeconomic policies. The list of policy recommendations concern: (1) fiscal discipline, (2) reorientation of public expenditures, (3) tax reform, (4), financial liberalization, (5) unified and competitive exchange rates, (6) trade liberalization, (7) openness to FDI, (8) privatization, (9) deregulation, and (10) secure property rights (Rodrik, 2006). For example, one motivation was that "in 1989 there was still widespread reluctance to accept foreign investment, including FDI. This did not make economic sense" (Williamson, 2004, pp. 8). Williamson (2004) did not intend this policy programme as a list of policy prescriptions but the policies were used extensively in policy advocacy by the World Bank and the IMF. In terms of policy implementation, the Washington consensus broadened beyond its initial conception and additionally focused on capital account liberalization and on the establishment of competitive exchange rates (Rodrik, 2006). The Washington consensus policies were extensively implemented in many developing countries, in particular in Latin American countries, and several policies were subject to rigorous reforms: FDI, fiscal policy, financial and trade policy, privatization and deregulation policies. Overall, the policy programme disastrously failed in delivering growth.

Partly in response to the failure of the Washington consensus programme, researchers became interested in explaining the degree to which some of the more 'ultimate' factors constrain and sustain growth. According to Szirmai (2012) 'ultimate' sources of growth consist of underlying factors of economic growth such as geographic location, climate, natural resources, demographic factors, culture and values, economic institutions, political institutions, labour market institutions, and social institutions, the distance to the technological frontier, and absorptive capacities. Some of these 'ultimate' sources of growth may have an impact on the effectiveness of the Washington consensus policies and may indirectly have an impact on more 
'proximate' sources of growth such as the behaviour of firms and the accumulation of capital. As such, one way to distinguish 'proximate' from 'ultimate' sources of growth is by considering 'proximate' sources of growth as factors that have a direct causal effect on growth and 'ultimate' sources of growth as factors that have an indirect causal effect on growth. Neither neoclassical growth theory nor endogenous growth theory give insight into how firms behave under different 'ultimate' constraints. However, for example, economic institutions may influence the decision of firms to invest in various factors of production. One expectation is that learning more about the role of institutions can help explain the vast difference in per capita income levels of developed versus developing countries.

North (1990) developed an analytical framework that describes the role of institutions, i.e. 'the rules of the game'. According to the work of North and based on the idea that institutions shape the incentives of individuals and organizations, institutions became identified as important 'ultimate' factors that generate distinct preconditions for a developmental outcome. The starting point of this work of North is the recognition that some of the assumptions of neoclassical economic theory ignore important behavioural aspects. Neoclassical economic theory builds on assumptions such as the economy is in equilibrium and that individuals have stable preferences and maximize preferences. To broadly summarize, as a result of complexities in the social-economic system the above mentioned assumptions are unlikely to holde.g. information is incomplete and multiple equilibria can arise - and economies can operate at non-optimal levels of economic activity for long periods of time. Various institutional rules are created in order to address information externalities and coordination problems and have a positive effect on economic development. Other institutional rules may have been created with similar intention but, e.g. as a result of rent-seeking behaviour, generate disproportionate advantages to various actors.

The theory of institutions developed by North (1990) builds on the transaction cost theory by Coase $(1960,1937)$ which implicitly discussed the role of institutions in reducing uncertainty. In the 'Nature of the Firm' Coase argues that transaction costs are the basic reason for firms to exist. Williamson (1979) further developed theory on transaction costs and proposed that the study of transaction costs ought to be integrated into mainstream economic thinking. Williamson framed this initiative under the term 'New Institutional Economics' (NIE) in 1975 but most major contributions in the field NIE were made since the early 1990's. In particular, several scholars (e.g. Mauro, 1995 and later Acemoglu et al., 2001) made an important mark in the literature by empirically establishing a relation between institutions and long-term growth. Researchers generally concluded that a small selection of countries has 'stronger' institutions than other countries and that the development of such 'stronger' institutions has made a significant increase in wealth possible over the past century. An additional outcome proposed in the literature is that of the formation of development clusters. The basic idea is that some economies have similar levels of state capacity, control of violence, respect for property rights, and redistributive policies, etc. and, as a consequence, some countries have similar levels of per capita income (see also Besley and Persson, 2011). 
Despite the general support for the Washington consensus package (at the time) several scholars are not in agreement with its policy prescription. Stiglitz (2008, pp. 41) insists that "there is no consensus except that the Washington consensus did not provide the answer." A post-Washington consensus came into existence in response to the criticism of the original Washington consensus and its overall failure in delivering growth. The post-Washington consensus development view entails both a broadening and deepening of policy reform. On the one hand, (in 2004) Williamson reflects on whether the Washington consensus policies amounted to a sound prescription and concludes that some countries had not gone far enough in the implementation of the policy package. On the other hand, inspired by the recognition that institutions matter, the focus of development economics shifted towards emphasizing the role of institutions. Rodrik (2006) describes in detail how this shift in focus led to the proposition of an augmented Washington consensus. ${ }^{1}$

In addition to the previously mentioned ten point Washington consensus policy list the augmented Washington consensus includes: (11) corporate governance, (12) anticorruption, (13) flexible labor markets, (14) WTO agreements, (15) financial codes and standards, (16) prudent capital-account opening, (17) non-intermediate exchange rate regimes, (18) independent central banks/inflation targeting, (19) social safety nets, (20) targeted poverty reduction (Rodrik, 2006). One observation drawn from this augmented policy framework is that macroeconomic policy involves a broad(er) range of policy options that are interrelated. For example, the augmented policy framework recognizes that development requires economic growth and a reduction of poverty. A second observation drawn from this augmented policy prescription is that it places more emphasis on macro-level rules and regulations. According to the policy prescription, in addition to policy reform, countries should also undergo institutional reform. One argument for institutional reform is that different rules and regulations are required to enforce the stipulated policies. According to the programme prescription, public expenditures should still be redirected from private sector subsidies towards education, primary health care and infrastructure investment, whilst at the same time preventing from finances disappearing into the pockets of corrupt officials.

Today, the overall importance of institutions is well recognized-as well as the importance of some key economic principles such as financial stability and accountability. For example, most scholars and policy makers agree that corruption is 'bad'. Jones and Romer (2010) assess the progress made in economic thinking since the adoption of neoclassical growth models (with particular reference to the Kaldor facts). According to Jones and Romer (2010, pp. 242) modern growth theory "must consider the interaction between ideas, institutions, population, and human capital" in order to explain growth accelerations and growth differences and this realization constitutes a major advancement in economic thinking. Specifically, Jones and Romer (2010, pp. 242) state that "institutions may have their most important effects on cross-country income differences by hindering the adoption and utilization of ideas from throughout the world".

\footnotetext{
${ }^{1}$ Rodrik is no supporter of the augmented Washington consensus; as discussed below he proposes a more tailored 'growth diagnostics' approach.
} 
The term 'governance' or 'good governance', is often interchangeably used with the term 'institutional quality'. Conceptually, governance refers to the "play of the game" and to the actual governance of contractual relations (Williamson, 2000, pp. 597). According to Williamson (2000), institutions include embedded informal institutions and formal institutional rules such as property rights institutions and bureaucracy. Additionally, according to Williamson, governance differs from institutions in the sense that the process of institutional change is slower than the speed by which governance changes. In the practice of policy making the distinction between institutions and governance is less clear. The perspective evoked by the augmented Washington consensus is that 'good governance' reflects the ideology that a government can actively pursue a development agenda that seeks to control corruption and establish strong property rights and democracy. This is related to the World Bank's conceptualization of 'actionable governance indicators' which are based on the assumption that a government can influence the country's score on an indicator by following the recommended policy agenda.

One point of view is that 'good governance' is a key vehicle to growth and that therefore developing countries can achieve higher long-term growth levels once they move towards an institutional system which is more in line with that of the USA and the rest of the Western world. Moreover, based on this premise, one possibility is that with the 'right' institutions in place, a neoliberal policy agenda can change the economic fortunes of developing countries for the better. one striking feature of the work of Kaufmann et al. (2005) is that the authors exclude the possibility that higher income has a causal effect on 'quality of governance'. The perspective outlined above is what Easterly (2008) calls the 'top down' view of institutions. Quite differently, the 'bottom up' view "sees current institutions as heavily constrained by previous institutions. Institutional change in the bottom up view is always gradual, evolutionary rather than revolutionary" (Easterly, 2008, pp. 95). It is possible that making 'good governance' a distinct goal is distracting developmental efforts away from alternative approaches to increase growth and development.

Aspects of the World Bank's neoliberal policy advocacy have persisted in the form of the Country Policy and Institutional Assessment (CPIA) programme (Wade, 2012). The CPIA is used to grade countries that are eligible for development aid under the International Development Association (IDA). ${ }^{2}$ The IDA provides these countries with concessional loans and grants which are dependent on their CPIA scores. Sixteen criteria are used to evaluate whether a country is maximizing its potential to grow and develop and whether it can effectively manage aid. According to the The World Bank Group these sixteen criteria are: (1) monetary and exchange rate polices, (2) fiscal policy, (3) debt policy and management, (4) trade, (5) financial sector, (6) business regulatory environment, (7) gender equality, (8) equity of public resource use, (9) building human resources, (10) social protection and labor, (11) policies and institutions for environmental sustainability, (12) property rights and rule-based governance, (13) quality of budgetary and financial management, (14) efficiency of revenue mobilization, (15) quality of public administration, and (16) transparency,

\footnotetext{
${ }^{2}$ The allocation of aid is also dependent on alternative indicators such as the Heritage Foundation index of economic freedom.
} 
accountability, and corruption in the public sector. Developing countries are scored on each of the criteria based on a set of conditions. One criteria which is more strongly associated with neoliberalism is 'trade'. For example, along with several other requirements, countries score high on the 'trade' criteria if the economy is fully open to trade and if it has both very low and uniform taxation on imports and exports. A high score on the 'property rights and rule-based governance' criteria requires that e.g. "all property rights are transparent and well protected. Contract enforcement is reliable, predictable, and not overly expensive" (The World Bank Group, pp. 38). It should come as no surprise that there is considerable overlap between the augmented Washington consensus policy prescription and the CPIA.

Chang (2002) argues that we expect too much from developing countries in terms of institutional development and in terms of 'laissez-faire' policies. Based on a historical analysis of the 'now developed economies' Chang finds that in 1913, when some of the 'now developed economies' had levels of income comparable to presentday Brazil, Turkey, Thailand, Mexico, and Colombia, their institutions were of a low-quality and the countries implemented interventionist and protectionist policies to stimulate industrial development. Chang concludes that, by advocating neoliberal policies, developed counties are 'kicking away the ladder' for developing countries to catch-up. Related is the argument of Grindle (2004) who argues for 'good enough governance' and a more realistic development agenda.

Despite that there are a lot of "unexploited degrees of freedom" in policy making (Cimoli et al., 2009a, pp. 543), several aspects of the neoliberal agenda remain at the forefront of policy advocacy. One reasons may be that since the Washington consensus no common understanding has been established that outlines more concretely what institutions and economic policies are essential in stimulating growth and development. Despite the recognition that 'institutions matter', theory on the causal dynamics by which institutions influence various policy and development remains underdeveloped. There is no clear evidence on the role that institutions play in redistributing opportunities for countries at different developmental stages, and/or for growing economies. Also, from a broader perspective, it remains far from clear which institutional characteristics are particularly important for stimulating different factors of development; e.g. human capital development, economic development, and eradicating poverty. Additionally, several researchers have established that there is a much weaker relation between institutions and short-run economic growth (e.g. this is also illustrated in De Crombrugghe and Farla, 2012). What remains is much ambiguity on the joint role of various policies in driving growth and even on the complementarity of the relation between policy, political economy and institutions.

Ocampo proposes that one of the shortcomings of the Washington consensus programme is "its disregard for the role that policy interventions in the productive sector can play in inducing investment and accelerating growth" (Ocampo, 2004, pp. 294). Ocampo specifically refers to the interventionist and protectionist structural industrial transformation strategies that were already implemented in Latin America in the 1960's. Some scholars are rather pessimistic about the role of economic policy. For example, Ocampo and Stiglitz (2008) investigate the relation between capital market liberalization and development and are rather cautious in claiming that 
financial liberalization yields benefits when (amongst others) a strong financial system and regulations are lacking. Moreover, according to Easterly and Levine (2003) and Rodrik et al. (2004) trade, inflation, and exchange rate policy (as well as geography) are not significantly related to long-term economic growth, after controlling for institutions.

Alternative considerations are that there are many routes to development (see also Rodrik, 2008). According to Hausmann et al. (2008) development economics should take a more bottom-up, and country-specific, approach towards 'growth diagnostics'. The 'growth diagnostics' approach aims to first identify the more 'proximate' constraints to growth. The next step is detecting the roots of the most binding ('proximate') growth constraint. For example, following the 'growth diagnostics' approach, one possibility is that a country lacks investment in fixed capital. This underinvestment can be caused by high costs of finance which in return can be caused by poor financial intermediation. The idea behind the 'growth diagnostics' approach is to focus on removing the most binding constraint to growth by means of tailored policies.

Even though the 'growth diagnostic' approach has its merits, for several reasons, it is beneficial to have some general understanding of what policies work best in certain regions and/or country clusters. Primarily, we seek to identify the key factors of growth and how these key factors are interrelated. Understanding the interrelations between growth factors would enable a better approximation of how to compensate for certain institutional and geographic constraints. One critique of the 'growth diagnostics' approach is that by only focusing on the most serious growth constraints we cannot learn enough about the interrelationships of policies in an economy. One argument we make is that policy makers require more specialized knowledge of the degree to which industrial support is compatible with a pro-market oriented policy approach. An additional concern with the 'growth diagnostics' approach is that international institutions ought to have a clear standpoint on global issues. This is particularly important when the industrial policy of one country is harmful to the industrial development and/or environment of other countries. The complexity of these issues is most apparent in WTO trade negotiations where the voice of developing countries is generally overshadowed by that of the WTO founding partners. To what degree do Sub-Saharan countries require protectionist policies in order to stimulate growth in their domestic industries? As a result of economic integration and global challenges, the policy-mix of different countries has become more integrated. This in return limits a country's ability to focus exclusively on its own 'growth diagnostics'.

Finally, to what extent can policies really influence the private sector? There is limited understanding on the role of individuals and organizations in shaping their economic fortune versus the effect of macroeconomic determinants such as institutions and policy. Macroeconomic literature has paid little attention to the heterogeneities that exist within economies. Yet, microeconomic studies on the behaviour of the firms have established the importance of factors such as a firm's age, training and managerial capacity and working conditions on productivity. Likewise, the interrelation between micro and macro factors in the development of the private sector remains understudied. 
This thesis bundles four empirical cross-country analyses. The red line that connects the various analyses is our interest in identifying the extent to which institutional and policy variations can explain differences in the economic performance of countries. In Chapter 4 and Chapter 5 we also focus on the relation between foreign investors and domestic investment. Chapter 2 and Chapter 3 use data on both developed and developing countries and Chapter 4 and Chapter 5 use data on developing and emerging economies. Each of the studies sets out with a distinct objective and yet the four studies are inherently related. In particular, we take a common approach towards measuring institutions and policy.

\subsection{Measuring Institutions and Policy in Cross- Country Research}

North (1990, pp. 107) proclaimed that "we cannot see, feel, touch, or even measure institutions; they are constructs of the human mind." If this statement is true, in this thesis we seek to do the impossible. We find that measuring institutions is no easy task but that it is possible to characterize a country's institutional framework using indicators. In fact, despite the pessimistic attitude of North towards measuring institutions, major empirical advancements in the field of NIE were launched (mostly still in a relative ad-hoc basis) in the 1990's. In particular, the development of subjective perception-based datasets have allowed for a richer exploration of the link between various dimensions of institutions, policy and development. In contrast to 'hard' data and 'de-jure' indicators for institutional concepts (such as corruption), perception-based data can better capture a 'de-facto' state. Measuring a 'de-facto' state entails approximating the actual implementation of rules of institutions including informal rules such as social norms, values, and beliefs. Arguably, the use of perception-based data in the comparative analysis of a country's governance and policy practices has become part of mainstream economics.

The most comprehensive attempt to collect datasets that capture or are related to the cross-country measurement of institutions is the Quality of Government dataset constructed by Teorell et al. (hereafter referred to as QoG). Using a wide range of sources the QoG combines roughly 700 variables in one dataset. This data collection includes composite indicators. The dataset includes 194 economies and most variables are available for the last decade or more. The QoG uses three categories to distinguish data type: 'What It Is,' 'How To Get it,' and 'What You Get.'

First, 'What It Is' includes data that seek to measure core features of the quality of government. According to the QoG dataset this category includes data on corruption, rule of law, bureaucratic quality, democracy, social security laws, human rights, women in parliament, freedom of the press, fiscal policy, debt policy, and trade openness. Because this first category includes data on economic institutions, political institutions as well as policy indicators, it is clear that quality of government is a broad concept. There is an additional observation that is important to mention at this point. Although the term 'quality of government' emphasizes the role of the public sector, in the field of New Institutional Economics the distinction between the public and 
private sector is not emphasized. One reason is that institutional rules are shaped and reinforced by public bodies, private organizations and individuals. According to North (1990, pp. 3-4), institutions "structure incentives in human exchange, whether political, social, or economic."

Second, 'How To Get it' includes data on factors that can promote the development of government quality. This category includes data on GDP, education, media ownership, globalization, FDI, veto power, inequality, central bank independence, colonial origin, religion, linguistic fractionalization, legal origin, and population. Some of the data in this category - e.g. religion, legal origins and language - are identified by several scholars as valid proxies and instrumental variables for governance and institutional quality.

Third, 'What You Get' includes data which capture the effect of achieving (or not achieving) governmental quality. This last category of the QoG dataset includes data on GDP growth, FDI, public investment, government revenue, agricultural subsidies, women in parliament, conflict, happiness, and support for democracy and market competition.

Following the basic logic of the QoG framework it is possible to study the causal relationship between preconditions for quality of government ('How To Get It'), institutions and policy aspects ('What It Is') and indicators of development ('What You Get'). For example, a high level of initial GDP may be a determinant of government quality which in return may lead to higher GDP growth. Similarly, FDI inflow may promote government quality which in return may cause FDI inflow. The examples above illustrate that (possibly) there is reverse causality affecting the institutions, policy and growth relationship. The possibility that economic growth $\rightarrow$ 'strong' institutions opposes the view of Kaufmann et al. described above. Moreover, it is evident that some scholars consider certain indicators (e.g. women in parliament) as both indicators of governmental quality and indicators that measure the effect of achieving governmental quality.

Despite the apparent richness of data collection in the field of institutions and policy and the substantial progress made in collecting various data, the measurement of institutions is still in its infancy. There also is a trade-off between using raw data and composite indicators as a proxy for a country's quality of government.

Raw data, i.e. unaggregated data, remains scarcely available to researchers. The Institutional Profiles Database (IPD) aims to fill this gap. The IPD provides free access to more than 350 variables that reflect different aspects of institutions and policy. The IPD survey is answered by French civil servants working abroad in the various external representations of the French Development Agency (AFD) and of the French ministry of Economics, Finance and Industry (MINEFI). Variables measuring institutional characteristics, policies, and related factors are strongly correlated. Likewise, conceptually, various aspects of institutions and policy are closely related making it challenging to distinguish between specific aspects of institutions and policies. Also, these variables are the result of the perceptions of the survey respondents. As such, when working with the IPD data, researchers need to be aware that the data may contain (French) bias. Likewise, it is important to be aware that perceptions about e.g. property rights or political development are subject to changes 
in opinion. One way to avoid working with a measurement that is highly susceptible to the opinion of an individual is to use household surveys or firm level surveys that aggregate the responses of several individuals where respondents are asked the same survey questions. Sometimes the aggregated data will be made publicly available to researchers but the raw data not and, in this case, researchers have limited or no insight in the distribution of the underlying individual responses. At the same time, using such aggregated data does not eliminate bias which stems from changes in opinion regarding the interpretation of the scale of a variable that are common across individuals.

Following the words of Kaufmann et al. (2005, pp. 30), "individual sources of governance data are imperfect and provide only noisy signals of unobserved governance." Because individual sources of data or data points are found to be rather unreliable, composite indicators such as the widely-used Corruption Perception Index and the Worldwide Governance Indicators are constructed under the assumption that data errors and misconceptions are smoothed-out when aggregating different data-sources together. However, institutional measures lack comparability across institutional dimensions, across countries, and over time. For example, it is possible that a change in the score of a country on a composite index reflects a change in the construction of the index and does not reflect institutional change. Therefore, the aggregation of this data comes at a cost. Best expressed by Oman and Arndt (2010), composite indicators lack transparency and include hidden biases.

This thesis uses a wide range of perception-based data to measure concepts of policy and institutions ranging from widely used composite indicators to more recently commenced projects collecting institutional data. Aware of the fallacies of perception-based indicators we employ several strategies. First, whenever a more precise notion of a policy, institution/governance concept is required we use raw data to build specific indicators. We avoid relying on single variables to measure a concept. Because different variables describing institutions and/or policies are highly correlated we rely on factor analysis techniques to distinguish the effect of characteristics of institutions on a country's economic performance. Alternatively, we use data from expert opinion surveys to measure relatively specific concepts. Finally, whenever a general measurement of policy, institutions/governance is required, we use one or more of the widely used composite indexes to gain a general understanding of tendencies without further pretending to have any specific knowledge about what particular concepts are captured by the indicator.

\subsection{Objectives and Outline}

As previously mentioned, the main objective of this thesis is to analyze to what extent variations in the level of economic performance are determined by countries' institutions and policies. Hereby, we focus on between-country differences in institutions and policy and seek to identify a causal relationship between countries' institutions and their policy and economic performance. Economic performance, the dependent variable of our analyses, takes the form of income levels, growth, investment, and financial development. 
Financial development, capital deepening, is one intermediary factor in the relation between institutions and growth. In developed economies the current discussion focuses on the excessive and risky lending behaviour made possible following recent financial innovations and on the volume and conditions of bailouts. It is apparent that in these economies inadequate institutional and financial rules and regulations are undermining the credibility of the financial system as well as a smooth recovery. In developing countries, the economic difficulties associated with underdeveloped credit markets are severe in the long-run as a result of weak institutional regulations governing the economies.

The first study, Chapter 2 in this thesis, aims to re-address the detrimental impact of the lack of financial development that persists in many developing and emerging economies. We focus on the role that institutions (as well as financial policies) play in determining private sectors' access to and reliance on credit markets. This study builds on the work of Acemoglu and Johnson (2005) and outlines the extent to which different institutional factors are related to financial development. In particular, we investigate to what degree the formalization of property rights, contracting, and competition institutions are positively related to an increase in the level of credit to the private sector.

Chapter 3 discusses and empirically investigates the impact of industrial policy on a country's income and growth level. First, using perception-based data for 59 countries covering 22 policy aspects we seek to empirically distinguish different components of industrial policy; policy that primarily targets the development of industry and policy that primarily stimulates free market development and competition. Next, we identify the relation between these two policy typologies in order to establish whether, at the macro-level, there is a trade-off between implementing the two policy types. We proceed by estimating the impact of these two policy concepts on economic performance: i.e. GDP growth and income levels. Additionally, we extend the analysis by investigating the relation between innovation policy and economic development.

Whereas Chapter 2 and Chapter 3 take a predominantly closed economy perspective, in the next two chapters we study the role of foreign investors in supporting a countries' domestic economy. Chapters 4 and 5 both contribute to research investigating the degree to which national economies benefit from opening borders and attracting foreign investment. In Chapter 4 we provide a brief overview of the literature on foreign direct investment (FDI) crowding-in/crowding-out domestic investment. We use the work of Morrissey and Udomkerdmongkol (2012) as a benchmark and examine the extent to which the results of the authors are robust to alternative choices of investment data and methodology. We study (i.) the impact of FDI on domestic investment, (ii.) the impact of institutions on domestic investment, and (iii.) the mediating impact of institutions on the relation between FDI and domestic investment.

Whilst the above-mentioned chapters exclusively use macro data to describe aggregate effects on country-level economic performance, in Chapter 5 we extend the analysis of the previous chapter and use both macro-level and micro-level data. Using a multilevel probit model we study the determinants of a firms' likelihood of investing 
and using a multilevel two-step Heckman selection model we study the determinants of a firm's investment to sales ratio. First, we outline the relative macro-level impact on a firm's investment behaviour. Second, we assess micro-level determinants focusing on the impact of foreign equity ownership on a firm's investment behaviour. Third, we present evidence on the impact of the interaction between macro and micro-level determinants on firms' investment behaviour. Here, we focus on establishing the mediating impact of institutions on the relation between foreign equity ownership and a firm's investment behaviour.

Chapter 6 summarizes the main conclusions brought forward in the different chapters. Moreover, we discuss the limitations of the findings and suggest some possibilities by which future research can overcome these challenges. 
Chapter 2

Institutions and Credit 


\subsection{Introduction}

Credit to the private sector in the Unites States, Japan, Canada, Germany, and China is higher than 100\% of GDP. In countries in Sub-Saharan Africa credit to the private sector is, on average, lower than $20 \%$ of GDP. Why do these wide differences occur? And are they important? Credit deepening makes possible an increase in investment, an expansion of production, technological change, and economic growth, and attracts foreign direct investment. Levine (2005, p. 921) summarizes that "empirical analyses, including firm-level studies, industry-level studies, individual country-level studies, time-series studies, panel investigations, and broad crosscountry comparisons, demonstrate a strong positive link between the functioning of the financial system and long-run economic growth". Similarly, the more recent study by Jeong and Townsend (2007) concludes that, in Thailand, financial deepening plays a substantial role in determining total factor productivity growth. Moreover, Greenwood et al. (2013, p. 211) estimate that "world output could increase by 53 percent if all countries adopted the best financial practice in the world." ${ }^{1}$ Closely related is the work of Greenwood et al. (2010) who establish a causal relation between the efficiency of financial intermediation, information frictions and economic development. On the basis of data on US firms, Gilchrist et al. (2013) specifically identify the degree of miss-allocation of resources that is attributable to financial market frictions. These authors use firms' borrowing costs as a proxy for financial market frictions and conclude that - in developed capital markets - financial market frictions only have a small effect on efficiency losses.

We propose that, especially in developing countries, the economic difficulties associated with underdeveloped credit markets are severe in the long-run as a result of weak institutional regulations governing the economies. One possible effect of the development of stronger institutions is reducing financial market frictions which for example can lower the cost of lending, generate a higher lending base, and increase the financing of more long-term commitments. In this study we investigate what type of institutional characteristics enable firms' access to credit markets, and hence are related to financial deepening.

Financial deepening is defined as an increase in the volume of credit as a proportion of GDP and the concept is measured using data on domestic credit to the private sector by financial intermediaries (the total value of loans, trade credits and nonequity securities), as a proportion of GDP. Credit data is commonly used in the literature on financial development. ${ }^{2}$ In comparison to other financing sources, (e.g. government finance, equity finance, and corporate bond finance) credit to the private sector is a good proxy for financial development in low-income countries. Especially in low income countries the financial system is bank dominated and the benefits from credit market development are greater. Firstly, in low income countries savings are relatively smaller than in high income countries, and savings tend to be invested in liquid forms and trade credits. Secondly, in low income countries there are relatively

\footnotetext{
1 When taking inefficiencies in the non-financial sector into account, this large potential impact of financial sector development on economic growth is substantially lower (Greenwood et al., 2013).

2 For example, Huang (2010); Quintyn and Verdier (2010); Baltagi et al. (2009); Djankov et al. (2007); Safavian and Sharma (2007); Acemoglu and Johnson (2005) use credit data in their studies.
} 
few credit worthy, reputable organizations that are worth investing in making bond and equity financing a challenge. Thirdly, compared to high income countries, low income countries have relatively few large firms; smaller firms rely more on bank financing as a source of formal credit allocation. Fourthly, corporate bond markets depend on formalized financial markets and institutional arrangements which, on average, low income countries have not acquired.

The types of institutions that we are interested in are (1) property rights institutions, (2) contracting institutions and (3) competition institutions. There are several channels by which these types of institutions may influence financial deepening. First, we expect that strong property rights institutions secure property ownership over time. Weak security of property rights can endanger investors' and borrowers' ability to retrieve future revenue from investment. This has a negative impact on firms' ability to borrow and invest and may lower the size of loans. Moreover, Bae and Goyal (2009) find that banks issue higher loan amounts with longer loan maturities and request relatively lower loan spreads in countries with strong property rights protection than in countries with weak property rights protection. Second, we expect that strong contracting institutions reduce information asymmetry, the costs of contracting, the risk of contractual breach, and can enhance the credibility of contracting. Even though personalized contracting systems may be sufficient to protect 'small' loans and short-run lending arrangements, it is likely that substantial credit deepening requires strong contracting institutions. Third, the absence of competition institutions may create an environment that only supports the development of the existing industry. The monopolization of industry creates entry restrictions and can cause firms to under invest. A lack of competition is especially detrimental to small organizations, risky projects, and 'infant' firms' willingness to borrow. Moreover, a lack of competition could result in concentrated sectoral allocation of investment and general inefficient allocation of investment across sectors and project owners. Finally, monopolization of the banking industry can cause frequent breaching of contracts, lack of risk-diversification, and could undermine credibility in the financial system.

This study is closely related to the work of Acemoglu and Johnson (2005) who find that property rights protection has a positive influence on financial deepening (as well as on other indicators of economic performance). The authors find no effect on contracting institutions on financial deepening and hypothesize that contracting institutions are relatively unimportant because agents can change financial intermediation and terms of contracts. ${ }^{3}$ We revisit the relationship between institutions and financial deepening using alternative measurements of property rights protection and contracting institutions and additionally estimate the effect of competition institutions. Contrary to the methodological approach of Acemoglu and Johnson (2005), we construct indicators for property rights, contracting, and competition institutions using the same data source. To the best of our knowledge, the relevance of this combination of institutional characteristics has not been previously

\footnotetext{
3 Similarly, Djankov et al. (2007) argue that private registries can stimulate the private sector by facilitating information exchange between firms. Djankov et al. also find evidence that in poorer countries the private credit to GDP ratio increases along with the introduction of credit registries.
} 
investigated in relation to financial development. The institutional indicators are transparent in their composition, comparable in scale and construction, and include both de-jure and de-facto perspectives on countries' institutional development. The institutional indicators describe institutional characteristics which are stable and inert in the medium/long-term. The Hausman-Taylor method with Amemiya-MaCurdy (1986) specification is used in order to retrieve the parameter estimates of these timeinvariant institutional indicators.

On the basis of panel data of 81 countries for the period 1994-2005, we conclude that there is a strong relationship between property rights, contracting and competition institutions and private sector credit deepening. Overall, the institutional indicators remain positive and significant when controlling for the effect of financial policy, and when using alternative measures of financial depth and investment.

\subsection{Empirical Approach}

\section{Institutional Indicators}

We construct institutional indicators using a relatively unexploited perception based survey, the Institutional Profiles Database (IPD, 2009). The variables selected describe institutional arrangements for property rights, contracting, and competition. ${ }^{4}$ Some of the IPD variables (explicitly) comprise of both a de-jure and de-facto assessment of a countries' institutional rules. The IPD data describes 'stable' institutional arrangements and do not focus on describing current change in states' rule. Moreover, an advantage of using institutional data from the same source is that there is no difference in data collection and treatment. The data are fit for cross-country comparison and for comparison across indicators. ${ }^{5}$

One observation is that, overall, higher scores on the variables are associated with formal institutional regulations. This observation is related to the work of Greif and Tabellini (2010) who argues that, in China, institutions rely more on an informal organization of enforcement and, in Europe, institutions rely more on a formal organization of enforcement. Hasan et al. (2009) note similar changes in institutions at the province level in China and argues that these changes have a positive effect on GDP growth. As such, in this study we will explore whether formal institutional rules are positively related to credit deepening.

The IPD variables are listed below on the basis of a tentative categorization. Property rights institutions refer to regulations that protect current and future tangible and intangible property and revenues that originate from property, i.e., land and non-land assets and intellectual property. Contracting institutions consist of arrangements protecting the security of contracts, government respect for contracts,

4 This variable selection does not include variables that describe local and sub-national institutional arrangements, variables that describe costs for foreign actors, variables that describe change and reforms, survey questions that are not relevant for all countries, and survey questions that are unclear, ambiguous, or may be particularly difficult for country experts to answer.

${ }^{5}$ Lack of cross-country and over time comparability is a weakness of data from the World Bank Worldwide Governance Indicators, the International Country Risk Rating (ICRG) / PRS Group, and the Fraser institute (de Crombrugghe, 2010). 
transparency in the banking system, enforcement of the justice system, creditor rights, the speed of rulings and effectiveness of commercial courts. Competition institutions refer to types of regulations that seek to "control or eliminate restrictive agreements or arrangements among enterprises, or mergers and acquisitions or abuse of dominant positions of market power, which limit access to markets or otherwise unduly restrain competition, adversely affecting domestic or international trade or economic development" (UNCTAD, 2007, p. 3). ${ }^{6}$

Property rights institutions

- Effectiveness of legal measures to defend property rights between private agents (A6000)

- Degree of reasonable compensation in the event of de-jure or de-facto expropriation of land property (A6001)

- Degree of reasonable compensation in the event of de-jure or de-facto expropriation of property for production (A6002)

- Frequency of arbitrary government pressure on private property (e.g. using red tape) (A6003)

- Respect for intellectual property protection in terms of manufacturing secrets, patents (B6020)

- Respect for intellectual property protection in terms of counterfeiting (B6021)

Contract institutions

- Predictability of the results of public procurement contract bids (A3040)

- Independence of the commercial courts from the government in commercial disputes (A6020)

- Extent of enforcement and speed of commercial court rulings (A6023)

- Extent of enforcement of bankruptcy law (A6030)

Competition institutions

- Degree of administrative barriers (e.g. red tape) restricting firm entry (B7000)

- Effectiveness of competition regulation arrangements (non-banking) to combat restrictive collective agreements i.e. cartels (B7020)

- Effectiveness of competition regulation arrangements (non-banking) to combat abuses of dominant positions (B7021)

- Existence of competition arrangements in the banking system to combat restrictive collective agreements i.e. cartels (C7010)

- Existence of competition arrangements in the banking system to combat abuse of dominant position (C7011)

We consider the IPD data an interesting alternative to the data used, for example, by Acemoglu and Johnson (2005) to measure property rights and contracting institutions. Acemoglu and Johnson (as well as Tressel and Detragiache, 2008 and Quintyn and Verdier, 2010) measure property rights protection using data from

\footnotetext{
6 Competition policy generally comprises the following elements: antitrust and cartels, market liberalization, state aid control, and merger control. Because competition policy is formalized in countries' legal framework, in the context of this study we prefer the label 'competition institutions'.
} 
Marshall and Jaggers (2009) as a proxy. ${ }^{7}$ This data may be unfit to capture property rights institutions because, as described by Glaeser et al. (2004), 'constraint on the executive' is a volatile measurement which is more a reflection of the result of elections. ${ }^{8}$ In order to measure the effect of contracting institutions on credit deepening, Acemoglu and Johnson (2005) use de-jure descriptions of legal arrangements intended to protect contracts. However, the existence of de-jure rules does not in itself guarantee that these rules are followed.

The core concern with estimating the effect of types of institutions on credit deepening when the using the IPD data is that the variables are empirically closely related: the correlation of the variables is around 0.6. We use principal component analysis (PCA) with varimax orthogonal rotation to create three institutional indicators. The varimax rotation method is chosen because it produces principal components (PCs) that contain high loadings for a few variables. ${ }^{9}$ Three PCs are retained because the variable selection is made with the objective to describe three institutional types (property rights, contracting and competition).

Figure 2.1 presents the results - the factor loadings - of the PCA. Principal component 1 (PC1) contains $32 \%$ of the total variation. This PC loads highly on the variables B7020, B7021, C7010, and C7011 which describe the degree of existence and effectiveness of competition regulations. PC1 is therefore interpreted as the component describing the degree of formalization of competition institutions. Countries that score highly on this PC are for example Ireland, Korea, and the Netherlands. Countries that score lowly on this PC are for example Kuwait, Qatar, and Mali. The lower bound of the PC captures countries that have little or no arrangements to stimulate competition.

Principal component 2 (PC2) contains $25 \%$ of the total variation and loads highly on the variables A6001 and A6002. These variables describe the degree of reasonable compensation granted in the event of expropriation of property. $\mathrm{PC} 2$ is therefore identified as describing institutional rules to secure property rights. The upper bound of PC2 describes countries that have secured property rights protection across sectors. Countries that score highly on this component are Slovenia, Czech Republic, and Kuwait. Countries that score lowly on component 2 are Pakistan, Cameroon, and Syria.

Principal component 3 (PC3) contains $21 \%$ of the total variation and loads highly on variable A3040 which describes the predictability of the results of public procurement contract bids. This PC captures the de-facto role of the state in contracting. Countries that have transparent contracting regulations score on the upper bound of this component, for example Finland, Cyprus, and Philippines.

7 Tressel and Detragiache (2008, p. 16) argue that only countries with stronger constrains on executive experience sustainable financial acceleration after a financial reform, and that creditor rights, contract enforcement, and legal origins do not determine the success of sustainable financial accelerations. Similarly, Quintyn and Verdier (2010) find that countries' probability to achieve a period of sustained long-run financial development after a financial acceleration is positively influenced by 'constraint on executive' and the durability of democracy.

${ }^{8}$ Following calculations on the basis of the sample of 88 countries used throughout this study, the indicator 'constraint on the executive' indeed has more variation over time than between countries.

9 The PCA is run using the 88 countries listed on page 34 in the appendix. The PCA is run using the Stata command 'factor' with specification pcf. 
Countries that score lowly on component 3 are Guatemala, Benin, and Chad. In the sequel, PC1 is referred to as Competition, PC2 as Property, and PC3 as Contract.

The results of the PCA do not fully confirm our tentative categorization of variables. In particular, we find that the variable B7000 which captures the degree of administrative barriers is relatively closer related to Contract. Also, variables B6021 and A6000 are relatively closer related to Contract than to Property. And, contrary to expectations, variables A6023 and A6030 load relatively higher on Competition. Excluding these variables from the PCA has no strong influence on the loadings of the other variables. ${ }^{10}$

Figure 2.1: Construction of Orthogonal Institutional Measurements

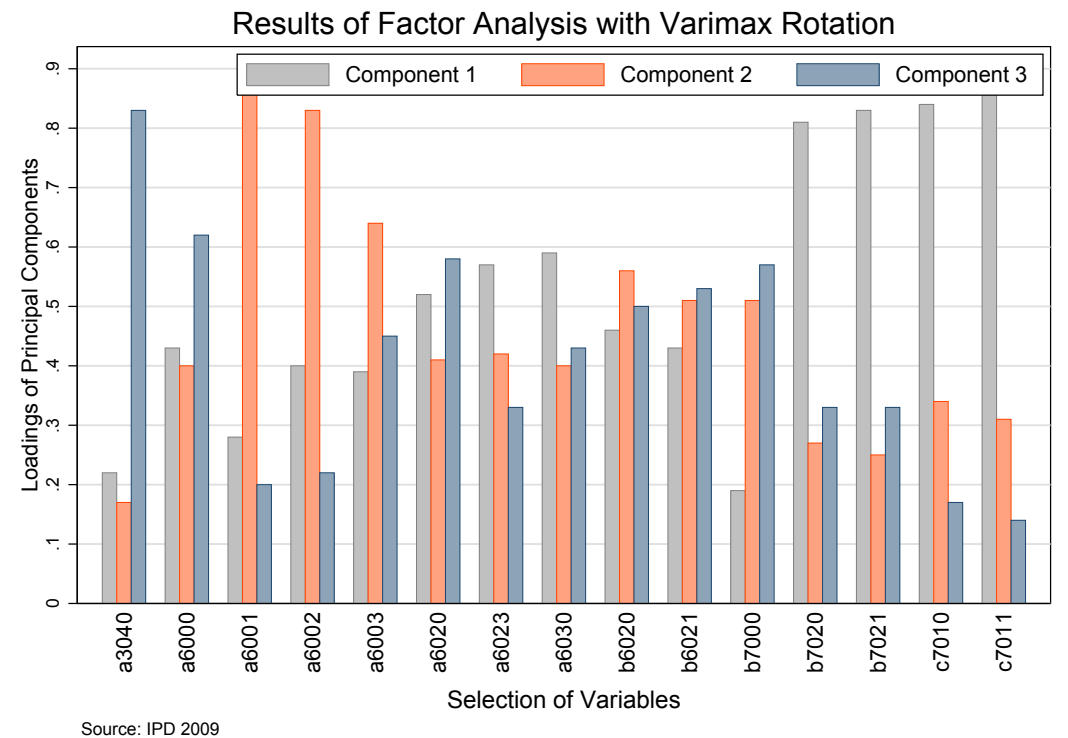

As illustrated by the scatter plots and the correlation table in the appendix of this chapter, higher levels of credit in the private sector are associated with higher values of Competition, Property, and Contract. European countries score on the upper bound of the institutional indicators but differ substantially in the level of credit to the private sector. Some more pronounced differences between the institutional indicators include Qatar and Kuwait that score lowly on Competition but highly on Property. Syria, Philippines, and Pakistan score lowly on Property but highly on Contract. Chad, and the Czech Republic score lowly on Contract but highly on Property. Argentina, Cameroon, China, and India score lowly on Property but highly on Competition. Guatemala and Korea score lowly on Contract but highly on Competition.

10 The estimation results (e.g. column 3 Table 2.1) are robust to the exclusion of the variables B7000, B6021, A6000, A6023, and A6030. 


\section{Model and Methodology}

The aim of this study is to estimate effects of the between-country difference of the institutional time-invariant (TI) indicators and both the between-county and overtime variation of the time-varying (TV) indicators. In this section, the basic model is introduced as well as some terminology that is used throughout the remainder of this study.

Our main methodological challenge is the estimation of the effect of TI institutional indicators without biases or inconsistencies. The model is estimated using a HausmanTaylor estimator with Amemiya-MaCurdy (1986) specification, hereafter AM. The AM method builds on the instrumental variable method proposed by Hausman and Taylor (HT) (1981). ${ }^{11}$ The HT method estimates the parameters using the $\mathrm{TV}$ variables both to estimate their own coefficients and as instruments for the endogenous TI variables (Hausman and Taylor, 1981). The HT method uses the time-average of the TV exogenous variables as instruments. Amemiya and MaCurdy (1986) propose combining the between-country and over-time information of the TV exogenous variables as instruments. The model is mathematically represented by equation 2.1 below.

$$
Y_{i, t}=\beta X_{i, t}+\gamma Z_{i}+\alpha_{i}+\epsilon_{i, t}
$$

$Y_{i, t}$ is the dependent variable, the ratio of credit to the private sector to GDP in country $i$ in year $t$. $\alpha_{i}$ represents the unobservable country-specific effects. $\alpha_{i}$ is assumed a random variable that is distributed independently across our country sample with constant variance $\sigma_{\alpha}^{2} . \epsilon_{i, t}$ is the error term and is assumed to have a zero mean and constant variance $\sigma_{\epsilon}^{2}$, conditional on $X_{i, t}$ and $Z_{i} . X_{i, t}$ is a vector of TV indicators and is assumed to contain both exogenous and endogenous indicators. $Z_{i}$ is a vector of TI indicators and also is assumed to contain both exogenous and endogenous indicators. The endogenous part of $Z_{i}$ contains the institutional indicators. Only the between-country variation of the institutional characteristics is observed and the institutional characteristics are assumed inert in the medium-term.

The vector $X_{i, t}$ includes several macroeconomic indicators. Data sources are given in the appendix of this chapter. We control for the effect of savings (Savings) on $Y_{i, t}$ because the availability of collateral is a major requirement for creditors. Countries' external debt (ExternalDebt) may be negatively related to financial development. Countries that have a large capital account surplus may rely on foreign funding for investment instead of stimulating saving and investment in the domestic economy. We control for the influence of exchange rates (ExchangeRate). Finally, we control for inflation (Inflation) measured as the rate of change in the consumer price index. High inflation discourages lending. All these variables are assumed to be exogenous, i.e., uncorrelated with $\alpha_{i}$ and $\epsilon_{i, t}$.

The following TI indicators are used: incidence of malaria (Malaria), temperate zones (Temperate), and ethnic (Ethnic), linguistic (Language), and religious fragmentation (Religion). ${ }^{12}$ These are all assumed to be exogenous.

\footnotetext{
11 The Hausman-Taylor estimator with Amemiya-MaCurdy specification is typically used less frequently than the estimator of Hausman and Taylor (1981) because it requires balanced data. One alternative application of the model in the field of finance is that of Tchakoute-Tchuigoa (2012).

12 Acemoglu and Johnson (2005) use an IV approach with legal origins and settler mortality as
} 
On the one hand, several scholars argue that the development of institutions is related to deep historical roots; for instance see Spolaore and Wacziarg (2013) for a comprehensive overview of this literature. For example, Engerman and Sokoloff (1997), propose that countries' natural resources and climate influences institutional development. Acemoglu et al. (2001) argue that the incentives of establishing early settlements and developing formal property rights is related to malaria incidence and tropical climates. Similarly, tropical climates may be related to relative underdevelopment of contracting institutions. Also, it is more likely that industry developed in countries with temperate zones favorable to agricultural development. As a result, in such areas there may be a higher need for competition institutions. On the other hand, institutional formalization may be related to class fragmentation. The formalization of competition regulations may be influenced by ethnic fragmentation; high ethnic fragmentation may contribute to the economic/political dominance of a (small) ethnic majority. Countries with high linguistic fragmentation may have established more formal regulations to facilitate business. In countries with religious fragmentation, states may have had more incentive to separate the church from private sector regulations. Thereby, such countries may have early establishments of a more formal institutional setting.

In order to assess the sensitivity of the data to unobserved unit effects and reverse causality, the model is also tested using OLS with panel corrected standard errors $(\mathrm{PCSE})^{13}$ and fixed effects vector decomposition, hereafter FEVD. ${ }^{14}$

A Hausman specification test rejects a random effects model over a fixed effects model. A Hausman test of the difference between a FE model and Amemiya-MaCurdy (AM) yields a $\chi^{2}$ value of 0.37 , which is insignificant; this supports estimating using AM. ${ }^{15}$ The low $\chi^{2}$ statistic indicates that the coefficients of the FE estimation and the AM estimation are close. A Hausman test based on the difference between HT and $\mathrm{AM}$ yields a $\chi^{2}$ value of 3.47 which also is insignificant. Thereby, this Hausman test does not reject the additional exogeneity assumptions of AM.

instruments for property rights and contracting. These frequently used indicators are both based on the argument that the legal system and institutional heritage of countries influence today's institutions. Scholars have extensively argued that these indicators suffer from measurement bias, reverse-causality and/or estimations may suffer from omitted variable bias, in particular see Albouy, 2012 for a critique of Acemoglu et al. (2001) and the use of settler mortality data.

13 PCSEs, as proposed by Beck and Katz (1995), correct for 'extreme overconfidence' and yield standard errors that are within $10 \%$ of the true variability, also for data containing heteroskedasticity and contemporaneously correlated errors. PCSE does not address unit effects.

14 The FEVD estimates for TV variables are the same as Fixed Effect (FE) estimates and are assumed endogenous. Unlike FE estimations, FEVD estimates TI variables in panel data models with unit effects. TI variables are assumed exogenous and the method does not control for causality. FEVD and HT estimators provide equal results when all TV variables are treated as endogenous and the TI variables are treated as exogenous (Breusch et al., 2011). FEVD has received several critiques, e.g. see Greene (2011), Chatelain and Ralf (2010) and Breusch et al. (2011). The FEVD estimations here are based on an updated 2009 version (xtfevd4.0beta.ado) with revised standard errors (Plumper and Troeger, 2011).

15 The Hausman tests are based on the estimations presented in Table 2.1 where Competition, Property, and Contract are endogenous. 


\section{$2.3 \quad$ Results}

\section{Descriptive Statistics}

This study is based on a balanced panel dataset for the period 1994 to 2005 . The sample of countries used throughout the analyses is listed in Table 2.5 in the appendix. ${ }^{16}$

There is substantial cross-country variation in the level of credit to the private sector. As illustrated by Figure 2.2 in the appendix, the average of countries' ratio of credit to the private sector to GDP during 1994-2005 ranges from less than $10 \%$ to more than $150 \% .{ }^{17}$ In Table 2.6 in the appendix are the summary statistics for the sample. The average level of credit to GDP is $47.35 \%$. Figure 2.3 in the appendix illustrates the variation of credit to GDP by geographic region. The data show that the level of credit to the private sector are high in some geographic regions and low in other regions. For example, in Sub-Saharan Africa the ratio of credit to GDP is low.

\section{Main Results}

Table 2.1 reports the relation between credit to the private sector and institutional characteristics whilst controlling for macroeconomic influences. Column 1 to 3 report the estimation results using the different regression methods. There is a strong and significant relationship between credit and the formalization of institutional characteristics. Unlike the OLS with PCSE and FEVD methods, the AM method seeks to control for endogeneity of the institutional indicators. The magnitude of the institutional coefficients is relatively similar which suggests that there is limited reverse causality between credit deepening and the development of formal institutional rules. Alternatively, one possibility is that the AM method is not sufficient to address endogeneity and therefore, we cannot exclude the possibility of reverse causality: i.e. that credit deepening triggers the establishment of more formal institutional rules.

The AM estimations in column 3 report that the formalization of competition, property and contract institutions is significantly and positively related to credit deepening. ${ }^{18}$ Temperate and Malaria are significant at a $10 \%$ level and have a direct impact on credit deepening. Following the results of the OLS estimation, Religion and Language are also related to credit deepening. ExternalDebt and Savings have the expected sign, are significant, and the estimations are relatively constant across

\footnotetext{
16 The countries Azerbaijan, Brazil, Bulgaria, Democratic Republic of Congo, Iran, India, Kazakhstan, Paraguay, Ukraine, Zimbabwe, and Zambia are not included in the sample because of hyperinflation rates and/or high levels of exchange rate over-valuation.

17 The dependent variable Credit has missing data for the following countries: Austria, Belgium, France, Mauritania, Netherlands, and Norway. These countries are excluded when using the variable Credit. In addition, Japan is excluded because of the country's high level of credit. For some countries, data on the credit claims includes credit to public enterprises.

18 The first PC (Competition) contains the highest of the total variation and therefore we expect that this PC is more closely related to the overall dimension of institutional formalization than Property and Contract. For this reason, the relative contribution of each institutional characteristics is not emphasized.
} 
regressions. The coefficients for Inflation and ExchangeRate are close to zero.

Column 4 in Table 2.1 reports the aggregate / combined magnitude of the formalization of institutional characteristics on the private sector, measured by Composite. Composite is measured by the first retained PC from an unrotated PCA on the total selection of IPD variables. Unrotated PCA yields only one strong institutional dimension. Composite contains $66 \%$ of the total variation and loads on all underlying variables. ${ }^{19}$ The coefficient of Composite indicates the overall degree to which the institutional characteristics are related to financial depth. ${ }^{20}$ The coefficient of Composite is higher than the coefficient of Competition, Property and Contract. The effect of overall institutional quality on financial deepening appears to be substantial. The coefficient of Composite in the AM model, column 4, suggests that, on average, a one standard deviation increase in this variable corresponds to a 0.71 standard deviation increase in credit to the private sector as a percentage of GDP. $^{21}$

One concern with data on credit to the private sector is that high levels of credit may be an indication of excess borrowing and of suboptimal allocation of credit. Especially since 2008, it is undeniable that rapid private credit build-up, caused by financial system deregulation and privatization, can have a negative impact on economic growth. Additionally, Arcand et al. (2013) shows that bailouts can cause the financial sector to increase beyond the socially optimum level. As such, there are limitations to the extent to which financial deepening is beneficial to growth. This has also been recognized by previous literature, such as Reinhart and Rogoff (2009) Kindleberger and Aliber (2005), and Minsky (1986). Arcand et al. (2012) find that financial deepening is negatively related to economic growth when the ratio of credit to GDP reaches (roughly) $100 \%$.

For the years 1994-2005, the average ratio of credit to GDP exceeds $100 \%$ for the following countries: New Zealand, Portugal, China, Germany, Thailand, South Africa, United Kingdom, Canada, Malaysia, Switzerland, United States, and Cyprus. The above mentioned countries are excluded in the analysis presented in column 5 and 6 of Table 2.1. By comparing the results in column 3, 4, 5, and 6 , we can identify the extent to which the estimations are influenced by countries with high levels of credit to the private sector.

In specific, the coefficient of Competition is lower in column 5 compared to column 3 suggesting that competition institutions is more important for countries with high levels of credit. One possible explanation is that countries that have a relatively small private sector are typically countries that have lower credit as a ratio of GDP. And, because in such countries there is a basic absence of competition there are less incentives to develop rules to stimulate competition. The coefficient for Property is higher in column 5 compared to column 3 suggesting that property rights protection is more important for countries with low or moderate levels of credit. Although this finding is somewhat surprising one explanation is that countries with a relatively high

\footnotetext{
19 The second PC contains $7 \%$ of the variation and the third PC contains $5 \%$ of the variation.

20 The results of the Hausman tests in section 2.2 are confirmed when Competition, Property, and Contract are replaced by Composite.

21 Analysis using FEVD and OLS with PCSE and the composite indicator likewise suggests a significant and positive relation between institutions and credit deepening.
} 
ratio of credit to GDP invest more in tertiary sectors which are less dependent on property rights protection. The magnitude of the coefficient of Composite is higher in column 3 than in column 5. This suggests that, overall, the private sector is less influenced by the formalization of institutional rules in countries with lower levels of credit.

Table 2.1: Regression Results: Dependent Variable Credit

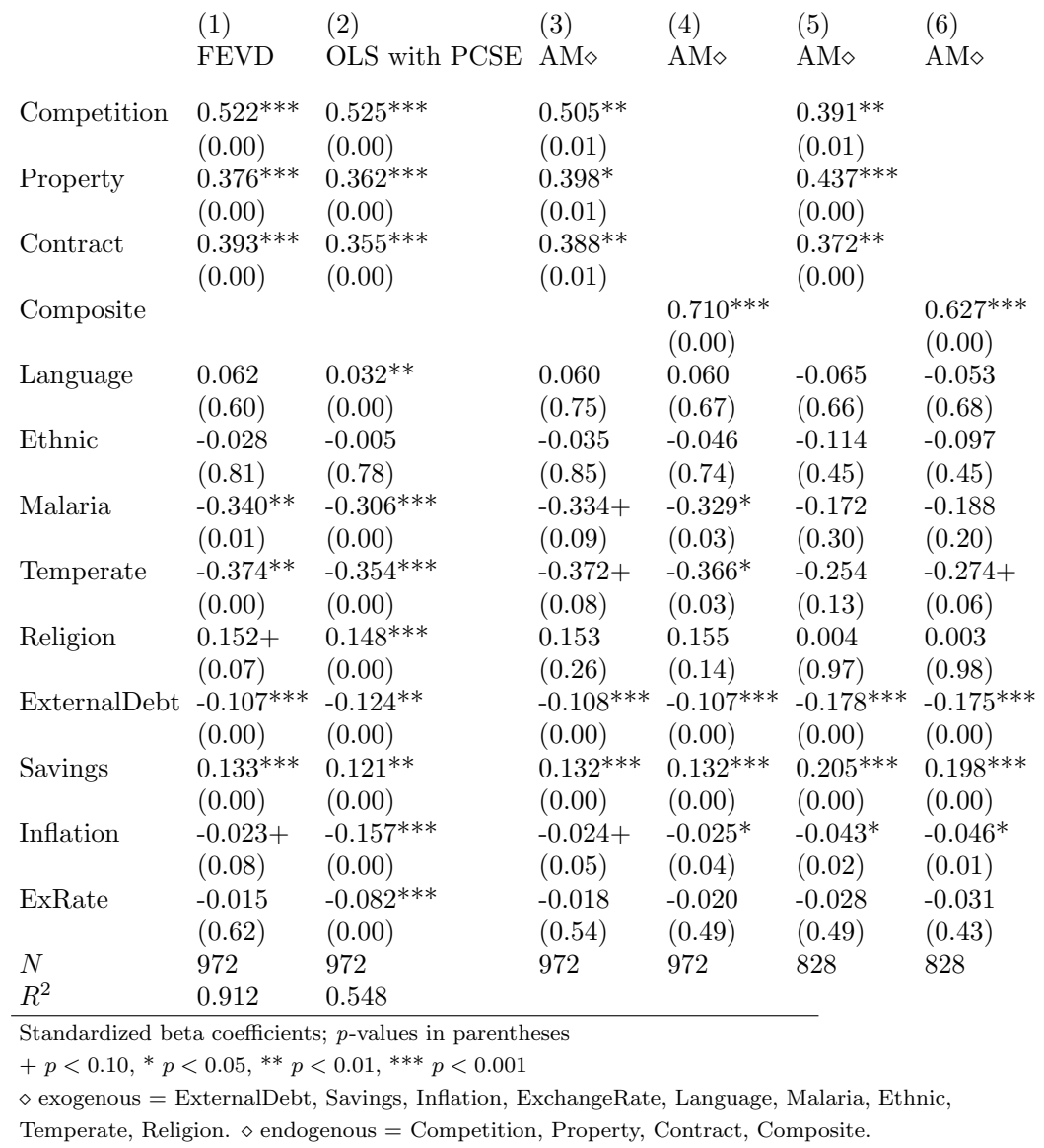

\section{Institutions - Policy Mix}

Financial policy is an important tool for states by which they can influence the allocation of credit. Financial policy may have a positive or a negative impact on credit deepening. We control for the effect of financial policy on credit to the private sector using three indicators from Abiad et al. (2010). We use a smaller sample of 
61 countries. $^{22}$ We control for the influence of the degree of privatization of banks (Privatization, decrease in State ownership), for the effect of the degree of bank supervision (Supervision, decrease in independence from executive influence), and for the effect of entry barriers in the banking sector (Barriers, decrease in state control over credit allocation). These TV policy indicators are assumed to be endogenous.

The privatization of banks could result in more lending to the private sector. La Porta et al. (2002) find that in countries with high government ownership of banks, financial development, productivity and growth is lower. ${ }^{23}$ Privatization could result in more efficient and effective allocation of credit. Furthermore, privatization could result in higher competition, increasing borrowing opportunities for organizations. Yet, in comparison to government-owned banks, the cost of borrowing is generally higher in privatized banks. ${ }^{24}$ High scores on this indicator indicates relatively more privatized banks.

Banking supervision may increase transparency. The implementation of prudential regulations can restrain the allocation of credit into unproductive, high risk projects. In the 1980's, the objective of most high-income countries was financial market deregulation. Since 2008, deregulation is heavily debated by stakeholders with the aim to re-gain control over financial safety. High scores on this indicator represent relatively more government intervention of the banking sector.

The indicator Barriers captures the degree of entry restrictions of banks' activities including restrictions on foreign banks and geographic restrictions on operations. Such entry barriers may restrict the lending capacity of the financial sector. Entry barriers may drive up the cost of borrowing which in return can cause a lower demand for credit. High scores on this indicator represent a more liberal banking sector.

Table 2.2 reports the regression results when the policy indicators are included. Column 1 and 2 report that the effect of banking supervision and entry barriers on the level of credit is significant, and the coefficient is positive, albeit low. We expect that the positive coefficient Barriers indicates that the overall level of credit to the private sector is higher in countries with less restrictions in the banking sector. One alternative possibility is that less restrictions in the banking sector is associated with small economies (low GDP). The coefficient for banking privatization is not significant. Temperate is significant at a $1 \%$ level, and Malaria is significant at a $5 \%$ level. The coefficients for Temperate and Malaria are substantially higher in Table 2.2 than in Table 2.1. Religion is significant at a $10 \%$ level. On the one hand, when controlling for policy, the coefficients of Contract, Property and Composite are higher. On the

\footnotetext{
22 The following countries are excluded because of missing policy data: Benin, Botswana, Central African Republic, Cyprus, Gabon, Honduras, Kuwait, Libya, Mali, Mongolia, Mauritania, Niger, Panama, Qatar, Saudi Arabia, Sudan, Slovak Republic, Slovenia, Syrian Arab Republic, Chad, and Togo. In addition, the following countries are excluded: Austria, Belgium, France, Netherlands, Norway, and Japan. See also footnote 17.

23 Following the political view, La Porta et al. (2002) explain that "government ownership leads to miss-allocation of resources" and that "governments are less able to use banks they own to redistribute wealth to political supporters when they are subject to greater oversight by the electorate. As a consequence they have less interest in owning such banks" (La Porta et al., 2002, p. 188,179).

24 Government-owned banks may select less risky projects to finance. On the basis of a model of banking Andrianova et al. (2008, p. 230) find that "where private and government-owned banks co-exist, the former will offer a higher interest rate to depositors reflecting the higher risk".
} 
other hand, the coefficient for Competition is lower. The change in the coefficient of Competition is not surprising because market competition regulations and the types of financial policy discussed above are closely related aspects in terms of public sector governance.

Table 2.2: AM Regression Results: Dependent variable Credit

$\begin{array}{ll}\text { Competition } & \begin{array}{l}0.39^{*} \\ (0.02)\end{array} \\ \text { Property } & \begin{array}{l}0.44^{* *} \\ (0.00)\end{array} \\ \text { Contract } & \begin{array}{l}0.40^{* *} \\ (0.00)\end{array} \\ \text { Composite } & \end{array}$

Composite

Privatization

$-0.02$

$(0.50) \quad(0.49)$

Supervision $\quad 0.07^{* *} \quad 0.07^{* *}$

$\begin{array}{lll} & (0.00) & (0.00)\end{array}$

Barriers $\quad 0.09^{* *} \quad 0.09^{* *}$

Language $\quad 0.02 \quad 0.01$

$\begin{array}{lll} & (0.91) & (0.93) \\ \text { Ethnic } & -0.03 & -0.01\end{array}$

(0.89) $(0.96)$

Malaria $\quad-0.42^{*} \quad-0.40^{*}$

$(0.03) \quad(0.02)$

Temperate $\quad-0.62^{* *}-0.61^{* *}$

(0.01) (0.00)

Religion $\quad 0.22+\quad 0.21+$

$(0.09) \quad(0.06)$

ExternalDebt $-0.15 * * *-0.15 * * *$

$\begin{array}{lll} & (0.00) & (0.00) \\ \text { Savings } & 0.24^{* * *} & 0.24^{* * *}\end{array}$

$(0.00) \quad(0.00)$

Inflation $\quad-0.02 \quad-0.02$

$(0.34) \quad(0.31)$

ExchangeRate $-0.04 \quad-0.05$

$(0.21) \quad(0.18)$

$N \quad 732 \quad 732$

$+p<0.10,{ }^{*} p<0.05,{ }^{* *} p<0.01,{ }^{* * *} p<0.001$

Exogenous $=$ ExternalDebt, Savings, Inflation, ExchangeRate,

Language, Malaria, Ethnic, Temperate, Religion. Endogenous = Competition,

Property, Contract, Composite, Privatization, Supervision, Barriers. 


\section{Alternative Dependent Variables}

In this section, we present the estimation results using alternative dependent variables. ${ }^{25}$ First, we test the impact of institutional characteristics on the level of domestic bank credit to the private sector (BankCredit). ${ }^{26}$ Unlike the dependent variable Credit, this indicator does not include the volume of credit issued by development banks. The correlation between these indicators is 0.97. Second, we test our model using the ratio of bank deposits to GDP. ${ }^{27}$ The correlation between Credit and BankDeposit is 0.85 . Third, the model is also estimated using investment as a share of GDP as the dependent variable (Investment). The correlation between Credit and Investment is 0.49 .

The estimations results are reported in Table 2.3. When using BankCredit as the dependent variable the AM method yields coefficients for the institutional indicators that are relatively similar to those presented in Table 2.2. In column 3 and 4, Property, Contract, and Composite are significantly related to the ratio of bank deposits to GDP, although their estimated impact is lower. The coefficient for Competition is not significant. This suggests that banks' lending capacity is dependent on the formalization of property rights and contracting but is unrelated to competition institutions.

The regression results in column 5, with Investment as the dependent variable, indicate that formal competition institutions has a positive and significant impact on the ratio of investment to GDP. Composite is likewise related to Investment, presumably because of the underlying competition indicator. The coefficients for Property and Contract are not significant. Countries that have substantially higher levels of investment have implemented formal competition institutions. Some oil rich countries have strong property rights protection but have relatively low competition and relatively lower levels of investment as a percentage of GDP. This could imply that the translation of credit deepening into higher levels of investment requires the implementation of competition regulations. When using investment as the dependent variable, the coefficients of Temperate are close to zero whilst the coefficients for ExternalDebt and Savings are high.

In contrast to the estimation results with $C$ redit as the dependent variables, the estimations in Table 2.3 report a significant impact of all policy indicators. The models in column 1 to 4 suggest that privatization of the banking sector has had a negative effect on the ratio of bank deposits to GDP and the ratio of bank credit to the private sector to GDP. From column 5 and 6 we conclude that privatization is important for stimulating investment, albeit its effect is small.

Overall, both the formalization of institutional characteristics and financial policy are important for countries' financial market. Nevertheless, the differences across the models support the thesis that the development of formal institutions is a stage by stage process.

\footnotetext{
25 As in section 2.3, countries with missing policy data are excluded. See also footnote 22. Data sources are given in the appendix.

26 This regression analysis does not include data for Austria, Belgium, Botswana, France, Japan, Netherlands, and Norway.

27 The countries Austria, Belgium, Bangladesh, China, France, Japan, Libya, Netherlands, and Qatar are excluded from this regression analysis.
} 
Table 2.3: AM Regression Results: Alternative Dependent Variables
(1)
$(2)$
(3)
(4)
(5)
(6)

BankCredit BankCredit BankDeposit BankDeposit Investment Investment

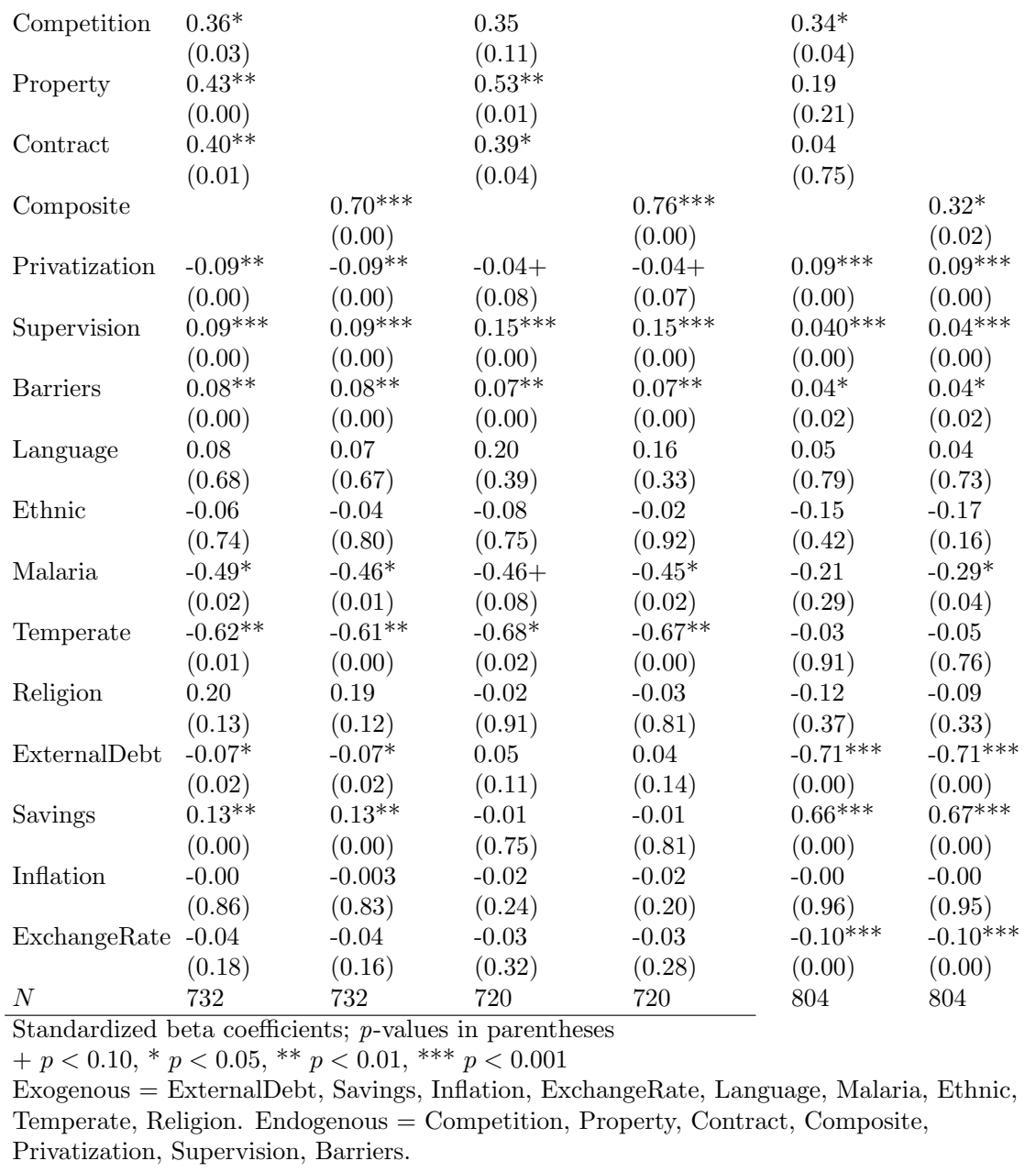

\section{Robustness}

The dynamics are further explored by lagging the TV macroeconomic and policy variables by one year. The importance of substituting a current value with a one year lag may be relevant for the estimation of some countries. The regulatory processes to obtain credit may be relatively slower in countries that have relatively low levels of credit. The estimation results with the lagged variables are reported in Table 2.4 column 1, 2, 3, and 4. As expected, the estimations for the institutional indicators remain positive and significant. Several coefficients of institutional indicators are 
lower than the coefficients of institutional indicators presented in Table 2.1 and Table 2.2 but overall the coefficients have similar magnitudes. This suggests that the effect of institutions on financial deepening is relatively stable. The coefficients of the policy variables are marginally lower but likewise remain positive and significant. This result suggests that, based on our sample of countries, banking supervision and financial barriers do not have a substantial delayed effect on credit markets. In addition, we smooth the TV data into five year average levels and growth rates. Current values are substituted for the average of the observations in the current year and for those in the previous four years. The results are presented in Table 2.4 column 5, 6, 7, and 8. Again, as expected, the institutional variables remain positive and significant. However, the policy indicators are not significant. This supports the thesis that financial policy only has an impact on short term macroeconomic changes. 
Table 2.4: Robustness Tests. AM Regression Results: Dependent Variable Credit Models with lags Models with smoothed averages

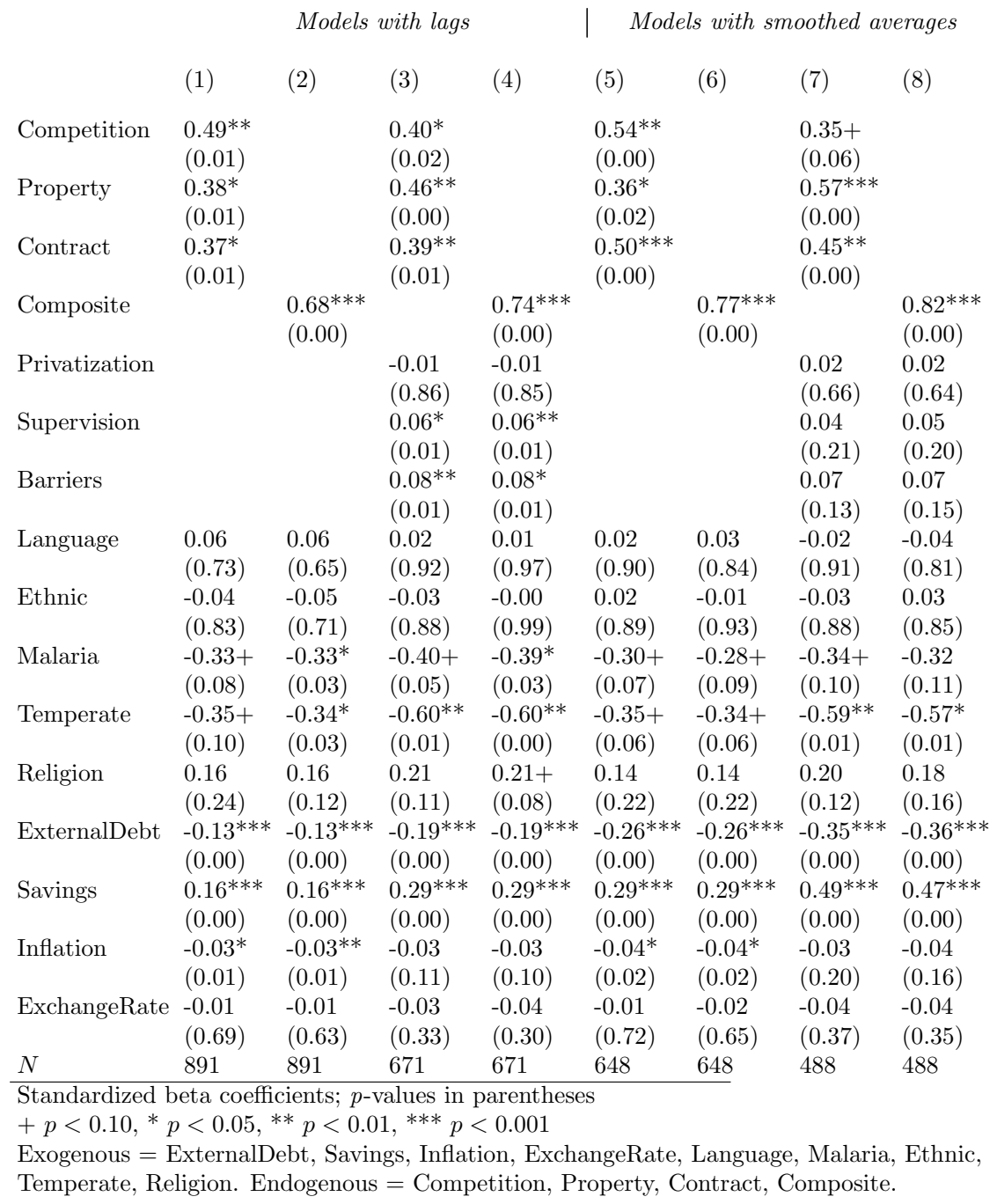

\subsection{Conclusion}

The results of this study only partially confirm those of Acemoglu and Johnson (2005). Following these authors' conclusive argument, property rights institutions are related to countries' level of credit to the private sector. However, the authors find that contracting institutions do not matter for credit deepening. Our findings are in line with the conclusions drawn by La Porta et al. (2000) who argue that creditor rights, which protect investors from expropriation, encourages financial development. We find empirical evidence that suggests a strong positive relationship 
between credit deepening and the development of formal property rights, contracting, and competition institutions. Our results also suggest that only property rights and contracting institutions are related to banks' lending capacity, and that only competition institutions have a positive impact on investment. Based on a broader indicator of institutional development we conclude that the development of formal institutions is positively related to financial deepening and to the ratio of investment to GDP.

The financial sector is an important intermediating factor in the institutions - growth relationship. Before the crisis, formal institutional rules were generally described as beneficial because of their association with high volumes of credit. Since the crisis, more focus is on understanding the extent to which credit deepening is beneficial for economic growth. We emphasize that a lack of credit to the private sector is expected to form an obstacle to growth and development.

This study documents why institutional characteristics are difficult to measure. On the one hand, composite institutions / governance indicators as well as broad institutional surveys can not be used to assess a country's performance on specific institutional aspects. On the other hand, specific institutional aspects are closely related amongst each other and are closely related to composite indicators. Therefore, we estimate the impact of closely related institutional characteristics by constructing orthogonal institutional indicators. Policymakers need to be careful when assessing a country's institutional development. Because of the interrelatedness of the institutional characteristics, institutions may be best documented on the basis of a more general institutional dimension.

This study would benefit from further analysis on the impact of institutional characteristics on credit markets, investment, and growth. Questions that arise include: Under what institutional conditions does credit deepening have a positive effect on growth? What is the effect of institutional formalization on informal lending? 


\subsection{Appendix 2A}

Table 2.5: Country List

\begin{tabular}{|l|l||l|l||l|l|}
\hline Code & Country & Code & Country & Code & Country \\
\hline ARG & Argentina & GHA & Ghana & PAK & Pakistan \\
AUS & Australia & GRC & Greece & PAN & Panama \\
BEN & Benin & GTM & Guatemala & PER & Peru \\
BFA & Burkina Faso & HND & Honduras & PHL & Philippines \\
BGD & Bangladesh & HUN & Hungary & POL & Poland \\
BOL & Bolivia & IND & India & PRT & Portugal \\
BWA & Botswana & IRL & Ireland & QAT & Qatar \\
CAF & Central African & ISR & Israel & ROM & Romania \\
& Republic & & & & \\
CAN & Canada & ITA & Italy & RUS & Russia \\
CHE & Switzerland & JOR & Jordan & SAU & Saudi Arabia \\
CHN & China & KEN & Kenya & SDN & Sudan \\
CIV & Cote d'Ivoire & KOR & Korea, Rep. & SEN & Senegal \\
CMR & Cameroon & KWT & Kuwait & SVK & Slovak Republic \\
COL & Colombia & LBY & Libya & SVN & Slovenia \\
CYP & Cyprus & LKA & Sri Lanka & SWE & Sweden \\
CZE & Czech Republic & LTU & Lithuania & SYR & Syria \\
DEU & Germany & LVA & Latvia & TCD & Chad \\
DNK & Denmark & MAR & Morocco & TGO & Togo \\
DOM & Dominican & MDG & Madagascar & THA & Thailand \\
& Republic & & & & \\
DZA & Algeria & MEX & Mexico & TUN & Tunisia \\
ECU & Ecuador & MLI & Mali & TUR & Turkey \\
EGY & Egypt & MNG & Mongolia & TZA & Tanzania \\
ESP & Spain & MOZ & Mozambique & UGA & Uganda \\
EST & Estonia & MYS & Malaysia & URY & Uruguay \\
FIN & Finland & NER & Niger & USA & United States \\
GAB & Gabon & Nepal & New Zealand & ZAF & Venezuela \\
GBR & United & Kingdom & & \\
& & & & \\
\hline
\end{tabular}




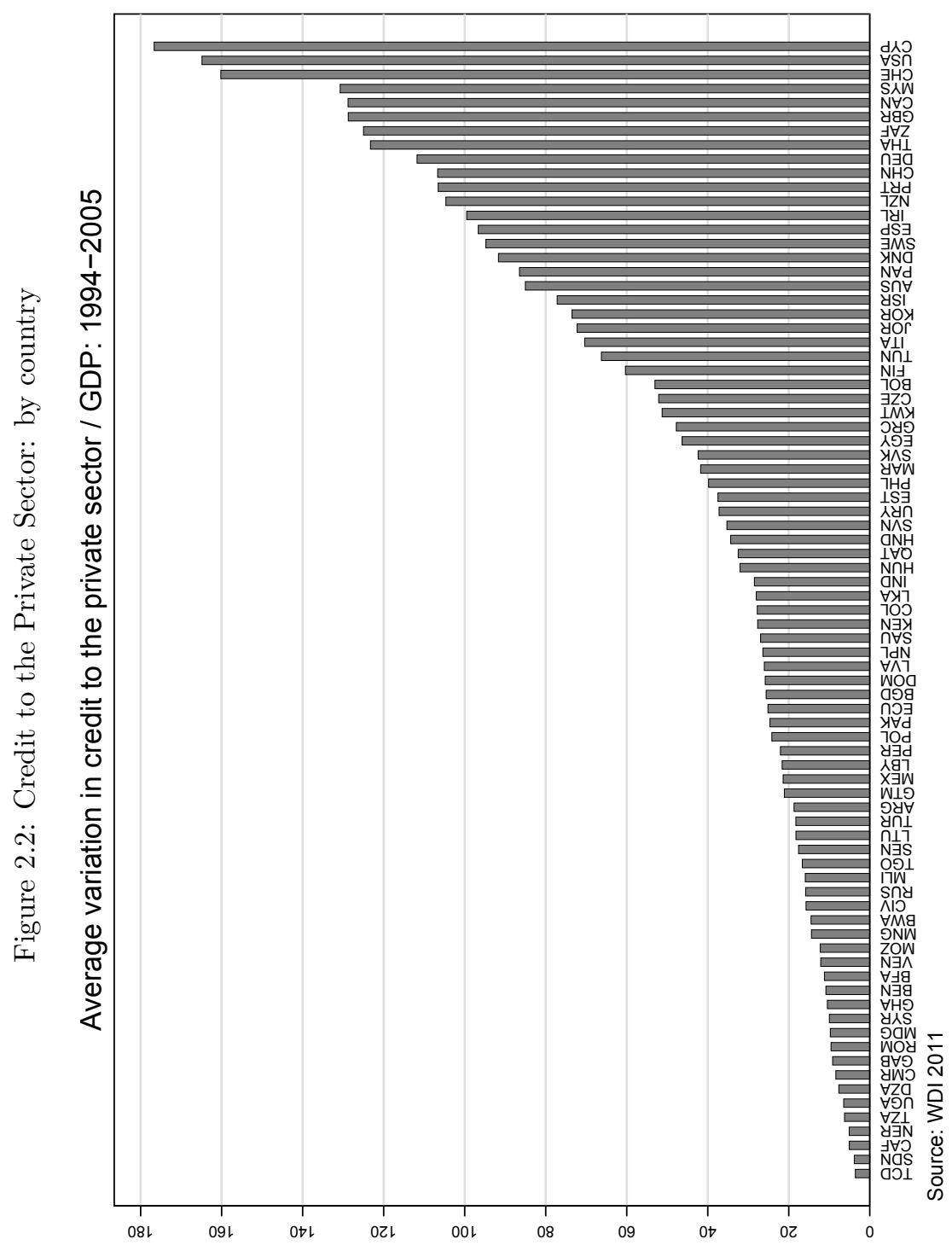


Figure 2.3: Credit to the Private Sector: by region

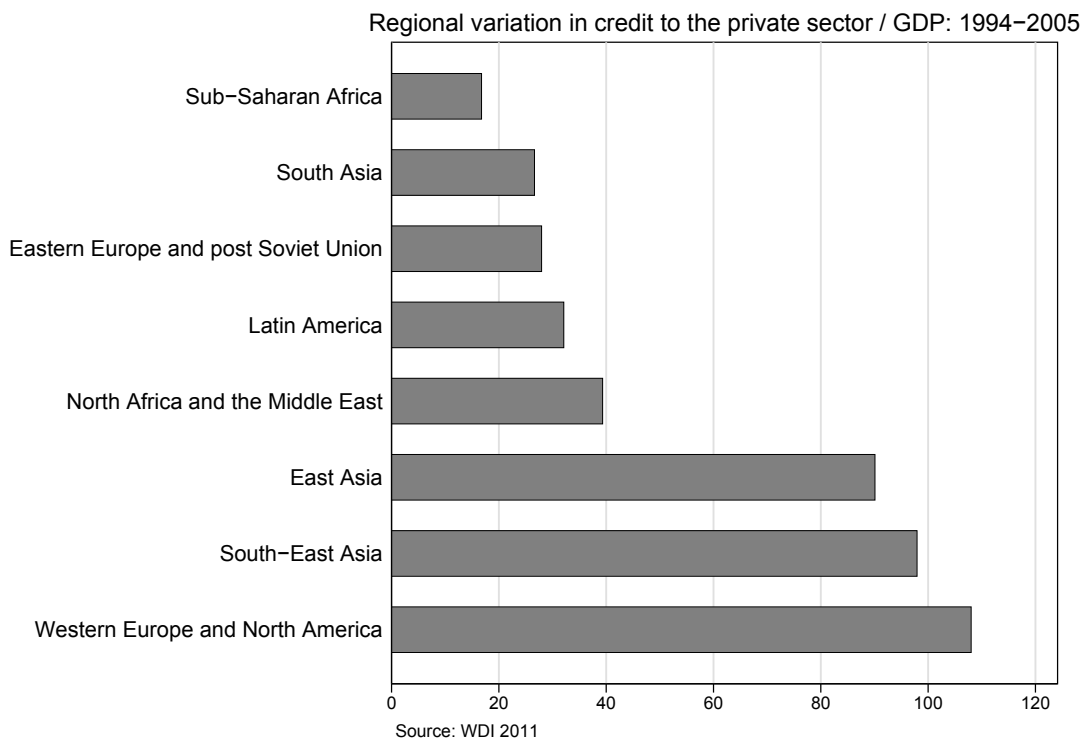

Table 2.6: Summary Statistics

\begin{tabular}{|l|lllll|}
\hline & Mean & $\begin{array}{l}\text { Standard } \\
\text { Deviation }\end{array}$ & Min & Max & $\begin{array}{l}\text { Number of } \\
\text { observations }\end{array}$ \\
\hline Credit & 47.35 & 45.10 & 0 & 231.70 & 972 \\
Credit* & 52.77 & 45.29 & 0 & 195.52 & 732 \\
BankCredit* & 65.10 & 48.32 & 1.89 & 225.17 & 732 \\
BankDeposit* & 43.76 & 28.84 & 6.66 & 151.28 & 720 \\
Investment* & 20.85 & 9.30 & 1.16 & 48.61 & 804 \\
Composite & 0.47 & 0.31 & 0 & 1 & 1056 \\
ExternalDebt & -1.66 & 10.73 & -100.97 & 44.95 & 1056 \\
Savings & 20.21 & 11.52 & -40.81 & 69.61 & 1056 \\
Inflation & 9.00 & 18.63 & -9.80 & 307.63 & 1056 \\
ExchangeRate & 182.71 & 382.12 & 0.03 & 2877.65 & 1056 \\
Privatization & 1.77 & 1.12 & 0 & 3 & 804 \\
Supervision & 1.64 & 0.92 & 0 & 3 & 804 \\
Barriers & 2.65 & 0.72 & 0 & 3 & 804 \\
\hline
\end{tabular}

*Summary statistics for sample with policy indicators 


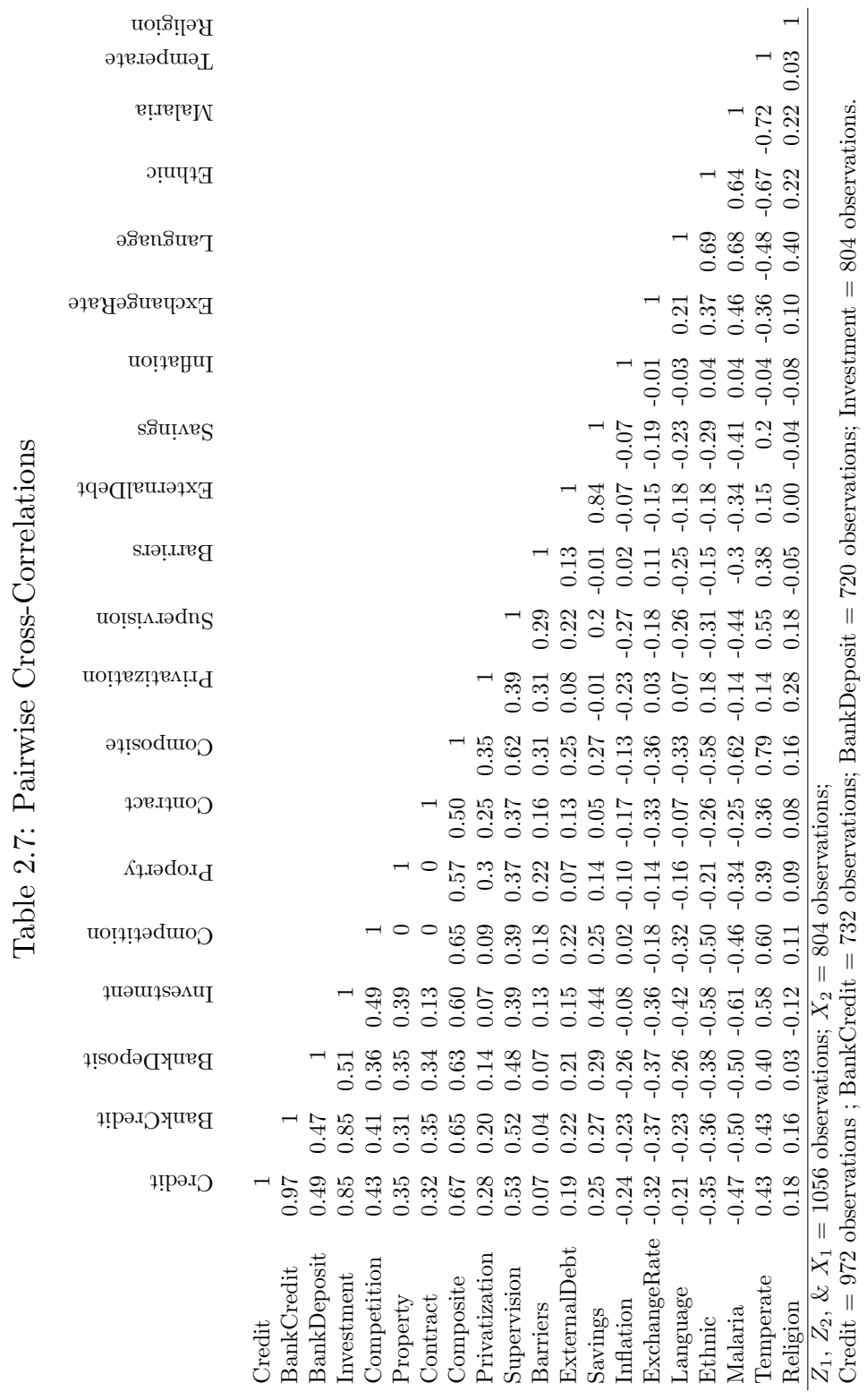


Figure 2.4: Scatter Plots: Credit and Institutional indicators
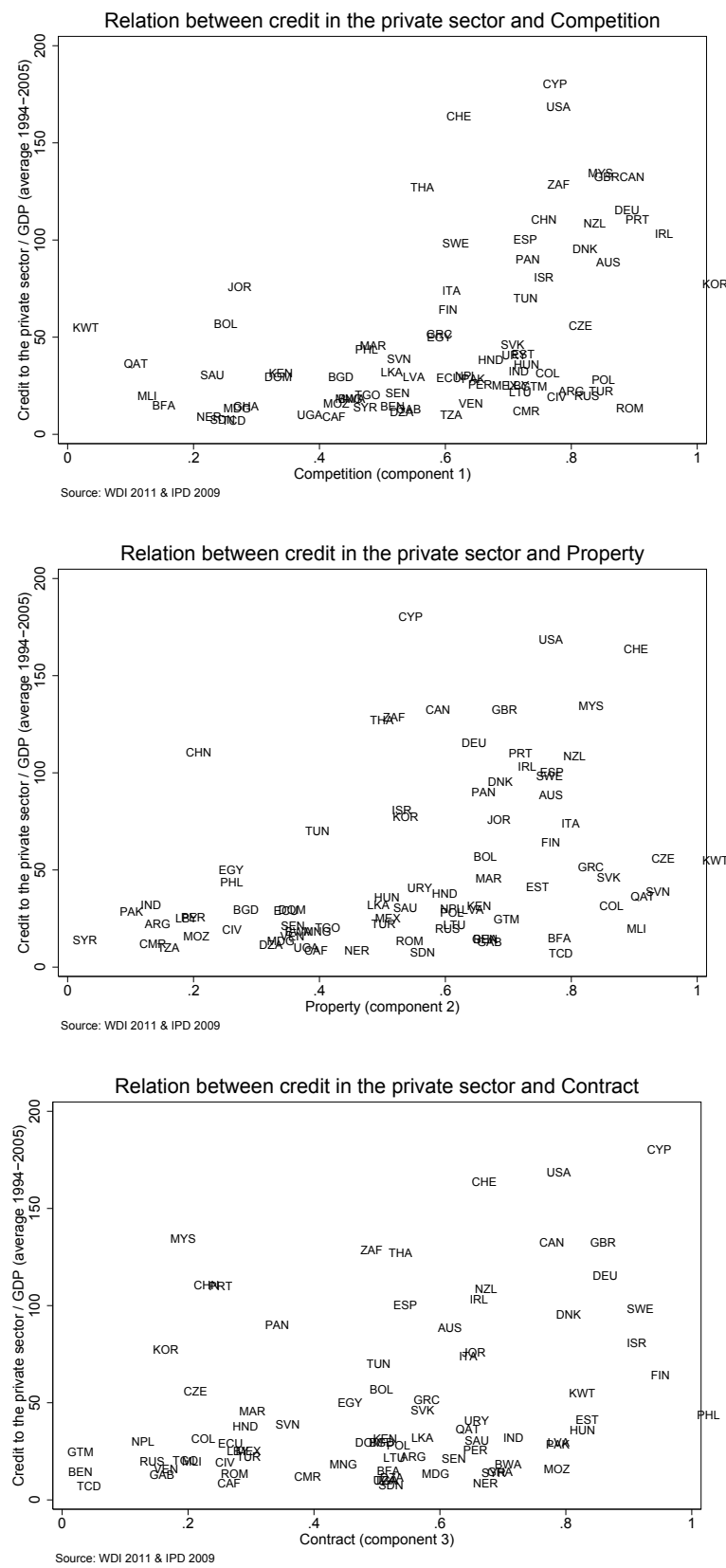
Figure 2.5: Scatter Plots: Credit and Composite

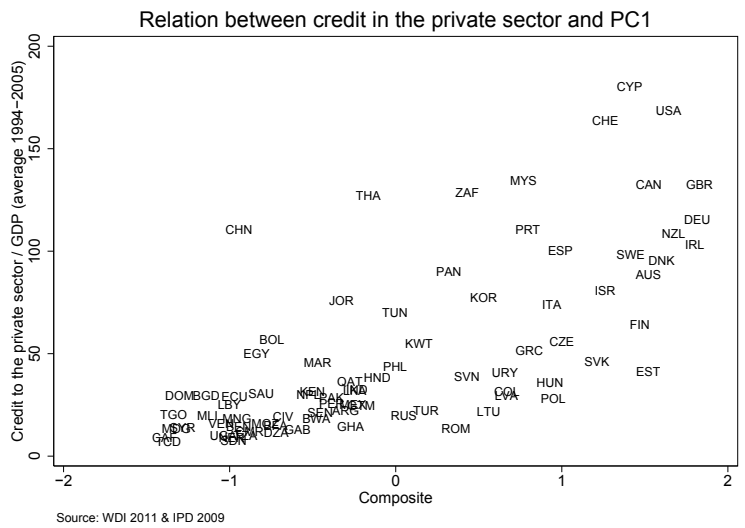

Table 2.8: Sources

\begin{tabular}{|c|c|c|c|}
\hline Variable & Definition & Source & Scale \\
\hline Credit & $\begin{array}{l}\text { Domestic credit to } \\
\text { private sector }\end{array}$ & $\begin{array}{l}\text { World Bank (2011), } \\
\text { IMF }\end{array}$ & $\%$ of GDP \\
\hline BankCredit & $\begin{array}{l}\text { Domestic } \\
\text { provided by banking } \\
\text { sector }\end{array}$ & $\begin{array}{l}\text { World Bank (2011), } \\
\text { IMF }\end{array}$ & $\%$ of GDP \\
\hline BankDeposit & $\begin{array}{l}\text { Deposits of deposit } \\
\text { monetary institutions }\end{array}$ & $\begin{array}{l}\text { Beck and Demirg-Kunt } \\
\text { (2009), IMF }\end{array}$ & $\%$ of GDP \\
\hline Investment & $\begin{array}{l}\text { Investment, Current } \\
\text { Price National } \\
\text { Accounts at PPPs }\end{array}$ & Heston et al. (2009) & $\%$ of GDP \\
\hline $\begin{array}{l}\text { Property, Contract, } \\
\text { Competition, } \\
\text { Composite }\end{array}$ & Institutional indicators & IPD (2009) & $\begin{array}{l}\text { Indicators } \\
\text { normalized on } \\
\text { scale of } 0=\text { low } \\
\text { formalization } \\
\text { rules to } 1=\text { high } \\
\text { formalization of rules. } \\
\text { Original data ranges } \\
\text { from } 0-4 \text { and } 1-4\end{array}$ \\
\hline Supervision & $\begin{array}{l}\text { Prudential regulations } \\
\text { and supervision of the } \\
\text { banking sector }\end{array}$ & Abiad et al. (2010) & $\begin{array}{l}\text { From } 0=\text { unregulated, } \\
\text { to } 3=\text { regulated }\end{array}$ \\
\hline Privatization & $\begin{array}{l}\text { State ownership in the } \\
\text { banking sector }\end{array}$ & Abiad et al. (2010) & $\begin{array}{l}\text { From } 0=\text { repressed, to } \\
3=\text { liberalized }\end{array}$ \\
\hline Barriers & $\begin{array}{l}\text { Entry barriers in the } \\
\text { banking sector }\end{array}$ & Abiad et al. (2010) & $\begin{array}{l}\text { From } 0=\text { repressed to } \\
3=\text { liberalized }\end{array}$ \\
\hline Inflation & $\begin{array}{l}\text { Rate of change in the } \\
\text { consumer price index }\end{array}$ & $\begin{array}{l}\text { World Bank (2011), } \\
\text { IMF }\end{array}$ & $\%$ change \\
\hline Savings & Gross domestic savings & World Bank (2011) & $\%$ of GDP \\
\hline ExternalDebt & $\begin{array}{l}\text { External balance on } \\
\text { goods and services }\end{array}$ & World Bank (2011) & $\%$ of GDP \\
\hline ExchangeRate & Exchange rate & Heston et al. (2009) & $\mathrm{US}=1$ \\
\hline
\end{tabular}

Continued on next page 
Continued from previous page

\begin{tabular}{|c|c|c|c|}
\hline & & & \\
\hline Malaria & $\begin{array}{l}\text { Population at risk of } \\
\text { malaria transmission in } \\
1994\end{array}$ & $\begin{array}{lr}\text { World } & \text { Health } \\
\text { Organization } & 1997 \\
\text { / Glaeser et al. } & (2004)\end{array}$ & $\begin{array}{l}\text { Probability of } 0=\text { no } \\
\text { malaria risk to } 1=\text { high } \\
\text { malaria risk }\end{array}$ \\
\hline Temperate & $\begin{array}{l}\text { Population in } \\
\text { Koeppen-Geiger } \\
\text { Climatic zone in } 1995\end{array}$ & $\begin{array}{l}\text { Gallup and Mellinger } \\
\text { and Sachs (2001) }\end{array}$ & $\%$ of population \\
\hline Religion & $\begin{array}{l}\text { Religious } \\
\text { fractionalization }\end{array}$ & Alesina et al. (2003) & $\begin{array}{l}\text { Probability of } 0= \\
\text { homogenous to } 1= \\
\text { fractionalized society }\end{array}$ \\
\hline Ethnic & $\begin{array}{l}\text { Ethnic } \\
\text { fractionalization }\end{array}$ & Alesina et al. (2003) & $\begin{array}{l}\text { Probability of } 0= \\
\text { homogenous to } 1= \\
\text { fractionalized society }\end{array}$ \\
\hline Language & $\begin{array}{l}\text { Linguistic } \\
\text { fractionalization }\end{array}$ & Alesina et al. (2003) & $\begin{array}{l}\text { Probability of } 0= \\
\text { homogenous to } 1= \\
\text { fractionalized society }\end{array}$ \\
\hline
\end{tabular}


Chapter 3

Industrial Policy for Growth 


\subsection{Introduction}

Followers of neoliberal theory believe in the efficient and self-organizing capacity of free markets to the extent that market liberalization, deregulation, openness, and competition are key to growth. Policies that favor given sectors or industries are generally criticized for inducing firms to lose competitive drive and lower investment. More recently, Aiginger (2007) argues that in developed countries policy supporting specific sectors and industry has re-emerged. Similarly, Peres (2009) finds that, contrary to the conventional notion, Latin American countries have implemented more industrial policy in combination with an outward oriented policy approach. What is the benefit of the government taking on a more active role in terms of market intervention? To what extent is industrial policy aimed at supporting existing industry competitiveness and/or at supporting market competition and consumer protection? Do such policies effectively stimulate growth? The main contribution of this study is that, based on a broad understanding of industrial policy which encompasses e.g. competition policies, we use cross-country data to study the relation of countries' industrial policy package and growth.

Industrial policy is generally understood to refer to a mix of policies that support the structural transformation and development of a country's industry. Industrial policy covers a broad range of policies. For example, Di Maio (2009) describes industrial policy as including the following policies: innovation and technology, education and skills formation, trade, targeted industry support measures, competitiveness, and competition regulation. Rodrik and Subramanian (2005) distinguish between policy that targets the development of business - 'pro-business' policy - and policy that targets the development of free markets - 'pro-market' policy. The authors define pro-business policies as policies that support the development of existing industry and are "aimed primarily at benefiting incumbents in the formal industrial commercial sector" (Rodrik and Subramanian, 2005, p. 215). Furthermore, the authors define pro-market polices as policies that are aimed at stimulating competition and benefit new entrants and consumers. Rodrik and Subramanian find that in India high levels of growth in the 1980's were triggered by pro-business rather than by pro-market policy. ${ }^{1}$ Also, Khan and Blankenburg (2009) and Acemoglu et al. (2006) suggest that in the first stage of development industrial policy should focus on supporting industrial development and in the second stage industrial policy should stimulate competition.

The policy classification as offered by Rodrik and Subramanian is particular useful for our analysis mainly because it allows for a de-facto distinction between policies rather than a de-jure distinction of policies. The distinction between promarket and pro-business policy is similar to the policy contrast of market-oriented and structuralist policy but we assume that the focus of the former is on industrial policies and that the focus of the latter additionally extends into other policy areas.

On the basis of perception-based policy data on industrial policy and principal

1 Rodrik and Subramanian (2005) study the variation in political alliances between state governments and the Indian national government and interpret this as a proxy for an attitudinal shift toward pro-business policy. 
component analysis we seek to differentiate between different aspects of policies that support business development (pro-business) and policies that support free markets (pro-market). We use cross-country data on 59 countries to empirically assess the extent to which there is a trade-off between the pro-market and pro-business policy types at the macro level. We find that it is possible to distinguish between promarket and pro-business type policies and, on the basis of this categorization of data, we construct an indicator for each policy type.

Contrary to the description of pro-market and pro-business policy that is proposed by Rodrik and Subramanian (2005), our policy measures do not specify which industries/actors are targeted by the policies. In particular, as a result of data limitations we cannot distinguish between policy that specifically targets incumbents and policy that specifically targets new market entrants. Our measures of pro-market and pro-business policy are positively correlated implying that at the macro-level there is no trade-off between the implementation of pro-market and pro-business type policy. We analyze the relationship between countries' industrial policy and economic performance. Fixed-effects analysis using data from 1995-2009 and 56 countries suggests that pro-business policy is positively related to growth but not to per capita income. We find no clear effect of pro-market policy on economic performance. In the final section of this study we extend the analysis and focus specifically on the contrast between competition policy and innovation policy which several scholars (e.g. Aiginger, 2007) describe are key concepts in industrial policy. Soete (2007) emphasizes the importance of innovation policy and argues that industrial development is much dependent on strong policy stimulating innovative advances. According to Soete, consumers and market take-up are lagging behind industry capacity in terms of green technologies; therefore there is a lack of incentive for further industrial development. Scholars have established a relation between innovation capacity and growth (Fagerberg and Srholec, 2008) but, overall, cross-country empirical evidence on the effect of innovation policy on growth is lacking. We measure innovation policy using a sub-set of indicators from our 'pro-business' policy indicator. We conclude that an industrial policy package which has a strong emphasis on supporting innovation and technological development is most successful in stimulating economic development because we find a relatively strong positive effect of innovation policy on growth as well as a small but nonetheless positive and significant effect on income.

\subsection{Some Recent Trends in Industrial Policy}

"Industrial policy is open to corruption and rent-seeking. Any system of incentives designed to help private investors venture into new activities can end up serving as a mechanism of rent transfer to unscrupulous businessman and self-interested bureaucrats" (Rodrik et al., 2004, pp. 17). North et al. (2009) argue that elite distribute rents in order to maintain political stability and hence, elite prosperity. Both pro-market and pro-business type policy are (possible) sources of rent distribution. On the one hand, an absence of anti-competition policy could be an indication that the economic elite exercises pressure in order to secure industry dominance (Acemoglu et al., 2006). And, pro-business policy reforms have been used 
to gain political support from the private sector (Rodrik and Subramanian, 2005). ${ }^{2}$ On the other hand, market liberalization and privatization have re-distributed large rents to elite under the pretext of market development (Schamis, 2002).

Industrial policy is heavily contested because industrial policy creates rent-seeking opportunities and is more rewarding to some individuals and firms (Pack and Saggi, 2006). Most economists share the belief that policies should refrain from 'picking winners'. Some economists view markets as self-regulating - developed countries are not in need of industrial policy, industrial policy should be largely non-existent. The neoliberal applications of the Washington consensus left little space for a generous industrial policy agenda (Cimoli et al., 2009b). As a result of the controversy around industrial policy, some governments downplay the role of the implemented policy mix, especially those policies that support particular industry. To some degree the term 'industrial policy' has been avoided altogether and replaced with new and less controversial terms such as 'competitiveness policy'. Moreover, industrial policy has been subject to several reforms.

Chang (2002) extensively outlines that almost every 'now-developed country' used infant industry policy in order to catch-up on industrial development. Even after the Second World War several developed economies heavily protected infant industries using an interventionist approach (Aghion et al., 2012). In the 1980's industrial policy shifted towards a policy-mix with a strong horizontal component (policy that does not favour specific sectors). For example, for the EU overall, this change implied giving up on policies that favoured specific sectors and industries and therefore generated an unfair competitive advantage in the common market (Aiginger and Sieber, 2006). In France this change implied that the previously large scale interventionist policies were remodeled (Cohen, 2007).

More recently, in developed countries the neoliberal approach to industrial policy is contrasted by several trends which suggest a re-emergence of industrial policy (Aiginger, 2007). First, since the onset of the financial crisis several governments have actively implemented policies that help 'save' industries and organizations (e.g. by means of bail-outs), combat unemployment, and generate fiscal stimulus. Second, the globalization of markets has emphasized the need to protect local industry and stimulate regional development. Third, as a result of structural changes in the economy, industrial policy has extended further into new industries. In particular, developments in industrial policy are organized more strategically along the lines of technology and innovation policy. In both the US and the European Union (EU) such policies are directed towards public private partnerships and research-industry cooperations, and regional clustering and specialization. In the EU, this 'new' type of industrial policy (i.e. implemented since 2005) has a strong horizontal component but the policy measures are tailored to specific sectors and industries of strategic importance (Zourek, 2007). This new approach is less extreme than both the previous 'interventionist' approach and neoliberal approach. Aiginger and Sieber (2006) has labeled this EC approach towards industrial policy as the 'matrix approach' (see also

${ }^{2}$ In democratic countries, the political elite is arguably less influenced by rent-seeking. Yet, as a result of strong industrial representation and lobbying, to some degree in developed countries industrial policy also favours the dominant industry (Acemoglu et al., 2013; Breschi and Cusmano, 2004). 
Aiginger, 2007) and Bianchi and Labory (2006) refers to this phase of EC industrial policy as 'pragmatic'.

Industry restructuring, diversification, and upgrading remain key components for continuous industrial development. Developing countries have experimented with a range of industrial policies and combinations of policy. Some (East Asian) countries have acquired considerable success following a strategic export-oriented strategy in combination with infant industry protection (Hiley, 2000). In particular, Zhu (2007) studies industrial policy in Thailand and China and argues that both economies combined an import-substituting industrialization (ISI) strategy with an export-oriented industrialization (EOI) strategy when the economies shifted to export promotion; Taiwan since the 1960's and China since the 1980's. According to $\mathrm{Zhu}$, the economic success of the economies is attributable to having implemented a combination of ISI and EOI strategies. Also other developing countries, under the agenda of import substitution, have provided significant support for public and privately owned enterprises (Amsden, 2008). In particular in African countries, infant industry support policies have played an important role in providing continued support for industrial development (Tribe, 2000). However, Wade (2009) suggests that low income countries to have done too little to steer industrial development and argues that these economies require more rigorous industrial policies that support and protect industries.

Similar to the experience in Western Europe, Wade (2012) argues that developing countries are showing a renewed interest in reinforcing industrial policy, for example because of increased international competition. In the 1980's, the Washington consensus heavily promoted a neoliberal policy agenda in Latin American countries; this included extensive privatization and financial liberalization. And, in the 1990's, several Latin American countries moved away from this policy trend. Melo (2001) surveys industrial policies implemented in Latin America and the Caribbean with particular emphasis on the emergence of new policies in 1994-1996. The author finds that these policies "aim to improve the competitiveness of domestic producers in a new, increasingly integrated and open world economy" by means of explicit government intervention (Melo, 2001, pp. 7). Based on an overview of industrial policy in Latin America, Peres (2009) argues that since the 1980's industrial policy still continues to have a sectoral focus although the experience within Latin America differs. For example, Chile also relied on a horizontal policy framework approach and in Costa Rica, Peru, and Uruguay the government provided support for specific firms (Peres, 2009). Moreover, according to Peres, Brazil and Mexico created technology funds and other specific programmes to stimulate technological development following a sectoral focus. With emphasis on the policy toolbox intended to stimulate financial access in Latin America, (e.g. the public provision of market infrastructure, structured finance, credit guarantee systems, and transaction cost subsidies) De la Torre et al. (2007) differentiate between interventionist policy, laissez-faire policy, and an intermediate policy variant that specifically targets, in a more restricted manner, a set of policy interventions that addresses market failures and supports private sector 
development. ${ }^{3}$ The authors find that several regional institutions are implementing more policy of the intermediate variant.

\subsection{Evidence and Theory on the Relation between Industrial Policy and Growth}

There is no clear understanding on the type of industrial policy that is most effective in stimulating growth. Yet most scholars argue that, at least under certain conditions, policies that support business development are effective in stimulating growth. In this section we provide a brief overview of this literature.

Aghion et al. (2012) develop a theoretical model and an empirical analysis using data on firms located in China to test the effect of sectoral policies (tariffs, subsidies, and tax) and competition on productivity. The authors find that sectoral policies are successful in delivering growth when allocated to competitive sectors. Similarly, using data on firms located in the UK, Criscualo et al. (2012) find a positive effect of investment subsidies on investment and employment. Acemoglu et al. (2013) are more skeptical of the benefits of R\&D subsidies on productivity growth. Using firm-level data from the US, the authors find a negative effect of subsidies allocated towards incumbents on productivity growth. Yet, the authors also find substantially higher growth when subsidies target both incumbents and new market entrants and, in addition, incumbents are (heavily) taxed. Buigues and Sekkat (2011) summarize additional empirical evidence on the effect of subsidies on firm performance and conclude that most studies suggest a positive relation of public support on R\&D. However, Buigues and Sekkat find that the effect of public support on productivity is inconclusive. In a related theoretical study Acemoglu et al. (2006) show that low competition may have negative long-run effects and may prevent catch-up. Acemoglu et al. also show that countries at early stages of development may benefit from anticompetitive policy that protects or supports incumbent industry development and, as a result, may experience faster growth and technological convergence.

Aside from the work of Rodrik and Subramanian (2005), several additional country-case studies conclude that industry support generates growth. Gerschenkron (1962) already proposed that government and banks' support towards business helped 'backward' economies in the nineteenth century to catch-up. This view is, for example, also shared by Cimoli et al. (2009a). Lee (2011) argues that, in Korea in the 1970's, infant industry protection resulted in industrial growth. Similarly, Khan (2008, p. 57) argues that, in Pakistan, "protection and subsidies proved to be extremely effective in driving investment in sectors that had previously been neglected", and "import substitution, as a method of developing new capabilities, was initially extremely successful in both India and Pakistan." Similar to the work of Rodrik and Subramanian, Khan and Blankenburg (2009) likewise distinguish between two industrial policy groups: strong and targeted policy and weak and horizontal

\footnotetext{
3 De la Torre et al. (2007) refer to this intermediate policy variant as 'pro-market activism'. Despite this wording, this intermediate policy variant is rather different from the 'pro-market' type policy (which is described by Rodrik and Subramanian, 2005).
} 
policy. The first group comprises policies that target firms or sectors to enable these to become competitive. The second group comprises policies that sustain productivity in competitive markets and thereby discourage permanent rent-seeking behaviour.

Building on the argument of Khan and Blankenburg (2009), a possible scenario is that countries' policy emphasis shifts from strong industry support to weak horizontal support as industrial development catches up. According to Khan and Blankenburg (2009), the first stage of industrial development requires pro-business type policies that protect the incumbent industries' knowledge acquisition. The second phase of industry development requires pro-market type policies that increase market competition with the aim to spread innovation and technology and set-off a Schumpeterian process of creative destruction (Khan and Blankenburg, 2009). Possas and Borges (2009) find that competition policy is only enforced gradually. Bianchi and Labory (2006) provide an overview of industrial policy in 8 countries (Italy, France, Germany, UK, Japan, Korea, Taiwan, and Singapore) and argue that in the phase of industrialization and at different phases of industrial restructuring these countries implemented relatively more protectionist and interventionist policy. But, from the 1980's these countries adopted more liberal policies. This is related to the progress made under WTO law, community law, and other trade agreements which altogether has resulted in a more limited implementation of policy instruments such as trade subsidies (Aiginger, 2007).

If industrial development is steered by the sequential implementation of probusiness and pro-market policy, at the macro level — or possibly at the industry levelthere may be a trade-off between these policies. Indeed, Rodrik and Subramanian (2005) describe pro-market and pro-business policy as opposing policy packages. One the one hand, this trade-off would imply that the degree of industry maturity determines whether to invoke either pro-business and pro-market type policies. In developing countries with a relatively weak institutional setting pro-business policies, including infant-industry protection, may play a relatively important role as a temporary short-run solution to market failure (Wade, 2012). Furthermore, scholars such as Greenwald and Stiglitz (2006) challenge conventional theory that trade generates growth and argue that restricting trade can be beneficial for technological spillovers, industrial development and growth. On the other hand, pro-business and pro-market policy may be inherently opposing to the extent that implementing both at the same time will cause the effectiveness of either policy to dwindle. Based on a study of Belgium firms, Buts and Jegers (2013) find a positive relation between subsidies (i.e. grants intended for investment in fixed assets) and firms' market share; this result implies that subsidies distort competition.

To what extent does the thesis of the sequential implementation of (a) probusiness policy and (b) pro-market policy and that of a possible policy trade-off contradict the re-emergence of industrial policy that targets industrial development as is witnessed in developed and some developing countries today? Valila (2006), who analyzes industrial policy using a more restricted definition, argues that the objectives of industrial policy are in conflict with the objectives of competition and trade policy. However, the author also argues that in practice conflict does not need to materialize, e.g. as in the case of pure horizontal policy. Likewise 
(Aiginger, 2007) argues that only the 'old' EU industrial policy conflicted with competition policy but the 'new' industrial policy does not i.e. as a result of increased transparency, tendering and cooperation. These view is also shared by Possas and Borges (2009, pp. 461) who specifically focus on competitions policy (as an integral part of industrial policy) and argue that "the potential conflict between industrial policies and competition policies tends to fade away in relatively advanced developing-but-industrialized countries because in such countries industrial policy focuses on competitiveness and technological development". One possibility is that, on average, in countries with a low industrial development pro-business type policies are implemented relatively more than pro-market type policies. In addition, possibly, pro-business type policies remain important in industrialized countries and, in these countries, these policies do not oppose pro-market type policies.

\subsection{Industrial Policy Indicators}

We are interested in policy data that covers a broad range of industrial policy aspects. This objective is particular challenging for several reasons. First, comprehensive indicators on industrial policies are lacking. For this reason, several scholars restrict their empirical analysis of industrial policy to one dimension (e.g. Bianchi and Labory, 2006). Second, 'hard' data on industrial policy lacks cross-country comparison because the definition and industrial policy measure are country (and industry) specific. For example, Buigues and Sekkat (2011) emphasize the difference in the measurement of subsidies across the OECD. Moreover, according to Livesey (2012) the framework of analysis of industrial policy in both developing and developed countries must be broad enough to capture the effect of (1) policies that target different industrial stages, (2) horizontal and vertical policy, (3) policy targeting firms of different sizes, and (4) policies for structural change and policies stimulating industrial upgrading. ${ }^{4}$ These challenges contribute to explain why empirical evidence on the effect of different industrial policy on growth is lacking.

With the ambition to distinguish between pro-business and pro-market policy we rely on perception-based data that allows for a broad cross-country comparison of policies. We use survey data from the IMD World Competitiveness Yearbook (IMD), hereafter referred to as WCY, because the data has a broad range of variables that describe policy that targets the private sector. We use a selection of 22 policy variables; these variables are listed in Table 3.1. ${ }^{5}$ The WCY survey data covers 59 countries and includes data for the years 1995-2011. However, the WCY did not systematically conduct surveys in all countries for all years and therefore there are

\footnotetext{
4 Livesey (2012) propose a meso-level framework approach that outlines specific industry comparative maturity. This specific approach can not be applied within the macro context.

5 The WCY survey data is collected with the intention to describe the degree of competitiveness of countries. The WCY survey is sent to executives working in a range of sectors. The sample size of each country is proportional to the countries' GDP. Data is collected during the period January to April. In 2011, the WCY collected 4,935 surveys (IMD, 2011). Survey respondents are asked to make a country assessment on the basis of a scale of 1 to 6 . The WCY presents the average country score per variable on a scale of 0 to 10 , where 10 is associated with high competitiveness.
} 
several missing observations in the data. The countries included in the WCY dataset are listed in Table 3.8 in the appendix.

Table 3.1: WCY 1995-2011

\begin{abstract}
Pro-business Development Policy
Exchange: Exchange rates support the competitiveness of enterprises (1997-2011)

Research: Laws relating to scientific research do encourage innovation (2004-2011)

Regulation: Technological regulation supports business development and innovation (2005-2011)

Funding: Funding for technological development is readily available (1995-2011)

Ventures: Public and private sector ventures are supporting technological development (2007-2011)

Legal: Development and application of technology are supported by the legal environment (19972011)

Labour: Labour regulations (hiring/firing practices, minimum wages, etc.) do not hinder business activities (1995-2011)

Creation: Creation of firms is supported by legislation (2002-2011)

Ease: Ease of doing business is supported by regulations (2003-2011)

Framework: The legal and regulatory framework encourages the competitiveness of enterprises (19972011)

Tax: Real corporate taxes do not discourage entrepreneurial activity (1997-2011)

Environment: Environmental laws and compliance do not hinder the competitiveness of businesses (1995-2011)
\end{abstract}

\title{
Pro-Market Development Policy
}

Immigration: Immigration laws do not prevent your company from employing foreign labor (19952011)

Competition: Competition legislation is efficient in preventing unfair competition (1995-2011)

Ownership: State ownership of enterprises is not a threat to business activities (2007-2011)

Subsidies: Subsidies do not distort fair competition and economic development (2003-2011)

Incentive: Investment incentives are attractive to foreign investors (2007-2011)

Market: Capital markets (foreign and domestic) are easily accessible (2004-2011)

Investor: Foreign investors are free to acquire control in domestic companies (1995-2011)

Contract: Public sector contracts are sufficiently open to foreign bidders (1995-2011)

Protection: Protectionism does not impair the conduct of your business (1995-2011)

Customs: Customs' authorities do facilitate the efficient transit of goods (1997-2011)

We analyze the selection of WCY policy data with the intention to identify a pattern for the pro-business and/or pro-market type policy variables. This analysis is done on the basis of principal component analysis (PCA). A PCA is run on the WCY policy indicators for the years 2007-2011, and two principal components (PCs) are retained. We retain two PCs because we are interested in identifying two policy domains. For the PCA we rely on data from 2007-2011 because prior years contain more missing observations. For the years 2007-2011, the following countries have missing observations for one or more years: United Arab Emirates for 2007-2010, Peru for 2007, Iceland for 2009, Kazakhstan for 2007, and Qatar for 2007-2008. ${ }^{6}$ In order to facilitate the interpretation of the PCs, the PCs are rotated using varimax rotation which computes orthogonal factors. The first PC contains $40 \%$ of the total variation, and the second $\mathrm{PC}$ contains $30 \%$ of the total variation. The loadings of the PCA are presented in Figure 3.1.

\footnotetext{
6 The total number of observations used in the PCA is 286.
} 
Figure 3.1: Analysis of Policy Indicators: loadings of PCA

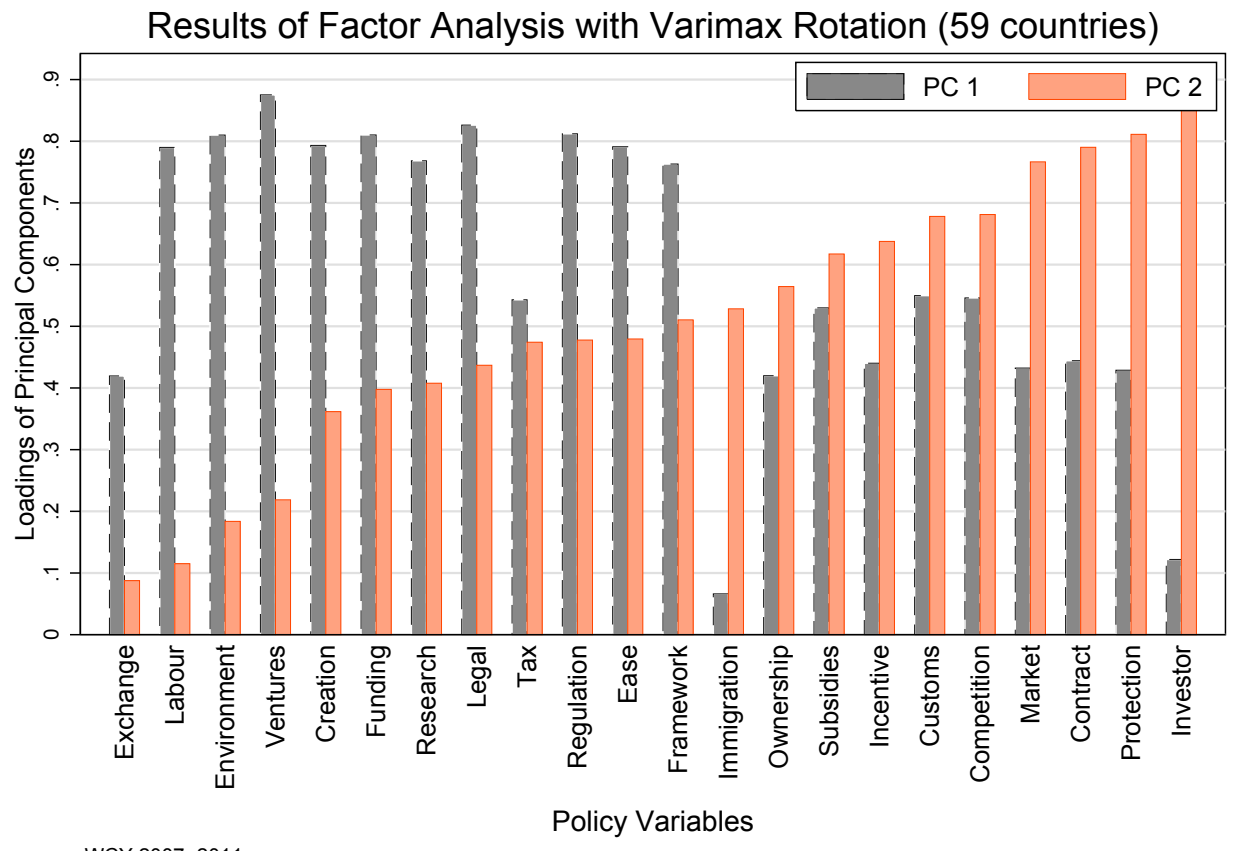

PC 1 loads high on the variables Labour, Environment, Ventures, Creation, Funding, Research, Legal, Tax, Ease, and Regulation. This PC also loads relatively high on the variables Framework and Exchange in comparison to the loadings of PC 2. PC 1 loads high on policy variables that support technological advancement and knowledge accumulation. PC 1 loads strongly on variables that describe the ease of access to funds to finance research and technological development. PC 1 also loads strongly on variables that support the existing industry competitiveness and development. These policies support industry that otherwise may be under-invested. PC 1 is related to the concept of pro-business policy (Rodrik and Subramanian, 2005) and strong and targeted policy (Khan and Blankenburg, 2009). However, unlike the industrial policy definition proposed by Rodrik and Subramanian, this measure of industrial policy does not specify incumbents as the industry target. ${ }^{7}$

PC 2 loads high on the variables Subsidies, Competition, Customs, Market, Investor, Contract, and Protection. Moreover, the loadings of the variables Ownership, Incentive and Immigration are relatively higher for PC 2 than for PC 1. PC 2 summarizes a group of variables that describe market liberalization, competition policy and deregulation. PC 2 describes regulations that are aimed at stimulating a

7 The WCY data is limited in the sense that it does not have any indicators of the degree to which policy favours either incumbents or new market entrants. 
free market economy. PC 2 can be considered a proxy for the following concepts: pro-market policy (Rodrik and Subramanian, 2005) and weak and horizontal policy (Khan and Blankenburg, 2009). ${ }^{8}$

Figure 3.2 presents a scatter plot of PC 1 and PC $2 .{ }^{9}$ The scatter plot gives a first indication of the extent to which a country scores relatively higher on probusiness policy rather than on pro-market policy. For example, Malaysia, Iceland, and Singapore score relatively higher on PC 1. Chile, New Zealand, and Ireland score relatively higher on $\mathrm{PC} 2$.

Figure 3.2: Analysis of Varimax Rotated Policy Indicators

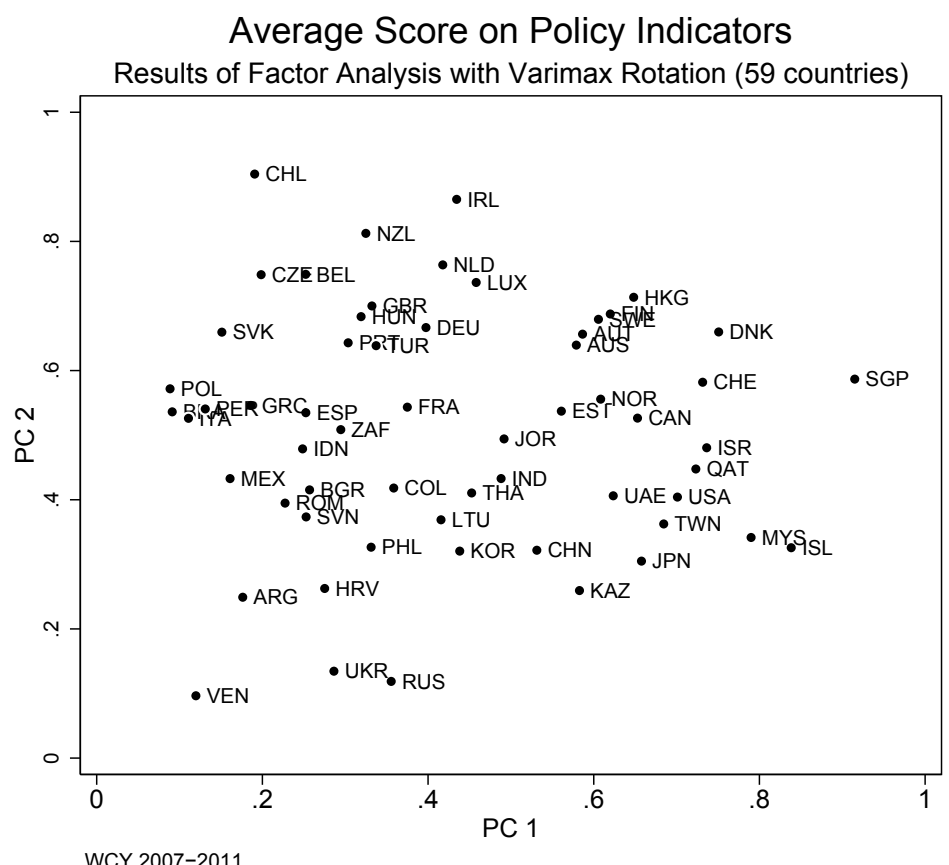

The orthogonality of these indicators inhibits their comparability with alternative indicators and does not allow for the study of countries' 'natural' scores. In particular, on the basis of the orthogonal indicators we cannot identify if there is a trade-off between the implementation of pro-business and pro-market type policy. Moreover, we are interested in studying the policy data for the years 1995-2011. Therefore, the results from the PCA with varimax rotation are used to separate the policy variables into two policy domains: pro-market and pro-business. Variables are identified as pro-market when they load relatively higher on PC2 and variables are identified as

\footnotetext{
8 In Appendix 3.8 we test the validity of this categorization of policies using external data.

9 The PCs are normalized on a scale of 0 to 1.
} 
pro-business when they load relatively higher on PC1 (see Figure 3.1). We calculate the average score of the pro-market policy variables and of the pro-business policy variables for each country and year; missing values are ignored. Finally, the indicators are normalized on a scale of 0 to 1 , where 1 is associated with more implementation of pro-market and pro-business policy. Hereafter, these indicators are referred to as Pro-market and Pro-business. Thus, the motivation for creating the Pro-market and Pro-business indicators is inspired by the conceptual framework of Rodrik and Subramanian and Khan and Blankenburg and the categorization of the underlying variables is made on the basis of exploratory empirical analysis.

The average scores over time of the resulting policy indicators are illustrated in Figure 3.3. Whereas Figure 3.2, as previously discussed, shows the relation between orthogonal policy indicators, Figure 3.3 shows the relation between non-orthogonal policy indicators.

Following Figure 3.3, Pro-market and Pro-business policy appear to be positively correlated. We find no evidence that, on average, at the macro-level countries that are in a catch-up stage implement relatively more pro-business policies. $^{10}$ Instead, Figure 3.3 suggests that pro-market and pro-business policies are complementary. ${ }^{11}$

\footnotetext{
10 In the Appendix 3.8 we plot the relation between pro-business and pro-market policy using alternative data that covers a wider range of developing countries. This analysis confirms that of a positive relation between Pro-market and Pro-business.

11 At the meso-level, when comparing across-industries, pro-business type policies may be more prominent in industries that are less mature and pro-market type policies may be relatively more enforced in mature industries.
} 
Figure 3.3: Analysis of Non-rotated Policy Indicators

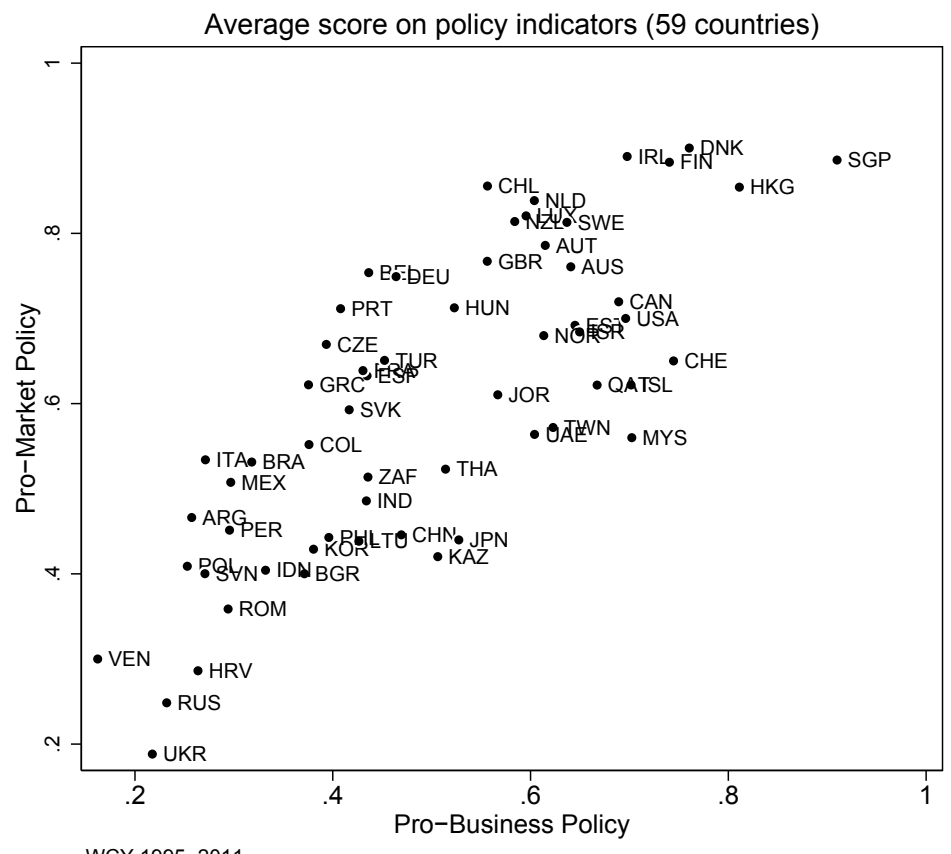

WCY 1995-2011 
Figure 3.4: Analysis of Policy Indicators over Time

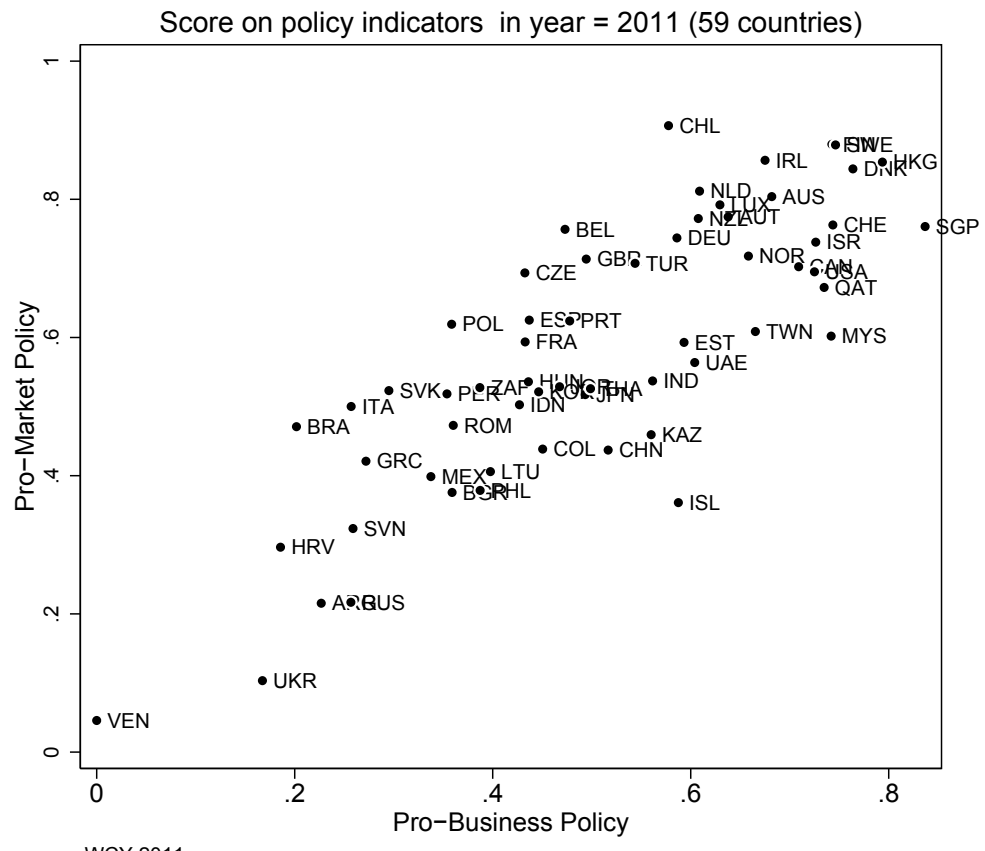

WCY 2011

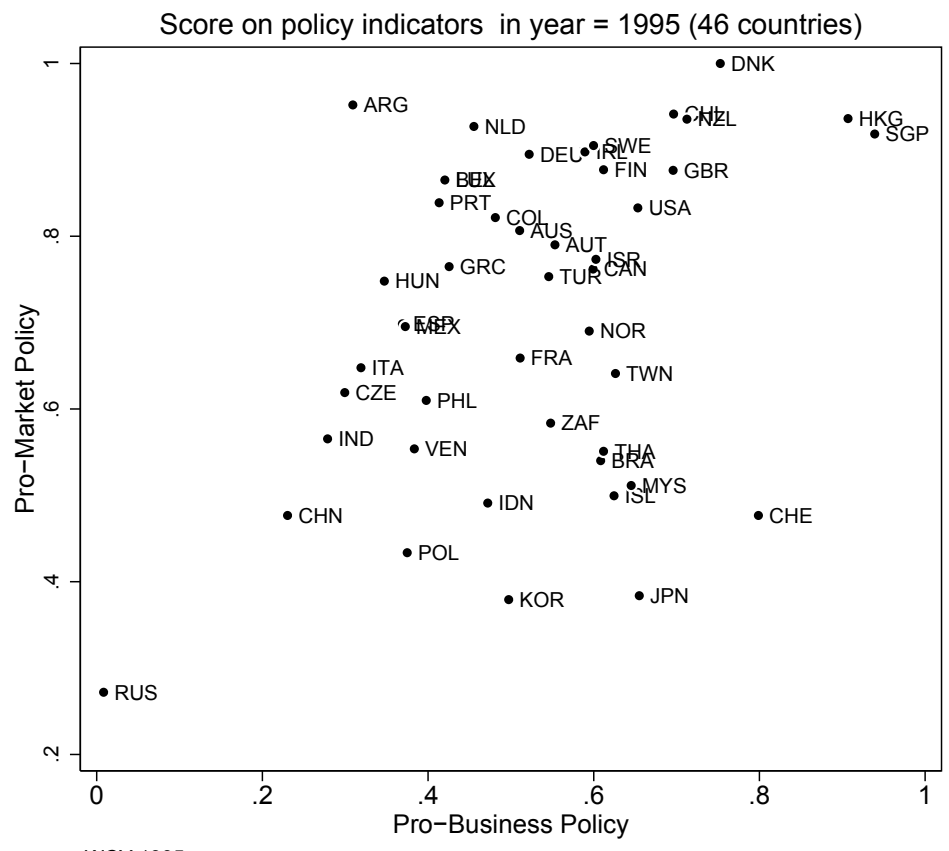

WCY 1995 
The first scatter plot illustrated in Figure 3.4 shows countries' scores on the policy indicators in 2011. Likewise, as in Figure 3.3, Pro-market and Pro-business policy have a strong linear relation. The correlation between these indicators in this year is 0.82 . The second scatter plot in Figure 3.4 illustrates the association between Pro-market and Pro-business policy for the year 1995. The correlation between the Pro-market and Pro-business indicators in year 1995 is 0.38 . This scatter plot illustrates that in 1995 the countries in the lower-right corner, e.g. Japan, Malaysia, Korea, Switzerland, and Brazil, had a stronger emphasis on pro-business policy than on pro-market policy. However, in 2011, this observation is no longer valid. In 1995, few countries scored high on the pro-business indicator. The overall dispersion of countries on the pro-business policy indicator is lower when using policy data from 1995 than when using policy data collected in 2011.

\subsection{Industrial Policy, Growth and Income}

\section{Model}

The following fixed effect models are used to investigate the effect of pro-market and pro-business type policy on economic performance:

$$
\begin{aligned}
& \text { Income }_{i, t}=\beta_{0}+\beta_{1} \text { Pro- }_{\text {market }}, t+\beta_{2} \text { Pro-business }_{i, t} \\
& +\beta_{3} \text { Gconsumption }_{i, t}+\beta_{4} \text { Openness }_{i, t}+\beta_{5} \text { Investment }_{i, t} \\
& +\beta_{6} \text { Education }_{i, t}+\beta_{7} \text { Institutions }_{i, t}+\epsilon_{i, t} \\
& \text { Growt }_{i, t}=\beta_{0}+\beta_{1} \text { Pro- }_{\text {market }} i, t+\beta_{2} \text { Pro-business }_{i, t} \\
& +\beta_{3} \text { Gconsumption }_{i, t}+\beta_{4} \text { Openness }_{i, t}+\beta_{5} \text { Investment }_{i, t} \\
& +\beta_{6} \text { Education }_{i, t}+\beta_{7} \text { Institutions }_{i, t}+\beta_{8} \text { Income }_{i, t-1}+\epsilon_{i, t}
\end{aligned}
$$

The dependent variable by which we measure economic performance takes the form of either Income (equation 3.1) or Growth (equation 3.2) in country $i$ and year $t$. Income is measured using natural logarithm of real GDP per capita and Growth is measured as the average annual growth rate of real GDP per capita. $\beta_{1}-\beta_{7}$ (equation 3.1 ) and $\beta_{1}-\beta_{8}$ (equation 3.2) are the various parameters of interest and $\epsilon_{i, t}$ is a disturbance term which has the usual characteristics. Our main focus is on the estimation of $\beta_{1}$ and $\beta_{2}$ which we expect to be positive indicating that both promarket and pro-business policy are successful in stimulating growth. The industrial policy types are measured using the average scores of the pro-market (Pro-market) and pro-business (Pro-business) variables from the WCY data for each country and year.

For both the growth and the income model (equation 3.1 and equation 3.2), we control for the effect of government consumption (Gconsumption), trade openness (Openness), level of investment (Investment), and for the average years of education for the country population aged 25 and above (Education). ${ }^{12}$ Additionally, we control

\footnotetext{
12 The definitions and sources of the control variables are given in Table 3.9 in the appendix.
} 
for a country's institutional development (Institutions) using two proxies: property rights protection (Property) and freedom from corruption (Corruption). We include these two indicators separately in the regression analysis. Recent literature has stressed the importance of institutions on growth (North et al., 2009; North, 1990) as well as the importance of institutions in influencing and constraining industrial policy (Rodrik, 2008; Rodrik et al., 2004). We expect the results to show that the sign of $\beta_{7}$ is positive indicating that institutional development (i.e. property rights protection and freedom from corruption) is positively related to economic performance. Finally, for the growth model (equation 3.2) we also control for the initial level of income using the log of real GDP per capita (Income).

Several of the pro-business indicators are related to government support for technological advancements and innovation. And, (as briefly explained in section 3.2) because innovation and technology policies have recently become a strong component of industrial policy in advanced economies we are interested in investigating the effect these policies on stimulating growth. On the basis of a conceptual approach we construct the indicator Innovation by computing the simple average of the variables Research, Regulation, Funding, Ventures, and Legal for each country and year. Hence, the indicator Innovation is in fact a sub-set of the indicator Pro-business. Additionally, in order to test the robustness of the relation between pro-business type policy and economic performance, we construct the indicator, Pro-business2. Pro-business 2 is a simple average of the pro-business type variables for each year and country that are not related to innovation and technological development. The variables included in this indicator are the following: Exchange, Labour, Creation, Ease, Framework, Tax, and Environment. We will produce additional estimations where we replace the indicator Pro-business with the indicator Innovation and with the indicator Pro-business2.

We conclude the analysis by experimenting with the degree to which the effect of industrial policy on growth shows up with a one year delay. Hence, we modify equation 3.2 and produce estimations following equation 3.3.

$$
\begin{array}{r}
\text { Growt }_{i, t}=\beta_{0}+\beta_{1} \text { Pro-market }_{i, t-1}+\beta_{2} \text { Pro-business }_{i, t-1} \\
+\beta_{3} \text { Gconsumption }_{i, t}+\beta_{4} \text { Openness }_{i, t}+\beta_{5} \text { Investment }_{i, t} \\
+\beta_{6} \text { Education }_{i, t}+\beta_{7} \text { Institutions }_{i, t}+\beta_{8} \text { Income }_{i, t-1}+\epsilon_{i, t}
\end{array}
$$

\section{Descriptive Statistics}

The growth and income models are estimated using an unbalanced dataset for the years 1995-2009 and 56 countries listed in Table 3.8 in the appendix. ${ }^{13}$ Iceland and Hong Kong are not included in the analysis because of missing data for the control variable Education. Moreover, there is no policy data for the United Arab Emirates for the years prior to 2010. Also, the data on institutions has additional missing observations for the year 1995 for the following countries: Belgium, Denmark, Finland, Luxembourg, Netherlands, Norway, New Zealand, and Switzerland.

\footnotetext{
13 The macroeconomic controls have missing data for the years 2010-2011.
} 
The summary statistics are presented in Table 3.2. On average, countries score higher on pro-market than on pro-business policy. Also, on average countries score higher on Property than on Corruption. Moreover, the average growth rate is $2.5 \%$ but some countries experienced high negative growth rates and other countries experienced high positive growth rates. The correlations between the various variables are presented in Table 3.3. For this sample, the Pro-market and Pro-business indicators are correlated 0.71. The correlation between Pro-market and Innovation is 0.60 . The correlation between the policy indicators and the institutional indicators is also high. ${ }^{14}$ The policy indicators have a low correlation with Growth and a positive and relatively high correlation with Income.

Table 3.2: Summary Statistics

\begin{tabular}{l|lllll}
\hline & MEAN & SD & MIN & MAX & N \\
\hline \hline Pro-market & 0.63 & 0.20 & 0.00 & 1.00 & 715 \\
Pro-business & 0.50 & 0.18 & 0.00 & 1.00 & 715 \\
Innovation & 0.60 & 0.18 & 0.00 & 1.00 & 715 \\
Pro-business2 & 0.52 & 0.17 & 0.00 & 1.00 & 715 \\
Income & 9.72 & 0.83 & 7.36 & 11.98 & 715 \\
Growth & 2.50 & 4.04 & -17.27 & 20.41 & 715 \\
Investment & 24.32 & 6.35 & 9.31 & 51.37 & 715 \\
Openness & 86.51 & 64.03 & 17.95 & 443.18 & 715 \\
Gconsumtion & 8.74 & 2.97 & 2.58 & 18.91 & 715 \\
Education & 9.83 & 2.53 & 3.50 & 14.20 & 715 \\
Property & 0.71 & 0.23 & 0.00 & 1.00 & 715 \\
Corruption & 0.55 & 0.27 & 0.00 & 1.00 & 715 \\
\hline Data from 1995-2009 & \multicolumn{5}{l}{} \\
Policy indicators and institutional indicators are normalized on a scale from 0 to 1
\end{tabular}

\footnotetext{
14 Despite these high correlations, variance inflation factors tests indicate no warning of multicollinearity.
} 
Table 3.3: Pairwise Cross-Correlations

\begin{tabular}{|c|c|c|c|c|c|c|c|c|c|c|c|c|}
\hline & 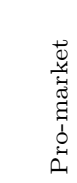 & 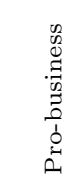 & 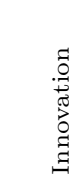 & 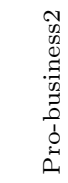 & 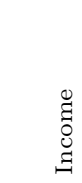 & 声 & 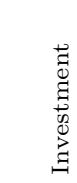 & 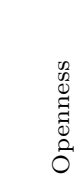 & $\begin{array}{l}\tilde{0} \\
\stackrel{0}{0} \\
0 \\
\Xi \\
0 \\
0 \\
0 \\
0 \\
0\end{array}$ & 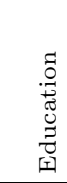 & $\begin{array}{l}\overrightarrow{0} \\
\text { D. } \\
0 \\
0 \\
0 \\
0 \\
0\end{array}$ & 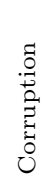 \\
\hline Pro-market & 1 & & & & & & & & & & & \\
\hline Pro-business & 0.71 & 1 & & & & & & & & & & \\
\hline Innovation & 0.60 & 0.84 & 1 & & & & & & & & & \\
\hline Pro-business 2 & 0.67 & 0.94 & 0.61 & 1 & & & & & & & & \\
\hline Income & 0.53 & 0.47 & 0.63 & 0.30 & 1 & & & & & & & \\
\hline Growth & -0.01 & 0.07 & -0.01 & 0.11 & -0.10 & 1 & & & & & & \\
\hline Investment & -0.04 & 0.20 & 0.08 & 0.24 & -0.07 & 0.31 & 1 & & & & & \\
\hline Openness & 0.29 & 0.43 & 0.35 & 0.40 & 0.26 & 0.07 & 0.27 & 1 & & & & \\
\hline Gconsumption & 0.14 & 0.12 & 0.15 & 0.09 & 0.13 & 0.10 & 0.03 & -0.01 & 1 & & & \\
\hline Education & 0.21 & 0.24 & 0.41 & 0.10 & 0.68 & -0.10 & -0.24 & 0.00 & 0.18 & 1 & & \\
\hline Property & 0.74 & 0.64 & 0.61 & 0.55 & 0.71 & -0.14 & -0.03 & 0.22 & 0.08 & 0.47 & 1 & \\
\hline Corruption & 0.70 & 0.69 & 0.75 & 0.55 & 0.79 & -0.10 & -0.02 & 0.25 & 0.15 & 0.53 & 0.83 & 1 \\
\hline
\end{tabular}

Data from 1995-2009

The scatter plots in Figure 3.5 provide a rough assessment of the relation between policy and countries' institutional development. ${ }^{15}$ Overall, we find that pro-market and pro-business policy has a positive and linear relation with property rights protection and control of corruption. As such, countries with a more developed and formalized institutional setting implement relatively more industrial policy. We find no evidence that governments implement relatively more pro-business policy to overcome market failure in countries with relatively weak institutions. On the contrary, the scatter plots suggest that countries' institutional setting plays an important role in defining a countries' policy space and hence, the implementation of a given policy package.

\footnotetext{
15 The property rights and corruption indicators are normalized on a scale of 0 to 1 .
} 
Figure 3.5: Institutions and Policy
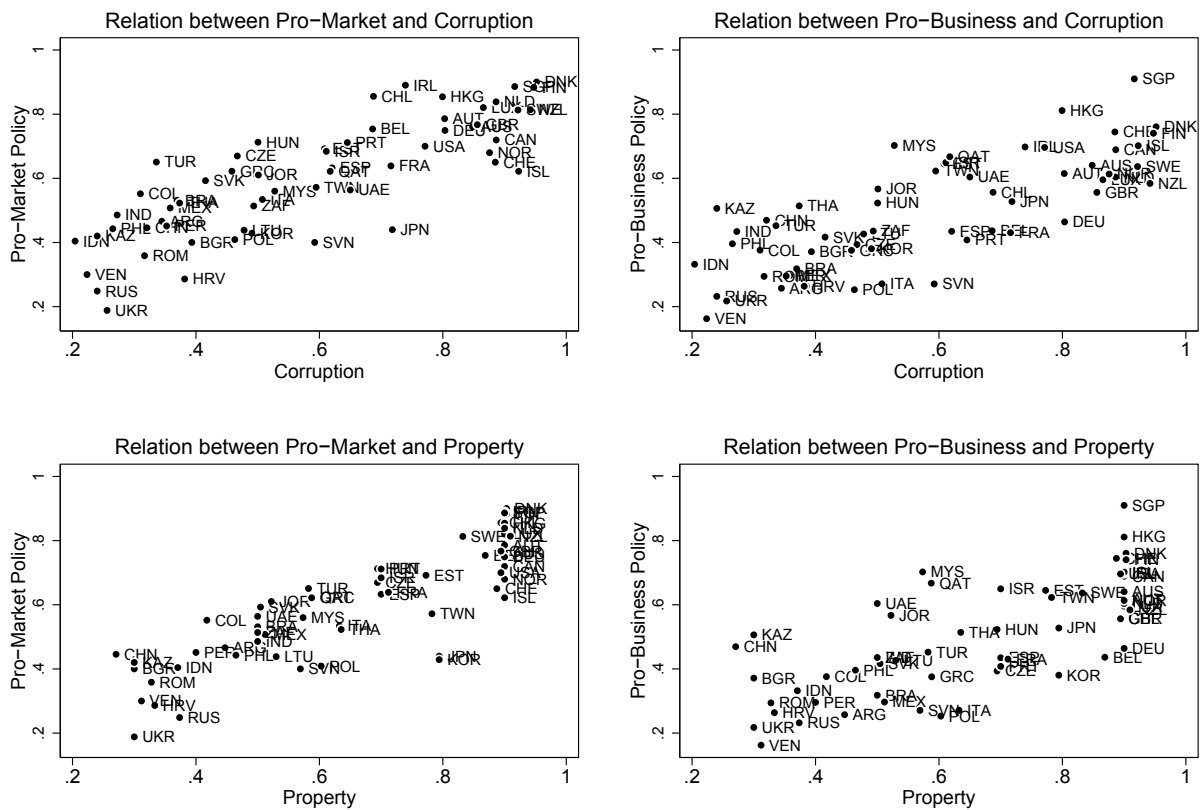

WCY 1995-2011 and Heritage Foundation 1995-2011

\section{Main Results}

In this section, we present the results of fixed effects estimations that study the effect of pro-market and pro-business policy on growth and on income. Standard errors (and hence significance levels) are cluster-robust to simultaneous correlation across both country effects and year effects. This method of two-way clustering approach is based on the approach outlined by Cameron et al. (2011).

First, we investigate the effect of the coefficient of Pro-market and that of Pro-business on income and growth levels. Table 3.4 reports the results for the growth regressions and Table 3.5 reports the results for the income regressions. For both tables, the preferred models are models 3 and $6 .^{16}$

In model 1 of Table 3.4 we include only the policy indicators. Here, we find a significant effect of the coefficient of Pro-business on growth and we find no effect of the coefficient of Pro-market on growth. In model 2 the macroeconomic controls are added to the model and as a result the coefficient of Pro - business changes

\footnotetext{
16 On the basis of the parameters used in Table 3.4 model 3 and model 6 we compute Hausman tests of the difference between fixed effects (FE) and random effects (RE). The Hausman tests yield $\chi^{2}$ values of 333.77 and 335.23 which are significant and thereby reject estimating using a RE model. The Hausman tests of the difference between FE and RE for the income models (3 and 6 of Table 3.5) fail to meet the asymptotic assumptions of the Hausman test.
} 
moderately but remains significant and does not change sign. Nevertheless, the coefficient of Pro-market remains relatively close to zero and remains insignificant. Relative to the other covariates, the coefficient of Pro-business is rather small in magnitude but unlike that of Pro-market, this coefficient is not close to zero. Following model 2, the estimated effect of a one standard deviation increase in probusiness policy leads to a 0.34 standard deviation increase in growth. As expected, the coefficients of Investment and Education are significant and positive. Likewise, the coefficient of Openness is significant and positive suggesting that more trade is related to higher growth levels. Government consumption has a negative effect on growth. And, the coefficient of Income is negative and significant and is relatively high in magnitude. In model 3 we control for the effect of Property and in model 6 we control for the effect of Corruption. After adding these additional covariates to the model we maintain that pro-business policy has a positive effect on growth. Contrary to expectations, the coefficient of Property is negative and significant and the coefficient of Corruption is negative but insignificant.

In models $4,5,7$, and 8 we experiment by estimating the effect of either Promarket or Pro - business on growth. Based on this experimentation we find that when not controlling for Pro - business the coefficient of Pro - market remains insignificant and when not controlling for Pro-market the coefficient of Probusiness remains positive and significant.

Table 3.4: FE regression results: pro-market policy versus pro-business policy

\begin{tabular}{|c|c|c|c|c|c|c|c|c|}
\hline & & DEPENDE & NT VARIAE & BLE: GRO & WTH & & & \\
\hline & $(1)$ & $(2)$ & (3) & $(4)$ & (5) & (6) & $(7)$ & (8) \\
\hline Pro-Market & -0.03 & -0.08 & -0.00 & 0.15 & & -0.09 & 0.09 & \\
\hline & $(0.93)$ & $(0.63)$ & $(0.98)$ & $(0.21)$ & & $(0.57)$ & $(0.49)$ & \\
\hline Pro-business & $0.46^{* *}$ & $0.34^{*}$ & $0.31^{*}$ & & $0.31^{* *}$ & $0.36^{*}$ & & $0.32 * *$ \\
\hline & $(0.01)$ & $(0.04)$ & $(0.05)$ & & $(0.01)$ & $(0.02)$ & & $(0.00)$ \\
\hline Investment & & $0.70^{* * *}$ & $0.74^{* * *}$ & $0.77^{* * *}$ & $0.74 * * *$ & $0.72^{* * *}$ & $0.75^{* * *}$ & $0.72^{* * *}$ \\
\hline & & $(0.00)$ & $(0.00)$ & $(0.00)$ & $(0.00)$ & $(0.00)$ & $(0.00)$ & $(0.00)$ \\
\hline Openness & & $1.41^{* * *}$ & $1.51^{* * *}$ & $1.58^{* * *}$ & $1.51^{* * *}$ & $1.41^{* * *}$ & $1.49^{* * *}$ & $1.39^{* * *}$ \\
\hline & & $(0.00)$ & $(0.00)$ & $(0.00)$ & $(0.00)$ & $(0.00)$ & $(0.00)$ & $(0.00)$ \\
\hline Gconsumption & & $-0.89^{*}$ & $-0.88^{* *}$ & $-0.94^{* *}$ & $-0.88^{* *}$ & $-0.85^{*}$ & $-0.93^{*}$ & $-0.86^{*}$ \\
\hline & & $(0.02)$ & $(0.01)$ & $(0.01)$ & $(0.01)$ & $(0.03)$ & $(0.02)$ & $(0.03)$ \\
\hline Education & & $2.36^{*}$ & $1.61+$ & $1.62+$ & $1.62+$ & $2.34^{*}$ & $2.37^{*}$ & $2.47^{*}$ \\
\hline & & $(0.02)$ & $(0.08)$ & $(0.09)$ & $(0.08)$ & $(0.02)$ & $(0.03)$ & $(0.02)$ \\
\hline Income & & $-5.46^{* * *}$ & $-5.18^{* * *}$ & $-5.12 * *$ & $-5.18^{* * *}$ & $-5.42^{* * *}$ & $-5.37^{* *}$ & $-5.45^{* * *}$ \\
\hline & & $(0.00)$ & $(0.00)$ & $(0.00)$ & $(0.00)$ & $(0.00)$ & $(0.00)$ & $(0.00)$ \\
\hline Property & & & $\begin{array}{l}-0.68^{* * *} \\
(0.00)\end{array}$ & $\begin{array}{l}-0.70^{* * *} \\
(0.00)\end{array}$ & $\begin{array}{l}-0.68^{* * *} \\
(0.00)\end{array}$ & & & \\
\hline Corruption & & & & & & $\begin{array}{l}-0.20 \\
(0.17)\end{array}$ & $\begin{array}{l}-0.13 \\
(0.38)\end{array}$ & $\begin{array}{l}-0.19 \\
(0.19)\end{array}$ \\
\hline$N$ & 715 & 715 & 715 & 715 & 715 & 715 & 715 & 715 \\
\hline$R^{2}$ & 0.04 & 0.39 & 0.43 & 0.42 & 0.43 & 0.39 & 0.37 & 0.39 \\
\hline
\end{tabular}


In Table 3.5 we repeat the exercise using Income at the dependent variable. In the first step we again estimate the effect of Pro- market and Pro-business without controlling for the effect of additional covariates (model 1). Here we find a negative and significant effect of pro-market policy on income and a positive and significant effect of pro-business policy on income. However, these findings are not robust when adding the macro-economic and institutional controls. Based on models 2,3 , and 6 we find no effect of industrial policy on income. As for the models displayed in Table 3.4, following the models displayed in Table 3.5 we find that the effect of Investment, Openness, and Education is significant and positive and that the effect of Gconsumption is significant and negative. We find no effect of institutions on income and the coefficients of Property and Corruption are close to zero.

Again, we explore whether the sign and significance of the coefficients of promarket and Pro - business change when these covariates are entered separately in the model. These results are reported in models 4, 5, 7, and 8. We find that, when not controlling for the effect of pro-business policy on income, the estimated effect of pro-market policy on income is positive and significant. As such, it may be that not controlling for the effect of pro-business policy may cause researchers to wrongly conclude that pro-market policy has a positive effect on income. The coefficient of Pro-business remains insignificant in models 5 and 8 .

Table 3.5: FE regression results: pro-market policy versus pro-business policy

\begin{tabular}{|c|c|c|c|c|c|c|c|c|}
\hline & DF & CPENDEN' & T VARIAE & LE: INCC & OME & & & \\
\hline & (1) & (2) & (3) & (4) & (5) & (6) & (7) & (8) \\
\hline Pro-Market & $-0.15^{* * *}$ & 0.01 & 0.01 & $0.03^{*}$ & & 0.01 & $0.02+$ & \\
\hline & $(0.00)$ & $(0.31)$ & $(0.27)$ & $(0.05)$ & & $(0.29)$ & $(0.06)$ & \\
\hline Pro-business & $0.13^{* *}$ & 0.02 & 0.02 & & 0.03 & 0.02 & & 0.03 \\
\hline & $(0.00)$ & $(0.27)$ & $(0.28)$ & & $(0.12)$ & $(0.25)$ & & $(0.11)$ \\
\hline Investment & & $0.07 * * *$ & $0.07^{* * *}$ & $0.07 * * *$ & $0.07 * * *$ & $0.07 * * *$ & $0.07 * * *$ & $0.07 * * *$ \\
\hline & & $(0.00)$ & $(0.00)$ & $(0.00)$ & $(0.00)$ & $(0.00)$ & $(0.00)$ & $(0.00)$ \\
\hline Openness & & $0.17 * * *$ & $0.18^{* * *}$ & $0.18^{* * *}$ & $0.18^{* * *}$ & $0.17^{* * *}$ & $0.18^{* * *}$ & $0.18^{* * *}$ \\
\hline & & $(0.00)$ & $(0.00)$ & $(0.00)$ & $(0.00)$ & $(0.00)$ & $(0.00)$ & $(0.00)$ \\
\hline Gconsumption & & $-0.10^{*}$ & $-0.10^{*}$ & $-0.11^{*}$ & $-0.10^{*}$ & $-0.10^{*}$ & $-0.11^{*}$ & $-0.10^{*}$ \\
\hline & & $(0.03)$ & $(0.03)$ & $(0.02)$ & $(0.03)$ & $(0.03)$ & $(0.02)$ & $(0.03)$ \\
\hline Education & & $0.59 * * *$ & $0.58 * * *$ & $0.59 * * *$ & $0.57 * * *$ & $0.59 * * *$ & $0.60^{* * *}$ & $0.58 * * *$ \\
\hline & & $(0.00)$ & $(0.00)$ & $(0.00)$ & $(0.00)$ & $(0.00)$ & $(0.00)$ & $(0.00)$ \\
\hline Property & & & -0.01 & -0.01 & -0.01 & & & \\
\hline & & & $(0.54)$ & $(0.49)$ & $(0.62)$ & & & \\
\hline Corruption & & & & & & 0.00 & 0.01 & 0.00 \\
\hline & & & & & & $(0.89)$ & $(0.72)$ & $(0.94)$ \\
\hline$N$ & 715 & 715 & 715 & 715 & 715 & 715 & 715 & 715 \\
\hline$R^{2}$ & 0.14 & 0.82 & 0.82 & 0.82 & 0.82 & 0.82 & 0.82 & 0.82 \\
\hline
\end{tabular}

Table 3.6 presents the estimation results when estimating using the policy indicator Innovation and the policy indicator Pro-business 2 instead of the indicator Pro-business. We produce estimations for the full models using either Property or Corruption as a proxy for institutional development and using either Growth or Income as the dependent variable. For all models (1-8) we find no effect of 
pro-market policy on economic development. This result is consistent with the previous estimations reported in models 3 and 6 of Tables 3.4 and 3.5. Moreover, the coefficient of Pro-market is close to zero and is neither systematically positive nor negative. The coefficient of Innovation is positive and significant for all models (1-4). The estimated effect of a one standard deviation increase in pro-business policy corresponds to a 0.33 standard deviation increase in growth (model 1). And, the estimated effect of a one standard deviation increase in pro-business policy corresponds to a 0.03 standard deviation increase in income.

We find a significant effect of pro-business type policies when using the indicator Pro - business 2 and estimating its effect on growth but not when using Income as the dependent variable. The coefficient of Pro-business in Table 3.4 model 3 is somewhat higher in magnitude than the coefficient of Pro-business 2 in Table 3.6 model 5. Also, regarding the results presented in Table 3.6, the magnitude of the coefficient of Pro-business in models 5 and 6 is roughly half the size of the coefficient of Innovation in models 1 and 2. Overall, we find no notable changes in the coefficients of the other macro covariates. One exception is the coefficient of Education which is no longer significant in model 1 of table 3.6. Overall, the results support the thesis that the positive growth effect of industrial policy are to large extent a result of policies that support advancements in technology and innovation.

Table 3.6: FE regression results: pro-market policy versus innovation/pro-business2 policy

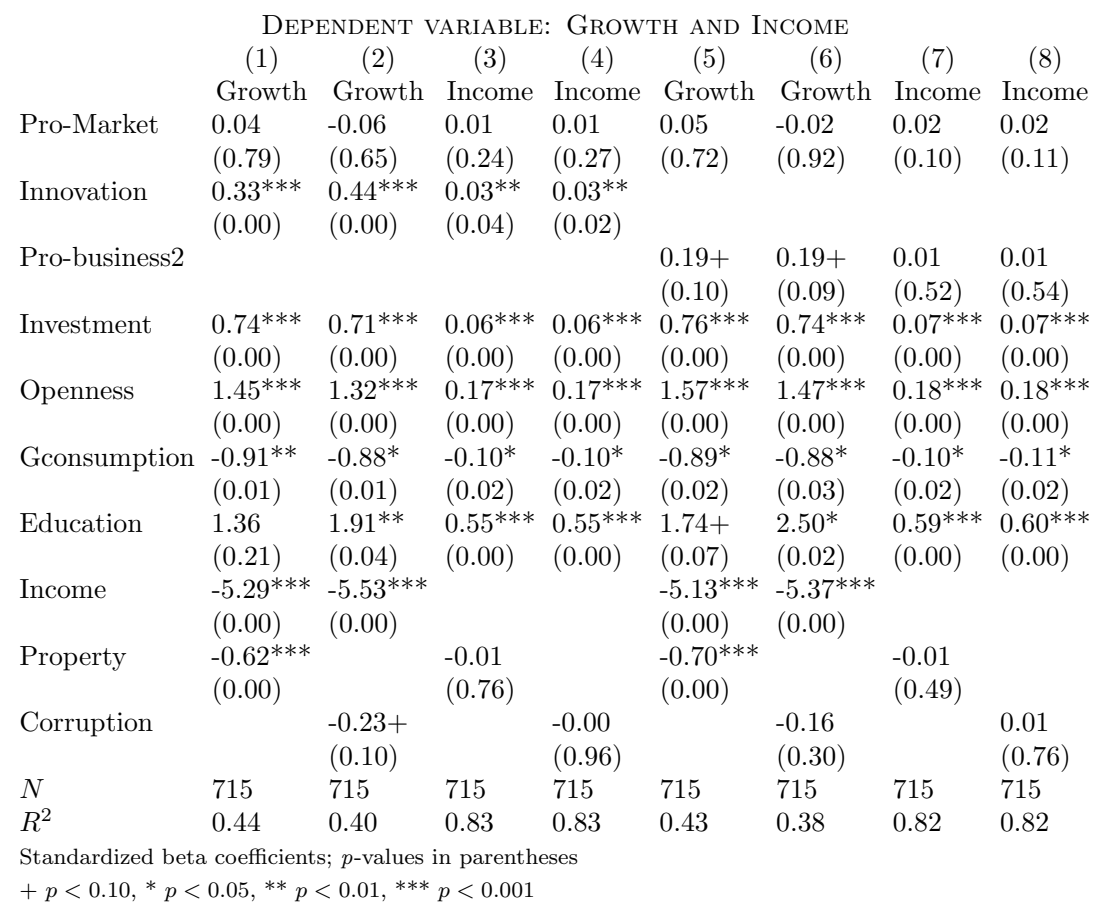


Finally, we test whether the effect of industrial policy on GDP growth is more pronounced when lagging the policy indicators with one year. We report all estimations results using the full models containing either Property or Corruption and the indicators for pro-business type policy: i.e. Pro-business, Innovation, and Pro-business2. These results are reported in Table 3.7. We find no effect of Pro- market $_{t-1}$ on growth and no effect of Pro-business $s_{t-1}$ and Pro-business $2_{t-1}$ on growth. We still find a positive and significant effect of Innovation $_{t-1}$ on growth, but in comparison with the result reported in models 1-2 of Table 3.6, the coefficient is smaller in magnitude. As such, even though the effect of industrial policy on growth may be more pronounced one or more years after a policy reform, when using perception-based policy data we find no strong evidence for a delayed time effect.

Table 3.7: FE regression results. Robustness check for delayed effects

\begin{tabular}{|c|c|c|c|c|c|c|}
\hline & DEPEND & ENT VA & BLE: & ROWTH & & \\
\hline & (1) & $(2)$ & $(3)$ & (4) & $(5)$ & $(6)$ \\
\hline${\text { Pro }- \text { Market }_{t-1}}$ & -0.03 & -0.09 & -0.03 & -0.10 & -0.00 & -0.05 \\
\hline & $(0.84)$ & $(0.53)$ & $(0.83)$ & $(0.45)$ & $(0.98)$ & $(0.69)$ \\
\hline Pro-business ${ }_{t-1}$ & 0.17 & 0.19 & & & & \\
\hline & $(0.21)$ & $(0.17)$ & & & & \\
\hline Innovation $_{t-1}$ & & & $0.25+$ & $0.33^{*}$ & & \\
\hline & & & $(0.07)$ & $(0.02)$ & & \\
\hline Pro-business $2_{t-1}$ & & & & & 0.11 & 0.10 \\
\hline & & & & & $(0.24)$ & $(0.30)$ \\
\hline Investment & $0.81^{* * *}$ & $0.79^{* * *}$ & $0.80^{* * *}$ & $0.79 * * *$ & $0.82^{* * *}$ & $0.80^{* * *}$ \\
\hline & $(0.00)$ & $(0.00)$ & $(0.00)$ & $(0.00)$ & $(0.00)$ & $(0.00)$ \\
\hline Openness & $1.69^{* * *}$ & $1.60 * * *$ & $1.63^{* * *}$ & $1.53^{* * *}$ & $1.71^{* * *}$ & $1.62^{* * *}$ \\
\hline & $(0.00)$ & $(0.00)$ & $(0.00)$ & $(0.00)$ & $(0.00)$ & $(0.00)$ \\
\hline Gconsumption & $-0.95^{*}$ & $-0.97^{*}$ & $-0.97^{* *}$ & $-0.98^{* *}$ & $-0.96^{*}$ & $-0.98^{*}$ \\
\hline & $(0.02)$ & $(0.02)$ & $(0.01)$ & $(0.01)$ & $(0.02)$ & $(0.02)$ \\
\hline Education & $1.70+$ & $2.52^{*}$ & 1.53 & $2.25^{*}$ & $1.75+$ & $2.55^{*}$ \\
\hline & $(0.10)$ & $(0.03)$ & $(0.13)$ & $(0.05)$ & $(0.09)$ & $(0.03)$ \\
\hline Income & $-5.58 * * *$ & $-5.85^{* * *}$ & $-5.73^{* * *}$ & $-6.05^{* * *}$ & $-5.50^{* * *}$ & $-5.75^{* * *}$ \\
\hline & $(0.00)$ & $(0.00)$ & $(0.00)$ & $(0.00)$ & $(0.00)$ & $(0.00)$ \\
\hline Property & $-0.69 * * *$ & & $-0.65^{* *}$ & & $-0.69^{* * *}$ & \\
\hline & $(0.00)$ & & $(0.01)$ & & $(0.00)$ & \\
\hline Corruption & & -0.27 & & -0.24 & & -0.20 \\
\hline & & $(0.14)$ & & $(0.20)$ & & $(0.32)$ \\
\hline$N$ & 658 & 658 & 658 & 658 & 658 & 658 \\
\hline$R^{2}$ & 0.43 & 0.39 & 0.43 & 0.40 & 0.43 & 0.38 \\
\hline dardized beta & cients; $p$ & lues in & enthese: & & & \\
\hline${ }^{k} p<0.05$ & & & & & & \\
\hline
\end{tabular}

\subsection{Conclusion}

The key contribution of this study has been that of systematically unbundling the effect of different industrial policies on growth. We have presented empirical evidence that compares and contrasts the success of a wide notion of industrial policy: market oriented policy and industry support. To some extent the pro-market and probusiness distinction made by Rodrik and Subramanian (2005) is empirically traceable. 
We construct a measure for pro-market policy that captures a country's degree of implementation of free-market type policy and we construct a measure for probusiness type policy that summarizes a country's degree of implementation of policy that supports the development of (incumbent) industry. Overall, there is no strict opposition between pro-market and pro-business policy. Rather, countries' industrial policy path consists of a gradual implementation of more pro-business and pro-market policies. Further research investigating the compatibility between infant-industry support and pro-market policy is necessary to enrich this understanding; such analysis would benefit from industry-level data.

We find that pro-business type policy, in particular investment in technology and innovation, is an essential part of countries' overall industrial policy package and investing in such policy has a positive effect on economic development. We expect that extending the work of Furman et al. (2002) - on the determinants of innovation capacity - by separating innovation policy and innovation capabilities or the 'innovation system' (Soete, 2007) will increase understanding of the degree to which policy encourages innovative behaviour and acts as a growth driver. Moreover, this research has not controlled for the relation between competition and innovation. Yet, according to Aghion et al. (2005) competition creates both incentives and disincentives for innovation. Peneder (2012, pp.1) refers to this as the "misguided antagonism between" the positive 'Arrow effect' theory that is valid under low levels of initial competition versus a negative 'Schumpeter effect' theory that is valid under conditions of high-level of initial competition and low initial profits. We hope that further research will reveal the extent to which the optimal pro-market and proinnovation policy mix is dependent on the level of competition. Finally, this study would benefit from further analysis comparing the perception-based policy data with qualitative data describing policy outcomes. 


\subsection{Appendix 3A}

Table 3.8: Country List

Code Country

$\begin{array}{ll}\text { ARG Argentina } & \text { JPN Japan } \\ \text { AUS Australia } & \text { KAZ Kazakhstan } \\ \text { AUT Austria } & \text { KOR Korea, South } \\ \text { BEL Belgium } & \text { LTU Lithuania } \\ \text { BGR Bulgaria } & \text { LUX Luxembourg } \\ \text { BRA Brazil } & \text { MEX Mexico } \\ \text { CAN Canada } & \text { MYS Malaysia } \\ \text { CHE Switzerland } & \text { NLD Netherlands } \\ \text { CHL Chile } & \text { NOR Norway } \\ \text { CHN China } & \text { NZL New Zealand } \\ \text { COL Colombia } & \text { PER Peru } \\ \text { CZE Czech Republic } & \text { PHL Philippines } \\ \text { DEU Germany } & \text { POL Poland } \\ \text { DNK Denmark } & \text { PRT Portugal } \\ \text { ESP Spain } & \text { QAT Qatar } \\ \text { EST Estonia } & \text { ROM Romania } \\ \text { FIN Finland } & \text { RUS Russia } \\ \text { FRA France } & \text { SGP Singapore } \\ \text { GBR United Kingdom } & \text { SVK Slovakia } \\ \text { GRC Greece } & \text { SVN Slovenia } \\ \text { HKG Hong Kong } & \text { SWE Sweden } \\ \text { HRV Croatia } & \text { THA Thailand } \\ \text { HUN Hungary } & \text { TUR Turkey } \\ \text { IDN Indonesia } & \text { TWN Taiwan } \\ \text { IND India } & \text { UAE United Arab Emirates } \\ \text { IRL Ireland } & \text { UKR Ukraine } \\ \text { ISL Iceland } & \text { USA United States } \\ \text { ISR Israel } & \text { VEN Venezuela } \\ \text { ITA Italy } & \text { ZAF South Africa } \\ \text { JOR Jordan } & \\ & \end{array}$


Table 3.9: Sources

\begin{tabular}{|c|c|c|c|}
\hline Variable & Definition & Source & Scale \\
\hline $\begin{array}{l}\text { Pro-market, pro- } \\
\text { business, Innovation, } \\
\text { Pro-business } 2\end{array}$ & Policy indicators & IMD (2011) & $\begin{array}{lr}\text { Indicators } & \text { are } \\
\text { normalized on } & \text { a } \\
\text { scale of } 0 \text { to } 1 . & \end{array}$ \\
\hline $\begin{array}{l}\text { Pro-market and pro- } \\
\text { business }\end{array}$ & Policy indicators & IPD (2009) & $\begin{array}{lr}\text { Indicators } & \text { are } \\
\text { normalized on } & \text { a } \\
\text { scale of } 0 \text { to } 1 . & \end{array}$ \\
\hline Income & $\begin{array}{l}\text { Real GDP per capita } \\
\text { (Constant } \\
\text { Chain series) }\end{array}$ & Heston et al. (2011) & \\
\hline Growth & $\begin{array}{l}\text { Growth rate of Real } \\
\text { GDP per capita } \\
\text { (Constant } \\
\text { Chain series) }\end{array}$ & Heston et al. (2011) & Logarithmic change \\
\hline Openness & $\begin{array}{l}\text { Openness at } 2005 \\
\text { constant prices }\end{array}$ & Heston et al. (2011) & $\%$ of GDP \\
\hline Investment & 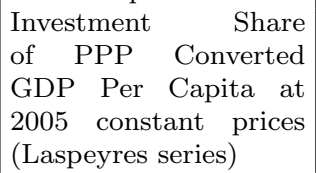 & Heston et al. (2011) & $\%$ of GDP \\
\hline Gconsumption & $\begin{array}{l}\text { Government } \\
\text { Consumption Share } \\
\text { of PPP Converted } \\
\text { GDP Per Capita at } \\
2005 \text { constant prices } \\
\text { (Laspeyres series) }\end{array}$ & Heston et al. (2011) & $\%$ of GDP \\
\hline Education & $\begin{array}{l}\text { Average of mean years } \\
\text { of education men and } \\
\text { mean age of education } \\
\text { woman; } 25 \text { and older }\end{array}$ & $\begin{array}{l}\text { Institute for Health } \\
\text { Metrics and Evaluation } \\
\text { (IHME) (2013) }\end{array}$ & $\begin{array}{l}\text { Average years of } \\
\text { education }\end{array}$ \\
\hline Property & Property Rights & $\begin{array}{l}\text { Heritage Foundation } \\
(2013)\end{array}$ & $\begin{array}{l}\text { From low property } \\
\text { rights protection }=0 \\
\text { to high property rights } \\
\text { protection }=1\end{array}$ \\
\hline Corruption & $\begin{array}{l}\text { Freedom } \\
\text { corruption }\end{array}$ & $\begin{array}{l}\text { Heritage Foundation } \\
(2013)\end{array}$ & $\begin{array}{l}\text { From lack of freedom } \\
\text { from corruption }=0 \\
\text { to high freedom from } \\
\text { corruption }=1\end{array}$ \\
\hline
\end{tabular}




\subsection{Appendix 3B}

\section{Validity of Policy Indicators}

In this section, the two policy domains constructed on the basis of the WCY data are compared with alternative policy indicators. We select variables from the Institutional Profiles Database (IPD) 2009 that are conceptually close to the variable selection of the WCY dataset. The policy indicators from the IPD are listed in Table 3.11. Based on the policy domains constructed for the WCY dataset, the IPD variable selection is sorted in order to describe either pro-business or pro-market policy.

We use Canonical Correlation Analysis (CCA) to compare the variable selection from the WCY with the variable selection from IPD. We assume that countries' score on pro-market and pro-business policy is relatively constant over time and therefore use the IPD data from 2009 and WCY data from the years 2007-2011. The CCA is based on 272 sample observations and 56 countries. Unlike the sample used for the PCA in section 3.4, the countries Croatia, Iceland, and Luxembourg are excluded in the CCA due to missing observations in the IPD 2009 dataset. The results of the CCA are presented in Figures 3.6 and 3.7. We focus on the first and second linear combinations. The Pearson canonical correlations of the first and second linear combination are 0.9 and $0.85 .{ }^{17}$

The raw coefficients of the first two linear combination of the CCA are presented in Figure 3.6. The raw coefficients are interpreted as the effect of a one unit increase in a variable on the corresponding canonical variate. We cannot identify a pattern across the pro-market and/or pro-business policy variables based on the first linear combination and the raw coefficients. The second linear combination does identify some pro-business variables from the WCY dataset that are positively associated with pro-business variables from the IPD dataset. The pro-business variable that describes the availability of funding for technological development (Funding) has a very high positive loading compared to the other variables in the WCY data. Also, in descending order, Framework, Research, and Environment have a positive loading and have previously been identified as pro-business variables. The three variables that have the highest positive loading amongst the IPD variables are classified under pro-business policy. These three variables describe government support for research and development (A5033), institutions that support research and technological acquisitions for SMEs (B5010), and government venture capital initiatives (C5010). The variables that have high negative loadings include both probusiness and pro-market variables.

The loadings resulting from the CCA are presented in Figure 3.7. Following Rencher (1992), the canonical loadings represent the correlation of the variables with their corresponding linear combination (canonical variate). The canonical loadings include less information than the raw coefficients do. However, the canonical loadings are useful to assist in the interpretation of results. The loadings of the first linear combination are high for most of the variables in both datasets. Some of the

17 The Wilks lambda, Pillai's trace, Lawley-Hotelling trace, and Roy's largest root tests are all significant at a $1 \%$ level. 
WCY variables have a relatively low loading (e.g Tax). These variables also have conceptually less relation with the IPD variables. The second linear combination distinguishes two groups of variables in both datasets. Most of the variables that have negative loadings have previously been identified as pro-market variables. And, most of the variables that have positive loadings are associated with pro-business policy.

Based on the raw coefficients, the canonical loadings, and the canonical correlations we find that (1) the WCY and IPD policy variables have similar variation (2), and for both datasets, the pro-market and pro-business policy variables can be distinguished.

Finally, we compute averages for the selection of pro-market variables and for the selection of pro-business policy variables from the IPD dataset. Table 3.10 presents the Pearson correlations for the WCY and IPD pro-market and pro-business indicators. The indicators are all positively correlated. The correlation amongst the WCY data is the highest. The correlation between the policy indicators constructed from the IPD data is 0.53 . The pro-business indicator from WCY has a higher correlation with the IPD pro-business indicator than with the IPD pro-market indicator. Also, the WCY pro-market indicator has a higher correlation with the IPD pro-market indicator than with the IPD pro-business indicator. 


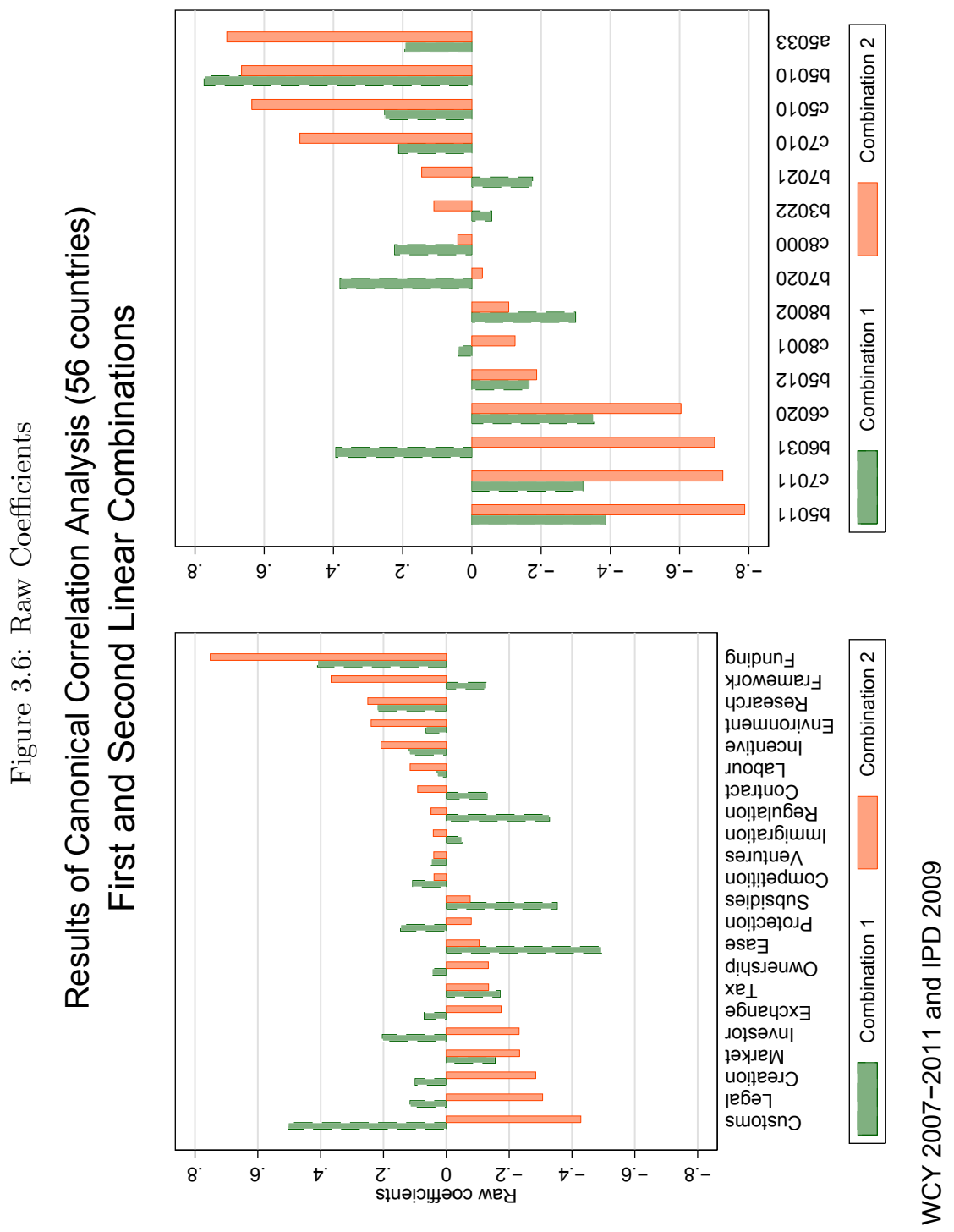




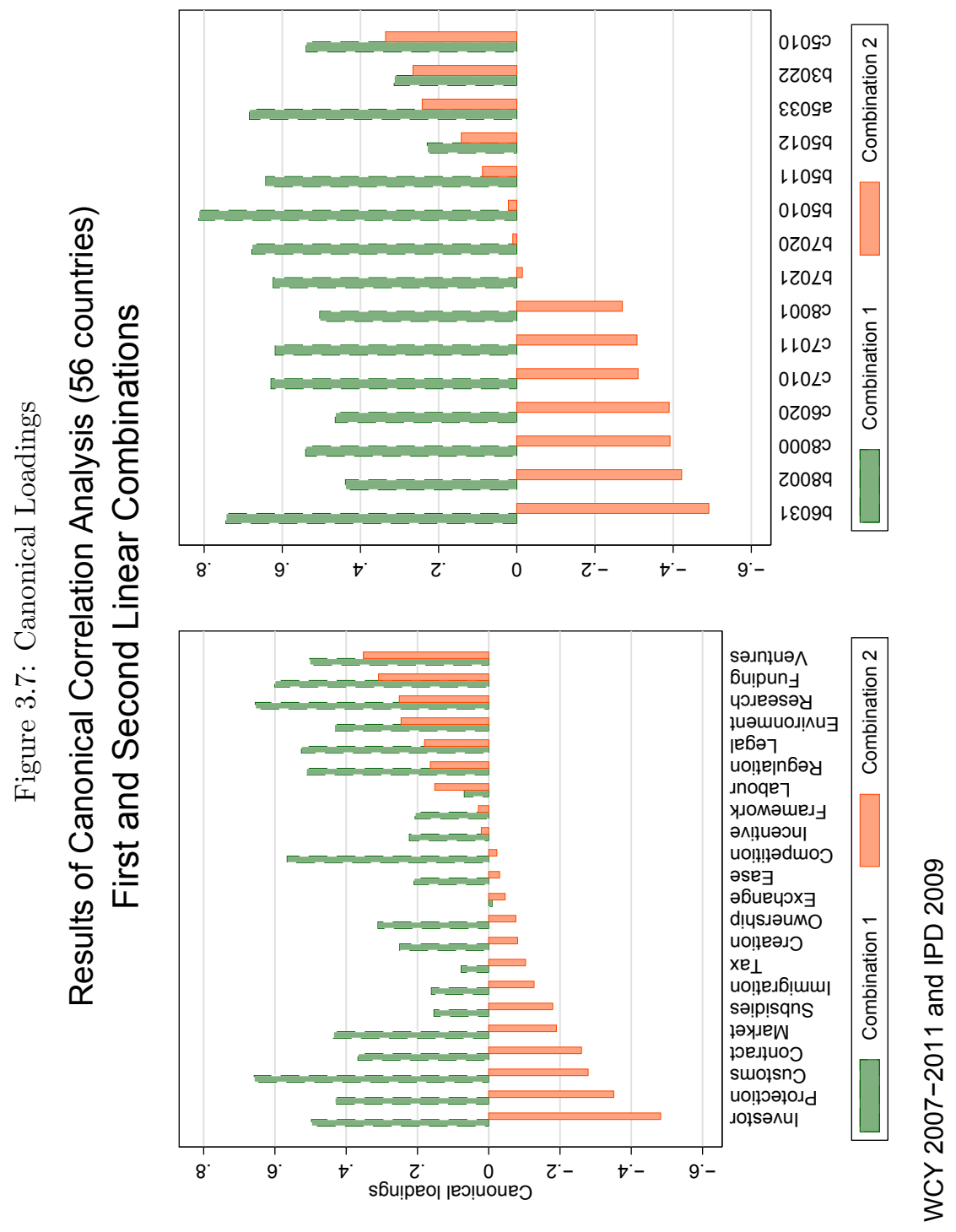


Table 3.10: Correlations between Policy Indicators (WCY 2007-2011 \& IPD 2009)

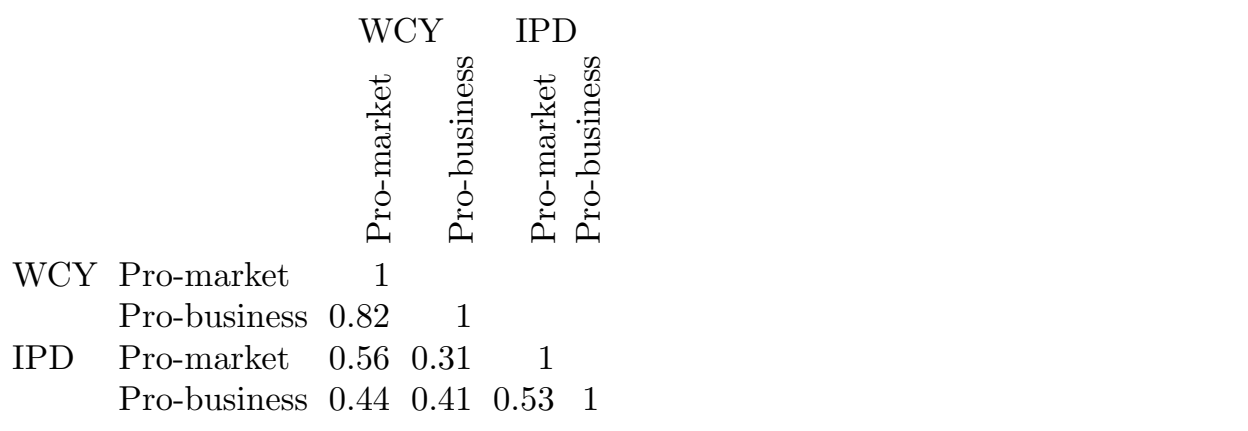

Table 3.11: IPD 2009

\section{Pro-business Development Policy}

A5033: Government support for private or public research \& development (1-4)

B3022: Existence of targeted support measures for emerging growth sectors (0-4)

B5010: Existence of institutions or arrangements to support research and technological acquisitions for SMEs (0-4)

B5011: Existence of institutions or arrangements to support research and technological acquisitions for large firms (0-4)

B5012: Existence of institutions or arrangements to encourage technology transfers and skills transfers from foreign players to domestic players (0-4)

C5010: Government venture capital incentives $(0-4)$

\section{Pro-market Development Policy}

B6031: Effectiveness of enforcement of international TRIPS arrangements for the protection of intellectual property $(0-4)$

B7020: Effectiveness of competition regulation arrangements (non-banking) to combat restrictive collective agreements i.e. cartels $(0-4)$

B7021: Effectiveness of competition regulation arrangements (non-banking) to combat abuses of dominant positions (0-4)

B8002: Restrictions on the issue of import licenses (1-4)

C6020: Publication requirement for firms issuing shares (0-4)

C7010: Existence of competition arrangements in the banking system to combat restrictive collective agreements i.e. cartels $(0-4)$

C7011: Existence of competition arrangements in the banking system to combat abuse of dominant position (0-4)

C8000: Openness of bank capital to foreign shareholding (0-4)

C8001: Right of establishment for foreign deposit banks and investment banks (0-4) 


\section{Extrapolation of Policy Indicators}

We are interested in mapping countries' industrial development path ranging from countries with low income and a fragile institutional setting to countries with high income and a strong institutional setting. We construct average pro-market and probusiness indicators for the 123 countries in the IPD 2009 data using the selection of policy indicators from IPD as discussed above in section 3.8. The IPD data contains more less developed countries than the WCY dataset.

Figure 3.8: Analysis of Policy Indicators using IPD data

Extrapolation of Policy Indicators

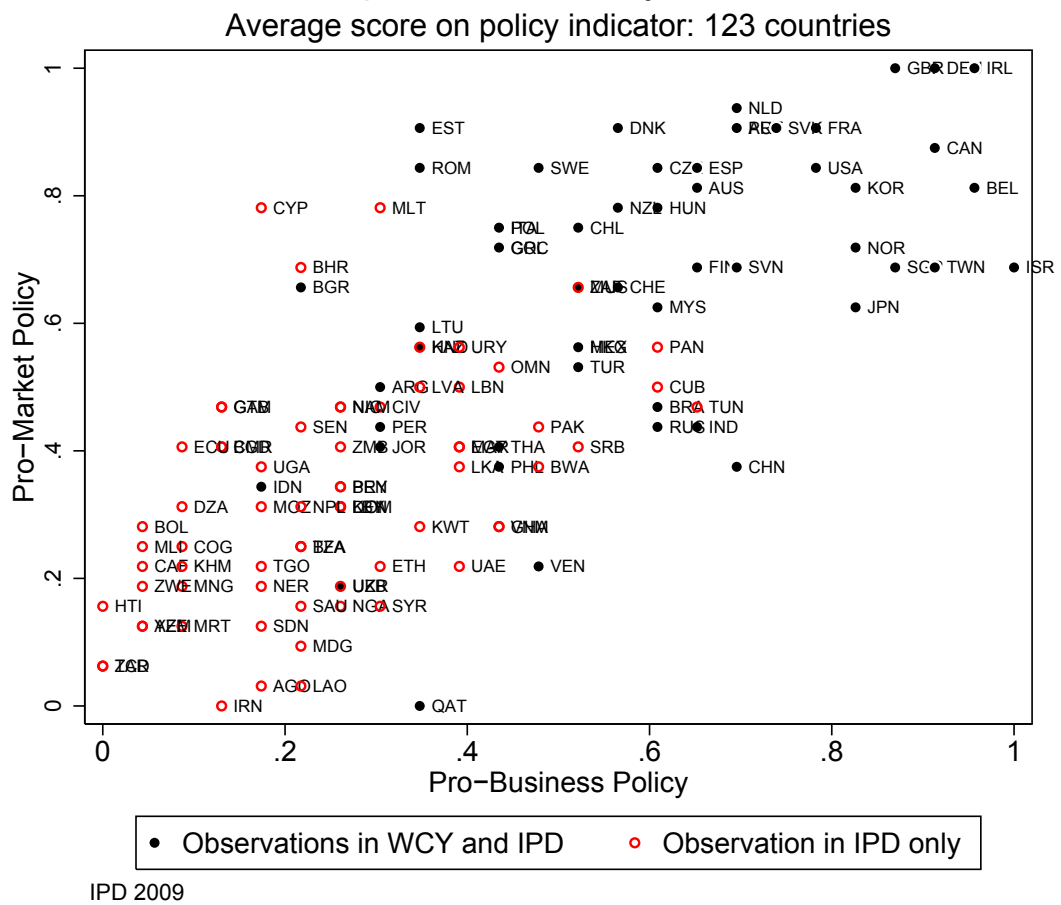

The scores of the 123 countries on the pro-market and pro-business indicators are illustrated in Figure 3.8. As indicated by the legend in the figure, the countries that we document using the WCY dataset are given a different label than the countries for which WCY has no data. Overall, the former group of countries score higher on the policy indicators than the latter group does. Based on this figure it seems that there is a linear relationship between the two policy indicators constructed using the IPD data. This result also confirms that countries that have a relatively low income level and weak institutional setting have implemented less industrial policy. 
Chapter 4

Institutions, Foreign Direct Investment, and Domestic Investment: crowding out or crowding in? 


\subsection{Introduction}

Foreign direct investment (FDI) is the type of capital inflow from abroad that is most directly related to the productive capacity of a country. Its effect of transferring foreign know-how, creating additional investment funds and even improving labour standards is often seen as one of the important benefits of globalization for growth and development of relatively poor countries. According to Kosovà (2010, pp. 861), "since the mid-1990s, FDI has become the main source of external finance for developing countries and is more than twice as large as official development aid". In order to build domestic capacity, some countries have adopted special policies targeting foreign investors, including investment treaties, preferential taxation schemes and preferential loans. Busse and Königer and Nunnenkamp, (2010) and Büthe and Milner (2008) provide evidence about the effectiveness of such policies in attracting FDI.

However, the role of FDI is not uncontroversial. It implies control of foreign firms over the domestic productive capacity, including technological knowledge. For some of the dynamic Asian economies that were growing rapidly in the second half of the 20th century, this was a reason to limit inward FDI, and instead focus on other channels for technology transfer (e.g., licensing or 'arms-length' relationships with foreign firms). This seems to have been the case for Japan (Goto and Odagiri, 2003), Korea (Kim, 2003, 1997) and Taiwan (Aw, 2003). On the other hand, in Singapore (Wong, 2003) and more recently China, inward FDI seems to be encouraged by policy makers.

The academic debate does not show any consensus on the benefits of FDI either. Here, two issues are central to the debate: whether or not FDI has positive productivity spillovers (through transfer of know-how) on domestic firms, and which effect FDI has on (private) domestic investment. With regard to the latter, one may either expect "crowding in", which means that FDI will lead to more investment from (private) domestic sources, or "crowding out", which is the opposite, i.e., FDI leads to less domestic (private) investment. Crowding in can be interpreted as beneficial for economic growth, but the effect of crowding out on economic growth is ambiguous. On this topic of crowding in or crowding out, it is sometimes argued that market entry of foreign owned firms pushes less efficient domestically owned firms out of the market, which may be beneficial for productivity, but implies a negative effect on investment and productive capacity. And, when foreign firms gain significant competition power, markets become less efficient, with a potentially negative effect on growth and investment. Crowding out is more likely to occur in markets with limited investment opportunity such as markets where competition is dependent on firmspecific assets, i.e. medium-tech and high-tech industries (Amsden, 2011). Moreover, crowding out is more likely when domestic firms have limited absorptive capacity and foreign firms have relatively more know-how, experience, innovation capacity, monitoring skills, better access to finance and skilled labour, and when foreign firms are relatively more productive.

In terms of the empirical evidence, some scholars find that increases in FDI crowd out domestic investment, implying that FDI has a limited effect on the development of domestic productivity capacity and growth (Morrissey and Udomkerdmongkol, 2012; Mutenyo et al., 2010; Titarenko, 2005). Other scholars find that FDI stimulates (or 
crowds in) private domestic investment (Al-Sadig, 2013; Ramirez, 2011; Ndikumana and Verick, 2008; Tang et al., 2008; de Mello, 1999; Bosworth and Collins, 1999; Borensztein et al., 1998). Several scholars find mixed evidence when using several lags for FDI or when splitting the country sample according to geographic region (Adams, 2009; Apergis et al., 2006; Agosin and Mayer, 2000; Misun and Tomsik, 2002; Agosin and Mayer, 2000), or find no effect of FDI on domestic investment (Lipsey, 2000). ${ }^{1}$

Similarly, the productivity spillovers of inward FDI is disputed in the literature. For example, Wooster and Diebel (2006) provide an overview of 32 econometric studies of the impact of FDI in developing countries (among which they include transition countries in Eastern Europe), covering a publication time span of 19832004. They find positive effects of spillovers in about half of the included observations (an observation is a regression result, of which there are generally more than one per paper analyzed), and slightly less than half of the reported coefficients - both positive and negative - are statistically significant.

At a more basic level, one may also ask whether, in a particular country context, the performance of foreign-owned firms differs from domestically-owned firms. Huang and Shiu (2009) study the effect of foreign ownership on stock market performance in Taiwan and find that stocks of firms with high foreign ownership rates outperform. Based on data from firms located in Venezuela, Aitken and Harrison (1999) find that small firms with a higher share of foreign ownership have relatively higher productivity than small firms that do not have foreign ownership. Related research on investment by Koo and Maeng (2006) shows that firms in Korea with high foreign ownership have relatively higher investment levels than firms with domestic ownership. Nevertheless, domestically owned firms may have better access to market knowledge and be more entrepreneurial (Amsden, 2011; Koo and Maeng, 2006). FDI inflow can free domestic capital and gives domestic investors more opportunity to invest in new business opportunities (Lipsey, 2000).

Further controversy lies in the role of institutions and governance in FDI and domestic investment, and their relationship (crowding in or crowding out). It is generally accepted that both foreign and domestic investors will prefer investing in countries with secured property rights, a stable institutional setting and other desirable institutional features which are broadly associated with the term 'good governance'. For this reason, 'good governance' is expected to have a positive effect on overall investment. However, what role institutions and governance may have on whether FDI crowds in or crowds out domestic private investment, is less clear. Morrissey and Udomkerdmongkol (2012), hereafter M\&U, estimate an equation for domestic private investment, and use FDI, a number of governance variables, and an interaction term between governance and FDI as explanatory variables. They find a negative coefficient both for the direct effect of FDI on domestic private investment, and for the interaction term between governance and FDI. This leads them to conclude that FDI crowds out domestic private investment, and that it does so in a stronger

\footnotetext{
${ }^{1}$ Similarly, cross-country evidence on the impact of public investment (e.g. investment by national governments, the World Bank, and the International Monetary Fund) on private sector investment also shows mixed results of crowding in and crowding out (Cavallo and Daude, 2011; Belloc and Vertova, 2006; Erden and Holcombe, 2006; Atukeren, 2010; Bird and Rowlands, 2001; Butkiewicz and Yanikkaya, 2005).
} 
way in countries with 'good governance'.

The theoretical model that M\&U use for justifying their regression approach starts from the assumption that foreign investors may insulate domestic investors from 'capital unfriendly' regimes. FDI may thus (partly) offset the negative effect of bad governance on (domestic) investment. While this may be a valid theoretical starting point, there are also other effects that FDI may have on (domestic) investment. Rent seeking (which is typically associated with 'bad governance') may play a role, with asymmetric effects between FDI and domestic investment. Or, one may hypothesize that FDI spillovers are likely to be stronger in countries with more developed institutions, because such countries offer better protection of intellectual property. If this effect is strong, institutions have a positive mediating effect on the relation between FDI and domestic investment. For example, Fu et al. (2011) find that benefits from technology spillovers are dependent on domestic market development as well as institutional development. This suggests that developing countries with relatively poor institutions and governance may lack the absorption capacity for domestic industry to benefit from FDI inflow.

The role that institutions play in mediating the effect of FDI on domestic investment (crowding in or crowding out) is the primary topic of this paper. We seek to investigate whether such a mediating effect exists, and whether, in our sample of developing and emerging economies, crowding in or crowding out dominates. We do not seek to develop new theory on this matter, but instead will briefly summarize the empirical perspectives that are found in the literature, and subsequently interrogate the data to find out which of the effects that are identified in the literature dominates. In formulating our regressions models, we will also ask critical questions about the variable definitions that have been used in the empirical literature. We especially question some of the definitions that have been used for domestic private investment, and experiment with alternative definitions to investigate whether the results in the literature are robust to such definitional changes. Finally, we question the way in which some studies in the field implement estimation methods, especially GMM, and experiment with alternative implementations, again with the aim to test robustness of the results found in the literature.

Overall, our results suggest that the accuracy of the results in the literature (in particular the work of $\mathrm{M} \& \mathrm{U}$ ) are severely compromised by the empirical difficulty in disentangling foreign capital formation from domestic capital formation, and by methodological problems related to the implementation of the GMM method. Using alternative definitions and estimation methods, we find no robust evidence that FDI crowds out private investment. Instead we conclude that foreign investment has a positive effect on investment. In addition, we find weak evidence indicating that 'good governance' is positively related to private investment. And, on the basis of an interaction between 'good governance' and FDI, we find some evidence that there is a negative mediating effect on investment. We interpret this finding as an indication that the negative effect of rent seeking interests in the provision of preferential treatment of foreign investors on investment is stronger than the positive spillover effect on investment and/or is stronger than the effect of rent seeking interests that deter foreign investors from entering markets. 


\subsection{Institutions, FDI and Domestic Investment}

Mauro (1995) found that corruption has a negative effect on private investment and that therefore corruption reduces growth. Subsequently, several studies have found a significant effect of institutional characteristics on investment as well as on FDI. Several scholars find evidence of a positive relation between foreign direct investment (FDI) on the one hand and institutions on the other hand, e.g. legal protection, rule of law, investment treaties, and trade agreements, political stability, government efficiency, control of corruption, and financial supervision (see Buchanan et al., 2012; Morrissey and Udomkerdmongkol, 2012; Ali et al., 2010; Javorcik and Wei, 2009; Daude and Fratzscher, 2008; Daude and Stein, 2007; Busse and Hefeker, 2007; Benassy-Quere et al., 2007).

However, in empirical work looking at the effect of FDI on domestic investment, it is not customary to take into account the effect of institutions. Only some researchers in this field control for the relation between institutions and investment. For example, Ndikumana and Verick (2008) analyze correlations between FDI and democracy and autocracy on the basis of data from Marshall and Jaggers (2009). These authors find a significant relation between democracy and domestic investment, but, because the coefficient is relatively small, Ndikumana and Verick (2008, pp. 720) conclude that "there is little evidence that FDI inflows are higher in countries that are more democratic". Adams (2009) and Borensztein et al. (1998) control for the effect of institutions on domestic investment (both using data describing political risk from ICRG) and find positive and significant effects. Blonigen (2005) explains that the lack of focus on the institutional dimension is a result of the difficulty in measuring institutions and/or corruption. If institutions and good governance are an important explanatory factor of FDI and the FDI domestic investment relation, failure to control for the effect of institutions causes omitted variable bias.

A major step forward in this respect is the analysis by M\&U. These authors attempt to empirically study the institutional dimension as an explanatory factor in the relation between FDI and investment. They follow the theoretical model of Dalmazzo and Marini (2000), which starts from the idea that governance impacts domestic investment. Thus, an "investment unfriendly regime" will tend to discourage investment from domestic sources. Although M\&U do not specify exactly what constitutes an "investment unfriendly regime", it is clear that this encompasses a range of indicators on governance and institutions, and that "investment (un)friendly" can be seen "as good (bad) governance".

The theory then assumes that the effect of investment unfriendly regimes can be mitigated by foreign investors. Foreign investors are assumed to be able to use political leverage (e.g., through their home governments). If a domestic investor turns to a foreign partner, i.e., seeks FDI to support her investment project, the project can be protected from the effects of bad governance. Should a corrupt regime attempt to seize investments, foreign ownership can protect against this by international trade agreements. In terms of the regression that $M \& U$ estimate, this leads to an interaction term between FDI and governance. Their dependent variable is domestic private investment (i.e., excluding FDI). Obviously, governance is one explanatory 
variable (to test the investment - governance relationship), and FDI is another one (to test crowding in or crowding out). While the expected effect of 'good governance' on investment is positive, (i.e., the effect of bad governance is negative), FDI will (partially) offset this effect, thus the interaction term is expected to be negative. Obviously, the interaction term adds both to the (marginal) effect of governance on investment, and to the (marginal) effect of FDI on investment, hence it also affects the conclusions on crowding in or crowding out. A negative (positive) interaction term between FDI and governance would make crowding out (in) stronger in countries with 'good governance'.

Overall, $\mathrm{M} \& \mathrm{U}$ conclude that crowding out is greater in countries with better governance and higher political stability, i.e., the interaction term between FDI and (good) governance is negative. This is not a surprising result in light of the theoretical model that is the starting point of their analysis, because this model treats domestic and foreign investment sources as substitutes, and identifies governance and institutions as the factor that steers the substitution trade-off.

The theoretical starting point of $\mathrm{M} \& \mathrm{U}$, although in principle interesting, appears to us as slightly limited. Other factors may influence the relationship between domestic investment, FDI and institutions and governance, and possibly there are effects that are adverse to the ones hypothesized by M\&U. One additional theoretical approach lies in the theory on political elite rent seeking, which can provide additional explanation for cross-country differences in the degree to which domestic private sectors' opportunities are different than foreign investors' opportunities. Rent seeking is broadly defined as the use of elite relations with the aim to generate rents and/or to distribute rents for personal gain. Rent seeking behaviour is practiced by both political and economic elite. ${ }^{2}$ Whereas the impact of political elite rent seeking has been studied in relation to e.g. foreign aid (Asiedu et al., 2009; Svensson, 2000), efficiency in the banking sector (Morck et al., 2011), and the onset of financial crisis (Wei and Wu, 2002; Johnson, 2009; Mishkin, 1996; Reinhart and Rogoff, 2009), the impact of rent seeking behaviour on investment has not been extensively explored using cross-country analysis. ${ }^{3}$

A revived interest on the impact of elite rent seeking in explaining the variation of economic growth is due to the contribution of North et al. (2009) who investigate the role of elite behaviour in regulating economic activity and social structure. North et al. characterize the 'Limited Access Order' (LAO) as a developmental state in which elite capture rents by reducing competition, differentiating rights, limiting access to trade and access to resources, and by restricting the entry and exit to organizations. Furthermore, the elite are described as protecting social order in order to accumulate

2 E.g. see La Porta et al., 1999 on the dominance of economic elite in the corporate sector and Johnson et al. (2000) on rent seeking behaviour (the diversion of corporate resources such as expropriation and transfer pricing) in the corporate sector. Rent seeking by the political elite can also be referred to as crony capitalism. Wei (2001, pp. 21) describe crony capitalism as following: "an economic environment in which relatives and friends of government officials are placed in positions of power and government decisions on the allocation of resources and judicial judgment on commercial disputes are distorted to favour these friends and relatives."

3 For example, Morck et al. (2011) find that, because of rent seeking costs, economic elite controlled banking and state controlled banking both create relatively larger efficiency losses than widely-held banks. 
future rents. Case studies on the application of LAO framework provide evidence of several channels elite use to collect economic rents: i.e. countries' regulatory framework in controlling competition and assuring dominance of firms and unions, the financial system, natural resources, foreign aid flows, political participation, and policies including land and property rights reform, privatization, and preferential taxation (North et al., 2009) Also, Keefer and Knack (2007) find public investment a powerful channel for rent seeking. ${ }^{4}$

Rent seeking may have a stronger negative effect on either domestic investors or on foreign investors. A tentative explanation of why rent seeking may have a stronger negative effect on domestic investors runs as follows. Domestic elite interest groups may have reasons to grant foreign investors preferential market access. Amsden (2007) finds that foreign firms operating in developing countries with resource intensive industries have a high degree of market power as well as political power. As a result, domestic investors who do not have access to dominant political elites are excluded and may be crowded out. In particular, domestic market potential can be rapidly destroyed when foreign firms operate in extractive industries or seize large amounts of land. Financial repression caused by elite rent seeking behaviour may also impede domestic investors. For example, as found in the work of Diaz-Cayeros (2013), elites in Mexico use personal connections to regulate economic activity and entrepreneurs and medium-sized companies have limited access to financial markets because capital allocation is skewed in favour of the dominant elite. If rent seeking behaviour is positively related to FDI inflow, rent seeking can have a positive mediating effect on the relation between FDI inflow and domestic investment. As a consequence, the negative effect of bad governance on total investment is lessened by the positive interaction between high rent seeking and FDI at the cost of domestic market development.

On the contrary, domestic elite interest groups may also have reasons to oppose financial globalization and foreign investors from entering markets. Countries with high levels of rent seeking may have stronger restrictions on foreign ownership in industries where elites collect large rents. This implies that (in certain industries) high rent seeking may be negatively related to FDI and that the interaction between governance and FDI inflow has a positive effect on countries' level of investment. If rent seeking has both a positive and a negative relation with FDI, and if rent seeking is related to institutions and governance, it will be hard to disentangle the empirical relations between domestic investment, governance and FDI.

An additional theoretical perspective on the role of institutions in the relationship between domestic investment and FDI is found in the literature on spillovers of FDI. Large spillovers from FDI to domestic producers suggest higher domestic investment, because they raise the rate of return to (domestic) investment. Thus, if spillovers are high, we may expect that FDI crowds in rather than crowds out domestic investment. Whether FDI generates large spillovers may depend on institutions and governance. Weak intellectual property rights protection may be associated with an overall lower

\footnotetext{
4 Alternatively, Keefer and Knack (2007) do not exclude the possibility that public investment is higher in countries with weak institutions because government seeks to compensate for poor investment climate.
} 
level of FDI inflow and with a relatively lower level of high technology investments (Crespo and Fontoura, 2007). For example, if intellectual property rights are not protected well, foreign firms may choose to not involve their R\&D or high-tech manufacturing activities in FDI. The resulting FDI is then likely to imply fewer spillovers, and hence the crowding in effect will be weaker. This suggests that an interaction term of the type that $\mathrm{M} \& \mathrm{U}$ use would have a positive sign, instead of the negative one that they assume.

Thus, we argue that there are arguments supporting both a possible negative and positive effect of institutions and governance on the crowding out or crowding in effect of FDI on domestic investment. $\mathrm{M} \& \mathrm{U}$ find that there is a negative interaction effect between institutions and FDI on domestic investment, which suggests crowding out. On the basis of rent seeking theory, we argue that if there is a negative interaction effect between FDI and the development of institutions, this effect can be interpreted as a sign that FDI is motivated (partly) by rent seeking and deters domestic investment. On the other hand, and also on the basis of rent seeking theory, we argue that a positive interaction between 'good governance' and FDI may be interpreted as a sign that, especially in countries with weak institutions, rent seeking interests deter foreign investors from entering markets. And, looking from the point of view of FDI spillovers, we would expect a positive sign on the interaction term between FDI and governance, leading to crowding in. With these contradictory effects associated with various theoretical arguments, whether the sign on the interaction terms is positive or negative is a matter of which effect is stronger than the other. This is what we set out to investigate using a regression framework for a sample of developing and emerging countries in the next section.

\subsection{Macroeconomic Evidence on Crowding in and Crowding out}

Table 4.17 in the Appendix provides an overview of existing research on the effect of FDI on investment. The last column in the table presents the overall conclusion on whether FDI crowds in (CI) or crowds out (CO) investment. ${ }^{5}$ In order to implement our empirical estimations, we start from the empirical approach of M\&U, who use GMM to estimate the following model:

$$
\begin{array}{r}
D P I_{i, t}=\beta_{0}+\beta_{1} D P I_{i, t-1}+\beta_{2} F D I_{i, t}+\beta_{3} G R O W T H_{i, t}+\beta_{4} P U B L I C_{i, t} \\
+\beta_{5} W G I_{i, t}+\beta_{6} W G I_{i, t} \times F D I_{i, t}+\epsilon_{i, t}
\end{array}
$$

Here, $D P I$ is domestic private investment as a fraction of GDP, FDI is FDI as a percentage of GDP, $P U B L I C$ is public investment as a percentage of GDP, GROWTH is past GDP growth, and $W G I$ is one of several indicators on governance and institutions. The $\beta$ s are parameters (to be estimated), and $\epsilon$ is a disturbance term with the usual characteristics. Our main interest is in the $\beta_{2}$ parameter (positive

\footnotetext{
5 Table 4.17 in the Appendix is completed to the best of our knowledge. Some studies did not specify the definition of investment data and method.
} 
for crowding in and negative for crowding out), the $\beta_{5}$ parameter (expected to be positive, indicating a relation between investment and 'good governance'), and the $\beta_{6}$ parameter (expected to be either negative of positive, depending on the nature of the mediating effect). We use the dataset that was constructed by $\mathrm{M} \& \mathrm{U}$, and which was kindly provided to us by these authors.

We start, below, by providing an overview of some estimation issues related to the above equation, and related approaches found in the literature. We then discuss some issues related to the data, including definitional issues that lead us to propose several new dependent variables. Finally, we present the empirical estimations.

\section{Methodology}

Several different methods are implemented in the literature on FDI crowding out or crowding in investment: one-step general method of moments (GMM) (Arellano and Bond, 1991), system general method of moments (GMM) (Blundell and Bond, 1998), pooled estimations of seemingly unrelated regressions (SUR), fixed-effect estimations, OLS, instrumental variable regression, VAR system with error correction model, and fully modified OLS. Some methods of estimation are more adept for dealing with a dynamic model. The advantage of GMM over fixed-effects estimations is that successful implementation of the dynamic model allows controlling for dynamic panel bias.

GMM is a technique aimed at data samples with a large number of 'individuals', here countries, and a small time dimension (Roodman, 2009a). The dataset constructed by $\mathrm{M} \& \mathrm{U}$, and used again here, consists of a balanced 12 year panel and 46 countries, which is a relatively small number of countries for GMM. In addition, M\&U use system GMM, which requires additional moment conditions. M\&U (2012, pp.5) stress that "system GMM can exhibit the problem of too many instruments if the number of instruments is greater than the number of cross-section observations." This is consistent with the discussion in (Roodman, 2009b, pp. 140), leading to a rule of thumb that the number of instruments used in GMM estimation should be lower than $\mathrm{N}$ (in our case 46).

$\mathrm{M} \& \mathrm{U}$ do not report the exact number of instruments used in their estimations, and neither do Agosin and Machado (2005), who use one-step difference GMM analysis with the robust estimator of the covariance matrix on the basis of data for the years 1971-2000 and 12 countries. Moreover, the latter authors do not report Hansen statistics for validity (exogeneity) of instruments, which is more appropriate under heteroskedasticity than the Sargan statistics that they do report. ${ }^{6}$ We replicate the M\&U estimations, using two-step system GMM. The variables $F D I, G R O W T H$, and $P U B L I C$ are treated as endogenous, only the second lags are used as instruments in the transformed equation and only the first differences are used as instruments in the levels equation. The $W G I$ s and the interaction terms are assumed strictly exogenous and therefore serve as standard instruments in the GMM estimations. These assumptions may be incorrect. Although $\mathrm{M} \& \mathrm{U}$ limit the number of lags

\footnotetext{
6 The Sargan test statistic is inconsistent when non-sphericity in the errors is suspected as is the case in multi-country data Roodman (2009b).
} 
used for the instrumental variables to two, the instrument count remains high. In particular, in our replication of the $\mathrm{M} \& \mathrm{U}$ estimations, the instrument count runs up to around 90, which is clearly higher than the number of countries (46). Also, the two covariance matrices of moment conditions for our replications (reproduced in tables 4.2 and 4.3) are singular. ${ }^{7}$ This evidence is in contradiction with the authors' argument that "the number of instruments is larger than the cross-section dimension so the excess instruments problem does not apply" (M\&U, 2012, pp.2). Moreover, the Hansen test statistics reported by the authors and those documented on the basis of our replication exercise below have a $p$-value of 1 , which indicates that the results suffer from instrument proliferation which $\mathrm{M} \& \mathrm{U}$ do not identify. Following Roodman (2009b), numerous instruments - instrument proliferation - can cause the instrumented variables to be over-fitted. This biases the coefficient "estimates towards those from non-instrumenting estimators" (Roodman, 2009b, pp. 139).

A next methodological issue lies in the fact that $\mathrm{M} \& \mathrm{U}$ use the two-step system GMM estimator, which uses a weighting matrix that is more asymptotically efficient than the one-step estimator but the coefficient standard errors "tend to be severely downward biased when the instrument count is high" (Roodman, 2009b, pp.141). Although Windmeijer (2005) proposes a correction for this problem, as far as we can see, this correction was not used by M\&U. Finally, as described by Roodman (2009b, pp. 128), "the autocorrelation test and the robust estimates of the coefficient standard errors assume no correlation across individuals in the idiosyncratic disturbances." By including time dummies in the estimation, this assumption becomes more plausible. Yet M\&U omit time dummies in their estimations. As a result, however precise the conclusions of $\mathrm{M} \& \mathrm{U}$ are formulated, we fear that these are drawn on the basis of biased results.

In order to overcome these methodological problems, we propose several modifications to the system GMM specification. First, in order to avoid contemporaneous correlation, time dummies are included to remove the time-related shocks from errors in GMM analysis. Next, we use the Windmeijer robust estimator for the two-step covariance matrix. Because M\&U assume that FDI is endogenous and treat $F D I$ as endogenous in the GMM regression analysis we also treat the interaction term between $F D I$ and $W G I$ as endogenous. ${ }^{8}$ Finally, in addition to capping the lags of the instrumental variables, the instrument matrix is collapsed to reduce instrument proliferation. As a result, the instrument count is reduced to 21 or slightly more (depending on the specific model), which is well below the number of countries (46). We also compare the results of GMM estimations to the results of fixed-effect estimations (FE), and to the results of pooled OLS (POLS) estimations. ${ }^{9}$ The FE and POLS results include cluster-robust variance estimates.

\footnotetext{
${ }^{7}$ Following Roodman (2009b), the matrix of moments becomes singular when data is limited and the number of instruments approaches $\mathrm{N}$.

${ }^{8}$ We maintain the assumption that WGI is exogenous in order to preserve comparability with the analysis of M\&U.

${ }^{9}$ In a simple autoregressive (AR) model, the fixed-effect and POLS estimates provide an estimated lower and upper bound, respectively, for the autoregressive coefficient. Although the present context is more complicated, since the AR model is extended with a regressor that may not be strictly exogenous, we still propose to use those two estimates as rough benchmarks, giving a likely range for consistent estimates.
} 


\section{Data}

Most scholars acknowledge that the estimations of the effect of FDI on domestic investment are severely troubled by the challenges related to separating foreign domestic investment from private domestic investment. ${ }^{10} \mathrm{M} \& U$ (2012) separate foreign investment from domestic private investment by subtracting net FDI inflow and public investment from gross fixed capital formation (GFCF). Adams (2009) takes a similar approach to that of M\&U and subtracts FDI inflow from GFCF to measure domestic investment. However, the comparison of foreign investment and domestic investment on the basis of data on FDI and data in GFCF is problematic.

As noted by Agosin and Machado (2005), FDI is a financial balance of payments concept whereas GFCF is a concept that is part of countries' national accounts, which implies that these two types of data are constructed using different conceptual frameworks. In fact, while the notion of GFCF starts from the idea of measuring how much new capital is added to the production capacity of a country, FDI does not start from such a notion. FDI measures investments of foreign firms in domestic productive capacity, and this includes existing capacity as well as newly installed capacity. This is related to the notion of greenfield FDI, which is, roughly, defined as setting up previously non-existing production capacity. Non-greenfield FDI means that foreign firms take ownership (either fully or partially) of existing domestic firms, and hence take control over existing capacity. In other words, non-greenfield FDI is not part of GFCF.

On the other hand, greenfield FDI is conceptually part of GFCF, but it is not the only part of GFCF that is under control of foreign ownership. If a firm that is foreign owned invests, this investment is part of GFCF, but not part of greenfield FDI. The latter point touches upon the issue of whether a stock or a flow variable of FDI needs to be used. While the idea of a stock of FDI is obviously not consistent with the idea of the (flow of) GFCF it is still likely that when the stock of FDI is large (relative to the domestic capital stock), a larger part of GFCF will be under foreign control.

As a result of these definitional problems, the measurements for domestic private investment that $\mathrm{M} \& \mathrm{U}$ construct contain negative observations, which are obviously difficult to interpret. ${ }^{11}$ This view is also shared by Ndikumana and Verick (2008, pp. 719) who argue that subtracting FDI from domestic private investment does not yield a more accurate measurement and that, by construction, such measure "would be negatively correlated with FDI". The latter observation relates to the fact that, in terms of the variables in our model, $D P I \equiv G F C F-P U B L I C-F D I$. Since $F D I$ and $P U B L I C$ appear as explanatory variables, subtracting them on the left hand side of the equation will tend to subtract 1 from the respective coefficients $\left(\beta_{1}\right.$ and $\left.\beta_{2}\right)$

\footnotetext{
10 An exception is the work of Tang et al. (2008, pp. 1302) who study the Chinese economy and argue that their measure of domestic investment does not include any type of foreign investment. As such, for some countries it may be possible to separate FDI from private domestic investment. Nevertheless, cross-country studies are limited in this respect. Another exception is the research by Titarenko (2005); Misun and Tomsik (2002) where the dependent variable is represented by the sum of domestic investment and FDI. Whether the authors construct the dependent variable by adding domestic investment and FDI inflows remains unclear.

${ }^{11}$ Following the summary statistics of $\mathrm{M} \& \mathrm{U}$, the minimum amount of domestic private investment over GDP is -37.4. The authors offer no interpretation of this negative value.
} 
on the right hand side, thus biasing these coefficients towards the negative domain. If FDI is relatively highly volatile, this may lead to an extreme downward bias in the estimated effect.

Because M\&U (2012) subtract net FDI inflow and public investment from GFCF (instead of subtracting FDI inflow), they conceptually aggravate the problem with the measure for private investment because this measure now also contains private disinvestments that are transfers of ownership from domestically owned establishments to foreign investors. Following the summary statistics of the authors, the minimum amount of net FDI is -14.4 and the overall effect of net FDI outflow on private domestic investment within the context of crowding out and crowding in remains unexplained. As a result, we suspect that the dependent variable used by $M \& U$ is a poor measure for total private domestic investment. Therefore, we will experiment with different dependent variables. We will add $F D I$, and later on $P U B L I C$, to the dependent variable of $\mathrm{M} \& \mathrm{U}$, thereby obtaining again, respectively, total private foreign controlled and domestic) and total investment (GFCF). This does not change the expected sign of the estimated coefficients (e.g., a negative sign on $F D I$ would still indicate crowding out).

The explanatory variables used in the study of M\&U (2012) are lagged domestic private investment (the dependent variable), FDI, growth $(G R O W T H)$, public investment $(P U B L I C)$, and governance. M\&U measure governance using data from the Worldwide Governance Indicators (hence the variable name $W G I$ ) collected by Kaufmann et al. (2009). The governance indicators are the following: voice and accountability $(V A)$, political stability and absence of violence $(P S)$, government effectiveness $(G E)$, regulatory quality $(R Q)$, rule of law $(R L)$, and control of corruption $(C C)$. M\&U do not report results for the effect of government effectiveness on investment. The $W G I$ s have missing data for the years 1997, 1999, and 2001. But, as reported in the appendix of $\mathrm{M} \& \mathrm{U}$, the authors use an unobserved components model to calculate estimates for the years 1997-2009 using data from 1996-2009. On the basis of the revised $W G I \mathrm{~s}$, the authors construct dummies for each governance indicator representing whether a country has either high (1) or low (0) governance. This classification is determined by whether a country scores higher than the 50th percentile on the governance indicator. The dataset used by M\&U consists of 46 countries and a balanced 12 year panel. ${ }^{12}$ The first section of Table 4.1 provides an overview of the data used by M\&U.

\footnotetext{
12 The following countries are included in the analysis: Argentina, Azerbaijan, Bangladesh, Belize, Bolivia, Brazil, Bulgaria, China, Chile, Colombia, Comoros, Costa Rica, Dominica, Dominican Republic, Ecuador, Egypt, Grenada, Guatemala, Guyana, Haiti, Indonesia, India, Kenya, Lithuania, Madagascar, Malawi, Malaysia, Mauritania, Mauritius, Mexico, Morocco, Namibia, Nicaragua, Panama, Papua New Guinea, Paraguay, Peru, Philippines, Romania, Seychelles, South Africa St. Lucia, St.Vincent, Thailand, Uruguay, and Venezuela.
} 
Table 4.1: Data

\begin{tabular}{|c|c|c|c|}
\hline Label & Variable & Construction & Source \\
\hline \multicolumn{4}{|c|}{ SECTION 1} \\
\hline DPI & Domestic private investment & & $\mathrm{M} \& \mathrm{U}$ \\
\hline PUBLIC & Public investment & & $\mathrm{M} \& \mathrm{U}$ \\
\hline GROWTH & Growth of real output & & $\mathrm{M} \& \mathrm{U}$ \\
\hline FDI & Net foreign direct investment & & $\mathrm{M} \& \mathrm{U}$ \\
\hline WGIs & $\mathrm{VA}, \mathrm{RQ}, \mathrm{RL}, \mathrm{PS}, \mathrm{CC}$ & & $\mathrm{M} \& \mathrm{U}$ \\
\hline \multicolumn{4}{|c|}{$\begin{array}{r}\text { SECTION } 2 \\
\end{array}$} \\
\hline WGI & 1st factor of WGIs & Factor analysis & $\mathrm{M} \& \mathrm{U}$ \\
\hline $\mathrm{PI}$ & Private investment & DPI + FDI & $\mathrm{M} \& \mathrm{U}$ \\
\hline GFCF & Gross fixed capital formation & $\mathrm{PI}+\mathrm{PUBLIC}$ & $\mathrm{M} \& \mathrm{U}$ \\
\hline $\mathrm{GFCF}^{*}$ & Gross fixed capital formation & & WDI \\
\hline GCF & Gross capital formation & & PWT \\
\hline STOCK & Stock of FDI & & UNCTAD \\
\hline
\end{tabular}

In order to provide a broader overview of the determinants of investment we complement the data from M\&U with alternative data. First, as explained above, we construct a measurement for private investment $(P I)$ and for $G F C F$ on the basis of data from $\mathrm{M} \& \mathrm{U}$. We add FDI to the measure for private domestic investment to capture the original measure for 'private investment', i.e., $P I=D P I+F D I$. Then we add public investment to $P I$ to measure $G F C F$, i.e., $G F C F=D P I+F D I+$ $P U B L I C$. The results of analysis using $G F C F$ are also compared with the results of analysis using data on GFCF from the World Development Indicators database, which is also the primary source for M\&U. ${ }^{13}$ We refer to the data on GFCF (as a percentage of GDP) from the WDI as ' $G F C F^{*}$ '. In addition, we use investment data from the Penn World Table (PWT 7.1) (Heston et al., 2012). This variable is denoted GCF. ${ }^{14}$

The $W G I \mathrm{~s}$ are broad measures of highly correlated governance indicators, especially considering the purpose of the study, which does not specify a very precise notion of governance. ${ }^{15}$ As an alternative to testing the sensitivity of the effect of the individual governance indicators on investment, we use the Kaufmann et al. data which $M \& U$ treated using an unobserved components model and construct a composite governance indicator. In the regression results, this will be denoted as $W G I$, whereas the individual variables of which this is made up will be denoted by their names as introduced above $(V A, P S, R Q, R L, C C)$. WGI is constructed by estimating the first principal component of the governance indicators used by $M \& U$ prior to the authors' data conversion to dummies. This approach is similar to that

\footnotetext{
13 These data have missing observations for Haiti (all years), Belize (2009) and Malawi (2002).

14 GCF is defined as the investment Share of PPP Converted GDP Per Capita and is measured on the basis of 2005 constant prices.

15 The WGI of Kaufmann et al. are based on data from 33 sources and 30 institutes. In order to construct the indicators Kaufmann et al. (2009) aggregate the underlying data giving more weight to data sources that have a closer correlation based on the premise that this data is more reliable.
} 
of e.g Faria and Mauro (2009) who calculate a simple average of the governance indicators.

The principal component is denoted $W G I P C$, and, as $\mathrm{M} \& \mathrm{U}$, we construct a dummy variable that has the value 1 when a given country scores higher than the 50 th percentile on $W G I P C$ (in every year). The dummy variable is denoted $W G I$.

Although not always clearly indicated, the literature uses a wide range of definitions of foreign direct investment in order to measure the effect of foreign investment on domestic investment: FDI stock, FDI inflow, and net inflows of FDI. Furthermore, Ramirez (2011, pp. 39) 'deflates' gross FDI inflows by subtracting repatriation of profits and dividends with the aim to measure the effect of the "net contribution of FDI to the financing of private capital formation." We control for the sensitivity of the definition of FDI by substituting the data on net FDI inflows by data of the stock of FDI as a ratio to GDP $(S T O C K)$. These data are taken from UNCTAD. ${ }^{16}$

\section{Replicating and checking robustness of the $M \& U$ estimations}

We start by replicating the estimations by M\&U. Table 4.2 presents the results without the interaction terms between $F D I$ and the governance variables. Table 4.3 presents the results with the interaction terms. These results are obtained by the GMM estimation method that is closest to M\&U, which suffers from the problems that we identified above. We have similar findings as M\&U, i.e., FDI crowds out domestic private investment (a negative and highly significant sign on $F D I$ ). Moreover, overall, the coefficients intended to measure the direct effect of governance on domestic investment are positive, with the exception of $C C$. In table 4.3 , these results are essentially unchanged, and the coefficients of the interaction terms between FDI and the governance indicators are also generally significant (with the exception of $R L$ ). The interaction terms for voice and accountability, regulatory quality, and control of corruption are negative and the coefficients for the interaction term with rule of law and political stability are positive.

In Table 4.4, we experiment with alternative estimation methods. We drop the separate governance indicators in order to save space, and substitute them with the single WGI dummy variable. Columns 1 and 2 of Table 4.4 present the results of the GMM analysis that is closest to the method used by M\&U (i.e., the same method as in the previous two tables), but using $W G I$ instead of the individual governance indicators. Here, we find that both the coefficient of $W G I$ and the coefficient of the interaction term between $W G I$ and $F D I$ are positive. The coefficient of $F D I$ is negative. Hence, the results in these two columns are close to the results in the previous two tables, and in $\mathrm{M} \& \mathrm{U}$.

The other columns in Table 4.4 investigate how robust these findings are to changes in the estimation method. Columns 3 and 4 of Table 4.4 present the analysis using the alternative system GMM method (GMM*) as outlined in section 4.3. In comparison

\footnotetext{
16 Following UNCTAD statistics the stock of FDI for the Dominican Republic for 1998 amounts to a negative accumulation of inflows (the exact level of FDI stock was not reported). We recode this observation to zero. Observations for Indonesia prior to 2003 include data on the stock of FDI in Timor-Leste.
} 
to the results presented in columns 1 and 2, the significance level of the estimations is lower, although the sign of the estimations does not change (except for the coefficient of $W G I$, column 4 which is insignificant). The significance of both lagged dependent variables decreases and the lagged dependent variable turns insignificant in column 3. Moreover, we no longer find a significant effect of GROWTH, the direct effect of governance and of the interaction term (the latter only in the equation with the interaction term). As expected, there is evidence of first-order serial correlation (AR1) (in column 2 only). However, we find no evidence of second-order serial correlation (AR2). The $p$-value of the Hansen test statistic remains insignificant, although now at more reasonable levels than the 1 in columns 1 and 2. For model 3 and 4 , the difference-in-Hansen test statistic, which provides additional information on the validity of instruments for the endogenous variable sub-group (D-in Hansen (levels)), yields a test statistic of zero because the model is exactly identified. As a result, we cannot detect invalid instruments based on this test statistic. Overall, the difference-in-Hansen test statistics for each of the endogenous variables' instrument subset, e.g. D-in Hansen $\left(D P I_{t-1}\right)$, indicate no further problems. Even though these diagnostics look much better than those in columns 1 and 2, we still want to check how the results hold up if we resort to fixed-effect estimations (despite the weakness of this method in the estimation of a dynamic model).

The fixed-effect results are displayed in columns 5 and 6 and indicate that FDI is negatively related to $D P I$. And, in contrast to the results displayed in columns 3 and 4 , both coefficients of $W G I$ are positive. The interaction term (column 6) is significant and negative. All other explanatory variables are not significant. An interesting feature of the FE estimations is that the $R^{2}$ is close to 1 . We take this as potential evidence of spurious correlation due to the definitional issues related to the dependent variable $D P I$ that were outlined above. The results of the POLS estimations methods are displayed in columns 7 and 8 . On the basis of this method we find that all explanatory variables are significantly related to $D P I$, except $P U B L I C$ in model 7 and 8, GROWTH in model 7, WGI in model 8 and the interaction variable in model 8.

\section{Robustness analysis with alternative dependent variables}

So far, using the dependent variable $D P I$, we consistently find a negative effect of net FDI on domestic private investment. In this section, we investigate whether this result is robust to using other dependent variables. As already stressed before, in terms of the effect of governance on investment, and either crowding in or crowding out of domestic investment by FDI, we do not expect that these definitional changes lead to any different signs of the explanatory variables. The results of the estimations using $P I, G F C F, G F C F^{*}$, and $G C F$ as the dependent variables are presented in Tables $4.5,4.6,4.7$, and 4.8 , respectively.

The conclusion on crowding in or crowding out changes drastically with $P I$ as the dependent variable (Table 4.5). The coefficient of FDI turns positive, pointing to crowding in rather than crowding out. This coefficient is significant is the case in the GMM specification that is most closely to that of M\&U (columns 1 and 2) and with fixed-effects (columns 5 and 6 ). The results for other variables also change, 
but these are less systematic. We do find that the GMM method of M\&U is most optimistic on the general significance level, and that the other methods together do not provide strong support for any other variable affecting $P I$, except GROWTH, which is significantly positive in GMM, GMM*, and POLS estimations. Following analysis with fixed-effects $W G I$ is significant and positive and the interaction term is negative and significant. The $p$-values of the Hansen test statistics remain implausibly 'perfect' for the GMM models reported in columns 1 and 2, and are lower for the models reported in columns 3 and 4 . The $p$-values of the Hansen test statistic reported in column 3 and 4 are 0.29 and 0.16 which suggests that the instruments are appropriately uncorrelated with the errors. However, the difference-in-Hansen test statistics of the lagged dependent variable instrument subset (D-in Hansen $P I_{t-1}$ ) reported in column 3 and 4 reveal that these instruments are not valid. Likewise, the difference-in-Hansen test statistics for $F D I$ and $F D I \_W G I$ are significant.

When using $G F C F$ as the dependent variable (Table 4.6) we find similar results as with the analysis using $P I$ as the dependent variable, with the exception of $P U B L I C$. While the coefficient on this variable was consistently negative before, we now find a positive and significant coefficient following analysis with FE, POLS, and M\&U's GMM specification without interaction effect (column 1). GMM analysis including the interaction terms (column 2 and 4) reveals that the coefficients of PUBLIC are insignificant and remain negative but their order of magnitude is relatively lower. This is clearly related to the fact that with $G F C F$ as the dependent variable, we do not deduct $P U B L I C$ on the left hand side, and hence do not have a downward bias on the coefficient of this variable on the right hand side of the equation. The coefficient of $F D I$ is positive and significant in the GMM specification of M\&U and with fixed effects. The other estimations find no significant effect of $F D I$ on this dependent variable. $W G I$ is positive and significant when using fixed effects and M\&U's GMM specification (column 1 only). The coefficient of the interaction term is negative and significant but only when using fixed effect analysis.

Table 4.7 presents the results of the analysis using data on GFCF retrieved from the WDI, i.e., the dependent variable $G F C F^{*}$. Although this should not make a real difference (M\&U's source for $G F C F$ is also WDI), it turns out that there is a clear difference. ${ }^{17}$ The coefficient of $F D I$ is now positive and significant in all estimation methods, i.e., we find strong evidence for crowding in with this variable. Moreover, on the basis of the fixed-effect estimations and POLS estimations displayed in columns 6 and 8 , we find that the variable $W G I$ is positive and significant and the interaction term between $F D I$ and $W G I$ is negative and significant. Thus, for fixed effects and POLS, we find that 'good governance' encourages investment, but this holds to a lesser extent for FDI, i.e., the effect of rent seeking on GFCF seems larger than the effect of technology spillovers. The order of magnitude of the coefficient of $W G I$ is considerably larger than the coefficient of the interaction term. In model 5 we also find a positive effect of $W G I$ on $G F C F^{*}$ although this coefficient is lower than the coefficient of $W G I$ in model 6. And, when using POLS and when not controlling for the interaction between $F D I$ and $W G I$, we find no direct effect of

\footnotetext{
17 We need to investigate further how this change may have occurred. Possibly, a revision of the data in WDI has taken place.
} 
governance on investment (column 7). Thus, the positive effect of 'good governance' may be underestimated when not controlling for the interaction between governance and foreign investment. The coefficient of $W G I$ of the GMM analysis presented in columns 1-2 has a negative sign in column 1 and has a positive sign in column 2 which includes the interaction term. Model 2 also suggests that the interaction term $F D I+W G I$ is negatively related to investment. The results of the analysis using

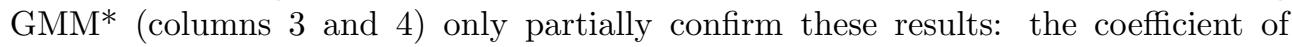
the interaction term is significant and negative but the coefficients of $W G I$ remain insignificant in these models.

Finally, because of the sensitivity to the exact source of the data on GFCF, we decided to use another source, i.e., the PWT. This is the dependent variable $G C F$, for which the results are presented in Table 4.8. These results are somewhat similar to those of the analysis using $G F C F^{*}$ as the dependent variable. On the basis of all methods we find that FDI crowds in investment. Moreover, following the results displayed in Table 4.8, when using the dependent variable $G C F$ we find a significant positive direct effect of 'good governance' in models 1, 2,6 and 8. By comparing model 5 and model 6 (fixed effects) and by comparing model 7 and 8 (POLS) we find that the relation between $W G I$ and investment only turns significant when controlling for the interaction term between $W G I$ and FDI. Furthermore, whereas in Table 4.7 the coefficient of the interaction term was always significant and negative, when using $G C F$ as the dependent variable variable this is no longer the case. We only find evidence that the interaction term between $F D I$ and $W G I$ is significantly and negatively related to investment when using M\&U's GMM specification. However, we suspect that the results of this GMM analysis are biased as a result of instrument proliferation. The fixed-effect models using $G F C F^{*}$ and $G C F$ yield a $R^{2}$ that ranges from 0.62 to 0.67 which is high but no indication of further complications.

The results of $\mathrm{GMM}^{*}$ analysis using both $G F C F^{*}$ and $G C F$ as the dependent variables support the theory on FDI crowding in investment and, in addition, provide some evidence for the mediating relation between $F D I$ and $W G I$ on investment. Nevertheless, these models do not suggest that governance matters for investment. The $p$-values of the Hansen test statistics for models 3 - 4 of Table 4.7 are 0.67 and 0.28 suggesting that the instruments are valid. Also none of the difference-in-Hansen test statistics for the endogenous variables are significant and thereby do not reject the validity of the additional moment conditions. The $p$-values of the Hansen test statistics for models 3-4 of Table 4.8 are reasonable in magnitude and these tests do not raise suspicion about the validity of instrument subsets. Again, the difference-inHansen test statistics for the levels equation cannot be computed for the GMM* models (Tables 4.7 and 4.8) because the models are exactly identified. We do report the difference-in-Hansen test statistics for each of the endogenous variables' instrument subset. And, some of these tests statistics (D-in Hansen $\left(G F C F_{t-1}\right)$ and D-in Hansen (FDI)) indicate that the instruments are invalid because they are correlated with the error term. 


\section{Robustness analysis with FDI stocks}

Tables $4.9,4.10,4.11,4.12,4.13$, present the results using the stock of FDI as a ratio of GDP as a proxy for the effect of foreign investment on domestic investment. As in the previous section, we replicate the analysis using the different dependent variables: $D P I, P I, G F C F, G F C F^{*}$, and $G C F$.

As before, we conclude that only on the basis of the dependent variable DPI we can find significant indication of a negative relation between FDI (in this case represented by $S T O C K$ ) and a country's level of investment. For DPI as the dependent variable (Table 4.9), we find negative and significant signs for STOCK for all estimation methods except our own preferred GMM specification (columns 3 and 4) and POLS (columns 7 and 8). Also, column 2 in Table 4.11 shows a significant and negative coefficient of $S T O C K$. The relation between $S T O C K$ and the dependent variables $G F C F^{*}$ and $G C F$ is positive and significant following all methodology except the results displayed in Table 4.12 column 5, (FE) 7 and 8 (POLS) and the results displayed in Table 4.13 column 3 and 4 (GMM*) and column 7 and 8 (POLS).

Overall, the choice of a different foreign investment proxy has some effect on the coefficient of $W G I$ and on the coefficient of the interaction term. Whereas the coefficient of the interaction term was significant and negative in column 8 Table 4.7 we find that this coefficient is no longer significant in column 8 in Table 4.12 using $G F C F^{*}$ as the dependent variable. The other results displayed in Tables 4.12 are similar to those displayed in Table 4.7 and also indicate that the positive effect of 'good governance' becomes more apparent when controlling for the mediating effect between $W G I$ and STOCK. Following Table 4.13, which presents the analysis using GCF as the dependent variable, both GMM using M\&U's specification and FE finds a significant and negative coefficient of the interaction term. This result is not found when using $\mathrm{GMM}^{*}$ and POLS estimations.

We maintain that FDI is positively related to investment and that the negative effect of rent seeking dominates the positive effect of technology spillovers. ${ }^{18}$ On the basis of GMM* results we find no clear evidence that 'good governance' is positively related to investment.

The $p$-values of the Hansen statistics remain high in most models and appear sensitive to the choice of dependent variable. As before, following the estimations

\footnotetext{
18 We further test the robustness of these results using a proxy for greenfield investment. This proxy is constructed using data on mergers and acquisitions (M\&A) and FDI inflow from the World Investment Report 2011 (UNCTAD, 2011). A significant amount of observations for (M\&A) and FDI inflow are coded as 'zero or negligible'. We recode these observations to zero. Both data on FDI inflow and M\&A contain negative values. Subtracting the indicator for M\&A from that of FDI inflow produces additional negative values for our indicator on greenfield investment. The greenfield data is converted from US dollar amount to a ratio of GDP using data on GDP from WDI. The greenfield data has missing observations for Comoros, Domenica, Grenada, Namibia, and St. Vincent and the Grenadines. Albeit the proxy for greenfield investment may be considered crude, FE and POLS estimations using this proxy support the conclusions drawn on the basis of the analysis using $F D I$ and $S T O C K$ as explanatory variables. In particular, the regression results using the dependent variables $G F C F^{*}$ and $G C F$ and 'greenfield' instead of the variables $S T O C K$ and FDI are somewhat similar to the results presented in Tables 4.7, 4.8, 4.12, and 4.13. When using the dependent variables $G F C F^{*}$ and $G C F$ and GMM $^{*}$ estimations we find a positive effect of 'greenfield' on investment but no significant effect of the coefficients of $W G I$ and the interaction term. This GMM* analysis is fragile as a result of invalid instruments.
} 
using the GMM* method, the difference-in-Hansen test statistics for the endogenous variable subset are based on an exactly identified model and as such we cannot assess the validity of this instrument subsets. Yet, for Table 4.12 columns 3 and 4, we cannot reject the null hypothesis of the difference-in-Hansen test statistics that assess the validity of the instruments for the endogenous variables separately; this supports the models. For Table 4.13 columns 3, the difference in Hansen test statistic for the instrument subset of GROWTH is significant. Because we can not fully exclude the possibility that the instruments are endogenous we also put some trust in the fixed effect analysis.

\section{Robustness analysis with rent seeking proxy's}

In this final robustness analysis we construct a measure for rent seeking behaviour. We relax the assumption that the WGI is a comprehensive set of proxies which describes 'good governance' and that, as a result, the WGI can indirectly capture the effect of rent seeking behaviour. Scholars have used a wide range of measures for rent seeking; including corruption indexes, trade restrictions, and volatility in public budget. ${ }^{19}$ With the objective of constructing a more direct measure for rent seeking behaviour we use perception based indicators from the Global Competitiveness Index (WCI) which is collected by the (World Economic Forum). The WCI perception data use a scale from 1-7 where higher values correspond to e.g. an absence of or low concern for rent seeking. The WCI data allows constructing a short panel for the years 2005-2010 using data for 68 developing countries. ${ }^{20}$

We measure political elite rent seeking behaviour on the basis of four survey questions: (1) the diversion of public funds to companies, individuals, or groups due to corruption, (2) favouritism by government officials to well-connected firms and individuals when deciding upon policies and contracts, (3) the wastefulness (efficiency) in the composition of public spending in providing necessary goods and services, and (4) the effectiveness of anti-monopoly policy in promoting competition. We construct a simple average of the above variables and refer to this rent seeking proxy as $R E N T_{p}$ (rent seeking in the public sector). In addition, because rent seeking behaviour is expected to be more prevalent in countries that lack market competition we construct a second rent seeking proxy using two survey questions. This second rent seeking proxy is measured by (1) countries' degree of intensity of competition in the local markets and by (2) the extent of domination of corporate activity by few business groups. As before, we construct an average of these variables and refer to this rent seeking proxy as $R E N T_{m}$ (rent seeking in the private sector). We complement the

\footnotetext{
19 See Del Rosal, 2011 for a summary on the empirical literature on rent seeking.

20 The following countries are included in the analysis: Albania, Algeria, Azerbaijan, Bangladesh, Benin, Bolivia, Bosnia and Herzegovina, Botswana, Brazil, Bulgaria, Burundi, Cambodia, Cameroon, Chad, China, Costa Rica, Croatia, Ecuador, Egypt, El Salvador, Ethiopia, Gambia, Georgia, Guyana, Honduras, India, Jordan, Kazakhstan, Kenya, Kyrgyz Republic, Latvia, Lesotho, Macedonia, Madagascar, Malaysia, Mauritania, Mauritius, Mexico, Mongolia, Montenegro, Morocco, Mozambique, Namibia, Nepal, Nicaragua, Pakistan, Panama, Peru, Philippines, Romania, Russia, Senegal, Serbia, South Africa, Sri Lanka, Syria, Tajikistan, Tanzania, Thailand, Tunisia, Turkey, Uganda, Ukraine, United Arab Emirates, Uruguay, Venezuela, Zambia, and Zimbabwe. Due to missing observations this sample excludes some countries that were included in the previous analysis.
} 
WCI dataset with data on GFCF, net FDI, public investment, and GDP growth from the World Bank (2012). ${ }^{21}$

The results using the rent seeking proxy $R E N T_{p}$ are displayed in Table 4.14 and the results using the rent seeking proxy $R E N T_{m}$ are displayed in Table 4.15. Columns 1 and 2 present the GMM estimations using our preferred GMM specification with one modification. Because the number of countries in this sample is relatively larger we do not limit the number of available lags to be used as instruments. Depending on the model, the instrument count is 26 or 31 . The $p$-values of the Hansen test statistic range from 0.26 to 0.64 and as such suggest the instruments are valid. However, the difference-in-Hansen test statistic which tests the validity of additional instruments for the levels equation is significant in model 1 and 2 of Table 4.14 and model 1 of Table 4.15. This test, as well as the other difference-in-Hansen tests indicate that some of our instruments are not valid. Additionally, the difference-in-Hansen test statistic for instrument validity of PUBLIC in model 2 of Table 4.15 is significant. Columns 3 and 4 of Tables 4.14 and 4.15 present FE estimations and columns 5 and 6 present POLS estimations. As before, the $p$-values of the FE and POLS results are based on cluster-robust variance estimates.

Following Table 4.14 and Table 4.15 and GMM*, FE, and POLS estimations, the coefficient of FDI is positive and significant suggesting that FDI positively contributes to GFCF. The exceptions are the coefficients of FDI following POLS estimations which are insignificant as is indicated in the columns 5 of both Table 4.14 and 4.15. Furthermore, we find that the choice of rent seeking proxy $\left(R E N T_{p}\right.$ or $\left.R E N T_{m}\right)$ generate similar results in terms of sign and significance of the variables. The coefficient of $R E N T_{p}$ is positive and significant in column 2,3,4, and 6 and the coefficient of $R E N T_{m}$ is positive and significant in column $1,2,3,4$, and 6 . We conduct a final robustness analysis using the data on 68 countries and a governance proxy $(W G I)$ using a simple average of the 6 Worldwide Governance Indicators i.e. including 'government effectiveness' (Kaufmann et al., 2009) (see Table 4.16). These results confirm that on the basis of this sample $W G I$ has a positive and significant effect on investment but only for GMM* and POLS estimations when including the interaction term FDI_WGI. Hence, both the results using $W G I$ and the rent seeking proxies show that the direct 'good governance'/'rent seeking' effect on private investment 'increases in significance' when controlling for the interaction between 'good governance'/'rent seeking' and FDI. Because the coefficients of our rent seeking proxies behave similar to the coefficients of WGI it is likely that (control of) rent seeking and 'good governance' are related. The coefficients of the interaction terms $F D I_{-} R E N T_{p}, F D I_{-} R E N T_{m}$, and also $F D I_{-} W G I$ are negative and significant following estimations with GMM*, FE, and POLS and therefore these results provide additional support for the hypothesis that foreign investors may benefit from rent seeking behaviour at the expense of domestic market development.

$21 P U B L I C=\mathrm{GFCF}-\mathrm{GFCF}$ to the private sector. 


\subsection{Conclusion}

We critically reviewed the results of the empirical macroeconomic literature on the impact of foreign investment on domestic investment, and the role of institutions and governance in this relationship. We conclude that the results of estimations depend both on the exact dependent variable used (proxy for investment) and on the estimation method. In terms of our preferred methods (properly specified GMM, or fixed effects) and dependent variables (total GFCF), we find that foreign direct investment positively influences a country's overall level of investment. Thus, we find evidence for crowding in, rather than for crowding out. This result strongly contradicts that of $\mathrm{M} \& \mathrm{U}$, which in many ways has been a benchmark for our methods. Nevertheless, because of the difficulty to separate foreign investment from private investment using macroeconomic data, we suggest that cross-country analysis on the basis of microeconomic data could yield more robust evidence describing the influence of foreign ownership on domestic investment behaviour. Although Koo and Maeng (2006) do this for Korean firms, to the best of our knowledge no cross-country study uses micro data to ask whether foreign investment crowds in or crowds out domestic investment.

We find weak evidence of a positive relation between 'good governance' and higher levels of investment and we find some evidence indicating that the interaction between foreign investment and governance has a negative mediating effect on investment. Unlike $\mathrm{M} \& \mathrm{U}$, we interpret this negative relationship as evidence that foreign investors have preferential access to industry as a result of elite rent seeking interests. This negative effect of rent seeking may have serious long-term consequences on domestic industry development. Because both FDI spillover and rent seeking are possible determinants of investment behaviour we can not exclude the possibility that the negative effect of rent seeking on investment may be underestimated, or that the positive effect of spillovers may be underestimated. Our results suggest that the negative effect of rent seeking dominates the positive effect of spillovers. In order to assess the overall costs of rent seeking, or the overall benefits of spillovers, further research is needed to distinguish the opposing effects of rent seeking and technology spillovers on investment behaviour. Finally, studying the aggregate effect of rent seeking and technology spillovers on domestic investment remains challenging because rent seeking and technology spillovers may only have a positive (negative) impact on a subset of firms (see also Crespo and Fontoura, 2007). Microeconomic analysis may help to identify which firms are vulnerable to FDI inflow and/or which firms benefit from FDI inflow.

This study does not focus on the role of market dynamics in foreign investment behaviour. Yet, in line with research by Kosovà (2010); Liu (2008); Aitken and Harrison (1999), we expect that the relations between foreign firm market entry, competition, productivity, and technology spillovers are dynamic in nature. Crosscountry research based on microeconomic data may provide more insight into the short-run and long-run impact of foreign investment on domestic investment. In particular cross-country micro analysis may provide insight on whether positive 
spillover effects in the long-term outweigh possible short run negative effects of foreign firm entry.

An additional open question is whether policy interventions are successful in preventing domestic firms from being crowded-out by foreign firm entry. Further analysis is needed to understand the degree to which policy (at the industry or macro level) has influenced the relation between foreign investment and domestic investment.

\subsection{Appendix 4A}

Table 4.2: Replicating M\&U (no interaction terms), dependent variable DPI

$\begin{array}{lllllll} & (1) & (2) & (3) & (4) & (5) & (6) \\ & & \text { VA } & \text { PS } & \text { RQ } & \text { RL } & \text { CC } \\ \text { DPI }_{t-1} & 0.42^{* * *} & 0.41^{* * *} & 0.41^{* * *} & 0.42^{* * *} & 0.41^{* * *} & 0.42^{* * *} \\ & (0.00) & (0.00) & (0.00) & (0.00) & (0.00) & (0.00) \\ \text { FDI } & -0.49^{* * *} & -0.50^{* * *} & -0.51^{* * *} & -0.48^{* * *} & -0.50^{* * *} & -0.48^{* * *} \\ & (0.00) & (0.00) & (0.00) & (0.00) & (0.00) & (0.00) \\ \text { PUBLIC } & -0.03 & 0.04 & -0.04 & 0.03 & -0.03 & 0.01 \\ & (0.26) & (0.21) & (0.49) & (0.53) & (0.38) & (0.86) \\ \text { GROWTH } & 0.15^{* * *} & 0.17^{* * *} & 0.15^{* * *} & 0.17^{* * *} & 0.16^{* * *} & 0.16^{* * *} \\ & (0.00) & (0.00) & (0.00) & (0.00) & (0.00) & (0.00) \\ \text { WGIs } & & 1.15^{* * *} & 0.94^{* * *} & 1.02^{* * *} & 0.80^{* * *} & -0.01 \\ & & (0.00) & (0.00) & (0.00) & (0.00) & (0.00) \\ \text { Constant } & 7.75^{* * *} & 6.61^{* * *} & 7.47^{* * *} & 6.48^{* * *} & 7.41^{* * *} & 7.18^{* * *} \\ & (0.00) & (0.00) & (0.00) & (0.00) & (0.00) & (0.00) \\ N & 552 & 552 & 552 & 552 & 552 & 552 \\ \text { Hansen J } & 1.00 & 1.00 & 1.00 & 1.00 & 1.00 & 1.00 \\ \text { \# of instruments } & 89 & 90 & 90 & 90 & 90 & 90 \\ \text { \# of countries } & 46 & 46 & 46 & 46 & 46 & 46 \\ \text { AR(1) } & 0.00 & 0.00 & 0.00 & 0.00 & 0.00 & 0.00 \\ \text { AR(2) } & 0.28 & 0.31 & 0.27 & 0.29 & 0.31 & 0.28\end{array}$

$p$-values in parentheses; $\mathrm{AR}(1), \mathrm{AR}(2)$, and Hansen $\mathrm{J}$ test statistics report the respective $p$-values

$+p<0.10,{ }^{*} p<0.05,{ }^{* *} p<0.01,{ }^{* * *} p<0.001$ 
Table 4.3: Replicating M\&U (with interaction terms), dependent variable DPI

\begin{tabular}{llllll} 
& $(1)$ & $(2)$ & $(3)$ & $(4)$ & $(5)$ \\
& $\mathrm{VA}$ & $\mathrm{PS}$ & $\mathrm{RQ}$ & $\mathrm{RL}$ & $\mathrm{CC}$ \\
$\mathrm{DPI}_{t-1}$ & $0.35^{* * *}$ & $0.37^{* * *}$ & $0.39^{* * *}$ & $0.37^{* * *}$ & $0.38^{* * *}$ \\
& $(0.00)$ & $(0.00)$ & $(0.00)$ & $(0.00)$ & $(0.00)$ \\
FDI & $-0.54^{* * *}$ & $-0.62^{* * *}$ & $-0.50^{* * *}$ & $-0.58^{* * *}$ & $-0.53^{* * *}$ \\
& $(0.00)$ & $(0.00)$ & $(0.00)$ & $(0.00)$ & $(0.00)$ \\
PUBLIC & $-0.14^{*}$ & $-0.16^{* * *}$ & $-0.08^{*}$ & $-0.08+$ & -0.00 \\
& $(0.01)$ & $(0.00)$ & $(0.03)$ & $(0.07)$ & $(0.94)$ \\
GROWTH & $0.16^{* * *}$ & $0.17^{* * *}$ & $0.18^{* * *}$ & $0.18^{* * *}$ & $0.16^{* * *}$ \\
& $(0.00)$ & $(0.00)$ & $(0.00)$ & $(0.00)$ & $(0.00)$ \\
WGIs & $1.37^{* * *}$ & $0.56^{* * *}$ & $1.64^{* * *}$ & $1.20^{* * *}$ & 0.34 \\
& $(0.00)$ & $(0.00)$ & $(0.00)$ & $(0.00)$ & $(0.11)$ \\
FDI_WGIs & $-0.06^{* * *}$ & $0.07^{* * *}$ & $-0.13^{* * *}$ & 0.00 & $-0.05^{* *}$ \\
& $(0.00)$ & $(0.00)$ & $(0.00)$ & $(0.83)$ & $(0.00)$ \\
Constant & $8.81^{* * *}$ & $9.12^{* * *}$ & $7.66^{* * *}$ & $8.24^{* * *}$ & $7.79^{* * *}$ \\
& $(0.00)$ & $(0.00)$ & $(0.00)$ & $(0.00)$ & $(0.00)$ \\
$N$ & 552 & 552 & 552 & 552 & 552 \\
Hansen J & 1.00 & 1.00 & 1.00 & 1.00 & 1.00 \\
\# of instruments & 91 & 91 & 91 & 91 & 91 \\
\# of countries & 46 & 46 & 46 & 46 & 46 \\
AR(1) & 0.00 & 0.00 & 0.00 & 0.00 & 0.00 \\
AR(2) & 0.31 & 0.31 & 0.34 & 0.36 & 0.29 \\
\hline
\end{tabular}

$p$-values in parentheses; $\operatorname{AR}(1), \operatorname{AR}(2)$, and Hansen $\mathrm{J}$ test statistics report the respective $p$-values

$+p<0.10,{ }^{*} p<0.05,{ }^{* *} p<0.01,{ }^{* * *} p<0.001$ 
Table 4.4: Alternative estimation methods. Dependent variable: DPI

\begin{tabular}{|c|c|c|c|c|c|c|c|c|}
\hline & (1) & $(2)$ & (3) & (4) & $(5)$ & (6) & (7) & (8) \\
\hline & GMM & GMM & $\mathrm{GMM}^{*}$ & GMM* $^{*}$ & $\mathrm{FE}$ & $\mathrm{FE}$ & POLS & POLS \\
\hline $\mathrm{DPI}_{t-1}$ & $\begin{array}{l}0.42^{* * *} \\
(0.00)\end{array}$ & $\begin{array}{l}0.37^{* * *} \\
(0.00)\end{array}$ & $\begin{array}{l}0.38 \\
(0.22)\end{array}$ & $\begin{array}{l}0.40+ \\
(0.10)\end{array}$ & $\begin{array}{l}0.00 \\
(0.87)\end{array}$ & $\begin{array}{l}0.00 \\
(0.88)\end{array}$ & $\begin{array}{l}0.66^{* * * *} \\
(0.00)\end{array}$ & $\begin{array}{l}0.66^{* * *} \\
(0.00)\end{array}$ \\
\hline FDI & $\begin{array}{l}-0.50^{* * * *} \\
(0.00)\end{array}$ & $\begin{array}{l}-0.62^{* * *} \\
(0.00)\end{array}$ & $\begin{array}{l}-0.64+ \\
(0.06)\end{array}$ & $\begin{array}{l}-0.48^{*} \\
(0.04)\end{array}$ & $\begin{array}{l}-0.99^{* * *} \\
(0.00)\end{array}$ & $\begin{array}{l}-0.98^{* * *} \\
(0.00)\end{array}$ & $\begin{array}{l}-0.41^{* * *} \\
(0.00)\end{array}$ & $\begin{array}{l}-0.47^{* * *} \\
(0.00)\end{array}$ \\
\hline PUBLIC & $\begin{array}{l}0.06 \\
(0.42)\end{array}$ & $\begin{array}{l}-0.05 \\
(0.29)\end{array}$ & $\begin{array}{l}0.48 \\
(0.53)\end{array}$ & $\begin{array}{l}-0.59 \\
(0.34)\end{array}$ & $\begin{array}{l}-0.35 \\
(0.23)\end{array}$ & $\begin{array}{l}-0.35 \\
(0.23)\end{array}$ & $\begin{array}{l}-0.00 \\
(0.95)\end{array}$ & $\begin{array}{l}-0.01 \\
(0.91)\end{array}$ \\
\hline GROWTH & $\begin{array}{l}0.17^{* * *} \\
(0.00)\end{array}$ & $\begin{array}{l}0.18^{* * *} \\
(0.00)\end{array}$ & $\begin{array}{l}0.28 \\
(0.19)\end{array}$ & $\begin{array}{l}0.22 \\
(0.15)\end{array}$ & $\begin{array}{l}-0.00 \\
(0.78)\end{array}$ & $\begin{array}{l}-0.00 \\
(0.79)\end{array}$ & $\begin{array}{l}0.19 \\
(0.10)\end{array}$ & $\begin{array}{l}0.20+ \\
(0.09)\end{array}$ \\
\hline WGI & $\begin{array}{l}1.14^{* * *} \\
(0.00)\end{array}$ & $\begin{array}{l}0.92^{* * *} \\
(0.00)\end{array}$ & $\begin{array}{l}1.40 \\
(0.23)\end{array}$ & $\begin{array}{l}-0.03 \\
(0.98)\end{array}$ & $\begin{array}{l}0.41^{*} \\
(0.05)\end{array}$ & $\begin{array}{l}0.49^{*} \\
(0.03)\end{array}$ & $\begin{array}{l}0.97+ \\
(0.10)\end{array}$ & $\begin{array}{l}0.47 \\
(0.42)\end{array}$ \\
\hline FDI_WGI & & $\begin{array}{l}0.05^{* * *} \\
(0.00)\end{array}$ & & $\begin{array}{l}0.16 \\
(0.42)\end{array}$ & & $\begin{array}{l}-0.02+ \\
(0.10)\end{array}$ & & $\begin{array}{l}0.11 \\
(0.31)\end{array}$ \\
\hline CONSTANT & $\begin{array}{l}6.39^{* * *} \\
(0.00)\end{array}$ & $\begin{array}{l}8.21^{* * *} \\
(0.00)\end{array}$ & $\begin{array}{l}5.08 \\
(0.35)\end{array}$ & $\begin{array}{l}12.51+ \\
(0.05)\end{array}$ & $\begin{array}{l}17.07^{* * *} \\
(0.00)\end{array}$ & $\begin{array}{l}17.08^{* * *} \\
(0.00)\end{array}$ & $\begin{array}{l}6.08^{* * *} \\
(0.00)\end{array}$ & $\begin{array}{l}6.26^{* * *} \\
(0.00)\end{array}$ \\
\hline$N$ & 552 & 552 & 552 & 552 & 552 & 552 & 552 & 552 \\
\hline$R^{2}$ & & & & & 0.971 & 0.971 & 0.780 & 0.782 \\
\hline Hansen J & 1.00 & 1.00 & 0.36 & 0.50 & & & & \\
\hline D-in Hansen (levels) & 1.00 & 1.00 & & & & & & \\
\hline D-in Hansen $\left(\mathrm{DPI}_{t-1}\right)$ & 1.00 & 1.00 & 0.40 & 0.49 & & & & \\
\hline D-in Hansen (FDI) & 1.00 & 1.00 & 0.45 & 0.64 & & & & \\
\hline D-in Hansen (GROWTH) & 1.00 & 1.00 & 0.20 & 0.71 & & & & \\
\hline D-in Hansen (PUBLIC) & 1.00 & 1.00 & 0.28 & 0.43 & & & & \\
\hline D-in Hansen (FDI_WGI) & & & & 0.47 & & & & \\
\hline D-in Hansen (iv) & 0.04 & 0.52 & & & & & & \\
\hline \# of instruments & 90 & 91 & 21 & 23 & & & & \\
\hline \# of countries & 46 & 46 & 46 & 46 & 46 & 46 & 46 & 46 \\
\hline $\mathrm{AR}(1)$ & 0.00 & 0.00 & 0.10 & 0.08 & & & & \\
\hline $\operatorname{AR}(2)$ & 0.29 & 0.35 & 0.50 & 0.38 & & & & \\
\hline
\end{tabular}

$p$-values in parentheses; models 3-8 contain year dummies; AR(1), AR(2), and Hansen J test statistics report the respective $p$-values $+p<0.10,{ }^{*} p<0.05,{ }^{* *} p<0.01,{ }^{* * *} p<0.001$ 
Table 4.5: Dependent variable: $P I$, all estimation methods

\begin{tabular}{|c|c|c|c|c|c|c|c|c|}
\hline & $(1)$ & $(2)$ & $(3)$ & $(4)$ & $(5)$ & $(6)$ & $(7)$ & $(8)$ \\
\hline & GMM & GMM & GMM $^{*}$ & GMM* & $\mathrm{FE}$ & $\mathrm{FE}$ & POLS & POLS \\
\hline \multirow[t]{2}{*}{$\mathrm{PI}_{t-1}$} & $0.92^{* * *}$ & $0.92^{* * *}$ & $0.51+$ & $0.65 * * *$ & $0.11^{*}$ & $0.11^{*}$ & $0.94^{* * *}$ & $0.94^{* * *}$ \\
\hline & $(0.00)$ & $(0.00)$ & $(0.06)$ & $(0.00)$ & $(0.02)$ & $(0.02)$ & $(0.00)$ & $(0.00)$ \\
\hline \multirow[t]{2}{*}{ FDI } & $0.03^{* * *}$ & $0.01^{* * * *}$ & 0.00 & 0.07 & $0.01+$ & $0.02^{*}$ & 0.02 & 0.01 \\
\hline & $(0.00)$ & $(0.00)$ & $(0.97)$ & $(0.22)$ & $(0.09)$ & $(0.02)$ & $(0.14)$ & $(0.31)$ \\
\hline \multirow[t]{2}{*}{ PUBLIC } & $-0.05^{* * *}$ & $-0.06^{* * *}$ & -0.00 & $-0.68+$ & -0.38 & -0.39 & -0.02 & -0.02 \\
\hline & $(0.00)$ & $(0.00)$ & $(1.00)$ & $(0.06)$ & $(0.20)$ & $(0.20)$ & $(0.32)$ & $(0.31)$ \\
\hline \multirow[t]{2}{*}{ GROWTH } & $0.03^{* * *}$ & $0.03^{* * *}$ & $0.30^{* *}$ & $0.16+$ & 0.01 & 0.01 & $0.07^{* *}$ & $0.07^{* *}$ \\
\hline & $(0.00)$ & $(0.00)$ & $(0.00)$ & $(0.06)$ & $(0.37)$ & $(0.35)$ & $(0.01)$ & $(0.01)$ \\
\hline \multirow[t]{2}{*}{ WGI } & $0.09^{*}$ & 0.02 & 0.97 & 0.29 & $0.35+$ & $0.43^{*}$ & 0.11 & 0.02 \\
\hline & $(0.02)$ & $(0.46)$ & $(0.42)$ & $(0.70)$ & $(0.06)$ & $(0.03)$ & $(0.38)$ & $(0.88)$ \\
\hline \multirow[t]{2}{*}{ FDI_WGI } & & $0.02^{* * *}$ & & -0.02 & & $-0.02+$ & & 0.02 \\
\hline & & $(0.00)$ & & $(0.87)$ & & $(0.09)$ & & $(0.31)$ \\
\hline \multirow[t]{2}{*}{ CONSTANT } & $1.25^{* * *}$ & $1.43^{* * *}$ & 6.56 & $9.68^{*}$ & $15.74^{* * *}$ & $15.76^{* * *}$ & $0.86+$ & 0.47 \\
\hline & $(0.00)$ & $(0.00)$ & $(0.14)$ & $(0.03)$ & $(0.00)$ & $(0.00)$ & $(0.05)$ & $(0.17)$ \\
\hline$N$ & 552 & 552 & 552 & 552 & 552 & 552 & 552 & 552 \\
\hline$R^{2}$ & & & & & 0.151 & 0.154 & 0.939 & 0.939 \\
\hline Hansen J & 1.00 & 1.00 & 0.29 & 0.16 & & & & \\
\hline D-in Hansen (levels) & 1.00 & 1.00 & & & & & & \\
\hline D-in Hansen $\left(\mathrm{PI}_{t-1}\right)$ & 1.00 & 1.00 & 0.09 & 0.04 & & & & \\
\hline D-in Hansen (FDI) & 1.00 & 1.00 & 0.09 & 0.09 & & & & \\
\hline D-in Hansen (GROWTH) & 1.00 & 1.00 & 0.17 & 0.54 & & & & \\
\hline D-in Hansen (PUBLIC) & 1.00 & 1.00 & 0.41 & 0.26 & & & & \\
\hline D-in Hansen (FDI_WGI) & & & & 0.09 & & & & \\
\hline D-in Hansen (iv) & 0.66 & 1.00 & & & & & & \\
\hline \# of instruments & 90 & 91 & 21 & 23 & & & & \\
\hline \# of countries & 46 & 46 & 46 & 46 & 46 & 46 & 46 & 46 \\
\hline $\mathrm{AR}(1)$ & 0.02 & 0.02 & 0.00 & 0.00 & & & & \\
\hline $\operatorname{AR}(2)$ & 0.68 & 0.69 & 0.97 & 0.92 & & & & \\
\hline
\end{tabular}


Table 4.6: Dependent variable: $G F C F$, all estimation methods

\begin{tabular}{|c|c|c|c|c|c|c|c|c|}
\hline & (1) & $(2)$ & (3) & (4) & (5) & (6) & (7) & (8) \\
\hline & GMM & GMM & GMM* & $\mathrm{GMM}^{*}$ & $\mathrm{FE}$ & $\mathrm{FE}$ & POLS & POLS \\
\hline \multirow[t]{2}{*}{$\mathrm{GFCF}_{t-1}$} & $0.93^{* * *}$ & $0.92^{* * *}$ & $0.57^{* *}$ & $0.71^{* * *}$ & $0.10+$ & $0.10+$ & $0.94^{* * *}$ & $0.94^{* * *}$ \\
\hline & $(0.00)$ & $(0.00)$ & $(0.01)$ & $(0.00)$ & $(0.05)$ & $(0.05)$ & $(0.00)$ & $(0.00)$ \\
\hline \multirow[t]{2}{*}{ FDI } & $0.03^{* * *}$ & $0.01^{* * *}$ & 0.03 & 0.06 & $0.01+$ & $0.02^{*}$ & 0.02 & 0.01 \\
\hline & $(0.00)$ & $(0.00)$ & $(0.76)$ & $(0.33)$ & $(0.10)$ & $(0.02)$ & $(0.12)$ & $(0.31)$ \\
\hline \multirow[t]{2}{*}{ PUBLIC } & $0.02^{* * *}$ & -0.00 & 0.17 & -0.48 & $0.62^{*}$ & $0.62^{*}$ & $0.06^{*}$ & $0.06^{*}$ \\
\hline & $(0.00)$ & $(0.91)$ & $(0.87)$ & $(0.15)$ & $(0.04)$ & $(0.04)$ & $(0.03)$ & $(0.03)$ \\
\hline \multirow[t]{2}{*}{ GROWTH } & $0.02^{* * *}$ & $0.02^{* * *}$ & $0.26^{*}$ & 0.11 & 0.01 & 0.01 & $0.08^{* *}$ & $0.08^{* *}$ \\
\hline & $(0.00)$ & $(0.00)$ & $(0.01)$ & $(0.12)$ & $(0.38)$ & $(0.36)$ & $(0.00)$ & $(0.00)$ \\
\hline \multirow[t]{2}{*}{ WGI } & $0.07^{* *}$ & -0.01 & 0.90 & 0.24 & $0.34+$ & $0.42^{*}$ & 0.10 & 0.02 \\
\hline & $(0.01)$ & $(0.56)$ & $(0.40)$ & $(0.80)$ & $(0.08)$ & $(0.04)$ & $(0.45)$ & $(0.92)$ \\
\hline \multirow[t]{2}{*}{ FDI_WGI } & & $0.02^{* * *}$ & & -0.00 & & $-0.02+$ & & 0.02 \\
\hline & & $(0.00)$ & & $(0.98)$ & & $(0.08)$ & & $(0.36)$ \\
\hline \multirow[t]{2}{*}{ CONSTANT } & $1.21^{* * *}$ & $1.48^{* * *}$ & 7.32 & $9.35+$ & $15.19^{* * *}$ & $15.20^{* * *}$ & 0.27 & $0.77+$ \\
\hline & $(0.00)$ & $(0.00)$ & $(0.16)$ & $(0.05)$ & $(0.00)$ & $(0.00)$ & $(0.42)$ & $(0.08)$ \\
\hline$N$ & 552 & 552 & 552 & 552 & 552 & 552 & 552 & 552 \\
\hline$R^{2}$ & & & & & 0.217 & 0.220 & 0.954 & 0.954 \\
\hline Hansen J & 1.00 & 1.00 & 0.15 & 0.09 & & & & \\
\hline D-in Hansen (levels) & 1.00 & 1.00 & & & & & & \\
\hline D-in Hansen $\left(\mathrm{GFCF}_{t-1}\right)$ & 1.00 & 1.00 & 0.58 & 0.30 & & & & \\
\hline D-in Hansen (FDI) & 1.00 & 1.00 & 0.03 & 0.03 & & & & \\
\hline D-in Hansen (GROWTH) & 1.00 & 1.00 & 0.12 & 0.27 & & & & \\
\hline D-in Hansen (PUBLIC) & 1.00 & 1.00 & 0.47 & 0.30 & & & & \\
\hline D-in Hansen (FDI_WGI) & & & & 0.10 & & & & \\
\hline D-in Hansen (iv) & 1.00 & 0.89 & 0.03 & & & & & \\
\hline \# of instruments & 90 & 91 & 21 & 23 & & & & \\
\hline \# of countries & 46 & 46 & 46 & 46 & 46 & 46 & 46 & 46 \\
\hline $\mathrm{AR}(1)$ & 0.00 & 0.00 & 0.00 & 0.01 & & & & \\
\hline $\operatorname{AR}(2)$ & 0.24 & 0.24 & 0.94 & 0.83 & & & & \\
\hline
\end{tabular}

$p$-values in parentheses; models 3-8 contain year dummies; $\operatorname{AR}(1), \operatorname{AR}(2)$, and Hansen J test statistics report the respective $p$-values $+p<0.10,{ }^{*} p<0.05,{ }^{* *} p<0.01,{ }^{* * *} p<0.001$ 
Table 4.7: Dependent variable: GFCF*, all estimation methods

\begin{tabular}{|c|c|c|c|c|c|c|c|c|}
\hline & (1) & $(2)$ & $(3)$ & (4) & (5) & (6) & $(7)$ & (8) \\
\hline & GMM & GMM & GMM* & GMM* & $\mathrm{FE}$ & $\mathrm{FE}$ & POLS & POLS \\
\hline \multirow[t]{2}{*}{$\mathrm{GFCF}_{t-1}^{*}$} & $0.52^{* * *}$ & $0.49^{* * *}$ & $0.56^{* * *}$ & $0.49^{* * *}$ & $0.50^{* * *}$ & $0.46^{* * *}$ & $0.67^{* * *}$ & $0.65^{* * *}$ \\
\hline & $(0.00)$ & $(0.00)$ & $(0.00)$ & $(0.00)$ & $(0.00)$ & $(0.00)$ & $(0.00)$ & $(0.00)$ \\
\hline \multirow[t]{2}{*}{ FDI } & $0.40^{* * *}$ & $0.62^{* * *}$ & $0.43^{* *}$ & $0.61^{* *}$ & $0.39^{* *}$ & $0.57^{* * *}$ & $0.23^{*}$ & 0.39 *** \\
\hline & $(0.00)$ & $(0.00)$ & $(0.01)$ & $(0.00)$ & $(0.00)$ & $(0.00)$ & $(0.02)$ & $(0.00)$ \\
\hline \multirow[t]{2}{*}{ PUBLIC } & $-0.12^{* *}$ & 0.03 & -0.54 & 0.05 & 0.19 & 0.14 & $0.15^{*}$ & $0.18^{*}$ \\
\hline & $(0.01)$ & $(0.63)$ & $(0.29)$ & $(0.95)$ & $(0.49)$ & $(0.63)$ & $(0.04)$ & $(0.04)$ \\
\hline \multirow[t]{2}{*}{ GROWTH } & $0.23^{* * *}$ & $0.25^{* * *}$ & $0.72^{* * *}$ & $0.79^{* * *}$ & $0.23^{* * *}$ & $0.24^{* * *}$ & $0.23^{* * *}$ & $0.22^{* *}$ \\
\hline & $(0.00)$ & $(0.00)$ & $(0.00)$ & $(0.00)$ & $(0.00)$ & $(0.00)$ & $(0.00)$ & $(0.00)$ \\
\hline \multirow[t]{2}{*}{ WGI } & $-0.59^{* * *}$ & $1.46^{* * *}$ & 0.12 & 1.96 & $1.05+$ & $2.85^{* * *}$ & -0.14 & $1.23^{*}$ \\
\hline & $(0.00)$ & $(0.00)$ & $(0.88)$ & $(0.11)$ & $(0.07)$ & $(0.00)$ & $(0.70)$ & $(0.03)$ \\
\hline FDI_WGI & & $\begin{array}{l}-0.42^{* * *} \\
(0.00)\end{array}$ & & $\begin{array}{l}-0.47+ \\
(0.08)\end{array}$ & & $\begin{array}{l}-0.42^{* * *} \\
(0.00)\end{array}$ & & $\begin{array}{l}-0.28^{* *} \\
(0.00)\end{array}$ \\
\hline CONSTANT & $9.00 * * *$ & $7.71^{* * * *}$ & $10.73^{* *}$ & 8.04 & $5.94^{*}$ & $7.75^{* *}$ & $3.76^{* *}$ & $4.14^{* *}$ \\
\hline & $(0.00)$ & $(0.00)$ & $(0.01)$ & $(0.15)$ & $(0.01)$ & $(0.00)$ & $(0.00)$ & $(0.01)$ \\
\hline$N$ & 537 & 537 & 537 & 537 & 537 & 537 & 537 & 537 \\
\hline$R^{2}$ & & & & & 0.622 & 0.666 & 0.779 & 0.795 \\
\hline Hansen J & 1.00 & 1.00 & 0.67 & 0.28 & & & & \\
\hline D-in Hansen (levels) & 1.00 & 1.00 & & & & & & \\
\hline D-in Hansen $\left(\mathrm{GFCF}_{t-1}^{*}\right)$ & 1.00 & 1.00 & 0.38 & 0.13 & & & & \\
\hline D-in Hansen (FDI) & 1.00 & 1.00 & 0.36 & 0.41 & & & & \\
\hline D-in Hansen (GROWTH) & 1.00 & 1.00 & 0.63 & 0.11 & & & & \\
\hline D-in Hansen (PUBLIC) & 1.00 & 1.00 & 0.78 & 0.49 & & & & \\
\hline D-in Hansen (FDI_WGI) & & & & 0.25 & & & & \\
\hline D-in Hansen (iv) & 0.40 & 1.00 & & & & & & \\
\hline \# of instruments & 90 & 91 & 21 & 23 & & & & \\
\hline \# of countries & 46 & 46 & 46 & 46 & 46 & 46 & 46 & 46 \\
\hline $\mathrm{AR}(1)$ & 0.02 & 0.03 & 0.01 & 0.01 & & & & \\
\hline $\operatorname{AR}(2)$ & 0.35 & 0.87 & 0.89 & 0.83 & & & & \\
\hline
\end{tabular}

$p$-values in parentheses; models 3-8 contain year dummies; $\operatorname{AR}(1), \operatorname{AR}(2)$, and Hansen J test statistics report the respective $p$-values $+p<0.10,{ }^{*} p<0.05,{ }^{* *} p<0.01,{ }^{* * *} p<0.001$ 
Table 4.8: Dependent variable: $G C F$, all estimation methods

\begin{tabular}{|c|c|c|c|c|c|c|c|c|}
\hline & (1) & $(2)$ & $(3)$ & (4) & (5) & (6) & (7) & (8) \\
\hline & GMM & GMM & GMM$^{*}$ & GMM$^{*}$ & $\mathrm{FE}$ & $\mathrm{FE}$ & POLS & POLS \\
\hline \multirow[t]{2}{*}{$\mathrm{GCF}_{t-1}$} & $0.62 * * *$ & $0.65^{* * *}$ & $0.72^{* * *}$ & $0.68^{* * *}$ & $0.55^{* * *}$ & $0.55^{* * *}$ & $0.78^{* * *}$ & $0.78^{* * *}$ \\
\hline & $(0.00)$ & $(0.00)$ & $(0.00)$ & $(0.00)$ & $(0.00)$ & $(0.00)$ & $(0.00)$ & $(0.00)$ \\
\hline \multirow[t]{2}{*}{ FDI } & $0.28^{* * *}$ & $0.37^{* * *}$ & $0.24^{* *}$ & $0.22^{* *}$ & $0.31^{* * *}$ & $0.39^{* *}$ & $0.17^{*}$ & $0.24+$ \\
\hline & $(0.00)$ & $(0.00)$ & $(0.00)$ & $(0.00)$ & $(0.00)$ & $(0.00)$ & $(0.02)$ & $(0.05)$ \\
\hline \multirow[t]{2}{*}{ PUBLIC } & $0.26^{* * *}$ & $0.19^{* * *}$ & 0.14 & 0.64 & 0.05 & 0.02 & $0.13+$ & $0.14+$ \\
\hline & $(0.00)$ & $(0.00)$ & $(0.85)$ & $(0.23)$ & $(0.82)$ & $(0.93)$ & $(0.06)$ & $(0.07)$ \\
\hline \multirow[t]{2}{*}{ GROWTH } & $0.34^{* * *}$ & $0.34^{* * *}$ & 0.17 & $0.31^{* *}$ & $0.38^{* * *}$ & $0.38^{* * *}$ & $0.30^{* *}$ & $0.29^{* *}$ \\
\hline & $(0.00)$ & $(0.00)$ & $(0.35)$ & $(0.01)$ & $(0.00)$ & $(0.00)$ & $(0.00)$ & $(0.00)$ \\
\hline \multirow[t]{2}{*}{ WGI } & $0.60 * * *$ & $1.57^{* * *}$ & 0.60 & 1.09 & 0.64 & $1.49^{* *}$ & 0.45 & $1.09+$ \\
\hline & $(0.00)$ & $(0.00)$ & $(0.33)$ & $(0.19)$ & $(0.34)$ & $(0.01)$ & $(0.30)$ & $(0.06)$ \\
\hline \multirow[t]{2}{*}{ FDI_WGI } & & $-0.20^{* * *}$ & & -0.10 & & -0.20 & & -0.13 \\
\hline & & $(0.00)$ & & $(0.38)$ & & $(0.13)$ & & $(0.26)$ \\
\hline \multirow[t]{2}{*}{ CONSTANT } & $3.78^{* * *}$ & $3.38^{* * *}$ & 1.28 & -1.00 & $6.53^{* *}$ & $6.64^{* *}$ & 0.47 & 0.25 \\
\hline & $(0.00)$ & $(0.00)$ & $(0.73)$ & $(0.73)$ & $(0.00)$ & $(0.00)$ & $(0.57)$ & $(0.76)$ \\
\hline$N$ & 552 & 552 & 552 & 552 & 552 & 552 & 552 & 552 \\
\hline$R^{2}$ & & & & & 0.634 & 0.643 & 0.828 & 0.830 \\
\hline Hansen J & 1.00 & 1.00 & 0.17 & 0.21 & & & & \\
\hline D-in Hansen (levels) & 1.00 & 1.00 & & & & & & \\
\hline D-in Hansen $\left(\mathrm{GCF}_{t-1}\right)$ & 1.00 & 1.00 & 0.07 & 0.05 & & & & \\
\hline D-in Hansen (FDI) & 1.00 & 1.00 & 0.10 & 0.04 & & & & \\
\hline D-in Hansen (GROWTH) & 1.00 & 1.00 & 0.49 & 0.33 & & & & \\
\hline D-in Hansen (PUBLIC) & 1.00 & 1.00 & 0.33 & 0.30 & & & & \\
\hline D-in Hansen (FDI_WGI) & & & & 0.43 & & & & \\
\hline D-in Hansen (iv) & 0.04 & 1.00 & & & & & & \\
\hline \# of instruments & 90 & 91 & 21 & 23 & & & & \\
\hline \# of countries & 46 & 46 & 46 & 46 & 46 & 46 & 46 & 46 \\
\hline $\mathrm{AR}(1)$ & 0.01 & 0.01 & 0.01 & 0.01 & & & & \\
\hline $\operatorname{AR}(2)$ & 0.16 & 0.17 & 0.19 & 0.22 & & & & \\
\hline
\end{tabular}


Table 4.9: Dependent variable: $D P I$, all estimation methods, stock FDI variables

\begin{tabular}{|c|c|c|c|c|c|c|c|c|}
\hline & (1) & $(2)$ & $(3)$ & (4) & (5) & (6) & (7) & (8) \\
\hline & GMM & GMM & GMM$^{*}$ & GMM* & $\mathrm{FE}$ & $\mathrm{FE}$ & POLS & POLS \\
\hline \multirow[t]{2}{*}{$\mathrm{DPI}_{t-1}$} & $0.69^{* * *}$ & $0.68^{* * *}$ & $1.01^{* * *}$ & $1.01^{* * *}$ & $0.29 * * *$ & $0.26^{* * *}$ & $0.79 * * *$ & $0.79^{* * *}$ \\
\hline & $(0.00)$ & $(0.00)$ & $(0.00)$ & $(0.00)$ & $(0.00)$ & $(0.00)$ & $(0.00)$ & $(0.00)$ \\
\hline \multirow[t]{2}{*}{ STOCK } & $-0.01^{* * *}$ & $-0.05^{* * *}$ & 0.06 & 0.08 & $-0.14^{* * *}$ & $-0.18^{* * *}$ & -0.01 & -0.01 \\
\hline & $(0.00)$ & $(0.00)$ & $(0.19)$ & $(0.45)$ & $(0.00)$ & $(0.00)$ & $(0.33)$ & $(0.35)$ \\
\hline \multirow[t]{2}{*}{ PUBLIC } & $-0.38^{* * *}$ & $-0.40^{* * *}$ & -0.09 & -0.34 & -0.56 & -0.48 & $-0.11+$ & $-0.11+$ \\
\hline & $(0.00)$ & $(0.00)$ & $(0.94)$ & $(0.41)$ & $(0.10)$ & $(0.19)$ & $(0.05)$ & $(0.06)$ \\
\hline \multirow[t]{2}{*}{ GROWTH } & $0.04^{* * *}$ & $0.05^{* * *}$ & $0.39+$ & $0.40^{*}$ & 0.02 & 0.02 & $0.18^{*}$ & $0.18+$ \\
\hline & $(0.00)$ & $(0.00)$ & $(0.08)$ & $(0.04)$ & $(0.83)$ & $(0.82)$ & $(0.04)$ & $(0.06)$ \\
\hline \multirow[t]{2}{*}{ WGI } & -0.36 & $-1.55^{* * *}$ & -1.16 & -0.81 & -0.55 & -2.26 & -0.16 & -0.38 \\
\hline & $(0.17)$ & $(0.00)$ & $(0.23)$ & $(0.61)$ & $(0.37)$ & $(0.14)$ & $(0.65)$ & $(0.43)$ \\
\hline \multirow{2}{*}{\multicolumn{2}{|c|}{ STOCK_WGI }} & $0.05^{* * *}$ & & -0.02 & & 0.06 & & 0.01 \\
\hline & & $(0.00)$ & & $(0.80)$ & & $(0.22)$ & & $(0.58)$ \\
\hline \multirow[t]{2}{*}{ CONSTANT } & $6.22^{* * *}$ & $7.44^{* * * *}$ & -0.52 & 0.63 & $16.14^{* * *}$ & $16.69^{* * *}$ & 1.59 & 1.75 \\
\hline & $(0.00)$ & $(0.00)$ & $(0.95)$ & $(0.90)$ & $(0.00)$ & $(0.00)$ & $(0.21)$ & $(0.22)$ \\
\hline$N$ & 552 & 552 & 552 & 552 & 552 & 552 & 552 & 552 \\
\hline$R^{2}$ & & & & & 0.450 & 0.459 & 0.693 & 0.693 \\
\hline Hansen J & 1.00 & 1.00 & 0.90 & 0.94 & & & & \\
\hline D-in Hansen (levels) & 1.00 & 1.00 & & & & & & \\
\hline D-in Hansen $\left(\mathrm{DPI}_{t-1}\right)$ & 1.00 & 1.00 & 0.85 & 0.89 & & & & \\
\hline D-in Hansen (STOCK) & 1.00 & 1.00 & 0.84 & 0.94 & & & & \\
\hline D-in Hansen (GROWTH) & 1.00 & 1.00 & 0.78 & 0.74 & & & & \\
\hline D-in Hansen (PUBLIC) & 1.00 & 1.00 & 0.68 & 0.73 & & & & \\
\hline D-in Hansen (STOCK_WGI) & & & & 0.95 & & & & \\
\hline D-in Hansen (iv) & 1.00 & 1.00 & & & & & & \\
\hline \# of instruments & 90 & 91 & 21 & 23 & & & & \\
\hline \# of countries & 46 & 46 & 46 & 46 & 46 & 46 & 46 & 46 \\
\hline $\mathrm{AR}(1)$ & 0.01 & 0.00 & 0.00 & 0.00 & & & & \\
\hline $\operatorname{AR}(2)$ & 0.19 & 0.19 & 0.29 & 0.31 & & & & \\
\hline
\end{tabular}


Table 4.10: Dependent variable: $P I$, all estimation methods, stock FDI variables

\begin{tabular}{|c|c|c|c|c|c|c|c|c|}
\hline & (1) & (2) & (3) & (4) & (5) & (6) & (7) & (8) \\
\hline & GMM & GMM & GMM* & GMM* $^{*}$ & $\mathrm{FE}$ & $\mathrm{FE}$ & POLS & POLS \\
\hline $\mathrm{PI}_{t-1}$ & $\begin{array}{l}0.91^{* * *} \\
(0.00)\end{array}$ & $\begin{array}{l}0.92^{* * * *} \\
(0.00)\end{array}$ & $\begin{array}{l}0.49^{* *} \\
(0.01)\end{array}$ & $\begin{array}{l}0.49^{* *} \\
(0.00)\end{array}$ & $\begin{array}{l}0.11^{*} \\
(0.02)\end{array}$ & $\begin{array}{l}0.11^{*} \\
(0.02)\end{array}$ & $\begin{array}{l}0.94^{* * *} \\
(0.00)\end{array}$ & $\begin{array}{l}0.94^{* * * *} \\
(0.00)\end{array}$ \\
\hline STOCK & $\begin{array}{l}0.00^{* * * *} \\
(0.00)\end{array}$ & $\begin{array}{l}-0.00 \\
(0.52)\end{array}$ & $\begin{array}{l}0.03 \\
(0.21)\end{array}$ & $\begin{array}{l}0.03 \\
(0.18)\end{array}$ & $\begin{array}{l}0.00 \\
(0.94)\end{array}$ & $\begin{array}{l}-0.00 \\
(0.71)\end{array}$ & $\begin{array}{l}0.00+ \\
(0.07)\end{array}$ & $\begin{array}{l}0.00 \\
(0.91)\end{array}$ \\
\hline PUBLIC & $\begin{array}{l}-0.07^{* * *} \\
(0.00)\end{array}$ & $\begin{array}{l}-0.05^{* *} \\
(0.00)\end{array}$ & $\begin{array}{l}-0.51 \\
(0.35)\end{array}$ & $\begin{array}{l}-0.68^{*} \\
(0.03)\end{array}$ & $\begin{array}{l}-0.38 \\
(0.20)\end{array}$ & $\begin{array}{l}-0.38 \\
(0.20)\end{array}$ & $\begin{array}{l}-0.03 \\
(0.28)\end{array}$ & $\begin{array}{l}-0.03 \\
(0.29)\end{array}$ \\
\hline GROWTH & $\begin{array}{l}0.02^{* * * *} \\
(0.00)\end{array}$ & $\begin{array}{l}0.03^{* * *} \\
(0.00)\end{array}$ & $\begin{array}{l}0.21 \\
(0.13)\end{array}$ & $\begin{array}{l}0.22 \\
(0.10)\end{array}$ & $\begin{array}{l}0.00 \\
(0.52)\end{array}$ & $\begin{array}{l}0.00 \\
(0.51)\end{array}$ & $\begin{array}{l}0.07^{* *} \\
(0.01)\end{array}$ & $\begin{array}{l}0.07^{* *} \\
(0.01)\end{array}$ \\
\hline WGI & $\begin{array}{l}0.07 \\
(0.14)\end{array}$ & $\begin{array}{l}-0.13 \\
(0.11)\end{array}$ & $\begin{array}{l}0.51 \\
(0.57)\end{array}$ & $\begin{array}{l}0.23 \\
(0.80)\end{array}$ & $\begin{array}{l}0.35+ \\
(0.07)\end{array}$ & $\begin{array}{l}0.32 \\
(0.11)\end{array}$ & $\begin{array}{l}0.08 \\
(0.52)\end{array}$ & $\begin{array}{l}-0.05 \\
(0.76)\end{array}$ \\
\hline STOCK_WGI & & $\begin{array}{l}0.01^{* * * *} \\
(0.00)\end{array}$ & & $\begin{array}{l}0.01 \\
(0.78)\end{array}$ & & $\begin{array}{l}0.00 \\
(0.74)\end{array}$ & & $\begin{array}{l}0.00 \\
(0.23)\end{array}$ \\
\hline CONSTANT & $\begin{array}{l}1.42^{* * * *} \\
(0.00)\end{array}$ & $\begin{array}{l}1.41^{* * *} \\
(0.00)\end{array}$ & $\begin{array}{l}9.73^{* *} \\
(0.00)\end{array}$ & $\begin{array}{l}10.53^{* * * *} \\
(0.00)\end{array}$ & $\begin{array}{l}15.77^{* * *} \\
(0.00)\end{array}$ & $\begin{array}{l}15.77^{* * *} \\
(0.00)\end{array}$ & $\begin{array}{l}0.87^{*} \\
(0.03)\end{array}$ & $\begin{array}{l}0.94^{*} \\
(0.02)\end{array}$ \\
\hline$N$ & 552 & 552 & 552 & 552 & 552 & 552 & 552 & 552 \\
\hline$R^{2}$ & & & & & 0.147 & 0.148 & 0.939 & 0.939 \\
\hline Hansen J & 1.00 & 1.00 & 0.49 & 0.63 & & & & \\
\hline D-in Hansen (levels) & 1.00 & 1.00 & & & & & & \\
\hline D-in Hansen $\left(\mathrm{PI}_{t-1}\right)$ & 1.00 & 1.00 & 0.54 & 0.67 & & & & \\
\hline D-in Hansen (STOCK) & 1.00 & 1.00 & 0.20 & 0.21 & & & & \\
\hline D-in Hansen (GROWTH) & 1.00 & 1.00 & 0.53 & 0.82 & & & & \\
\hline D-in Hansen (PUBLIC) & 1.00 & 1.00 & 0.43 & 0.42 & & & & \\
\hline D-in Hansen (STOCK_WGI) & & & & 0.49 & & & & \\
\hline D-in Hansen (iv) & 1.00 & 1.00 & & & & & & \\
\hline \# of instruments & 90 & 91 & 21 & 23 & & & & \\
\hline \# of countries & 46 & 46 & 46 & 46 & 46 & 46 & 46 & 46 \\
\hline $\mathrm{AR}(1)$ & 0.02 & 0.02 & 0.01 & 0.01 & & & & \\
\hline $\mathrm{AR}(2)$ & 0.69 & 0.70 & 0.86 & 0.82 & & & & \\
\hline
\end{tabular}


Table 4.11: Dependent variable: $G F C F$, all estimation methods, stock FDI variables

\begin{tabular}{|c|c|c|c|c|c|c|c|c|}
\hline & (1) & (2) & $(3)$ & (4) & (5) & (6) & (7) & (8) \\
\hline & GMM & GMM & GMM$^{*}$ & GMM* $^{*}$ & $\mathrm{FE}$ & $\mathrm{FE}$ & POLS & POLS \\
\hline \multirow[t]{2}{*}{$\mathrm{GFCF}_{t-1}$} & $0.92^{* * *}$ & $0.93^{* * *}$ & $0.55^{* *}$ & $0.52^{* *}$ & $0.10^{*}$ & $0.10^{*}$ & $0.93^{* * *}$ & $0.93^{* * *}$ \\
\hline & $(0.00)$ & $(0.00)$ & $(0.00)$ & $(0.00)$ & $(0.05)$ & $(0.05)$ & $(0.00)$ & $(0.00)$ \\
\hline \multirow[t]{2}{*}{ STOCK } & $0.00^{* * *}$ & $-0.00^{* * *}$ & 0.05 & $0.05+$ & -0.00 & -0.00 & $0.00^{*}$ & -0.00 \\
\hline & $(0.00)$ & $(0.00)$ & $(0.14)$ & $(0.07)$ & $(0.97)$ & $(0.64)$ & $(0.05)$ & $(0.86)$ \\
\hline \multirow[t]{2}{*}{ PUBLIC } & $0.03^{* * *}$ & 0.02 & -0.69 & -0.46 & $0.62^{*}$ & $0.62^{*}$ & $0.06^{*}$ & $0.06^{*}$ \\
\hline & $(0.00)$ & $(0.25)$ & $(0.44)$ & $(0.23)$ & $(0.04)$ & $(0.04)$ & $(0.03)$ & $(0.04)$ \\
\hline \multirow[t]{2}{*}{ GROWTH } & $0.02^{* * *}$ & $0.03^{* * *}$ & 0.36 & 0.27 & 0.00 & 0.00 & $0.08^{* *}$ & $0.08^{* *}$ \\
\hline & $(0.00)$ & $(0.00)$ & $(0.21)$ & $(0.10)$ & $(0.54)$ & $(0.53)$ & $(0.00)$ & $(0.00)$ \\
\hline \multirow[t]{2}{*}{ WGI } & $0.08^{*}$ & $-0.19^{* * *}$ & -0.11 & 0.60 & $0.34+$ & 0.32 & 0.08 & -0.07 \\
\hline & $(0.01)$ & $(0.00)$ & $(0.94)$ & $(0.62)$ & $(0.08)$ & $(0.11)$ & $(0.56)$ & $(0.66)$ \\
\hline \multirow[t]{2}{*}{ STOCK_WGI } & & $0.01^{* * *}$ & & -0.01 & & 0.00 & & 0.00 \\
\hline & & $(0.00)$ & & $(0.75)$ & & $(0.75)$ & & $(0.12)$ \\
\hline \multirow[t]{2}{*}{ CONSTANT } & $1.30 * * *$ & $1.39^{* * *}$ & $12.35^{* *}$ & $11.20^{* * *}$ & $15.21^{* * *}$ & $15.21^{* * *}$ & 0.30 & 0.38 \\
\hline & $(0.00)$ & $(0.00)$ & $(0.00)$ & $(0.00)$ & $(0.00)$ & $(0.00)$ & $(0.37)$ & $(0.27)$ \\
\hline$N$ & 552 & 552 & 552 & 552 & 552 & 552 & 552 & 552 \\
\hline$R^{2}$ & & & & & 0.214 & 0.214 & 0.954 & 0.954 \\
\hline Hansen J & 1.00 & 1.00 & 0.84 & 0.71 & & & & \\
\hline D-in Hansen (levels) & 1.00 & 1.00 & & & & & & \\
\hline D-in Hansen $\left(\mathrm{GFCF}_{t-1}\right)$ & 1.00 & 1.00 & 0.77 & 0.65 & & & & \\
\hline D-in Hansen (STOCK) & 1.00 & 1.00 & 0.60 & 0.56 & & & & \\
\hline D-in Hansen (GROWTH) & 1.00 & 1.00 & 0.56 & 0.44 & & & & \\
\hline D-in Hansen (PUBLIC) & 1.00 & 1.00 & 0.96 & 0.95 & & & & \\
\hline D-in Hansen (STOCK_WGI) & & & & 0.75 & & & & \\
\hline D-in Hansen (iv) & 1.00 & 1.00 & & & & & & \\
\hline \# of instruments & 90 & 91 & 21 & 23 & & & & \\
\hline \# of countries & 46 & 46 & 46 & 46 & 46 & 46 & 46 & 46 \\
\hline $\mathrm{AR}(1)$ & 0.00 & 0.00 & 0.06 & 0.00 & & & & \\
\hline $\operatorname{AR}(2)$ & 0.24 & 0.25 & 0.60 & 0.68 & & & & \\
\hline
\end{tabular}


Table 4.12: Dependent variable: $G F C F^{*}$, all estimation methods, stock FDI variables

\begin{tabular}{|c|c|c|c|c|c|c|c|c|}
\hline & (1) & (2) & (3) & (4) & (5) & (6) & (7) & (8) \\
\hline & GMM & GMM & GMM* $^{*}$ & GMM* & $\mathrm{FE}$ & $\mathrm{FE}$ & POLS & POLS \\
\hline $\mathrm{GFCF}_{t-1}^{*}$ & $\begin{array}{l}0.73^{* * *} \\
(0.00)\end{array}$ & $\begin{array}{l}0.69^{* * *} \\
(0.00)\end{array}$ & $\begin{array}{l}0.68^{*} \\
(0.02)\end{array}$ & $\begin{array}{l}0.56^{* *} \\
(0.00)\end{array}$ & $\begin{array}{l}0.56^{* * *} \\
(0.00)\end{array}$ & $\begin{array}{l}0.49^{* * *} \\
(0.00)\end{array}$ & $\begin{array}{l}0.74^{* * *} \\
(0.00)\end{array}$ & $\begin{array}{l}0.72^{* * *} \\
(0.00)\end{array}$ \\
\hline STOCK & $\begin{array}{l}0.02^{* * *} \\
(0.00)\end{array}$ & $\begin{array}{l}0.10^{* * *} \\
(0.00)\end{array}$ & $\begin{array}{l}0.06+ \\
(0.09)\end{array}$ & $\begin{array}{l}0.21^{*} \\
(0.03)\end{array}$ & $\begin{array}{l}0.05 \\
(0.11)\end{array}$ & $\begin{array}{l}0.13^{*} \\
(0.02)\end{array}$ & $\begin{array}{l}0.01 \\
(0.34)\end{array}$ & $\begin{array}{l}0.03 \\
(0.27)\end{array}$ \\
\hline PUBLIC & $\begin{array}{l}-0.12^{*} \\
(0.02)\end{array}$ & $\begin{array}{l}-0.05 \\
(0.39)\end{array}$ & $\begin{array}{l}-0.84 \\
(0.56)\end{array}$ & $\begin{array}{l}-1.43^{*} \\
(0.02)\end{array}$ & $\begin{array}{l}0.20 \\
(0.47)\end{array}$ & $\begin{array}{l}0.09 \\
(0.72)\end{array}$ & $\begin{array}{l}0.18^{* *} \\
(0.00)\end{array}$ & $\begin{array}{l}0.18^{* *} \\
(0.00)\end{array}$ \\
\hline GROWTH & $\begin{array}{l}0.25^{* * *} \\
(0.00)\end{array}$ & $\begin{array}{l}0.23^{* * *} \\
(0.00)\end{array}$ & $\begin{array}{l}0.97^{* *} \\
(0.00)\end{array}$ & $\begin{array}{l}1.03^{* * *} \\
(0.00)\end{array}$ & $\begin{array}{l}0.22^{* *} \\
(0.00)\end{array}$ & $\begin{array}{l}0.22^{* *} \\
(0.00)\end{array}$ & $\begin{array}{l}0.21^{* *} \\
(0.01)\end{array}$ & $\begin{array}{l}0.21^{*} \\
(0.01)\end{array}$ \\
\hline WGI & $\begin{array}{c}-0.14+ \\
(0.10)\end{array}$ & $\begin{array}{l}2.27^{* * * *} \\
(0.00)\end{array}$ & $\begin{array}{l}-0.38 \\
(0.73)\end{array}$ & $\begin{array}{l}2.71 \\
(0.13)\end{array}$ & $\begin{array}{l}1.33^{*} \\
(0.01)\end{array}$ & $\begin{array}{l}4.51^{* *} \\
(0.01)\end{array}$ & $\begin{array}{l}0.34 \\
(0.28)\end{array}$ & $\begin{array}{l}1.06 \\
(0.13)\end{array}$ \\
\hline STOCK_WGI & & $\begin{array}{l}-0.08^{* * *} \\
(0.00)\end{array}$ & & $\begin{array}{l}-0.14+ \\
(0.09)\end{array}$ & & $\begin{array}{l}-0.11^{*} \\
(0.03)\end{array}$ & & $\begin{array}{l}-0.02 \\
(0.31)\end{array}$ \\
\hline CONSTANT & $\begin{array}{l}5.08^{* * *} \\
(0.00)\end{array}$ & $\begin{array}{l}3.58^{* * *} \\
(0.00)\end{array}$ & $\begin{array}{l}9.30 \\
(0.25)\end{array}$ & $\begin{array}{l}12.95^{*} \\
(0.03)\end{array}$ & $\begin{array}{l}5.46^{* *} \\
(0.01)\end{array}$ & $\begin{array}{l}6.26^{* *} \\
(0.00)\end{array}$ & $\begin{array}{l}2.93^{* *} \\
(0.00)\end{array}$ & $\begin{array}{l}2.64^{* *} \\
(0.00)\end{array}$ \\
\hline$N$ & 537 & 537 & 537 & 537 & 537 & 537 & 537 & 537 \\
\hline$R^{2}$ & & & & & 0.501 & 0.533 & 0.743 & 0.746 \\
\hline Hansen J & 1.00 & 1.00 & 0.49 & 0.53 & & & & \\
\hline D-in Hansen (levels) & 1.00 & 1.00 & & & & & & \\
\hline D-in Hansen $\left(\mathrm{GFCF}_{t-1}^{*}\right)$ & 1.00 & 1.00 & 0.98 & 0.37 & & & & \\
\hline D-in Hansen (STOCK) & 1.00 & 1.00 & 0.39 & 0.67 & & & & \\
\hline D-in Hansen (GROWTH) & 1.00 & 1.00 & 0.45 & 0.46 & & & & \\
\hline D-in Hansen (PUBLIC) & 1.00 & 1.00 & 0.38 & 0.85 & & & & \\
\hline D-in Hansen (STOCK_WGI) & & & & 0.70 & & & & \\
\hline D-in Hansen (iv) & 1.00 & 1.00 & & & & & & \\
\hline \# of instruments & 90 & 91 & 21 & 23 & & & & \\
\hline \# of countries & 46 & 46 & 46 & 46 & 46 & 46 & 46 & 46 \\
\hline $\mathrm{AR}(1)$ & 0.06 & 0.05 & 0.02 & 0.02 & & & & \\
\hline $\operatorname{AR}(2)$ & 0.33 & 0.33 & 0.60 & 0.62 & & & & \\
\hline
\end{tabular}


Table 4.13: Dependent variable: $G C F$, all estimation methods, stock FDI variables

\begin{tabular}{|c|c|c|c|c|c|c|c|c|}
\hline & (1) & (2) & (3) & (4) & (5) & (6) & (7) & (8) \\
\hline & GMM & GMM & GMM* $^{*}$ & GMM* $^{*}$ & $\mathrm{FE}$ & $\mathrm{FE}$ & POLS & POLS \\
\hline $\mathrm{GCF}_{t-1}$ & $\begin{array}{l}0.75^{* * * *} \\
(0.00)\end{array}$ & $\begin{array}{l}0.76^{* * *} \\
(0.00)\end{array}$ & $\begin{array}{l}0.73^{* * *} \\
(0.00)\end{array}$ & $\begin{array}{l}0.77^{* * *} \\
(0.00)\end{array}$ & $\begin{array}{l}0.58^{* * *} \\
(0.00)\end{array}$ & $\begin{array}{l}0.56^{* * *} \\
(0.00)\end{array}$ & $\begin{array}{l}0.80^{* * *} \\
(0.00)\end{array}$ & $\begin{array}{l}0.80^{* * * *} \\
(0.00)\end{array}$ \\
\hline STOCK & $\begin{array}{l}0.02^{* * * *} \\
(0.00)\end{array}$ & $\begin{array}{l}0.03^{* * *} \\
(0.00)\end{array}$ & $\begin{array}{l}0.08 \\
(0.15)\end{array}$ & $\begin{array}{l}0.12 \\
(0.33)\end{array}$ & $\begin{array}{l}0.04+ \\
(0.05)\end{array}$ & $\begin{array}{l}0.08^{*} \\
(0.02)\end{array}$ & $\begin{array}{l}0.01 \\
(0.32)\end{array}$ & $\begin{array}{l}0.01 \\
(0.54)\end{array}$ \\
\hline PUBLIC & $\begin{array}{l}0.37 * * * \\
(0.00)\end{array}$ & $\begin{array}{l}0.29^{* * *} \\
(0.00)\end{array}$ & $\begin{array}{l}-1.47 \\
(0.31)\end{array}$ & $\begin{array}{l}-1.04 \\
(0.12)\end{array}$ & $\begin{array}{l}0.07 \\
(0.74)\end{array}$ & $\begin{array}{l}0.01 \\
(0.95)\end{array}$ & $\begin{array}{l}0.16^{*} \\
(0.01)\end{array}$ & $\begin{array}{l}0.16^{*} \\
(0.01)\end{array}$ \\
\hline GROWTH & $\begin{array}{l}0.45^{* * *} \\
(0.00)\end{array}$ & $\begin{array}{l}0.44^{* * *} \\
(0.00)\end{array}$ & $\begin{array}{l}0.78 \\
(0.14)\end{array}$ & $\begin{array}{l}0.47 \\
(0.32)\end{array}$ & $\begin{array}{l}0.38^{* * *} \\
(0.00)\end{array}$ & $\begin{array}{l}0.37^{* * *} \\
(0.00)\end{array}$ & $\begin{array}{l}0.30^{* * *} \\
(0.00)\end{array}$ & $\begin{array}{l}0.30^{* * *} \\
(0.00)\end{array}$ \\
\hline WGI & $\begin{array}{l}0.65^{* * * *} \\
(0.00)\end{array}$ & $\begin{array}{l}1.32^{* * *} \\
(0.00)\end{array}$ & $\begin{array}{l}-0.93 \\
(0.51)\end{array}$ & $\begin{array}{l}1.58 \\
(0.55)\end{array}$ & $\begin{array}{l}0.91 \\
(0.13)\end{array}$ & $\begin{array}{l}2.44^{* *} \\
(0.01)\end{array}$ & $\begin{array}{l}0.75^{*} \\
(0.04)\end{array}$ & $\begin{array}{l}0.75 \\
(0.12)\end{array}$ \\
\hline STOCK_WGI & & $\begin{array}{l}-0.02^{* * *} \\
(0.00)\end{array}$ & & $\begin{array}{l}-0.08 \\
(0.41)\end{array}$ & & $\begin{array}{l}-0.06+ \\
(0.09)\end{array}$ & & $\begin{array}{l}0.00 \\
(1.00)\end{array}$ \\
\hline CONSTANT & $\begin{array}{l}0.33 \\
(0.60)\end{array}$ & $\begin{array}{l}0.37 \\
(0.49)\end{array}$ & $\begin{array}{l}10.78 \\
(0.29)\end{array}$ & $\begin{array}{l}6.53 \\
(0.25)\end{array}$ & $\begin{array}{l}4.93^{*} \\
(0.02)\end{array}$ & $\begin{array}{l}6.56^{* * *} \\
(0.00)\end{array}$ & $\begin{array}{l}0.09 \\
(0.90)\end{array}$ & $\begin{array}{l}0.09 \\
(0.90)\end{array}$ \\
\hline$N$ & 552 & 552 & 552 & 552 & 552 & 552 & 552 & 552 \\
\hline$R^{2}$ & & & & & 0.562 & 0.569 & 0.815 & 0.815 \\
\hline Hansen J & 1.00 & 1.00 & 0.24 & 0.38 & & & & \\
\hline D-in Hansen (levels) & 1.00 & 1.00 & & & & & & \\
\hline D-in Hansen $\left(\mathrm{GCF}_{t-1}\right)$ & 1.00 & 1.00 & 0.31 & 0.22 & & & & \\
\hline D-in Hansen (STOCK) & 1.00 & 1.00 & 0.23 & 0.53 & & & & \\
\hline D-in Hansen (GROWTH) & 1.00 & 1.00 & 0.09 & 0.22 & & & & \\
\hline D-in Hansen (PUBLIC) & 1.00 & 1.00 & 0.54 & 0.87 & & & & \\
\hline D-in Hansen (STOCK_WGI) & & & & 0.67 & & & & \\
\hline D-in Hansen (iv) & 1.00 & 1.00 & & & & & & \\
\hline \# of instruments & 90 & 91 & 21 & 23 & & & & \\
\hline \# of countries & 46 & 46 & 46 & 46 & 46 & 46 & 46 & 46 \\
\hline $\mathrm{AR}(1)$ & 0.01 & 0.01 & 0.01 & 0.01 & & & & \\
\hline $\operatorname{AR}(2)$ & 0.18 & 0.18 & 0.34 & 0.30 & & & & \\
\hline
\end{tabular}


Table 4.14: Dependent variable: $G F C F^{*}$

\begin{tabular}{|c|c|c|c|c|c|c|}
\hline & (1) & $(2)$ & (3) & $(4)$ & $(5)$ & (6) \\
\hline & $\mathrm{GMM}^{* *}$ & $\mathrm{GMM}^{* *}$ & $\mathrm{FE}$ & $\mathrm{FE}$ & POLS & POLS \\
\hline \multirow[t]{2}{*}{$\mathrm{GFCF}_{t-1}$} & $0.58^{* * *}$ & $0.57^{* * *}$ & $0.40^{* * *}$ & $0.42^{* * *}$ & $0.80^{* * *}$ & $0.79^{* * *}$ \\
\hline & $(0.00)$ & $(0.00)$ & $(0.00)$ & $(0.00)$ & $(0.00)$ & $(0.00)$ \\
\hline \multirow[t]{2}{*}{ FDI } & $0.33^{*}$ & $2.47 * *$ & $0.15+$ & $1.01^{*}$ & 0.09 & $0.86^{* * *}$ \\
\hline & $(0.03)$ & $(0.00)$ & $(0.06)$ & $(0.01)$ & $(0.22)$ & $(0.00)$ \\
\hline \multirow[t]{2}{*}{ PUBLIC } & 0.05 & 0.13 & $0.61^{* * *}$ & $0.59 * * *$ & $0.13^{* *}$ & $0.14^{* *}$ \\
\hline & $(0.78)$ & $(0.49)$ & $(0.00)$ & $(0.00)$ & $(0.01)$ & $(0.01)$ \\
\hline \multirow[t]{2}{*}{ GROWTH } & 0.13 & $0.21+$ & $0.25^{* * *}$ & $0.23^{* * *}$ & 0.10 & 0.08 \\
\hline & $(0.36)$ & $(0.10)$ & $(0.00)$ & $(0.00)$ & $(0.33)$ & $(0.40)$ \\
\hline \multirow[t]{2}{*}{ Rent $_{p}$} & 0.37 & $2.53^{* *}$ & $1.35+$ & $2.73^{* * *}$ & -0.06 & $1.11^{* *}$ \\
\hline & $(0.48)$ & $(0.00)$ & $(0.08)$ & $(0.00)$ & $(0.80)$ & $(0.00)$ \\
\hline \multirow[t]{2}{*}{$F D I \_R E N T_{p}$} & & $-0.64^{* *}$ & & $-0.28^{*}$ & & $-0.24^{* * *}$ \\
\hline & & $(0.00)$ & & $(0.02)$ & & $(0.00)$ \\
\hline \multirow[t]{2}{*}{ CONSTANT } & $6.17^{* *}$ & -1.68 & 3.39 & -0.78 & $3.41 * *$ & 0.12 \\
\hline & $(0.00)$ & $(0.68)$ & $(0.16)$ & $(0.74)$ & $(0.00)$ & $(0.91)$ \\
\hline$N$ & 318 & 318 & 318 & 318 & 318 & 318 \\
\hline$R^{2}$ & & & 0.544 & 0.575 & 0.789 & 0.804 \\
\hline Hansen J & 0.26 & 0.47 & & & & \\
\hline D-in Hansen (levels) & 0.07 & 0.08 & & & & \\
\hline D-in Hansen $\left(\mathrm{GFCF}_{t-1}\right)$ & 0.02 & 0.02 & & & & \\
\hline D-in Hansen (FDI) & 0.90 & 0.16 & & & & \\
\hline D-in Hansen (GROWTH) & 0.68 & 0.86 & & & & \\
\hline D-in Hansen (PUBLIC) & 0.04 & 0.04 & & & & \\
\hline D-in Hansen $\left(F D I_{-} R E N T_{p}\right)$ & & 0.17 & & & & \\
\hline D-in Hansen (iv) & 0.34 & 0.68 & & & & \\
\hline \# of instruments & 26 & 31 & & & & \\
\hline \# of countries & 68 & 68 & 68 & 68 & 68 & 68 \\
\hline $\mathrm{AR}(1)$ & 0.00 & 0.00 & & & & \\
\hline $\operatorname{AR}(2)$ & 0.21 & 0.34 & & & & \\
\hline
\end{tabular}


Table 4.15: Dependent variable: $G F C F^{*}$

\begin{tabular}{|c|c|c|c|c|c|c|}
\hline & (1) & $(2)$ & (3) & (4) & (5) & (6) \\
\hline & $\mathrm{GMM}^{* *}$ & $\mathrm{GMM}^{* *}$ & $\mathrm{FE}$ & $\mathrm{FE}$ & POLS & POLS \\
\hline \multirow[t]{2}{*}{$\mathrm{GFCF}_{t-1}$} & $0.57^{* * *}$ & $0.58^{* * *}$ & $0.39^{* * *}$ & $0.39^{* * *}$ & $0.79^{* * *}$ & $0.78^{* * *}$ \\
\hline & $(0.00)$ & $(0.00)$ & $(0.00)$ & $(0.00)$ & $(0.00)$ & $(0.00)$ \\
\hline \multirow[t]{2}{*}{ FDI } & $0.34^{*}$ & $2.26^{*}$ & $0.15+$ & $1.42^{* *}$ & 0.09 & $1.02^{* *}$ \\
\hline & $(0.01)$ & $(0.02)$ & $(0.05)$ & $(0.00)$ & $(0.21)$ & $(0.00)$ \\
\hline \multirow[t]{2}{*}{ PUBLIC } & 0.09 & 0.15 & $0.62^{* * *}$ & $0.63^{* * *}$ & $0.14^{* *}$ & $0.14^{* *}$ \\
\hline & $(0.54)$ & $(0.26)$ & $(0.00)$ & $(0.00)$ & $(0.00)$ & $(0.00)$ \\
\hline \multirow[t]{2}{*}{ GROWTH } & 0.11 & 0.16 & $0.23^{* * *}$ & $0.24^{* * *}$ & 0.09 & 0.10 \\
\hline & $(0.35)$ & $(0.13)$ & $(0.00)$ & $(0.00)$ & $(0.36)$ & $(0.29)$ \\
\hline \multirow[t]{2}{*}{$\mathrm{RENT}_{m}$} & $1.07+$ & $2.50^{* *}$ & $2.32^{* *}$ & $4.12^{* * *}$ & 0.41 & $1.40^{* *}$ \\
\hline & $(0.06)$ & $(0.00)$ & $(0.01)$ & $(0.00)$ & $(0.29)$ & $(0.01)$ \\
\hline$F D I \_R E N T_{m}$ & & $\begin{array}{l}-0.48+ \\
(0.06)\end{array}$ & & $-0.33^{* *}$ & & $-0.24^{* *}$ \\
\hline \multirow{2}{*}{ CONSTANT } & 3.02 & $\begin{array}{l}(0.06) \\
-3.71\end{array}$ & -1.18 & $\begin{array}{c}(0.01) \\
-8.02^{*}\end{array}$ & 1.76 & $\begin{array}{l}(0.00) \\
-2.03\end{array}$ \\
\hline & $(0.23)$ & $(0.41)$ & $(0.69)$ & $(0.02)$ & $(0.22)$ & $(0.25)$ \\
\hline$N$ & 318 & 318 & 318 & 318 & 318 & 318 \\
\hline$R^{2}$ & & & 0.557 & 0.588 & 0.790 & 0.799 \\
\hline Hansen J & 0.30 & 0.64 & & & & \\
\hline D-in Hansen (levels) & 0.09 & 0.16 & & & & \\
\hline D-in Hansen $\left(\mathrm{GFCF}_{t-1}\right)$ & 0.02 & 0.10 & & & & \\
\hline D-in Hansen (FDI) & 0.81 & 0.94 & & & & \\
\hline D-in Hansen (GROWTH) & 0.67 & 0.71 & & & & \\
\hline D-in Hansen (PUBLIC) & 0.05 & 0.08 & & & & \\
\hline D-in Hansen $\left(F D I \_R E N T_{m}\right)$ & 0.92 & & & & & \\
\hline D-in Hansen (iv) & 0.32 & 0.34 & & & & \\
\hline \# of instruments & 26 & 31 & & & & \\
\hline \# of countries & 68 & 68 & 68 & 68 & 68 & 68 \\
\hline $\mathrm{AR}(1)$ & 0.00 & 0.00 & & & & \\
\hline $\operatorname{AR}(2)$ & 0.22 & 0.26 & & & & \\
\hline
\end{tabular}


Table 4.16: Dependent variable: $G F C F^{*}$

\begin{tabular}{|c|c|c|c|c|c|c|}
\hline & (1) & $(2)$ & (3) & (4) & (5) & (6) \\
\hline & $\mathrm{GMM}^{* *}$ & $\mathrm{GMM}^{* *}$ & $\mathrm{FE}$ & $\mathrm{FE}$ & POLS & POLS \\
\hline \multirow[t]{2}{*}{$\mathrm{GFCF}_{t-1}$} & $0.59^{* * *}$ & $0.58^{* * *}$ & $0.41^{* * *}$ & $0.39^{* * *}$ & $0.79^{* * *}$ & $0.78^{* * *}$ \\
\hline & $(0.00)$ & $(0.00)$ & $(0.00)$ & $(0.00)$ & $(0.00)$ & $(0.00)$ \\
\hline \multirow[t]{2}{*}{ FDI } & $0.34^{*}$ & $0.24^{* *}$ & $0.15+$ & 0.06 & 0.08 & 0.04 \\
\hline & $(0.03)$ & $(0.01)$ & $(0.06)$ & $(0.33)$ & $(0.27)$ & $(0.54)$ \\
\hline \multirow[t]{2}{*}{ PUBLIC } & 0.06 & 0.18 & $0.63^{* * *}$ & $0.67^{* * *}$ & $0.14^{* *}$ & $0.14^{* *}$ \\
\hline & $(0.70)$ & $(0.31)$ & $(0.00)$ & $(0.00)$ & $(0.00)$ & $(0.00)$ \\
\hline \multirow[t]{2}{*}{ GROWTH } & 0.12 & $0.25^{* *}$ & $0.25^{* * *}$ & $0.28^{* * *}$ & 0.10 & 0.11 \\
\hline & $(0.41)$ & $(0.00)$ & $(0.00)$ & $(0.00)$ & $(0.31)$ & $(0.22)$ \\
\hline \multirow[t]{2}{*}{ WGI } & 0.48 & $2.46^{* * *}$ & 1.29 & 2.06 & 0.43 & $1.22^{*}$ \\
\hline & $(0.43)$ & $(0.00)$ & $(0.58)$ & $(0.34)$ & $(0.23)$ & $(0.03)$ \\
\hline \multirow[t]{2}{*}{ FDI_WGI } & & $-0.54^{* * *}$ & & $-0.33^{* *}$ & & $-0.21+$ \\
\hline & & $(0.00)$ & & $(0.00)$ & & $(0.07)$ \\
\hline \multirow[t]{2}{*}{ CONSTANT } & $7.25^{* *}$ & $6.33^{*}$ & $7.65^{* * *}$ & $8.14^{* * *}$ & $3.55^{* * *}$ & $3.84^{* * *}$ \\
\hline & $(0.01)$ & $(0.01)$ & $(0.00)$ & $(0.00)$ & $(0.00)$ & $(0.00)$ \\
\hline$N$ & 318 & 318 & 318 & 318 & 318 & 318 \\
\hline$R^{2}$ & & & 0.536 & 0.568 & 0.790 & 0.797 \\
\hline Hansen J & 0.23 & 0.50 & & & & \\
\hline D-in Hansen (levels) & 0.06 & 0.17 & & & & \\
\hline D-in Hansen $\left(\mathrm{GFCF}_{t-1}\right)$ & 0.01 & 0.47 & & & & \\
\hline D-in Hansen (FDI) & 0.80 & 0.44 & & & & \\
\hline D-in Hansen (GROWTH) & 0.64 & 0.79 & & & & \\
\hline D-in Hansen (PUBLIC) & 0.04 & 0.20 & & & & \\
\hline D-in Hansen (FDI_WGI) & 0.66 & & & & & \\
\hline D-in Hansen (iv) & 0.24 & 0.40 & & & & \\
\hline \# of instruments & 26 & 31 & & & & \\
\hline \# of countries & 68 & 68 & 68 & 68 & 68 & 68 \\
\hline $\mathrm{AR}(1)$ & 0.00 & 0.00 & & & & \\
\hline $\operatorname{AR}(2)$ & 0.21 & 0.37 & & & & \\
\hline
\end{tabular}




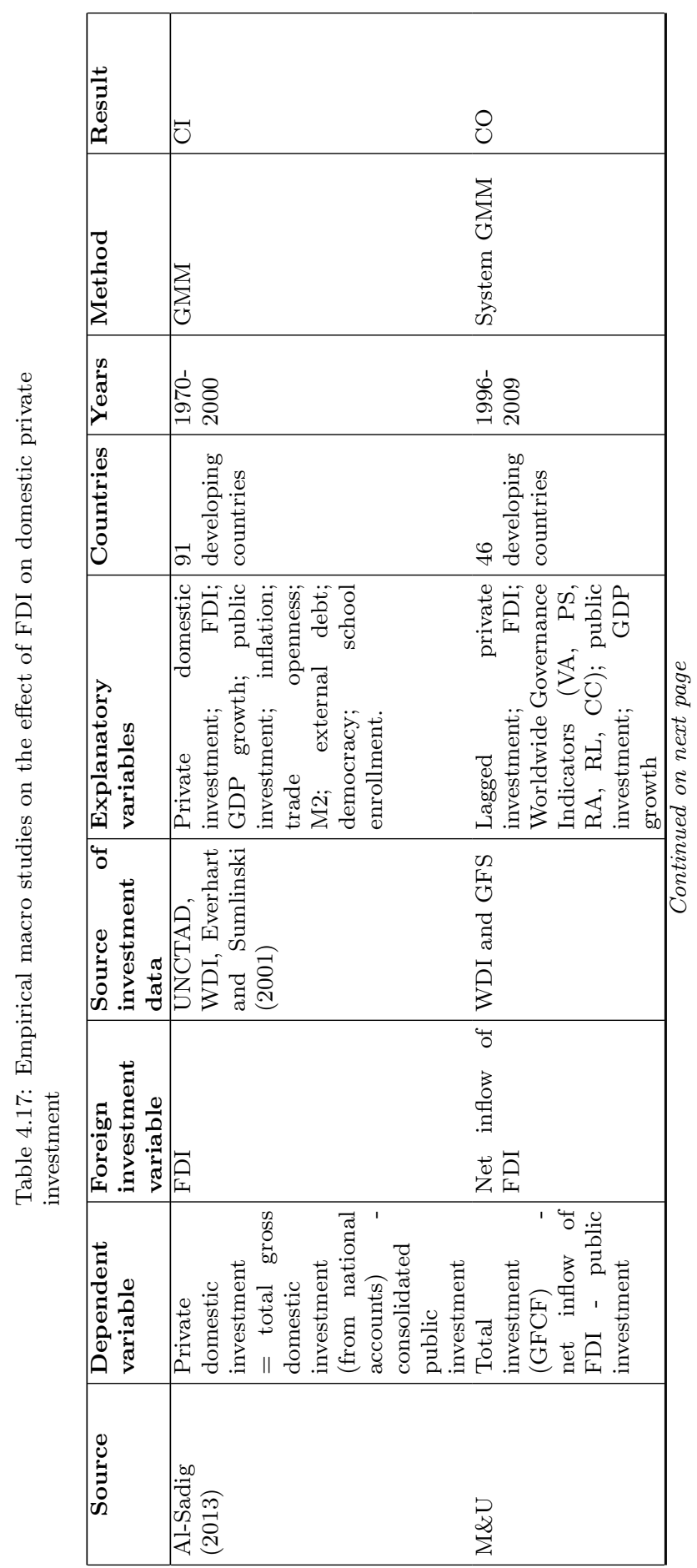




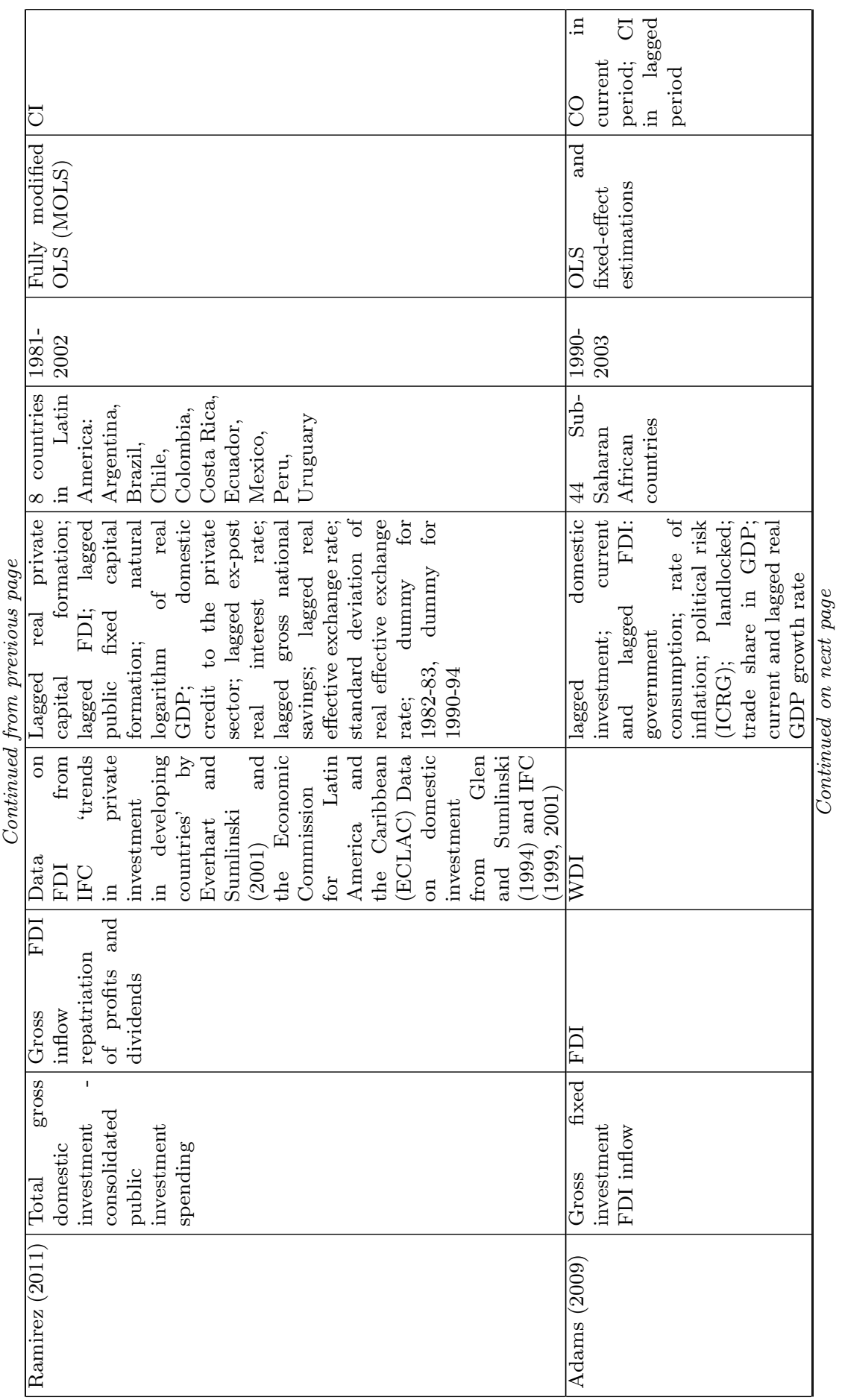




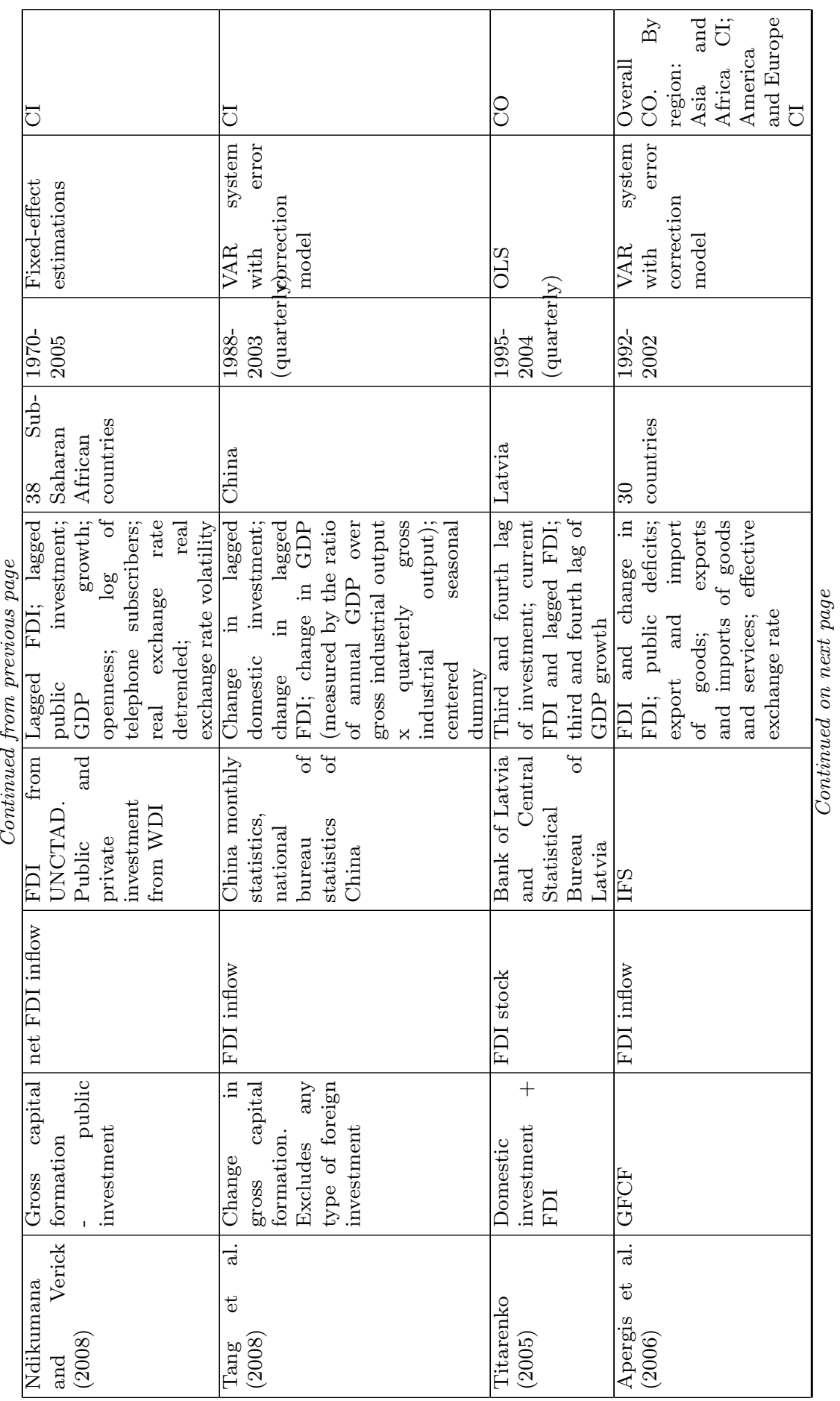




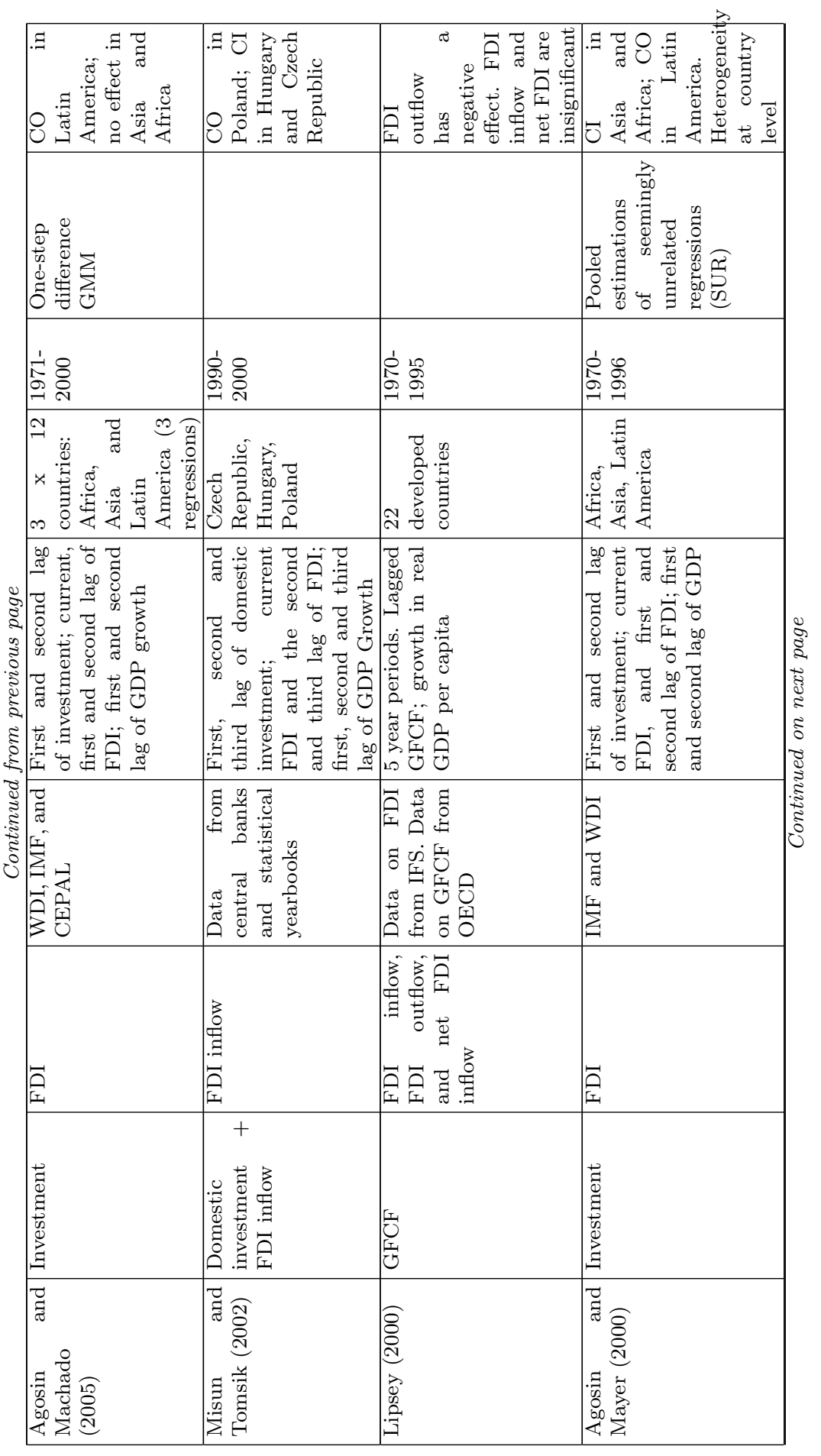




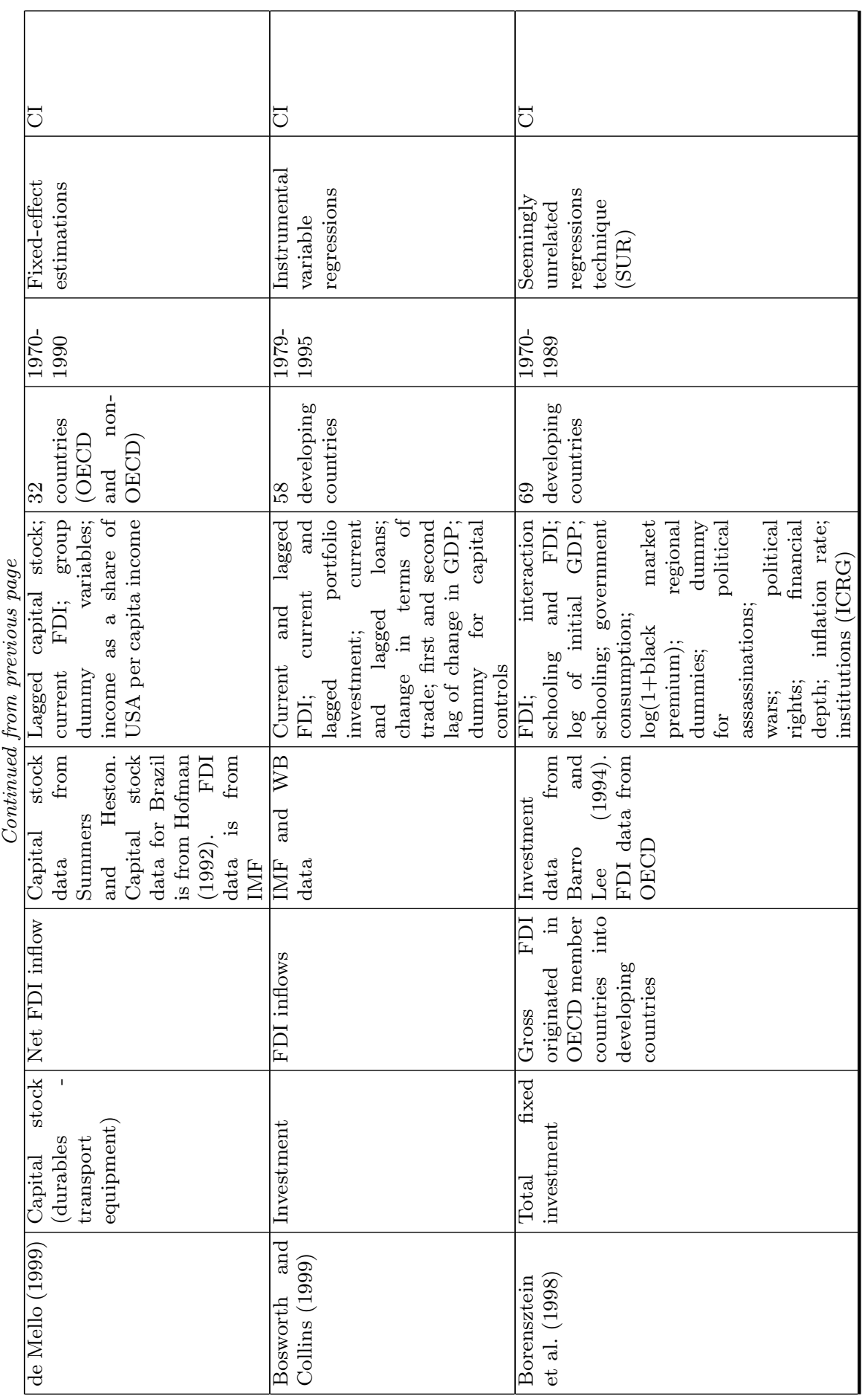


Chapter 5

Determinants of Firms' Investment Behaviour: a multilevel approach 


\subsection{Introduction}

Investors' confidence in making a profit is fundamentally important to economic success and long-term development. There is a large literature that investigates the role of risk in determining investors' willingness to invest and both the empirical literature as well as theory concludes that uncertainty over future revenues influences investment behaviour. Investment in fixed capital is particularly costly when investment is highly irreversible, i.e. when investors are limited in their possibility to resell such capital goods because of the firm-specific nature of investment or lacking second-hand markets for capital (Pindyck, 1991). As a result of high irreversibility of investment, uncertainty causes firms to delay investment (e.g. see Pattillo, 1998).

This study contributes to the literature by empirically exploring the extent to which systemic uncertainties, e.g. related to countries' institutional and political environment, as well as other macroeconomic factors have an impact on firms' investment behaviour. An extensive macroeconomic literature suggests a strong relation between institutions and political stability and investment (e.g. Everhart et al., 2009; Acemoglu and Johnson, 2005; Mauro, 1995). We assess the relative impact of these and other macroeconomic factors on both the likelihood of investment and on firms' investment to sales ratio.

In addition, this study aims at contributing to the literature by investigating the extent to which private sector investment is influenced by firm-specific factors. We primarily focus on determining the degree to which there may be advantages associated with foreign equity ownership. If foreign investors have better access to finance, attracting foreign investors (i.e. in terms of equity ownership shares) can be an important source for the accumulation of capital. Yet, because cross-country microeconomic studies of the effect of foreign equity ownership on investment are scarce, there is no or limited evidence that provides an understanding of the extent to which firms with foreign ownership invest relatively more or relatively less. On the one hand, foreign equity ownership may decrease financing constraints and risks associated with investment and hence, foreign ownership may be related to relatively high investment in fixed capital. On the other hand, foreign investors may operate relatively more intensely in industries that require less long-term commitments. ${ }^{1}$ And, if this hypothesis holds, we expect to see a negative relation between foreign ownership and investment. Additionally, we investigate whether there is a mediating effect of institutions on the relationship between foreign ownership and investment. Again, we assess both the determinants of the likelihood of investment and the determinants of firms' investment to sales ratio. We expect that countries with stronger protection of property rights and control of corruption are better able to attract foreign equity.

Whilst on the basis of macroeconomic studies, it is difficult to empirically separate foreign investment from domestic investment (e.g. see Agosin and Machado, 2005 and Chapter 4), the microeconomic literature has been more successful in determining the relative benefit of foreign capital investment over investment under national

1 One possibility is that foreign investors are relatively more dominantly active in or alongside extractive industries and/or high growth industries which require large initial investments but are less capital intensive over time. This hypothesis is merely tentative and more industry specific expertise is required to outline the dynamics of foreign investors' behaviour. 
control. For example, Koo and Maeng (2006) finds that Korean firms with high foreign ownership have relatively higher investment levels because foreign ownership decreases cash-flow sensitivity. ${ }^{2}$ We are unaware of previous studies on the effect of foreign ownership on investment in a cross-country (firm-level) setting. Yet, several scholars do find a positive effect of foreign equity ownership on firms' performance, (Goedhuys and Srholec, 2010; Aitken and Harrison, 1999) and on firms' innovative behaviour (Srholec, 2010).

If firms' behaviour is influenced by the countries' institutional-policy mix, and is also determined by firm specific characteristics, to what extent is the investment level of a firm determined by a country's institutional environment? Furthermore, under what conditions is an increase in private sector investment associated with foreign equity ownership and other firm specificities? In order to reconcile evidence from the microeconomic investment literature with evidence from the macroeconomic investment literature, this study aims to unbundle firm-level and macroeconomic determinants of investment behaviour. We use a multilevel model to take into account both the firm-level and macroeconomic variation. To the best of our knowledge, this research is the first to use investment data from a large sample of developing countries for this purpose.

In conformity with previous studies on investment in developing countries, we find a high incidence of non-investment. As such, we resort to examine both the determinants of a firm's decision to invest and the determinants of a firm's investment to sales ratio in a multilevel context. On the basis of 101 countries and data for 45,580 firms and a probit model we find no clear evidence of a (positive or negative) relationship between foreign ownership and a firms' decision to invest. However, a negative relation between foreign equity ownership and investment becomes clearly visible following the results of a Heckman outcome model that examines the determinants of a firm's investment to sales ratio. A predictor of country-specific effects is used to determine the effect of a country's overall macroeconomic context on investment behaviour. Our analysis indicates a significant but relatively small impact of a country's overall macroeconomic context on investment (i.e. the likelihood of investment and the investment to sales ratio). This finding highlights that firms are heterogeneous in nature and are relatively unconstrained, in terms of investment, by a country's macroeconomic context. We find a significant effect of some macrolevel variables on investment. For example, the likelihood of investment is higher in countries with relatively stronger property rights protection and control of corruption. Additionally we find a positive mediating effect of property rights protection and control of corruption on the relation between foreign ownership and investment.

\subsection{Literature Review}

In this study we aim to assess specific micro and macro determinants of investment. We focus on establishing the effect of foreign equity ownership and of institutions

\footnotetext{
2 Koo and Maeng (2006) use GMM and firm data from 1992-2002. Investment is measured as the ratio of capital expenditure at the beginning of each year over the capital stock at the beginning of each year.
} 
on firms' investment behaviour. These factors contribute to explaining a firm's degree of investment related uncertainty to the extent that foreign equity ownership and e.g. property rights protection may help reduce investment related risk. The relation between investment and uncertainty is described in real option theory. Real options investment theory generally predicts a negative relation between investment and uncertainty because high uncertainty is associated with high risk and therefore uncertainty causes investors to reduce investment in fixed capital (Pindyck, 1991). Especially when investment is highly irreversible, uncertainty can cause firms to delay investment. Overall, real options theory outlines a micro-mechanism by means of which different factors that influence uncertainty are related to investment.

Aside from foreign equity ownership and institutions, there are several other factors that influence the investment uncertainty relation: e.g. risk attitudes (Nickell, 1978), competition, financing constraints, and other macroeconomic factors. And, some of these other factors may set-off a positive relation between investment and uncertainty. Likewise on the basis of real options theory, Hartman (1972) argues that investment increases with the marginal revenue product of capital. And, Abel et al. (1996, pp 754) argue that "the future acquisition price of capital may be higher than its current acquisition price" and thereby, under uncertainty, firms may be more limited in their possibility to expand investment in the future. Several studies aim at determining the overall effect of uncertainty on investment or seek to establish the effect of macro-level uncertainties on investment. First, we proceed by providing a brief overview of the micro literature on investment and uncertainty. Second, we provide an overview of the macro literature that emphasizes the importance of the development of institutions for investment.

Empirical evidence on the effect of uncertainty on investment is inconclusive on the direction of this relationship but largely suggests that the negative investment uncertainty relation dominates the positive investment uncertainty relation (e.g. Fuss and Vermeulen, 2008; Lensink et al., 2005; Green et al., 2001; Guiso and Parigi, 1999 and see also the literature review by Carruth et al., 2000 and meta-analysis by Koetse et al., 2009). In particular, most evidence on the investment uncertainty relationship in developing countries suggests that uncertainty (as well as irreversibility) has a negative effect on investment. Here, researchers follow two distinct approaches. On the one hand, researchers measure uncertainty using micro data; for instance Ninh et al. (2004), Darku (2000), and Pattillo (1998) proxy uncertainty using firms' expectations of future sales, supply, and/or sales growth and Leefmans (2011), Shiferaw (2009), and Bo and Zhang (2002) measure uncertainty using data on firms' volatility of supply and/or demand and/or labour costs. On the other hand, Kumo (2006), Aizenman and Marion (1999), Serven (1998), and Serven and Solimano (1993) conduct a macroeconomic study where uncertainty measurements include volatility of GDP growth, volatility of real effective exchange rate, term of trade volatility, inflation. ${ }^{3}$ Alternatively, Bigsten et al. (2005) find evidence for irreversibility by studying the dynamics of investment behaviour. Using investment data on African

\footnotetext{
3 Contrary to evidence on a negative uncertainty investment relation are the findings by AbdulHaque and Shaoping (2008) who measure uncertainty using data about Chinese stock market return volatility and find that uncertainty positively effects investment.
} 
manufacturing firms, Bigsten et al. (2005, pp. 22) show that "firms refrain from investing during extended periods of time, rarely sell off capital stock, and adjust slowly to a new long-run equilibrium".

In addition to firm-specific sources of risk, it is likely that a country's institutional and political environment also influences investment behaviour. The role of macroeconomic factors in influencing firm-level investment behaviour has already been discussed in the work of Bernanke (1983). Examples of macroeconomic factors that drive investment include shocks from property markets, agriculture, trade, and monetary, fiscal, and regulatory policy (Bernanke, 1983). Several studies use microeconomic data to capture the effect of firm idiosyncratic factors on investment behaviour but do not specifically distinguish between idiosyncratic and systemic factors of uncertainty. Such studies rely on controlling for macroeconomic effects by means of time dummies and fixed effects in panel data analysis (for instance the work of Fuss and Vermeulen, 2008). Otherwise, firm-level studies on investment are limited to a cross-section analysis of a given country. For example, Darku (2000) studies firm investment behaviour using a cross-section of firms located in Uganda and interprets the negative uncertainty investment relation as partly stemming from investors' perceptions on macroeconomic policy i.e. privatization, trade liberalization, taxation, and interest rates.

Aside from macroeconomic factors, a country's institutional environment can arguably play an important role in determining firms' competitiveness and return to investment and can potentially act as a major growth driver influencing investment, R\&D, innovation, and new business take-off. In developing countries where institutions are weak and/or failing, investment risk is higher. If 'bad' institutions are a source of uncertainty, a weak institutional development will negatively influence firms' choice to invest and possibly also firms' investment level. In fact, the macroeconomic literature concludes that favourable institutions and political stability are positively related to a country's level of (foreign and domestic) investment (Everhart et al., 2009; Daude and Stein, 2007; Acemoglu and Johnson, 2005; Mauro, 1995).

There are few attempts in the literature to investigate the impact of (crosscountry) institutional factors on domestic investment on the basis of firm-level data. Asiedu and Freeman (2009); Batra et al. (2003); Gaviria (2002) find a negative effect of corruption on firm-level investment growth. However, because the authors measure investment growth as the percentage of growth of investment over a three year period the data does not capture the underlying structure of investment, i.e. frequent noninvestment, low investment levels, as well as lumpy investments.

Literature on firm-level evidence on the relation between institutions and foreign direct investment yields more robust evidence on investment behaviour (Ayca; Javorcik and Wei, 2009; Kinda, 2010; Kesternich and Schnitzer, 2010; Henisz, 2000; James R. Hines, 1995). One interesting study in this respect is the cross-country study of Javorcik and Wei (2009), who specifically focus on the relation between corruption and foreign direct investment (FDI). According to the authors' theory, FDI and ownership structure is influenced by corruption because corruption increases the cost of obtaining licenses and permits. Javorcik and Wei (2009) also find that 
joint ventures can decrease transaction costs associated with corruption. The study of Kinda (2010) likewise uses cross-country firm data and finds a negative relation between some 'institutional problems' (e.g. firms' perception on crime) and FDI.

\subsection{Data}

\section{Micro Data}

This study is primarily based on firm data from the World Bank Enterprise Surveys (ES). ${ }^{4}$ The firms included in the analysis are surveyed in the years 2006-2011 on the basis of a comparable data collection method over countries. This ES data collection is based on stratified random sampling with replacement where the strata are firm size, geographic region, and sector; stratification reflects the non-agricultural economic structure of each country. ${ }^{5}$ Our analysis (and overall the ES data) excludes firms with $100 \%$ public ownership and firms operating in the following sectors: utilities, financial intermediation, real estate, and renting activities. The number of regions where surveys are conducted differs across countries. A relatively larger number of surveys are conducted in regions and economies that are larger in size and have a relatively high income level. Overall, firm size is stratified according to the number of permanent employees: small (5-19 employees), medium (20-99 employees), and large (100 or more employees).

Our dataset consists of 45,480 firms, 121 surveys, and data for 101 developing and emerging economies (20 countries are surveyed twice). Table 5.7 in Appendix A lists the countries considered in the analysis. By country, we also list the (fiscal) year(s), the total number of firms and the number of firms that invest, the number of firms defined as foreign owned, and the number of firms categorized by sector and by firm size. Overall, the sample consists of a reasonable number of observations given the limited availability of firm-level data that is fit for comparing developing countries. Nevertheless, because the samples are relatively small we remain mindful that the country samples are merely approximations for investment behaviour of each respective economy. As a result of item non-response, miss-codifications and sampling errors a total of 14,759 firms are excluded from the analysis.

Investment data collected in the surveys measure the total annual expenditure for purchases of equipment and machinery during a given fiscal year. The definitions of the firm-level variables are indicated in Table 5.8 in Appendix A. We code firms to have zero investment whenever a firm indicated that it did not invest in fixed assets in the last fiscal year and data on the amount of investment is also missing. ${ }^{6}$ Whenever

\footnotetext{
4 The data used in this study are collected from the ES 'comprehensive' dataset that combines various country survey data sets.

5 The ES contain sampling weights but these weights were not used in the analysis mainly because some of the weights are extreme, causing single observations to impact results.

6 From the sample of firms used in this study, 161 firms reported to not have invested but in fact did report a positive level of investment. Another 232 firms reported to have invested (in either machinery and equipment or land and buildings) but did not report the amount of investment in machinery and equipment and neither invested in land and buildings. We expect that this (possible) bias does not affect estimations because of the relative small number of occurrences. For
} 
investment is larger than zero, our dependent variable (Investment) is equal to the natural logarithm of the investment to sales ratio and hence excludes all observations with zero investment. As shown in the first histogram of Figure 5.3 in Appendix A, Investment has a log-normal distribution. Alternative measures for firms' investment level used in the literature are the natural logarithm of investment, investment as a ratio of the capital stock, and capital as a ratio of labour. Because of ES data limitations we prefer the measure of investment to sales over the later two alternative measures and prefer our scaled measure of investment over the non-scaled measure. The dependent variable (i.e. investment and sales data) is the biggest culprit of item non-response and causes the exclusion of 8,707 observations. Still, overall, we expect that the item non-response follows a random process and does not inflict serious bias.

In agreement with the findings of Gebreeyesus (2009) and Bigsten et al. (2005) on investment in Africa, a significant share of firms in our sample of developing countries invest close to zero or do not invest. The total number of firms that do not invest is 21,$829 ; 52 \%$ of the firms in our sample invest. The average percentage of firms located in Africa that invest is $45 \%$. This percentage is lower than the average percentage of firms that invest in Latin and Central America which is $56 \%$ and in Eastern Europe which is $60 \%$. This pattern of non-investment is different from that documented by Lensink et al. (2005) who use a sample of firms located in the Netherlands, out of which about $87 \%$ have positive investment. In order to capture a firm's decision to invest we construct a binary dependent variable 'Invest'. This variable is equal to 1 whenever a firm invests and otherwise is equal to 0 .

As already mentioned, many firms in our sample invest close to zero. When only taking into account the firms that invest, the median level of investmentmeasured as the investment to sales ratio - is 3\%. Overall, this suggests that firms frequently postpone investment, possibly because investment is largely irreversible. The distribution of investment as a ratio of sales is plotted in the second histogram of Figure 5.3 in Appendix A. To improve data visualization, a ceiling is placed on values where the investment to sales ratio is higher than 1 . Still, it is clear that the distribution is positively skewed and has a long right-tail. Mainly because this distribution has such a strong degree of skewness we prefer to measure investment as the natural logarithm of the investment to sales ratio.

We measure the effect of foreign ownership using dummy variables. Because the effect of partial foreign ownership on investment may be different from that of completely foreign equity ownership on investment we experiment with a dummy which is equal to 1 if a firm has any level of foreign equity ownership but not a 100\% ownership share (P_Foreign, 2,739 firms). And, we construct a dummy which captures the effect of whether a firm has a $100 \%$ share of foreign equity ownership (Foreign 100, 3,028 firms). ${ }^{7}$

We control for the effect of labour costs (wages, salaries, and bonuses) as a ratio of sales revenue (Labour) and for the effect of a firm's age (Age). ${ }^{8}$ Moreover, on

methodological reasons, countries (i.e. surveys) where none of the firms have positive investment are not included in our sample. Also, the surveys for Nigeria-2007, Venezuela-2006, and Pakistan-2007 are not considered in the analysis because of missing variables.

7 The distribution of foreign equity shares is illustrated in Figure 5.4 in Appendix A.

${ }^{8}$ Labour $=\ln ($ labour costs $)-\ln ($ sales $) ; A g e=\ln ($ year in which the surveys were sampled - year of 
the one hand, we expect that the propensity of investment in fixed assets (including investment in replacement equipment and machinery) is relatively higher for large firms than for small firms. Large firms have a greater production capacity and are more able to redistribute the cost of capital and adjustment costs over time. On the other hand, we expect that the relative fixed cost of investment is higher for smaller firms than for larger firms, for example because of scale effects. Therefore, in a given year, we expect that on average smaller firms invest less in fixed assets than larger firms. As a proxy for size we use the logarithm of the number of permanent full-time employees (Size). Observations are excluded when the number of full-time permanent employees of the firm is less than five. ${ }^{9}$ Additionally, we control for the effect of firms' access to foreign markets using the variable Export. Export is a binary variable that is equal to 1 when a least part of a firms' sales are exported and that is equal to 0 when all the establishments' sales are national.

The Enterprise Surveys are based on a range of difference industry classifications. We adopt the following industry classification: (1) leather, garments and textiles, (2) food, (3), metals and machinery, (4) chemicals and pharmaceuticals, (5) other manufacturing, (6) retail and wholesale trade, (7) hotels, restaurants and other services, and (8) construction and transportation and include these sector classifications as additional dummy variables in the analysis.

Finally, three variables are used as controls for a firm's decision to invest and as selection variables required for the analysis on firms' investment to sales ratio. These variables measure the perception of a given firm/entrepreneur on obstacles that could inhibit investment: access to land (Land), access to finance (Finance), and informal sector competitors (Competitor). We expect that entrepreneurs that are interested in investing are relatively more concerned with obstacles related to finance, acquiring land and competitors. We recode these variables as dummy variables where 0 represents no obstacles, minor obstacles, or that the obstacle is not applicable to the firm. And, the variables are coded 1 whenever a firm indicated the obstacles are moderate, major, or very severe.

\section{Macro Data}

Why do firms invest less or less frequent in, for example, Angola than in Brazil? Why do some countries attract more foreign equity than other countries do? In an attempt to explain some of this cross-country variation in investment we explore the impact of macro determinants on investment. We control for real GDP per capita $(G D P)$ in constant prices, and growth measured as the logarithmic change in GDP with respect to the previous year (Growth) from Heston et al. (2012) (chain series). Moreover, we control for a country's degree of de jure financial openness (Kaopen) using data collected by Chinn and Ito (2008) (updated to 2010) and de facto trade openness

establishment +1$)$. A small number of firms were established in the year the survey was conducted.

9 As a result of stratification difficulties, the variable used to stratify firms according to size does not always correspond to the number of full-time permanent employees reported on the basis of the survey analysis. We only exclude observations that are outside our sample population of interest. 
(Openness) using data from Heston et al. (2012). In addition, we control for the percentage of real interest rates (Interest) using data from World Bank (2012). ${ }^{10}$

A country's institutional development is measured using two proxies. First, property rights protection (Property) is measured using data from the Heritage Foundation (2013). ${ }^{11}$ Second, data from Transparency International (2011) is used to measure control of corruption $(C P I) .{ }^{12}$ In agreement with the macroeconomic literature on institutions, we expect that investment is positively related to property rights protection and control of corruption. We additionally use a proxy for political stability from Marshall and Jaggers (2009) (Polity) in the regression analysis. Polity2 measures the degree to which the political economy of a country approximates either a democratic or an autocratic regime. Higher values of Polity 2 correspond to more democracy. Because property rights, corruption and political economy are closely related we do include these variables in the same regression model.

Because of missing data the analysis with macro data excludes data on the following countries: Afghanistan, Benin, Burkina Faso, Cote d'Ivoire, Democratic Republic of Congo, El Salvador, Eritrea, Ghana, Guinea, Guinea-Bissau, Kazakhstan, Kosovo, Mali, Montenegro, Niger, Senegal, Serbia, Timor Leste, Togo, Turkey, Uzbekistan, Vanuatu, and Zimbabwe. Analysis using Property additionally excludes data on Iraq. Analysis using CPI additionally excludes data on Samoa and Micronesia, and analysis using the Polity 2 data additionally excludes data on the following countries: Bosnia and Herzegovina, Iraq, Micronesia, Samoa, Tonga, and Trinidad and Tobago. Unless indicated otherwise, the micro data are matched with the macro data on the basis of the last complete fiscal year in which investment and sales data are recorded $-1 .^{13}$ As such, we assume that (on average) when deciding whether and how much to invest firms are sensitive to country-level signals from the preceding year.

\subsection{Method}

At this point, it is unrealistic to assume that a firm's observed investment is independent of country effects given our observed covariates. In particular, we wish to relax the assumption that the effect of foreign ownership on investment is the same across countries. On the basis of a random-intercept model we account for the nested structure of our dataset and identify the extent to which firms' behaviour is influenced by both firms' specificities as well as by the macroeconomic and institutional structure

\footnotetext{
10 To avoid the exclusion of several firms from the analysis we replacing missing data on interest rates in 2009 for Ecuador with data from 2006. And, we replace missing data on interest rates in 2010 for Ethiopia with data from 2008.

11 To avoid excluding several countries because of missing data on property rights, we replace data on property rights from 2009 for the missing observations of the following counties: Bhutan, Micronesia, Tonga, and Samoa. Additionally, we use data from 2006 to replace missing data for Angola (2005 only) and Burundi.

12 To avoid excluding several countries as a result of missing observations, we replace Transparency International (2011) data from 2005 or 2006 for the missing CPI data for 2005 for Burundi, Mauritania, Rwanda, and Swaziland. Also, we use data from 2005 for the missing CPI data for 2008 for Fiji.

13 The last complete fiscal year of a firm is either one or two years prior to the data collection.
} 
of a firms' country. The random-intercept model can also be referred to as a multilevel model, a hierarchical model, or as a mixed effects model. ${ }^{14}$ The advantage of a multilevel modelling approach is that we can estimate the degree of dependency of a firm on a given country context. Also, the standard errors of multilevel models are more accurate than those of a single-level model because they are dependent on the number of countries on the basis of which we identify the country effects and they are not dependent on the number of firms. A random-intercept model with level-one (micro) and level-two (macro) covariates is given in equation 5.1.

$$
\begin{aligned}
& y_{i j}^{*}=\beta_{1}+\beta_{2}^{\prime} x 1_{i j}+\beta_{3}^{\prime} x 2_{j}+\varepsilon_{i j}+v_{j} \\
& =\left(\beta_{1}+v_{j}\right)+\beta_{2}^{\prime} x 1_{i j}+\beta_{3}^{\prime} x 2_{j}+\varepsilon_{i j}
\end{aligned}
$$

Here the latent variable, investment, is denoted by $y_{i j}^{*}$, where i represents a given firm and $\mathrm{j}$ represents a given country. $x 1_{i j}$ is a vector that contains the micro-level covariates and $x 2_{j}$ is a vector that contains the macro-level covariates. The total residual error component contains a level-one residual and a level-two residual: $\epsilon_{i j}$ $\equiv v_{j}+\varepsilon_{i j}$. We assume that $E\left(v_{j} \mid x 1_{i j}, x 2_{j}\right)=0$ and that $E\left(\varepsilon_{i j} \mid x 1_{i j}, x 2_{j}, v_{j}\right)=0$. Hereafter, the $\beta_{1}, \beta_{2}$, and $\beta_{3}$ are also referred to as 'fixed' parameters and $v_{j}$ is referred to as a 'random' parameter that remains constant within a country.

We produce a two-step Heckman selection model (type II Tobit) that takes into account the non-linear nature of our investment variable that is caused by the high level of non-investment as was discussed in section 5.3. The first step of the Heckman selection model consist of a probit model that estimates the determinants of firms' decision to invest. Here, the decision to invest is summed as a binary dependent variable $y_{i j}=1\left[y_{i j}^{*}>0\right]$. Following equation 5.1 and the probit model, the error terms $v_{j} \mid x 1_{i j}, x 2_{j}$ and $\varepsilon_{i j} \mid x 1_{i j}, x 2_{j}, v_{j}$ have a probabilistic distribution.

In the second step of the Heckman selection model we use a random-effect model to estimate the determinants of firms' investment to sales ratio. This second step of the Heckman selection model is also referred to as the 'outcome' model. Here, $y_{i j}=$ $y_{i j}^{*} \times 1\left[y_{i j}^{*}>0\right]$. As such, the specification of $y_{i j}^{*}$ (equation 5.1) is different between the probit and the outcome model (i.e. for step one and step two of the Heckman selection model). In the second step, the Heckman selection model uses the so-called inverse Mills ratio $(\lambda)$ as an additional explanatory variable to correct for the fact that the probability of investment is higher for certain types of firms. The inverse Mills ratio is computed on the basis of the $\hat{\beta}$ estimates of our probit model and corresponds to the respective ratio of the standard normal density distribution function over the cumulative standard normal distribution function: i.e. $\lambda(\mathrm{z})=\frac{\phi(z)}{\Phi(z)}$.

In section 5.3 we already outlined three variables Land, Finance, and Competitor, that may help control for the selection bias. These three variables are part of vector $x 1_{i j}$ in the probit selection model. Darku (2000), Bigsten et al. (1999) and Pattillo (1998) also use a Heckman selection model to estimate investment levels. These authors do not find a significant selection effect (of the coefficient of $\lambda$ ) in the outcome model. To investigate the impact of the selection effect on our covariates of interest we also produce random-effect models that do not include $\lambda$. Finally, in order to

\footnotetext{
14 See for example the work of Greenland (2000) for an introduction to multilevel modelling.
} 
improve our prediction of $v_{i j}$ we use restricted maximum likelihood estimation, which in contrast to unrestricted maximum likelihood estimation, corrects for the loss in degrees of freedom and therefore does not suffer from downward bias in estimating the between-country population variance (Rabe-Hesketh and Skrondal, 2008).

We are fairly comfortable assuming that, within the context of analysis, our analysis on the effect of macroeconomic variables on investment does not suffer from endogeneity problems. Specifically, it is unlikely that the investment behaviour of a single firm has a significant influence on macro-level outcomes. However, as a result of unobserved heterogeneity some of the firm-level explanatory variables may not be strictly exogenous. For example, labour costs may be lower in underdeveloped countries that lack protection in the form of formal labour rights and/or minimum wages and have lower educational achievement. Moreover, some countries may have regulations that are beneficial for start-ups and small enterprises which can stimulate such firms to invest more. Some scholars find evidence that foreign equity concentration can have a positive spillover effect on domestic firms (i.e. stimulating investment) as well as crowd-out domestic firms (i.e. reducing investment). According to Aitken and Harrison (1999), in Venezuela, foreign equity ownership negatively influences the overall productivity of domestic firms. And, Kosovà (2010) studying firms located in the Czech Republic and Backer and Sleuwaegen (2003) studying firms located in Belgium find that foreign firm presence increases domestic firms sales growth and/or survival. However, both authors also find that foreign entry is positively related to domestic firms exiting the market (indicating a short-term crowding out effect). A Hausman test comparing a fixed and random effects model typically (as in our case) yields a significant test statistic, thereby rejecting the random-effect model over a fixed-effect model. In our case, we seek to identify macroeconomic determinants of investment and we require a non-linear model in the first step of the Heckman selection model and therefore a fixed-effect model is not a feasible option. However, the endogeneity issue may be alleviated by the inclusion of the macroeconomic variables. We follow the suggestion of Mundlak (1978) and augment our model introducing country means of Labour, Size, Age, and of the percentage of foreign equity ownership in our analysis (i.e. $\overline{\operatorname{Labour}}, \overline{\operatorname{Size}}, \overline{A g e}$, and $\overline{\text { Foreign }}) .{ }^{15}$ Hereafter, these country mean firm-level variables are also referred to as the 'Mundlak' covariates. The covariates are part of vector $x 2_{j}$. We expect that the macro covariates and 'Mundlak' covariates can act as controls for the (possibly) endogenous firm-level variables and contribute to the estimation of the corresponding within-effects.

\footnotetext{
15 Mundlak (1978) provides proof for the equivalence of a linear random-effect model with additional time-averaged covariates and a linear fixed-effect model. The assumptions of Mundlak may not apply to our context of 'firm-series' on a cross-section of countries and non-linear models and therefore we merely expect that the 'Mundlak' covariates help alleviate endogeneity issues.
} 
For both the Probit and Heckman selection model we also empirically examine the (possible) effect of institutions and political economy on the relationship between foreign ownership and investment. Formally, we express this model as following:

$$
\begin{array}{r}
y_{i j}^{*}=\beta_{1}+\beta_{2}^{\prime} x 1_{i j}+\beta_{3}^{\prime} x 2_{j} \\
+\beta_{4} P_{-} \text {Foreign } \times G_{i j}+\beta_{5} \text { Foreign } 100 \times G_{i j} \\
+\varepsilon_{i j}+v_{j}
\end{array}
$$

$P_{-}$Foreign $\times G_{i j}$ represents the interaction term between the binary variable P_Foreign (partially foreign owned) and either Property, CPI or Polity2. Foreign $100 \times G_{i j}$ represents the interaction term between Foreign 100 (100\% foreign owned) and either Property, CPI or Polity2.

Most of the analysis in this study is based on a conventional random-intercept model as presented in equations 5.1 and 5.2. Yet, in the final section of this study we augment the model outlined in equation 5.2. Two additional random coefficients are included in the model with the aim of identifying the extent of crosscountry differences in the foreign ownership investment relation. Here, in addition to the country specific-intercept, we produce country-specific slopes for the binary variables $P_{-}$Foreign and Foreign 100 . The random coefficient model is presented in equation 5.3. $\delta_{1 j}$ is the slope for $P_{-}$Foreign $_{i j}$ and $\delta_{2 j}$ is the slope for Foreign $100_{i j}$. Empirically, the random effect parameters are expressed in units of standard deviation and show the degree to which the intercept and the slope coefficients are distributed around the estimated mean of each country.

$$
\begin{array}{r}
y_{i j}^{*}=\beta_{1}+\beta_{2}^{\prime} x 1_{i j}+\beta_{3}^{\prime} x 2_{j} \\
+\beta_{4} P_{-} \text {Foreign } \times G_{i j}+\beta_{5} \text { Foreign } 100 \times G_{i j} \\
+\varepsilon_{i j}+v_{j}+\delta_{1 j} P_{-} \text {Foreign }_{i j}+\delta_{2 j}{\text { Foreign } 100_{i j}}
\end{array}
$$

\subsection{Results}

We begin the analysis by studying the effect of micro-level factors on investment behaviour. Thereafter, we gradually include more variables to the models. First, presented in Table 5.1 are the results of a probit selection model (model 1), a random effect (RE) regression (model 2), and the results of a two-step Heckman selection outcome model (model 3-referred to as 'Outcome'). These models take into account the degree to which firms are clustered by countries, i.e. the models are multi-level models. The RE and outcome models are based on the selection of firms which report a level of investment that is higher than zero. The difference between the RE model and the outcome model is that the later model includes $\lambda$ which is computed on the basis of the probit selection model (model 1).

The results show that several of the covariates are highly significant in the probit selection model and in the RE and outcome models. P_Foreign is not significant in models 1-3 and Foreign 100 is not significant in model 1 . The coefficient of Foreign 100 has a negative sign and is significant in models 2 and 3 . This result 
suggests that firms that are completely foreign owned invest less, relative to sales, than domestic firms. ${ }^{16}$ Based on this contrasting evidence, it is clear that the effect of foreign equity ownership on investment is dependent on the degree of foreign equity ownership.

As expected, the coefficient of Age is negative, indicating that older firms invest less in fixed capital. The coefficient of Export is positive and significant following the probit selection model (firms that export invest more frequently). This coefficient is not significant in model 2 and is positive and significant in model 3 (firms that export invest relatively more). The coefficient of Labour has a negative sign and is significant in the selection model but is significant and positive in model 2 and model 3. The coefficient Size is significant in models 1-3; however the coefficient is positive in the probit model and is negative in the models using Investment as the dependent variable. This result means that larger firms invest more frequently than smaller firms but when smaller firms invest, they invest more relative to their sales volume. Two of the selection variables are significant and positive: the probability of investment is higher for firms that indicate they face obstacles related to land and informal competitors. These positive coefficients may indicate that firms that seek to invest are confronted by restrictions with respect to access to land and market share. Additionally, a possible interpretation for the positive coefficient of Competitor is that competition stimulates investment. The coefficient of Finance is not significant. Model 3 includes the inverse Mills ratio $(\lambda)$ which is used to correct for the selection bias. $\lambda$ is computed on the basis of the estimations of the probit selection model in model 1 and has a significant and positive effect on the level of investment indicating that the additional covariate $\lambda$ statistically improves the models fit. Following the multilevel models, when correcting for selection bias the sign of the coefficient for Export turns significant.

Finally, we are interested in the estimates for the 'random' (unobserved) part of our models. The population variance $\sigma_{v}^{2}$ (indicated as standard deviation $\sigma_{v}$ ) denotes the variance of $v_{j}$, the country-level random-intercept. ${ }^{17}$ The log restricted-likelihood ratio (LR) test statistics which test $H_{0}: \sigma_{v}^{2}=0$ against $\mathrm{H}_{a}: \sigma_{v}^{2}>0$ are significant for models 4-6 and thereby indicate the presence of country effects. The degree of significance of the LR test statistics are reported next to the coefficients of $\sigma_{v}$.

$\rho$ is an estimate of the residual between-country correlation such that $\rho=\frac{\sigma_{v}^{2}}{\left(\sigma_{v}^{2}+\sigma_{\varepsilon}^{2}\right)}$ where $\sigma_{\varepsilon}^{2}$ is the variance of $\varepsilon_{i j}$. We are particularly interested in the estimated values of $\rho$ which is an indicator of the degree of country dependency with possible range of $[0,1] .{ }^{18}$ Following the selection model $1, \widehat{\rho}$ is 0.12 and following the $\mathrm{RE}$ and outcome models the $\widehat{\rho}$ are 0.06 . These results suggest that the variance at the country-level is much less than the variance at the firm-level and thereby indicate that firm heterogeneity is relatively independent of the country-specific context.

\footnotetext{
16 In Appendix B are provided additional estimations using alternative measures of investment. Overall, these analysis confirm that firms that are completely foreign owned invest relatively less.

17 The significance of the 'random effects' is tested at $p<0.05$ and $p<0.01$.

$18 \rho$ is also known as the variance partition coefficient and the measure of intraclass correlation.
} 
Table 5.1: Multilevel models with and without 'Mundlak' covariates

Dependent variable: Invest (models 1 \& 4) and Investment (models 2, 3, 5 \& 6 )

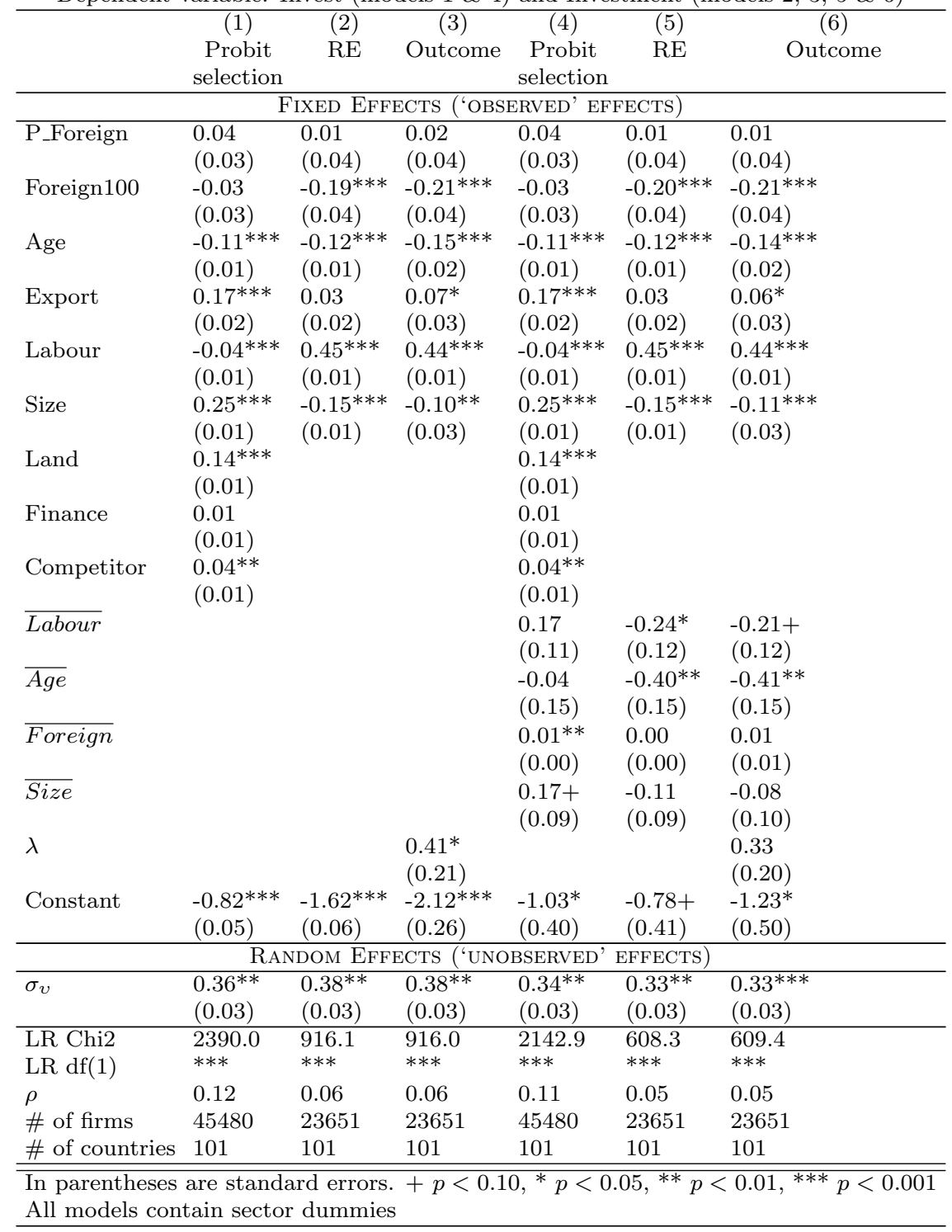

Up to now, we have assumed that macro-level covariates have an impact on the 'random effect' of a country and that these effects are captured by the intercept. We further extend the analysis of the probit selection, RE, and outcome models by including the variables $\overline{\text { Labour }}, \overline{\text { Size }}, \overline{\text { Age }}$, and $\overline{\text { Foreign }}$ as additional controls. As explained in section 5.4, adding the 'Mundlak' covariates to the models possibly reduces endogeneity. These results are presented in models 4-6 of Table 5.1. Overall, 
we find that our variables of interest are not sensitive to the inclusion of the additional variables. As a result of adding these country-level covariates the $\widehat{\rho}$ decrease from 0.12 to 0.11 and from 0.06 to 0.05 depending on the model. Regarding the probit selection model, $\sigma_{v}$ marginally decreases from 0.36 (model 1) to 0.34 (model 4). With respect to the results discussed earlier, we find no systematic change in the sign or significance of the other covariates presented in model 1. Adding the 'Mundlak' covariates changes the coefficient of Foreign 100 from -0.19 to -0.20 in the RE model but the coefficient remains significant. Following the results of the outcome model, the coefficient of P_Foreign changes from 0.02 to 0.01 but remains insignificant. Additionally, for the outcome model, we observe some marginal changes in the coefficients of Age, Export, and Size.

Regarding the 'Mundlak' covariates, only the coefficients of $\overline{\text { Foreign }}$ and $\overline{\text { Size }}$ are significant in the probit selection model. And, following the RE and outcome models (5-6), only the coefficients of $\overline{\text { Labour }}$ and $\overline{A g e}$ are significant. Here, perhaps the most interesting is the coefficient of $\overline{A g e}$ which in comparison to the coefficient Age is high and negative. This result can be interpreted as an indication that countries with a favourable investment climate have relatively more start-ups. The coefficient of $\lambda$, whilst significant in model 3 , is no longer significant in model 6 . We find no major discrepancies between the two models with the exception of the coefficient of Export which is significant in the outcome model but is not significant in the RE model.

Following the results described above, country-level factors have a relatively stronger effect on a firm's decision to invest than on a firm's decision on the relative level of investment. Still, the estimated $\rho$ are rather low suggesting a low countrylevel dependency. As suggested by Hawawini et al. (2004) one possibility is that country-effects are less pronounced because markets are to some extent economically and politically integrated. Despite the relative low intraclass correlation, the LR test statistics computed for the random-intercept models described above are all significant at $p<0.01$ and therefore are in favour of analysis including a country effect component. Moreover, considering the context of analysis we still consider these $\rho$ relatively substantial in size. A $12 \%$ macro-level dependency on a firm's decision to invest and a $6 \%$ effect on a firm's level of investment should not be understated when considering that these factors may determine if a country chronically under-invests (or over-invests). These considerations motivate further inquiry into the meaning of $\sigma_{v}$.

Table 5.2 presents the correlations between the estimate of $v_{j}$ of model 3 and model 6 (Table 5.3) and our country-level variables of interest. We find that the correlations between $\widehat{v}_{j}$ of model 3 and the macro-level variables aside from Openness, Growth and Interest are rather high. $\widehat{v}_{j}$ of model 6 are predicted values following the outcome model that includes $\overline{\text { Labour }}, \overline{\text { Size }}, \overline{\text { Age }}$, and $\overline{\text { Foreign }}$ as additional covariates. On average, the correlations between $\widehat{v}_{j}$ model 6 and the macroeconomic and institutional variables are lower. For example, the correlation between $\widehat{v}_{j}$ model 3 and Property is equal to -0.16 and the correlation between $\widehat{v}_{j}$ model 6 and Property is equal to -0.14. The correlation between $\widehat{v}_{j}$ model 3 and Growth is low and negative but the correlation between $\widehat{v}_{j}$ model 6 and Growth is slightly higher and positive. In conclusion, because the correlation between several of the macro-level variables and 
$\widehat{v}_{j}$ of model 3 and 6 are not close to zero, these descriptive results support including the macro variables in the analysis as additional covariates.

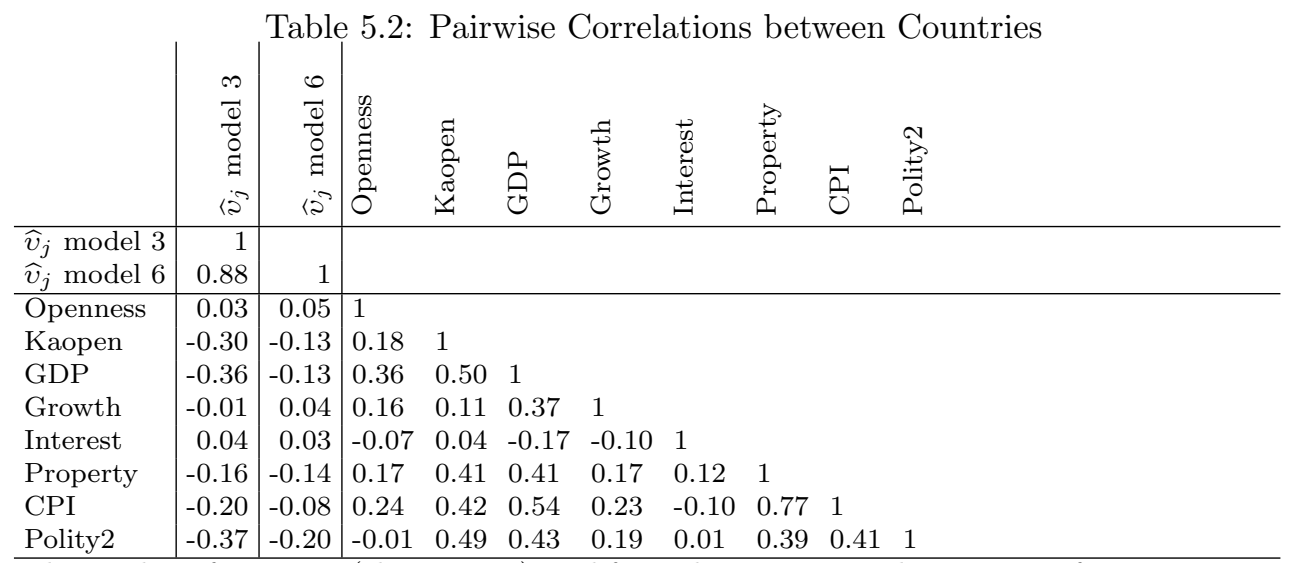

The number of countries (observations) used for each pairwise correlation ranges from 101 to 75 .

Next, we include the additional macro-level variables Openness, Kaopen, GDP, Growth, Interest, Polity2, CPI and Property in the regression analysis. The institutional and political indicators are entered separately in the analysis. We first present the results of the probit selection models in Table 5.3. Model 1 presents the results including Property, model 2 includes $C P I$ and model 3 includes Polity2. The effect of adding the macro-level variables to the model has little or no effect on the significance and the magnitude of the coefficients of the micro-level regressors. As before, we find no significant effect of foreign ownership on the probability of investment. Several of the macro-variables are not significant. The coefficient of Growth is significant and rather surprisingly negative. The coefficient of Interest is positive and significant in models 2 and 3 . Additionally, we find a positive and significant effect of control of corruption $(C P I)$ and property rights protection (Property) on the probability of investment. The coefficient of Polity 2 is not significant. We test whether the coefficients of the country-level variables are zero using a Wald test and reject this hypothesis for each of estimation results presented in models 1, 2 and 3. Following model 3, the $\rho$ is 0.10 which is lower than the $\rho$ documented in Table 5.1 model 4. We suspect that the decreasing effect of adding additional macro-level covariates is not fully observable in models 1-3 of Table 5.3 because of the change in sample size.

In models 4, 5 and 6 of Table 5.3 we control for the effect of institutions (Property and Corruption) and political economy on relation between foreign ownership and the probability of investment. We find that property rights protection and control of corruption have a positive mediating effect on the relation between completely foreign owned firms and the probability of investment. This result can be interpreted as evidence that foreign firms invest more frequently in countries that are (viewed as) having better institutions. We find no significant effect of institutions and political economy on the relation between partial foreign ownership and the probability of 
investment. The coefficient of Foreign 100 turns significant and negative in the models 4, 5 and 6 that include the interaction terms. This indicates that the probability of investment is lower for firms that are $100 \%$ foreign owned.

Table 5.3: Multilevel Probit selection equations with macro-level covariates and with and without interaction terms

\begin{tabular}{|c|c|c|c|c|c|c|}
\hline & $(1)$ & $(2)$ & $(3)$ & $(4)$ & $(5)$ & $(6)$ \\
\hline \multicolumn{7}{|c|}{ FIXED EFFECTS ('OBSERVED' EFFECTS) } \\
\hline P_Foreign & $\begin{array}{l}0.04 \\
(0.03)\end{array}$ & $\begin{array}{l}0.04 \\
(0.03)\end{array}$ & $\begin{array}{l}0.03 \\
(0.03)\end{array}$ & $\begin{array}{l}-0.02 \\
(0.08)\end{array}$ & $\begin{array}{l}0.05 \\
(0.08)\end{array}$ & $\begin{array}{l}0.02 \\
(0.05)\end{array}$ \\
\hline Foreign 100 & $\begin{array}{l}-0.03 \\
(0.03)\end{array}$ & $\begin{array}{l}-0.03 \\
(0.03)\end{array}$ & $\begin{array}{l}-0.04 \\
(0.03)\end{array}$ & $\begin{array}{l}-0.23^{* *} \\
(0.07)\end{array}$ & $\begin{array}{l}-0.23^{* *} \\
(0.08)\end{array}$ & $\begin{array}{l}-0.10^{*} \\
(0.04)\end{array}$ \\
\hline Age & $\begin{array}{l}-0.11^{* * *} \\
(0.01)\end{array}$ & $\begin{array}{l}-0.11^{* * *} \\
(0.01)\end{array}$ & $\begin{array}{l}-0.11^{* * *} \\
(0.01)\end{array}$ & $\begin{array}{l}-0.11^{* * *} \\
(0.01)\end{array}$ & $\begin{array}{l}-0.11^{* * * *} \\
(0.01)\end{array}$ & $\begin{array}{l}-0.11^{* * *} \\
(0.01)\end{array}$ \\
\hline Export & $\begin{array}{l}0.18^{* * *} \\
(0.02)\end{array}$ & $\begin{array}{l}0.18^{* * *} \\
(0.02)\end{array}$ & $\begin{array}{l}0.18^{* * *} \\
(0.02)\end{array}$ & $\begin{array}{l}0.18^{* * * *} \\
(0.02)\end{array}$ & $\begin{array}{l}0.18^{* * *} \\
(0.02)\end{array}$ & $\begin{array}{l}0.18^{* * *} \\
(0.02)\end{array}$ \\
\hline Labour & $\begin{array}{l}-0.05^{* * *} \\
(0.01)\end{array}$ & $\begin{array}{l}-0.05^{* * *} \\
(0.01)\end{array}$ & $\begin{array}{l}-0.05^{* * *} \\
(0.01)\end{array}$ & $\begin{array}{l}-0.05^{* * *} \\
(0.01)\end{array}$ & $\begin{array}{l}-0.05^{* * *} \\
(0.01)\end{array}$ & $\begin{array}{l}-0.05^{* * *} \\
(0.01)\end{array}$ \\
\hline Size & $\begin{array}{l}0.26^{* * *} \\
(0.01)\end{array}$ & $\begin{array}{l}0.26^{* * *} \\
(0.01)\end{array}$ & $\begin{array}{l}0.26^{* * *} \\
(0.01)\end{array}$ & $\begin{array}{l}0.26^{* * *} \\
(0.01)\end{array}$ & $\begin{array}{l}0.26^{* * *} \\
(0.01)\end{array}$ & $\begin{array}{l}0.26^{* * *} \\
(0.01)\end{array}$ \\
\hline Land & $\begin{array}{l}0.14^{* * *} \\
(0.02)\end{array}$ & $\begin{array}{l}0.14^{* * *} \\
(0.02)\end{array}$ & $\begin{array}{l}0.14^{* * *} \\
(0.02)\end{array}$ & $\begin{array}{l}0.14^{* * *} \\
(0.02)\end{array}$ & $\begin{array}{l}0.14^{* * *} \\
(0.02)\end{array}$ & $\begin{array}{l}0.14^{* * *} \\
(0.02)\end{array}$ \\
\hline Finance & $\begin{array}{l}0.00 \\
(0.01)\end{array}$ & $\begin{array}{l}0.00 \\
(0.01)\end{array}$ & $\begin{array}{l}0.01 \\
(0.01)\end{array}$ & $\begin{array}{l}0.00 \\
(0.01)\end{array}$ & $\begin{array}{l}0.00 \\
(0.01)\end{array}$ & $\begin{array}{l}0.01 \\
(0.01)\end{array}$ \\
\hline Competitor & $\begin{array}{l}0.05^{* *} \\
(0.01)\end{array}$ & $\begin{array}{l}0.04^{* *} \\
(0.01)\end{array}$ & $\begin{array}{l}0.05^{* *} \\
(0.01)\end{array}$ & $\begin{array}{l}0.05 * * \\
(0.01)\end{array}$ & $\begin{array}{l}0.04^{* *} \\
(0.01)\end{array}$ & $\begin{array}{l}0.05^{* *} \\
(0.02)\end{array}$ \\
\hline Openness & $\begin{array}{l}-0.00 \\
(0.00)\end{array}$ & $\begin{array}{l}-0.00 \\
(0.00)\end{array}$ & $\begin{array}{l}-0.00 \\
(0.00)\end{array}$ & $\begin{array}{l}-0.00 \\
(0.00)\end{array}$ & $\begin{array}{l}-0.00 \\
(0.00)\end{array}$ & $\begin{array}{l}-0.00 \\
(0.00)\end{array}$ \\
\hline Kaopen & $\begin{array}{l}-0.04 \\
(0.02)\end{array}$ & $\begin{array}{l}-0.02 \\
(0.02)\end{array}$ & $\begin{array}{l}-0.01 \\
(0.02)\end{array}$ & $\begin{array}{l}-0.04 \\
(0.02)\end{array}$ & $\begin{array}{l}-0.02 \\
(0.02)\end{array}$ & $\begin{array}{l}-0.01 \\
(0.02)\end{array}$ \\
\hline GDP & $\begin{array}{l}-0.01 \\
(0.06)\end{array}$ & $\begin{array}{l}-0.06 \\
(0.06)\end{array}$ & $\begin{array}{l}0.03 \\
(0.06)\end{array}$ & $\begin{array}{l}-0.02 \\
(0.06)\end{array}$ & $\begin{array}{l}-0.07 \\
(0.06)\end{array}$ & $\begin{array}{l}0.03 \\
(0.06)\end{array}$ \\
\hline Growth & $\begin{array}{l}-0.02^{* *} \\
(0.01)\end{array}$ & $\begin{array}{l}-0.02^{* *} \\
(0.01)\end{array}$ & $\begin{array}{l}-0.01^{*} \\
(0.01)\end{array}$ & $\begin{array}{l}-0.02^{* *} \\
(0.01)\end{array}$ & $\begin{array}{l}-0.02^{* *} \\
(0.01)\end{array}$ & $\begin{array}{l}-0.01^{*} \\
(0.01)\end{array}$ \\
\hline Interest & $\begin{array}{l}0.00 \\
(0.00)\end{array}$ & $\begin{array}{l}0.01^{* *} \\
(0.00)\end{array}$ & $\begin{array}{l}0.01^{* *} \\
(0.00)\end{array}$ & $\begin{array}{l}0.00 \\
(0.00)\end{array}$ & $\begin{array}{l}0.01^{* *} \\
(0.00)\end{array}$ & $\begin{array}{l}0.01^{* *} \\
(0.00)\end{array}$ \\
\hline Property & $\begin{array}{l}0.01^{* *} \\
(0.00)\end{array}$ & & & $\begin{array}{l}0.01^{* *} \\
(0.00)\end{array}$ & & \\
\hline CPI & & $\begin{array}{l}0.20^{* * *} \\
(0.04)\end{array}$ & & & $\begin{array}{l}0.19^{* * *} \\
(0.04)\end{array}$ & \\
\hline Polity2 & & & $\begin{array}{l}0.00 \\
(0.01)\end{array}$ & & & $\begin{array}{l}0.00 \\
(0.01)\end{array}$ \\
\hline P_Foreign $\times$ Property & & & & $\begin{array}{l}0.00 \\
(0.00)\end{array}$ & & \\
\hline Foreign $100 \times$ Property & & & & $\begin{array}{l}0.00^{* *} \\
(0.00)\end{array}$ & & \\
\hline P_Foreign $\times$ CPI & & & & & $\begin{array}{l}-0.00 \\
(0.02)\end{array}$ & \\
\hline Foreign100 $\times \mathrm{CPI}$ & & & & & $\begin{array}{l}0.06^{* * *} \\
(0.02)\end{array}$ & \\
\hline P_Foreign $\times$ Polity 2 & & & & & & $\begin{array}{l}0.00 \\
(0.01)\end{array}$ \\
\hline Foreign100 $\times$ Polity 2 & & & & & & $\begin{array}{l}0.01^{*} \\
(0.01)\end{array}$ \\
\hline
\end{tabular}




\begin{tabular}{|c|c|c|c|c|c|c|}
\hline \multicolumn{7}{|c|}{ Continued from previous page } \\
\hline Constant & $\begin{array}{c}-1.48^{*} \\
(0.64)\end{array}$ & $\begin{array}{c}-1.13+ \\
(0.61)\end{array}$ & $\begin{array}{l}-1.64^{*} \\
(0.65)\end{array}$ & $\begin{array}{l}-1.46^{*} \\
(0.64)\end{array}$ & $\begin{array}{c}-1.11+ \\
(0.61)\end{array}$ & $\begin{array}{l}-1.62^{*} \\
(0.65)\end{array}$ \\
\hline \multicolumn{7}{|c|}{ RANDOM EFFECTS ('UNOBSERVED' EFFECTS) } \\
\hline$\overline{\sigma_{v}}$ & $\begin{array}{l}0.37^{* *} \\
(0.04)\end{array}$ & $\begin{array}{l}0.35^{* *} \\
(0.03)\end{array}$ & $\begin{array}{l}0.34^{* *} \\
(0.04)\end{array}$ & $\begin{array}{l}0.37^{* *} \\
(0.04)\end{array}$ & $\begin{array}{l}0.35^{* *} \\
(0.03)\end{array}$ & $\begin{array}{l}0.34^{* *} \\
(0.04)\end{array}$ \\
\hline LR Chi2 & 1642.1 & 1582.3 & 1491.7 & 1642.5 & 1586.9 & 1494.7 \\
\hline LR df(1) & $* * *$ & $* * *$ & $* * *$ & $* * *$ & $* * *$ & $* * *$ \\
\hline$\rho$ & 0.12 & 0.11 & 0.10 & 0.12 & 0.11 & 0.10 \\
\hline \# of firms & 37471 & 37997 & 36691 & 37471 & 37997 & 36691 \\
\hline \# of countries & 77 & 76 & 72 & 77 & 76 & 72 \\
\hline \multicolumn{7}{|c|}{$\begin{array}{l}\text { In parentheses are standard errors. }+p<0.10,{ }^{*} p<0.05,{ }^{*} p<0.01,{ }^{* * *} p<0.001 \\
\text { All models contain sector dummies } \\
\text { Results for } \overline{\text { Labour }}, \overline{\text { Age }}, \overline{\text { Size }} \text { and } \overline{\text { Foreign }} \text { are available upon request }\end{array}$} \\
\hline
\end{tabular}

Table 5.4 presents the results of the RE and outcome models including the macroeconomic and institutional variables. Again, Property, CPI, and Polity 2 are entered separately in the models. The various $\lambda$ included in the outcome models are based on the regression output of models 1-3 of Table 5.3. Unlike in Table 5.1 model 6 , where the coefficient of $\lambda$ was not significant, the coefficient of $\lambda$ is significant in Table 5.4 models 2,4 , and 6 . As such, we give preference to the results presented in model 2 (including Property), model 4 (including CPI), and model 6 (including Polity2). With the exception of $\lambda$, we find that the sign and significance of the coefficients of the micro-level covariates are not sensitive to the addition of the macro-level covariates. Export remains only positive and significant when correcting for sample selection bias.

No significant effect is found of Openness and Kaopen on firms' investment to sales ratio. The coefficient of $G D P$ is significant and negative in all models which suggests that firms located in countries with a relatively lower level of GDP per capita invest relatively more in fixed capital. The coefficient of Growth is significant and positive in the RE models that do not control for selection bias (model 1, 3, and 5) and is also significant when controlling for selection bias and using Polity2 (model 6). In addition, Interest has a negative and significant effect on investment in RE model 3 but this covariate is insignificant in all other models. We do not find a significant effect of institutions on investment when using the proxies CPI and Property. However, the coefficient of Polity2 is significant (following both model 5 and 6) and, somewhat contrary to expectations, is negative. ${ }^{19}$ According to the work of Mathur and Singh (2013), one explanation is that investment is driven by economic freedoms and not by political freedoms and that, as a result of competing political interest, countries with emerging democratic institutions may lack the ability to enforce economic freedoms. ${ }^{20}$

\footnotetext{
19 Estimation results for Table 5.4 using robust standard errors computed using maximum likelihood estimation (instead of restricted maximum likelihood estimation) yield similar results. Wald tests based of the estimations presented in models 1-6 reject the hypothesis that the coefficients of the country-level variables are zero.

20 Mathur and Singh (2013) studies determinants of FDI using a macroeconomic framework. The authors' theory may contribute to explain why, for example, China scores low on democracy and high on property rights protection and is able to attract high flows of FDI.
} 
Table 5.4: Multilevel RE and outcome models with macro-level covariates

Dependent variable: Investment

\begin{tabular}{|c|c|c|c|c|c|c|}
\hline & $\begin{array}{l}(1) \\
\mathrm{RE}\end{array}$ & $\begin{array}{c}(2) \\
\text { Outcome }\end{array}$ & $\begin{array}{l}(3) \\
\mathrm{RE}\end{array}$ & $\begin{array}{c}(4) \\
\text { Outcome }\end{array}$ & $\begin{array}{l}(5) \\
\mathrm{RE}\end{array}$ & $\begin{array}{c}(6) \\
\text { Outcome }\end{array}$ \\
\hline \multicolumn{7}{|c|}{ FIXED EFFECTS ('OBSERVED' EFFECTS) } \\
\hline P_Foreign & $\begin{array}{l}0.02 \\
(0.04)\end{array}$ & $\begin{array}{l}0.03 \\
(0.04)\end{array}$ & $\begin{array}{l}0.02 \\
(0.04)\end{array}$ & $\begin{array}{l}0.03 \\
(0.04)\end{array}$ & $\begin{array}{l}0.01 \\
(0.04)\end{array}$ & $\begin{array}{l}0.02 \\
(0.04)\end{array}$ \\
\hline Foreign 100 & $\begin{array}{l}-0.19^{* * *} \\
(0.04)\end{array}$ & $\begin{array}{l}-0.21^{* * *} \\
(0.04)\end{array}$ & $\begin{array}{l}-0.18^{* * *} \\
(0.04)\end{array}$ & $\begin{array}{l}-0.20^{* * *} \\
(0.04)\end{array}$ & $\begin{array}{l}-0.18^{* * *} \\
(0.04)\end{array}$ & $\begin{array}{l}-0.20^{* * *} \\
(0.04)\end{array}$ \\
\hline Age & $\begin{array}{l}-0.11^{* * *} \\
(0.02)\end{array}$ & $\begin{array}{l}-0.16^{* * *} \\
(0.02)\end{array}$ & $\begin{array}{l}-0.11^{* * *} \\
(0.02)\end{array}$ & $\begin{array}{l}-0.16^{* * *} \\
(0.02)\end{array}$ & $\begin{array}{l}-0.11^{* * *} \\
(0.02)\end{array}$ & $\begin{array}{l}-0.15^{* * *} \\
(0.02)\end{array}$ \\
\hline Export & $\begin{array}{l}0.02 \\
(0.03)\end{array}$ & $\begin{array}{l}0.10^{* *} \\
(0.03)\end{array}$ & $\begin{array}{l}0.02 \\
(0.03)\end{array}$ & $\begin{array}{l}0.09 * * \\
(0.03)\end{array}$ & $\begin{array}{l}0.02 \\
(0.03)\end{array}$ & $\begin{array}{l}0.08^{*} \\
(0.03)\end{array}$ \\
\hline Labour & $\begin{array}{l}0.44^{* * *} \\
(0.01)\end{array}$ & $\begin{array}{l}0.42^{* * *} \\
(0.01)\end{array}$ & $\begin{array}{l}0.44^{* * *} \\
(0.01)\end{array}$ & $\begin{array}{l}0.42^{* * * *} \\
(0.01)\end{array}$ & $\begin{array}{l}0.44^{* * *} \\
(0.01)\end{array}$ & $\begin{array}{l}0.42^{* * * *} \\
(0.01)\end{array}$ \\
\hline Size & $\begin{array}{l}-0.15^{* * *} \\
(0.01)\end{array}$ & $\begin{array}{l}-0.04 \\
(0.03)\end{array}$ & $\begin{array}{l}-0.15^{* * *} \\
(0.01)\end{array}$ & $\begin{array}{l}-0.05+ \\
(0.03)\end{array}$ & $\begin{array}{l}-0.15^{* * *} \\
(0.01)\end{array}$ & $\begin{array}{c}-0.06^{*} \\
(0.03)\end{array}$ \\
\hline Openness & $\begin{array}{l}0.00 \\
(0.00)\end{array}$ & $\begin{array}{l}0.00 \\
(0.00)\end{array}$ & $\begin{array}{l}0.00 \\
(0.00)\end{array}$ & $\begin{array}{l}0.00 \\
(0.00)\end{array}$ & $\begin{array}{l}0.00 \\
(0.00)\end{array}$ & $\begin{array}{l}0.00 \\
(0.00)\end{array}$ \\
\hline Kaopen & $\begin{array}{l}-0.01 \\
(0.03)\end{array}$ & $\begin{array}{l}-0.03 \\
(0.03)\end{array}$ & $\begin{array}{l}-0.01 \\
(0.03)\end{array}$ & $\begin{array}{l}-0.02 \\
(0.03)\end{array}$ & $\begin{array}{l}-0.00 \\
(0.03)\end{array}$ & $\begin{array}{l}-0.01 \\
(0.03)\end{array}$ \\
\hline GDP & $\begin{array}{c}-0.13^{*} \\
(0.05)\end{array}$ & $\begin{array}{c}-0.14^{*} \\
(0.05)\end{array}$ & $\begin{array}{c}-0.13^{*} \\
(0.06)\end{array}$ & $\begin{array}{l}-0.16^{* *} \\
(0.06)\end{array}$ & $\begin{array}{c}-0.12^{*} \\
(0.06)\end{array}$ & $\begin{array}{c}-0.11+ \\
(0.06)\end{array}$ \\
\hline Growth & $\begin{array}{l}0.02^{* *} \\
(0.01)\end{array}$ & $\begin{array}{l}0.01 \\
(0.01)\end{array}$ & $\begin{array}{l}0.02^{* *} \\
(0.01)\end{array}$ & $\begin{array}{l}0.01 \\
(0.01)\end{array}$ & $\begin{array}{l}0.02^{* *} \\
(0.01)\end{array}$ & $\begin{array}{l}0.02^{*} \\
(0.01)\end{array}$ \\
\hline Interest & $\begin{array}{l}-0.00 \\
(0.00)\end{array}$ & $\begin{array}{l}-0.00 \\
(0.00)\end{array}$ & $\begin{array}{l}-0.00+ \\
(0.00)\end{array}$ & $\begin{array}{l}-0.00 \\
(0.00)\end{array}$ & $\begin{array}{l}-0.00 \\
(0.00)\end{array}$ & $\begin{array}{l}-0.00 \\
(0.00)\end{array}$ \\
\hline Property & $\begin{array}{l}-0.00 \\
(0.00)\end{array}$ & $\begin{array}{l}0.00 \\
(0.00)\end{array}$ & & & & \\
\hline CPI & & & $\begin{array}{l}-0.03 \\
(0.04)\end{array}$ & $\begin{array}{l}0.05 \\
(0.04)\end{array}$ & & \\
\hline Polity 2 & & & & & $\begin{array}{l}-0.02+ \\
(0.01)\end{array}$ & $\begin{array}{l}-0.02+ \\
(0.01)\end{array}$ \\
\hline$\lambda$ & & $\begin{array}{l}0.86^{* * *} \\
(0.20)\end{array}$ & & $\begin{array}{l}0.78^{* * *} \\
(0.19)\end{array}$ & & $\begin{array}{l}0.68^{* *} \\
(0.21)\end{array}$ \\
\hline Constant & $\begin{array}{l}-0.15 \\
(0.58)\end{array}$ & $\begin{array}{l}-1.54^{*} \\
(0.67)\end{array}$ & $\begin{array}{l}-0.39 \\
(0.58)\end{array}$ & $\begin{array}{l}-1.48^{*} \\
(0.65)\end{array}$ & $\begin{array}{l}-0.60 \\
(0.63)\end{array}$ & $\begin{array}{c}-1.79 * \\
(0.73)\end{array}$ \\
\hline \multicolumn{7}{|c|}{ RANDOM EFFECTS ('UNOBSERVED' EFFECTS) } \\
\hline$\sigma_{v}$ & $\begin{array}{l}0.31^{* *} \\
(0.03)\end{array}$ & $\begin{array}{l}0.31^{* *} \\
(0.03) \\
\end{array}$ & $\begin{array}{l}0.31^{* *} \\
(0.03)\end{array}$ & $\begin{array}{l}0.31^{* *} \\
(0.03)\end{array}$ & $\begin{array}{l}0.31^{* *} \\
(0.03)\end{array}$ & $\begin{array}{l}0.31^{* *} \\
(0.03)\end{array}$ \\
\hline $\begin{array}{l}\text { LR Chi2 } \\
\text { LR df(1) }\end{array}$ & $\begin{array}{l}437.3 \\
* * *\end{array}$ & $\begin{array}{l}447.8 \\
* * *\end{array}$ & $\begin{array}{l}471.1 \\
* * *\end{array}$ & $\begin{array}{l}481.2 \\
* * *\end{array}$ & $\begin{array}{l}442.4 \\
* * *\end{array}$ & $\begin{array}{l}446.5 \\
* * *\end{array}$ \\
\hline$\rho$ & 0.04 & 0.04 & 0.04 & 0.04 & 0.04 & 0.04 \\
\hline \# of firms & 19978 & 19978 & 20143 & 20143 & 19571 & 19571 \\
\hline \# of countries & 77 & 77 & 76 & 76 & 72 & 72 \\
\hline $\begin{array}{l}\text { In parentheses } \\
\text { All models con } \\
\text { Results for } \overline{L a t}\end{array}$ & $\begin{array}{l}\text { are stand } \\
\text { tain secto } \\
\frac{\text { our }}{\text { Age }}\end{array}$ & $\begin{array}{l}\text { rd errors. } \\
\text { dummies } \\
\text { Size and }\end{array}$ & $+p<0$ & ${ }^{*} p<$ & $\overline{5}, * * p$ & $\begin{array}{l}0.01,{ }^{* * *} p<0.001 \\
\text { quest }\end{array}$ \\
\hline
\end{tabular}

Table 5.5, models 1-6 present the results of the multilevel selection models that include the macro variables and the interaction terms for foreign ownership and institutions/political economy. The $\lambda$ included in the outcome models are based on the probit selection models 4-6 of Table 5.3. Adding the interaction terms to the models has some effect on the coefficient of P_Foreign but does not systematically change 
the other micro-level covariates. In contrast to the findings previously discussed, we find that the coefficient of $P_{-}$Foreign is significant and negative in the RE model that includes the interaction term for $P_{-}$Foreign and $C P I$. In the outcome model and the models including Property and Polity 2 as covariates we do not find any evidence that partially foreign owned firms invest less relative to sales. The coefficient of Foreign100 remains significant and negative in all models. Similar to the results presented in Table 5.5 we find that, overall, growth is positively related to investment and GDP is negatively related to investment. Moreover, the coefficient of Polity2 remains significant and negative in models 5-6 of Table 5.6 and the coefficients of $C P I$ and Property remain insignificant.

The interaction terms P_Foreign $\times C P I$ (models 3 and 4) and Foreign $100 \times$ Property (model 2 only) are significant and positive but the other interaction terms are not significant. Hence, in agreement with some scholars (Asiedu and Lien, 2011; Kinda, 2010; Javorcik and Wei, 2009) that study the effect of governance on FDI, we find some evidence which suggests that countries with low corruption can attract more foreign capital. We also find weak evidence indicating that firms with 100 percent foreign equity ownership avoid investing in countries with poor protection of property rights. Based on our sample, countries that score relatively high on the variables $C P I$ and Property are Chile, Estonia and Uruguay and countries that score relatively low on these variables are Angola, Chad and Venezuela.

Across country-level averages, what is the relation between foreign equity ownership and investment? The analysis including the additional random slope parameters are presented in models 1-6 of Table 5.6. The random slope effects are expressed in units of standard deviation with respect to $P_{-}$Foreign and Foreign 100 . We refer to these random effect estimates as $\sigma_{P_{-} \text {Foreign }}$ and $\sigma_{\text {Foreign } 100}$. The random effect estimates are distinctly estimated (i.e. we allow for covariance). The join LR test statistics are significant (even though the resulting p-values are conservative) and thereby indicate cross-country differences in $\sigma_{P \_ \text {Foreign }}$ and $\sigma_{\text {Foreign } 100}$. Models 2,4 , and 6 build upon the inverse Mills ratios computed following the estimation results of probit selection models with interaction terms $(4,5$ and 6$)$ of Table 5.3.

The inclusion of the additional random coefficients has some effect on the magnitude of the coefficients but does not influence our interpretation. The interaction term Foreign $100 \times$ Property in model 2 (including $\lambda$ ) and the interaction terms $P$ Foreign $\times C P I$ (models $3-4$ ) remain significant. Also, we find some positive and significant effect of Openness following models 1 and 3 that do not include $\lambda$ (the coefficients are close to zero). The inverse mills ratio, the coefficient of $\lambda$ is significant in models 2,4 , and 6 and as such we prefer these estimation results over those presented in models 1,3 , and 5 . In comparison to the results presented in Table 5.5 , we do not find any other systematic differences in the estimation results. ${ }^{21}$

Next, we compute the - full-conditional marginal effects of foreign ownership on investment. These results are presented in the line plots Figures 5.1 and 5.2. The point estimates are based on the results of models 2, 4, and 6 presented in Table 5.6

21 We also experimented using the natural logarithm of the ratio of investment in machinery, equipment, land, and buildings over sales as the dependent variable. Analysis using this alternative dependent variable supports the results of the analysis reported in Table 5.6. 
which include random-coefficients. We estimate the marginal effect of $P$ Foreign on Investment and of Foreign100 on Investment given different values of Property, $C P I$, or Polity2. We use the values that correspond to the 5 th, $25 \mathrm{th}, 50 \mathrm{th}, 75 \mathrm{th}$, and 95th percentiles of the institutional and political economy indicators that are defined at the country-level. These indicators are placed on the horizontal axis of the different line plots; as ordered from top to bottom Property, CPI, and Polity2. Figure 5.1 presents the marginal effect of $P_{-}$Foreign on investment and Figure 5.2 presents the marginal effect of Foreign 100 on investment. These results show that the marginal effect of P_Foreign and Foreign 100 on investment changes along with institutional development (Property and $C P I$ ) but remains fairly constant for different values of Polity2. In particular, the marginal effect of P_Foreign on Investment whilst negative at high levels of corruption turns positive at lower levels of corruption (i.e. control of corruption). However, these marginal effects remain close to zero and are insignificant. The marginal effect of Foreign100 on Investment is usually negative and significant. These line plots indicate that firms that are completely foreign owned invest relatively more when these firms are located in countries with better protection of property rights and control of corruption. In fact, the negative marginal effect of foreign ownership is lower for countries that score high on Property and CPI. This effect is not captured by the interaction term Foreign $100 \times C P I$ in the outcome model.

Finally, we interpret the random effects $\sigma_{P_{-} \text {Foreign }}$ and $\sigma_{\text {Foreign } 100 .}$ In order to interpret these random effects we assume that they have a normal distribution. Figure 5.5 in Appendix A plots the distribution of the random effects (as well as that of the random intercept) that are derived on the basis of model 2 of Table 5.6. ${ }^{22}$ Overall, the distributions look approximately normal. Model 2 shows that the fixed effect coefficient of Foreign 100 is equal to -0.47. The coefficients' corresponding random effect parameter shows that for $95 \%$ of our sample population of countries the coefficient of Foreign 100 falls within the range of $[-0.94,0.00]$. This result is derived as following: $-0.47 \pm 1.96 \times 0.24$. This result suggests that, indeed in the majority of countries, the country-averages are that completely foreign owned firms invest less than domestic firms and partially foreign-owned firms. Using model 2 as a reference, the proportion of countries for which the average slope is equal to or larger than 0 amounts to $2.51 \%$ (which corresponds to a z-score of 1.96 ). Following model 4, which uses $C P I$ as a covariate, the random effect parameter of Foreign 100 suggests that on average in the majority of countries foreign-owned firms invest less than domestic firms. Here, based on a normal distribution assumption, the coefficient of Foreign 100 for $95 \%$ of our sample population of countries falls within the range [-0.78, 0.12]. This range includes positive values and as such suggests that, in several countries in our sample, firms that are $100 \%$ foreign owned on average invest relatively more. Given a $\mathrm{z}$-score of 1.43 , the percentage of countries in which foreign owned firms invest the same or more than domestically owned firms is $7.58 \%$. Model 6 yields somewhat similar evidence; i.e. in $14.92 \%$ of the countries' foreign firms invest the same or relatively more than domestically owned firms. Therefore, despite that foreign equity ownership appears to be associated with relatively less investment, our results by no

\footnotetext{
22 To save space we do not report the distributions of the random slopes for the other models.
} 
means contradict the work of Koo and Maeng (2006) who on the basis of a country case study (on Korea) argue that foreign ownership positively influences investment.

The coefficient of $P_{-}$Foreign in model 3 that uses $C P I$ as a proxy is significant and negative. Following model 3 , the random effect parameter $\sigma_{P \_ \text {Foreign }}$, the $95 \%$ range of the coefficient for partially foreign-owned firms is [-0.77, 0.21]. Following this model, on average, in $13.14 \%$ of the countries (i.e. about 10 countries) partially foreign owned firms invest the same or more than domestically owned firms and completely foreign owned firms. The coefficients of $P$ _Foreign in model 1,2,4,5 and 6 (i.e. including either Property or Polity 2 and/or including $\lambda$ ) are not significant and the coefficients are substantially smaller in magnitude albeit the spread of $\sigma_{P_{-} \text {Foreign }}$ remains wide. Altogether, this evidence suggests that the point estimate coefficients of $P_{-}$Foreign are rather unreliable.

Table 5.5: Multilevel RE and outcome models with macro-level covariates and interaction terms

Dependent variable: Investment

\begin{tabular}{|c|c|c|c|c|c|c|}
\hline & $(1)$ & $(2)$ & $(3)$ & (4) & $(5)$ & (6) \\
\hline & $\mathrm{RE}$ & Outcome & $\mathrm{RE}$ & Outcome & $\mathrm{RE}$ & Outcome \\
\hline \multicolumn{7}{|c|}{ FIXED EFFECTS ('OBSERVED' EFFECTS) } \\
\hline \multirow[t]{2}{*}{ P_Foreign } & -0.06 & -0.05 & $-0.23^{*}$ & -0.18 & 0.03 & 0.04 \\
\hline & $(0.10)$ & $(0.10)$ & $(0.11)$ & $(0.11)$ & $(0.07)$ & $(0.07)$ \\
\hline \multirow[t]{2}{*}{ Foreign100 } & $-0.33^{* *}$ & $-0.41^{* * *}$ & $-0.23^{*}$ & $-0.29^{* *}$ & $-0.19^{* *}$ & $-0.24^{* * *}$ \\
\hline & $(0.10)$ & $(0.10)$ & $(0.11)$ & $(0.11)$ & $(0.06)$ & $(0.06)$ \\
\hline \multirow[t]{2}{*}{ Age } & $-0.11^{* * *}$ & $-0.16^{* * *}$ & $-0.11^{* * *}$ & $-0.16^{* * *}$ & $-0.11^{* * *}$ & $-0.16^{* * *}$ \\
\hline & $(0.02)$ & $(0.02)$ & $(0.02)$ & $(0.02)$ & $(0.02)$ & $(0.02)$ \\
\hline \multirow[t]{2}{*}{ Export } & 0.02 & $0.10^{* *}$ & 0.02 & $0.09^{* *}$ & 0.02 & $0.08^{*}$ \\
\hline & $(0.03)$ & $(0.03)$ & $(0.03)$ & $(0.03)$ & $(0.03)$ & $(0.03)$ \\
\hline \multirow[t]{2}{*}{ Labour } & $0.44^{* * *}$ & $0.42 * * *$ & $0.44^{* * *}$ & $0.42^{* * *}$ & $0.44^{* * *}$ & $0.42^{* * *}$ \\
\hline & $(0.01)$ & $(0.01)$ & $(0.01)$ & $(0.01)$ & $(0.01)$ & $(0.01)$ \\
\hline \multirow[t]{2}{*}{ Size } & $-0.15^{* * *}$ & -0.04 & $-0.15^{* * *}$ & $-0.06^{*}$ & $-0.15^{* * *}$ & $-0.06+$ \\
\hline & $(0.01)$ & $(0.03)$ & $(0.01)$ & $(0.03)$ & $(0.01)$ & $(0.03)$ \\
\hline \multirow[t]{2}{*}{ Openness } & 0.00 & 0.00 & 0.00 & 0.00 & 0.00 & 0.00 \\
\hline & $(0.00)$ & $(0.00)$ & $(0.00)$ & $(0.00)$ & $(0.00)$ & $(0.00)$ \\
\hline \multirow[t]{2}{*}{ Kaopen } & -0.01 & -0.03 & -0.02 & -0.02 & -0.00 & -0.01 \\
\hline & $(0.03)$ & $(0.03)$ & $(0.03)$ & $(0.03)$ & $(0.03)$ & $(0.03)$ \\
\hline \multirow[t]{2}{*}{ GDP } & $-0.14^{*}$ & $-0.14^{* *}$ & $-0.13^{*}$ & $-0.16^{* *}$ & $-0.12^{*}$ & $-0.11+$ \\
\hline & $(0.05)$ & $(0.05)$ & $(0.06)$ & $(0.06)$ & $(0.06)$ & $(0.06)$ \\
\hline \multirow[t]{2}{*}{ Growth } & $0.02^{* *}$ & 0.01 & $0.02^{* *}$ & 0.01 & $0.02^{* *}$ & $0.02^{*}$ \\
\hline & $(0.01)$ & $(0.01)$ & $(0.01)$ & $(0.01)$ & $(0.01)$ & $(0.01)$ \\
\hline \multirow[t]{2}{*}{ Interest } & -0.00 & -0.00 & $-0.00+$ & -0.00 & -0.00 & -0.00 \\
\hline & $(0.00)$ & $(0.00)$ & $(0.00)$ & $(0.00)$ & $(0.00)$ & $(0.00)$ \\
\hline \multirow[t]{2}{*}{ Property } & -0.00 & 0.00 & & & & \\
\hline & $(0.00)$ & $(0.00)$ & & & & \\
\hline \multirow[t]{2}{*}{ CPI } & & & -0.04 & 0.04 & & \\
\hline & & & $(0.04)$ & $(0.04)$ & & \\
\hline Polity2 & & & & & $-0.02+$ & $-0.02+$ \\
\hline \multirow{2}{*}{ P_Foreign $\times$ Property } & 0.00 & 0.00 & & & & \\
\hline & $(0.00)$ & $(0.00)$ & & & & \\
\hline \multirow[t]{2}{*}{ Foreign $100 \times$ Property } & 0.00 & $0.00 *$ & & & & \\
\hline & $(0.00)$ & $(0.00)$ & & & & \\
\hline \multirow[t]{2}{*}{ P_Foreign $\times$ CPI } & & & $0.07^{*}$ & $0.06^{*}$ & & \\
\hline & & & $(0.03)$ & $(0.03)$ & & \\
\hline
\end{tabular}




\begin{tabular}{|c|c|c|c|c|c|c|}
\hline \multicolumn{7}{|c|}{ Continued from previous page } \\
\hline Foreign100 $\times \mathrm{CPI}$ & & & $\begin{array}{l}0.02 \\
(0.03)\end{array}$ & $\begin{array}{l}0.03 \\
(0.03)\end{array}$ & & \\
\hline P_Foreign $\times$ Polity 2 & & & & & $\begin{array}{l}-0.00 \\
(0.01)\end{array}$ & $\begin{array}{l}-0.00 \\
(0.01)\end{array}$ \\
\hline Foreign $100 \times$ Polity 2 & & & & & $\begin{array}{l}0.00 \\
(0.01)\end{array}$ & $\begin{array}{l}0.01 \\
(0.01)\end{array}$ \\
\hline$\lambda$ & & $\begin{array}{l}0.84^{* * *} \\
(0.20)\end{array}$ & & $\begin{array}{l}0.73^{* * *} \\
(0.19)\end{array}$ & & $\begin{array}{l}0.70^{* * *} \\
(0.21)\end{array}$ \\
\hline Constant & $\begin{array}{l}-0.13 \\
(0.58) \\
\end{array}$ & $\begin{array}{c}-1.49^{*} \\
(0.67)\end{array}$ & $\begin{array}{l}-0.36 \\
(0.58)\end{array}$ & $\begin{array}{c}-1.39^{*} \\
(0.65)\end{array}$ & $\begin{array}{l}-0.60 \\
(0.63)\end{array}$ & $\begin{array}{c}-1.83^{*} \\
(0.73)\end{array}$ \\
\hline \multicolumn{7}{|c|}{ RANDOM EFFECTS ('UNOBSERVED' EFFECTS) } \\
\hline$\sigma_{v}$ & $\begin{array}{l}0.31^{* *} \\
(0.03)\end{array}$ & $\begin{array}{l}0.31^{* *} \\
(0.03)\end{array}$ & $\begin{array}{l}0.31^{* *} \\
(0.03)\end{array}$ & $\begin{array}{l}0.32^{* *} \\
(0.03)\end{array}$ & $\begin{array}{l}0.31^{* *} \\
(0.03)\end{array}$ & $\begin{array}{l}0.31^{* *} \\
(0.03)\end{array}$ \\
\hline $\begin{array}{l}\text { LR Chi2 } \\
\text { R df(1) }\end{array}$ & $\begin{array}{l}439.1 \\
* * *\end{array}$ & $\begin{array}{l}449.3 \\
* * *\end{array}$ & $\begin{array}{l}472.2 \\
* * *\end{array}$ & $\begin{array}{l}481.5 \\
* * *\end{array}$ & $\begin{array}{l}442.4 \\
* * *\end{array}$ & $\begin{array}{l}446.9 \\
* * *\end{array}$ \\
\hline$\rho$ & 0.04 & 0.04 & 0.04 & 0.04 & 0.04 & 0.04 \\
\hline \# of firms & 19978 & 19978 & 20143 & 20143 & 19571 & 19571 \\
\hline \# of countries & 77 & 77 & 76 & 76 & 72 & 72 \\
\hline
\end{tabular}

In parentheses are standard errors. $+p<0.10,{ }^{*} p<0.05,{ }^{* *} p<0.01,{ }^{* * *} p<0.001$ All models contain sector dummies

Results for $\overline{\text { Labour }}, \overline{\text { Age }}, \overline{\text { Size }}$ and $\overline{\text { Foreign }}$ are available upon request

Table 5.6: RE and outcome random-coefficient models models with macro-level covariates and interaction terms

Dependent variable: Investment

\begin{tabular}{|c|c|c|c|c|c|c|}
\hline & $\begin{array}{l}(1) \\
\mathrm{RE}\end{array}$ & $\begin{array}{c}(2) \\
\text { Outcome }\end{array}$ & $\begin{array}{l}\text { (3) } \\
\mathrm{RE}\end{array}$ & $\begin{array}{c}\text { (4) } \\
\text { Outcome }\end{array}$ & $\begin{array}{l}(5) \\
\mathrm{RE}\end{array}$ & $\begin{array}{c}(6) \\
\text { Outcome }\end{array}$ \\
\hline \multicolumn{7}{|c|}{ FIXED EFFECTS ('OBSERVED' EFFECTS) } \\
\hline \multirow[t]{2}{*}{ P_Foreign } & -0.07 & -0.06 & $-0.28^{*}$ & -0.23 & 0.01 & 0.02 \\
\hline & $(0.14)$ & $(0.14)$ & $(0.14)$ & $(0.14)$ & $(0.09)$ & $(0.09)$ \\
\hline \multirow[t]{2}{*}{ Foreign 100} & $-0.38^{* *}$ & $-0.47^{* * *}$ & $-0.27+$ & $-0.33^{*}$ & $-0.20^{*}$ & $-0.24^{* *}$ \\
\hline & $(0.13)$ & $(0.14)$ & $(0.14)$ & $(0.14)$ & $(0.08)$ & $(0.08)$ \\
\hline \multirow[t]{2}{*}{ Age } & $-0.11^{* * *}$ & $-0.16^{* * *}$ & $-0.11^{* * *}$ & $-0.16^{* * *}$ & $-0.11^{* * *}$ & $-0.16^{* * *}$ \\
\hline & $(0.02)$ & $(0.02)$ & $(0.02)$ & $(0.02)$ & $(0.02)$ & $(0.02)$ \\
\hline \multirow[t]{2}{*}{ Export } & 0.02 & $0.10^{* *}$ & 0.02 & $0.09^{* *}$ & 0.02 & $0.09 * *$ \\
\hline & $(0.03)$ & $(0.03)$ & $(0.03)$ & $(0.03)$ & $(0.03)$ & $(0.03)$ \\
\hline \multirow[t]{2}{*}{ Labour } & $0.44^{* * *}$ & $0.42 * * *$ & $0.44^{* * *}$ & $0.42^{* * *}$ & $0.44^{* * *}$ & $0.42 * * *$ \\
\hline & $(0.01)$ & $(0.01)$ & $(0.01)$ & $(0.01)$ & $(0.01)$ & $(0.01)$ \\
\hline \multirow[t]{2}{*}{ Size } & $-0.15^{* * *}$ & -0.04 & $-0.15 * * *$ & $-0.06^{*}$ & $-0.15^{* * *}$ & $-0.06+$ \\
\hline & $(0.01)$ & $(0.03)$ & $(0.01)$ & $(0.03)$ & $(0.01)$ & $(0.03)$ \\
\hline \multirow[t]{2}{*}{ Openness } & $0.00+$ & 0.00 & $0.00+$ & 0.00 & 0.00 & 0.00 \\
\hline & $(0.00)$ & $(0.00)$ & $(0.00)$ & $(0.00)$ & $(0.00)$ & $(0.00)$ \\
\hline \multirow[t]{2}{*}{ Kaopen } & -0.01 & -0.03 & -0.02 & -0.03 & 0.00 & -0.00 \\
\hline & $(0.02)$ & $(0.03)$ & $(0.02)$ & $(0.02)$ & $(0.03)$ & $(0.03)$ \\
\hline \multirow[t]{2}{*}{ GDP } & $-0.15^{* *}$ & $-0.15^{* *}$ & $-0.16^{* *}$ & $-0.18^{* * *}$ & $-0.13^{*}$ & $-0.11^{*}$ \\
\hline & $(0.05)$ & $(0.05)$ & $(0.05)$ & $(0.05)$ & $(0.05)$ & $(0.05)$ \\
\hline \multirow[t]{2}{*}{ Growth } & $0.02 * *$ & 0.01 & $0.02 * *$ & 0.01 & $0.02^{* *}$ & $0.02 *$ \\
\hline & $(0.01)$ & $(0.01)$ & $(0.01)$ & $(0.01)$ & $(0.01)$ & $(0.01)$ \\
\hline \multirow[t]{2}{*}{ Interest } & -0.00 & -0.00 & -0.00 & -0.00 & -0.00 & -0.00 \\
\hline & $(0.00)$ & $(0.00)$ & $(0.00)$ & $(0.00)$ & $(0.00)$ & $(0.00)$ \\
\hline \multirow[t]{2}{*}{ Property } & -0.00 & 0.00 & & & & \\
\hline & $(0.00)$ & $(0.00)$ & & & & \\
\hline
\end{tabular}


Continued from previous page

\begin{tabular}{|c|c|c|c|c|c|c|}
\hline CPI & & & $\begin{array}{l}-0.03 \\
(0.04)\end{array}$ & $\begin{array}{l}0.05 \\
(0.04)\end{array}$ & & \\
\hline Polity2 & & & & & $\begin{array}{c}-0.02^{*} \\
(0.01)\end{array}$ & $\begin{array}{c}-0.02^{*} \\
(0.01)\end{array}$ \\
\hline P_Foreign $\times$ Property & $\begin{array}{l}0.00 \\
(0.00)\end{array}$ & $\begin{array}{l}0.00 \\
(0.00)\end{array}$ & & & & \\
\hline Foreign100 $\times$ Property & $\begin{array}{l}0.00 \\
(0.00)\end{array}$ & $\begin{array}{l}0.01+ \\
(0.00)\end{array}$ & & & & \\
\hline P_Foreign $\times$ CPI & & & $\begin{array}{l}0.09^{*} \\
(0.04)\end{array}$ & $\begin{array}{l}0.08^{*} \\
(0.04)\end{array}$ & & \\
\hline Foreign100 × CPI & & & $\begin{array}{l}0.02 \\
(0.04)\end{array}$ & $\begin{array}{l}0.04 \\
(0.04)\end{array}$ & & \\
\hline P_Foreign $\times$ Polity 2 & & & & & $\begin{array}{l}0.00 \\
(0.01)\end{array}$ & $\begin{array}{l}0.00 \\
(0.01)\end{array}$ \\
\hline Foreign100 × Polity 2 & & & & & $\begin{array}{l}0.00 \\
(0.01)\end{array}$ & $\begin{array}{l}0.00 \\
(0.01)\end{array}$ \\
\hline$\lambda$ & & $\begin{array}{l}0.84^{* * *} \\
(0.20)\end{array}$ & & $\begin{array}{l}0.74^{* * *} \\
(0.19)\end{array}$ & & $\begin{array}{l}0.71^{* * * *} \\
(0.21)\end{array}$ \\
\hline Constant & $\begin{array}{l}-0.13 \\
(0.55)\end{array}$ & $\begin{array}{c}-1.46^{*} \\
(0.64)\end{array}$ & $\begin{array}{l}-0.21 \\
(0.55)\end{array}$ & $\begin{array}{c}-1.25^{*} \\
(0.62)\end{array}$ & $\begin{array}{l}-0.71 \\
(0.60)\end{array}$ & $\begin{array}{l}-1.93^{* *} \\
(0.70)\end{array}$ \\
\hline \multicolumn{7}{|c|}{ RANDOM EFFECTS ('UNOBSERVED' EFFECTS) } \\
\hline$\sigma_{P \_ \text {Foreign }}$ & $\begin{array}{l}0.27^{* *} \\
(0.08)\end{array}$ & $\begin{array}{l}0.27^{* *} \\
(0.08)\end{array}$ & $\begin{array}{l}0.25^{* *} \\
(0.08)\end{array}$ & $\begin{array}{l}0.25^{* *} \\
(0.08)\end{array}$ & $\begin{array}{l}0.30^{* *} \\
(0.08)\end{array}$ & $\begin{array}{l}0.29 * * \\
(0.08)\end{array}$ \\
\hline$\sigma_{\text {Foreign } 100}$ & $\begin{array}{l}0.24^{* *} \\
(0.07)\end{array}$ & $\begin{array}{l}0.24^{* *} \\
(0.07)\end{array}$ & $\begin{array}{l}0.23^{* *} \\
(0.07)\end{array}$ & $\begin{array}{l}0.23^{* *} \\
(0.07)\end{array}$ & $\begin{array}{l}0.24^{* *} \\
(0.08)\end{array}$ & $\begin{array}{l}0.23^{* *} \\
(0.08)\end{array}$ \\
\hline$\sigma_{v}$ & $\begin{array}{l}0.32^{* *} \\
(0.03)\end{array}$ & $\begin{array}{l}0.33^{* *} \\
(0.03)\end{array}$ & $\begin{array}{l}0.33^{* *} \\
(0.03)\end{array}$ & $\begin{array}{l}0.33^{* *} \\
(0.03)\end{array}$ & $\begin{array}{l}0.32^{* *} \\
(0.03)\end{array}$ & $\begin{array}{l}0.33^{* *} \\
(0.03)\end{array}$ \\
\hline $\begin{array}{l}\text { Joint LR Chi2 } \\
\text { Joint LR df(6) }\end{array}$ & $\begin{array}{l}454.9 \\
* * *\end{array}$ & $\begin{array}{l}465.1 \\
* * *\end{array}$ & $\begin{array}{l}487.5 \\
* * *\end{array}$ & $\begin{array}{l}496.7 \\
* * *\end{array}$ & $\begin{array}{l}460.3 \\
* * *\end{array}$ & $\begin{array}{l}464.9 \\
* * *\end{array}$ \\
\hline$\rho$ & 0.04 & 0.05 & 0.05 & 0.05 & 0.04 & 0.05 \\
\hline \# of firms & 19978 & 19978 & 20143 & 20143 & 19571 & 19571 \\
\hline \# of countries & 77 & 77 & 76 & 76 & 72 & 72 \\
\hline $\begin{array}{l}\text { In parentheses are stan } \\
\text { All models contain sect } \\
\text { Results for } \overline{\text { Labour }}, \overline{A g}\end{array}$ & $\begin{array}{l}\text { lard err } \\
\overline{\text { Size a }}\end{array}$ & $\begin{array}{l}+p< \\
\text { Foreig }\end{array}$ & $10,{ }^{*} p$ & $0.05, * *$ & $\begin{array}{l}<0.01 \\
\text { quest }\end{array}$ & ${ }^{*} p<0.0$ \\
\hline
\end{tabular}


Figure 5.1: Conditional marginal effects of $P_{-}$Foreign on investment Percentiles defined at the country-level.

Random coefficient models: Table 5.9 Models 2, 4, \& 6

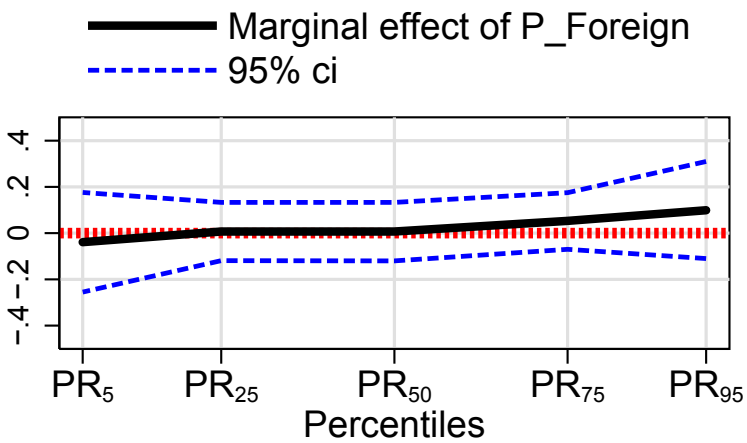

ES \& HF (PR = Property)

Marginal effect of $P_{-}$Foreign

95\% ci

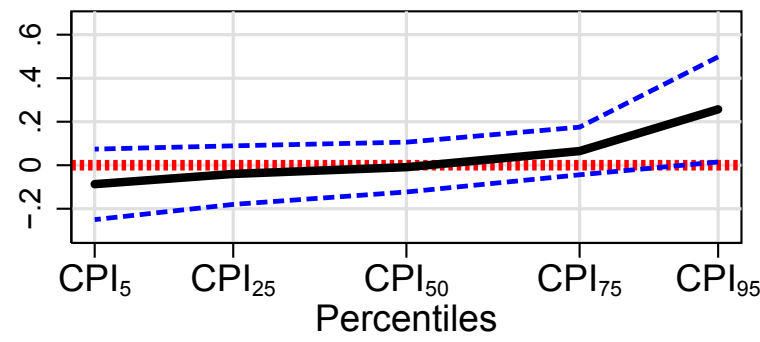

ES \& TI

Marginal effect of $\mathrm{P} \_$Foreign $95 \%$ ci

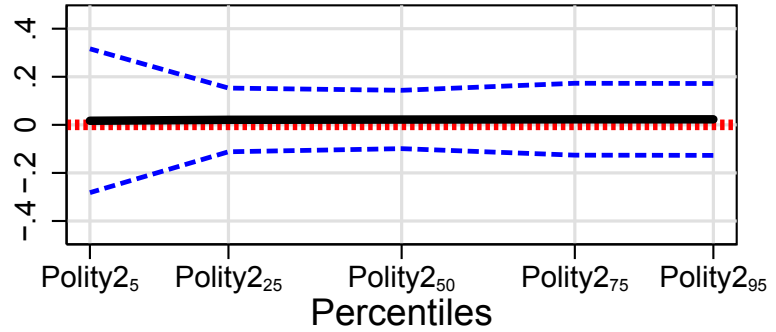

ES \& Polity IV 
Figure 5.2: Conditional marginal effects of Foreign100 on investment Percentiles defined at the country-level.

Random coefficient models: Table 5.9 Models 2, 4, \& 6

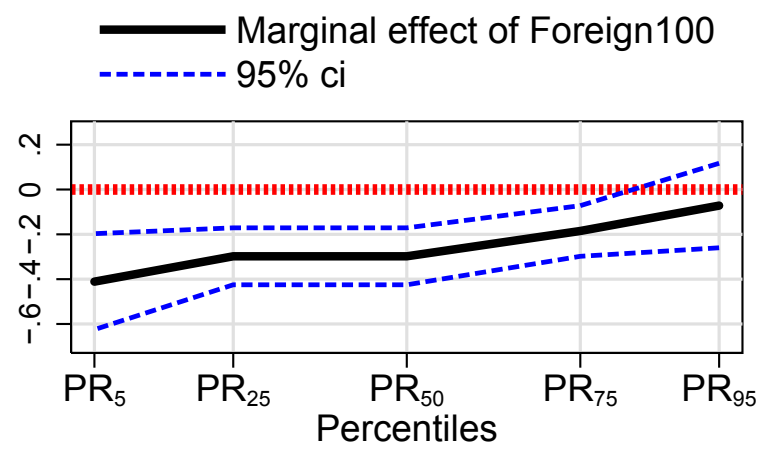

ES \& HF (PR = Property)

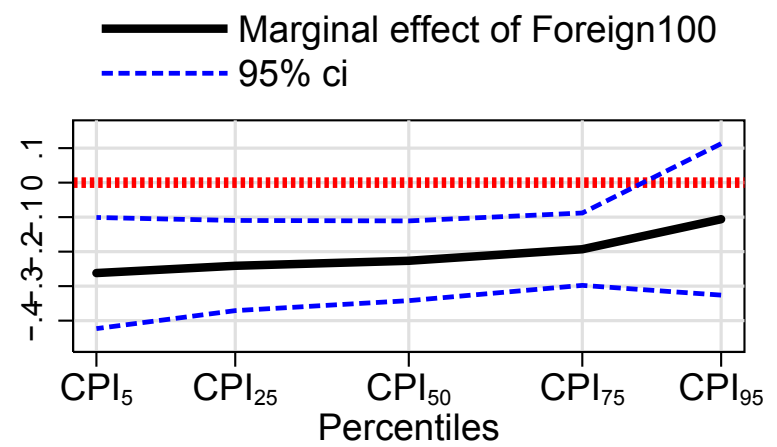

ES \& TI

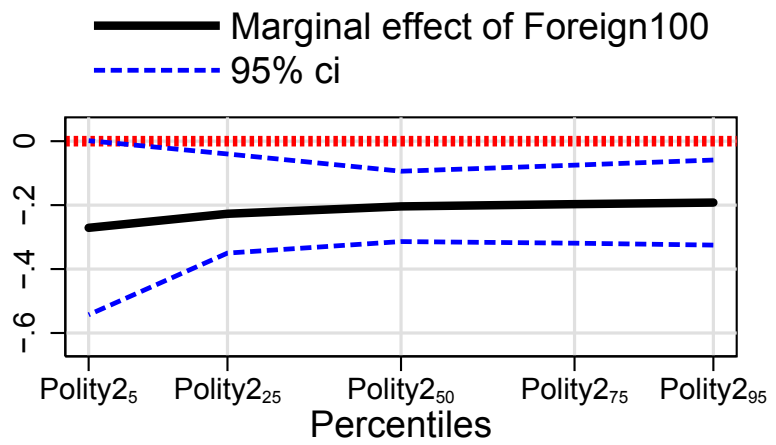

ES \& Polity IV 


\subsection{Conclusion}

In this study we have discussed how uncertainty related to irreversibility of fixed capital in developing countries can hamper investment. In conformity with previous studies on investment in developing countries we find that the high level of noninvestment across firms suggests that irreversibility of fixed capital is a strong obstacle to investment.

We further investigate the role of foreign equity ownership on investment behaviour and find substantial evidence suggesting that there is a negative relation between foreign ownership and firms' level of investment relative to sales. More specifically, we find that, on average, firms that are completely foreign owned invest relatively less in fixed capital. We find weak evidence which suggests that firms that are $100 \%$ foreign owned invest less frequently and we find no such evidence for partially foreign owned firms. This distinction suggests that, under specific conditions, limiting foreign equity ownership could have a beneficial effect on overall investment levels provided that such limitations on ownership do not discourage foreign investors to enter the market and/or limit domestic industry development. Further research is required to outline the specific conditions under which foreign firms invest relatively less than domestically owned firms. Nonetheless, analysis using random-effect models reveals that in a minority of countries there is, on average, a positive relation between foreign equity ownership and investment.

The second major contribution of this study is the identification of the effect of macroeconomic factors and institutions on investment behaviour. We find that such determinants have relatively little explanatory power on the level of firms' investment. In comparison with this result, a country's macroeconomic and institutional context has a relatively higher impact on the probability that a firm invests e.g. in new investment opportunities, replacement capital and/or restructuring. Further research assessing the sensitivity of investment behaviour to a country's macroeconomic environment in specific (innovative) industries would enrich this understanding.

The overall lack of explanatory power of the macroeconomic indicators in our sample of mostly developing countries may indicate that the ability of investors located in these countries in forecasting expected revenues on the basis of macroeconomic signals is low. Moreover, in some countries, markets are highly volatile and therefore macroeconomic indicators can be poor predictors. Regardless of the underlying cause, should this interpretation be correct, positive macroeconomic trends may fail to further stimulate investment behaviour and markets may not be able to act as stabilizers and accelerators or growth. The effectiveness of policy may also be limited in this respect. Darku (2000, pp. 21) states that "the best way out is to ensure more policy credibility and stability that will lead to a reduction in firms' perceived uncertainty".

Further research on the extent to which this pattern may be different in developed economies could provide more insight on the way forward. For example, macroeconomic predictors, such as growth and interest rates (as well as real estate markets and stock markets) are generally considered strong predictors of investors' confidence in developed countries and, as a result, it is possible that the country-level 
effect on firm-level investment is greater in developed countries. Previous research on the determinants of firms' performance suggests the contrary. Hawawini et al. (2004) decompose firm-level, industry, and country effects on firms' performance in six developed countries and find that the country effect is small-smaller than the country-effect documented in this study. Using a broader set of 37 countries, Burstein Goldszmidt et al. (2011) find similar levels of country-effects as documented in our study and the authors argue that the country-level effect on firm performance is larger in emerging economies than in developed economies.

This research has had the ambition to close the gap between a macro approach towards studying investment and a micro approach towards studying investment. We have gained a preliminary understanding on the degree to which micro and macro evidence on investment behaviour is complementary; e.g. in suggesting that control of corruption is positively related to (the probability of) investment. The extent to which the negative effect of political economy on firms' investment levels is robust and/or can be explained using a theoretical model may require further exploration. Moreover, the inability of this study to explore investment dynamics has been a major limitation. Our application of a multilevel, cross-country investment model can be extended with the exploration of the dynamic relation between a firm's past investment behaviour and firms' outlook on future investment. As a result of firm-level heterogeneity we expect that such research avenues will be an important development towards better understanding investment behaviour. 


\subsection{Appendix 5A}

Table 5.7: Countries and Number of Firms

\begin{tabular}{|c|c|c|c|c|c|c|c|c|c|c|c|}
\hline $\begin{array}{l}\vec{Z} \\
\underset{\Xi}{\Xi} \\
0 \\
\circlearrowright\end{array}$ & 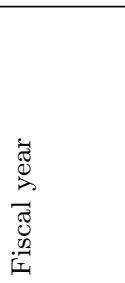 & 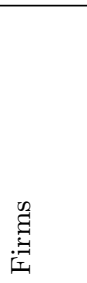 & 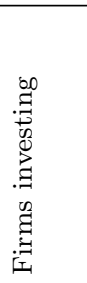 & 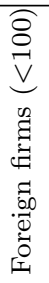 & 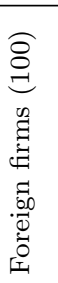 & 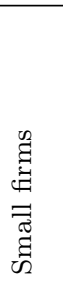 & 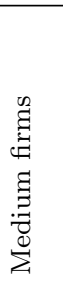 & 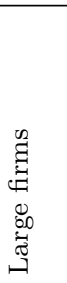 & 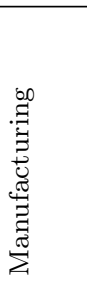 & 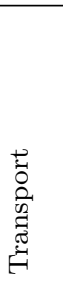 & 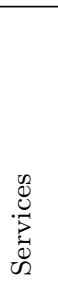 \\
\hline Afghanistan & 2007 & 356 & 142 & 15 & 1 & 242 & 94 & 20 & 91 & 110 & 155 \\
\hline Albania & 2006 & 157 & 91 & 10 & 15 & 91 & 55 & 11 & 54 & 19 & 84 \\
\hline Angola & $2005 / 09$ & 685 & 265 & 95 & 35 & 498 & 150 & 37 & 376 & 21 & 288 \\
\hline Argentina & $2005 / 09$ & 1,627 & 1,110 & 90 & 152 & 514 & 648 & 465 & 1,175 & 39 & 413 \\
\hline Armenia & 2007 & 238 & 120 & 17 & 7 & 133 & 72 & 33 & 83 & 23 & 132 \\
\hline Azerbaijan & 2007 & 306 & 102 & 22 & 14 & 156 & 107 & 43 & 89 & 27 & 190 \\
\hline Bangladesh & 2006 & 1,475 & 699 & 18 & 18 & 474 & 427 & 574 & 1,251 & 75 & 149 \\
\hline Belarus & 2007 & 164 & 111 & 14 & 3 & 48 & 64 & 52 & 65 & 9 & 90 \\
\hline Benin & 2008 & 71 & 35 & 7 & 5 & 43 & 20 & 8 & 27 & 5 & 39 \\
\hline Bhutan & 2008 & 237 & 112 & 2 & 12 & 119 & 91 & 27 & 84 & 59 & 94 \\
\hline Bolivia & 2005/09 & 594 & 362 & 54 & 35 & 292 & 209 & 93 & 342 & 39 & 213 \\
\hline Bosnia and & 2007 & 238 & 174 & 16 & 4 & 87 & 91 & 60 & 90 & 30 & 118 \\
\hline \multicolumn{12}{|l|}{ Herzegovina } \\
\hline Botswana & $2005 / 09$ & 528 & 308 & 79 & 166 & 303 & 157 & 68 & 210 & 51 & 267 \\
\hline Brazil & 2007 & 1,032 & 705 & 35 & 30 & 373 & 422 & 237 & 786 & 14 & 232 \\
\hline Bulgaria & $2006 / 07$ & 1,018 & 603 & 57 & 59 & 401 & 400 & 217 & 834 & 110 & 74 \\
\hline Burkina Faso & 2008 & 262 & 134 & 22 & 12 & 159 & 70 & 33 & 73 & 32 & 157 \\
\hline Burundi & 2005 & 268 & 153 & 6 & 41 & 221 & 41 & 6 & 139 & 12 & 117 \\
\hline Cameroon & 2008 & 299 & 146 & 33 & 21 & 128 & 109 & 62 & 96 & 12 & 191 \\
\hline Cape Verde & 2008 & 106 & 59 & 13 & 7 & 47 & 46 & 13 & 40 & 15 & 51 \\
\hline Chad & 2008 & 111 & 71 & 14 & 17 & 61 & 37 & 13 & 41 & 14 & 56 \\
\hline Chile & $2005 / 09$ & 1,600 & 1,105 & 68 & 87 & 483 & 689 & 428 & 1,152 & 34 & 414 \\
\hline Colombia & $2005 / 09$ & 1,696 & 943 & 70 & 40 & 787 & 596 & 313 & 1,189 & 89 & 418 \\
\hline Costa Rica & 2009 & 352 & 230 & 12 & 44 & 129 & 147 & 76 & 222 & 4 & 126 \\
\hline Cote d'Ivoire & 2007 & 345 & 142 & 23 & 40 & 218 & 91 & 36 & 137 & 11 & 197 \\
\hline Croatia & 2006 & 454 & 352 & 34 & 18 & 168 & 158 & 128 & 310 & 24 & 120 \\
\hline Czech Republic & 2007 & 160 & 127 & 16 & 13 & 53 & 65 & 42 & 68 & 15 & 77 \\
\hline Congo, DR & $2005 / 09$ & 542 & 250 & 33 & 64 & 401 & 109 & 32 & 273 & 25 & 244 \\
\hline Dominican & 2009 & 305 & 139 & 22 & 31 & 95 & 113 & 97 & 103 & 13 & 189 \\
\hline \multicolumn{12}{|l|}{ Republic } \\
\hline Ecuador & $2005 / 09$ & 800 & 507 & 61 & 74 & 319 & 311 & 170 & 402 & 23 & 375 \\
\hline El Salvador & $2005 / 09$ & 789 & 439 & 57 & 62 & 305 & 293 & 191 & 469 & 39 & 281 \\
\hline Eritrea & 2008 & 92 & 16 & 2 & 3 & 59 & 28 & 5 & 51 & 2 & 39 \\
\hline Estonia & 2007 & 204 & 154 & 12 & 27 & 74 & 74 & 56 & 71 & 30 & 103 \\
\hline Ethiopia & 2010 & 363 & 144 & 5 & 11 & 181 & 120 & 62 & 363 & 0 & 0 \\
\hline Fiji & 2008 & 73 & 45 & 10 & 6 & 39 & 28 & 6 & 18 & 5 & 50 \\
\hline Gambia, the & 2005 & 165 & 104 & 20 & 31 & 113 & 47 & 5 & 62 & 12 & 91 \\
\hline Georgia & 2007 & 223 & 94 & 10 & 4 & 110 & 83 & 30 & 78 & 40 & 105 \\
\hline Ghana & 2006 & 491 & 228 & 12 & 13 & 368 & 93 & 30 & 289 & 1 & 201 \\
\hline Guatemala & $2005 / 09$ & 811 & 439 & 37 & 61 & 304 & 293 & 214 & 513 & 44 & 254 \\
\hline Guinea & 2005 & 220 & 122 & 8 & 16 & 196 & 18 & 6 & 134 & 7 & 79 \\
\hline Guinea-Bissau & 2005 & 154 & 60 & 5 & 10 & 136 & 17 & 1 & 77 & 5 & 72 \\
\hline Honduras & $2005 / 09$ & 520 & 207 & 32 & 30 & 256 & 162 & 102 & 288 & 48 & 184 \\
\hline
\end{tabular}

Continued on next page 
Continued from previous page

\begin{tabular}{|c|c|c|c|c|c|c|c|c|c|c|c|}
\hline Hungary & 2007 & 252 & 120 & 23 & 29 & 78 & 88 & 86 & 99 & 25 & 128 \\
\hline Indonesia & 2008 & 1,028 & 285 & 28 & 47 & 593 & 242 & 193 & 824 & 20 & 184 \\
\hline Iraq & 2010 & 641 & 234 & 1 & 7 & 509 & 127 & 5 & 403 & 40 & 198 \\
\hline Jamaica & 2009 & 245 & 86 & 19 & 8 & 113 & 106 & 26 & 87 & 8 & 150 \\
\hline Kazakhstan & 2007 & 382 & 188 & 14 & 6 & 115 & 163 & 104 & 135 & 52 & 195 \\
\hline Kenya & 2006 & 630 & 363 & 29 & 50 & 289 & 213 & 128 & 392 & 54 & 184 \\
\hline Kosovo & 2007 & 130 & 68 & 0 & 0 & 93 & 31 & 6 & 45 & 16 & 69 \\
\hline Kyrgyz & 2007 & 164 & 60 & 19 & 8 & 71 & 71 & 22 & 74 & 20 & 70 \\
\hline \multicolumn{12}{|l|}{ Republic } \\
\hline Laos & 2007 & 353 & 87 & 20 & 43 & 165 & 123 & 65 & 142 & 13 & 198 \\
\hline Latvia & 2007 & 206 & 178 & 20 & 26 & 67 & 65 & 74 & 69 & 24 & 113 \\
\hline Lithuania & 2007 & 190 & 151 & 7 & 16 & 70 & 68 & 52 & 70 & 23 & 97 \\
\hline Macedonia & 2007 & 272 & 191 & 26 & 13 & 102 & 117 & 53 & 96 & 41 & 135 \\
\hline Madagascar & 2007 & 326 & 154 & 50 & 83 & 126 & 144 & 56 & 156 & 21 & 149 \\
\hline Malawi & 2008 & 121 & 81 & 11 & 26 & 39 & 41 & 41 & 53 & 10 & 58 \\
\hline Mali & 2006/09 & 574 & 224 & 20 & 20 & 476 & 90 & 8 & 329 & 11 & 234 \\
\hline Mauritania & 2005 & 227 & 81 & 18 & 8 & 182 & 40 & 5 & 123 & 12 & 92 \\
\hline Mauritius & 2007 & 299 & 182 & 14 & 23 & 145 & 111 & 43 & 140 & 14 & 145 \\
\hline Mexico & 2005/09 & 2,464 & 1,011 & 128 & 104 & 1016 & 771 & 677 & 1,980 & 41 & 443 \\
\hline Micronesia & 2007 & 52 & 31 & 7 & 4 & 36 & 16 & 0 & 9 & 3 & 40 \\
\hline Moldova & 2007 & 295 & 175 & 24 & 11 & 106 & 122 & 67 & 94 & 32 & 169 \\
\hline Mongolia & 2007 & 316 & 198 & 14 & 7 & 138 & 121 & 57 & 114 & 51 & 151 \\
\hline Montenegro & 2007 & 69 & 50 & 2 & 2 & 32 & 26 & 11 & 24 & 3 & 42 \\
\hline Mozambique & 2006 & 471 & 155 & 26 & 64 & 307 & 141 & 23 & 335 & 6 & 130 \\
\hline Namibia & 2005 & 314 & 168 & 19 & 52 & 221 & 78 & 15 & 145 & 11 & 158 \\
\hline Nepal & 2008 & 341 & 145 & 11 & 3 & 182 & 130 & 29 & 118 & 1 & 222 \\
\hline Nicaragua & $2005 / 09$ & 516 & 191 & 22 & 26 & 302 & 165 & 49 & 344 & 16 & 156 \\
\hline Niger & 2008 & 78 & 39 & 9 & 8 & 51 & 22 & 5 & 21 & 2 & 55 \\
\hline Panama & 2005/09 & 511 & 239 & 20 & 39 & 287 & 163 & 61 & 249 & 78 & 184 \\
\hline Paraguay & $2005 / 09$ & 587 & 365 & 33 & 33 & 259 & 254 & 74 & 328 & 31 & 228 \\
\hline Peru & $2005 / 09$ & 1,301 & 869 & 101 & 68 & 475 & 506 & 320 & 887 & 22 & 392 \\
\hline Philippines & 2008 & 909 & 338 & 138 & 95 & 297 & 411 & 201 & 665 & 18 & 226 \\
\hline Poland & 2007 & 210 & 125 & 7 & 14 & 97 & 61 & 52 & 77 & 25 & 108 \\
\hline Romania & 2007 & 253 & 178 & 20 & 18 & 81 & 82 & 90 & 91 & 30 & 132 \\
\hline Russia & 2007 & 609 & 424 & 23 & 15 & 145 & 232 & 232 & 431 & 33 & 145 \\
\hline Rwanda & $2005 / 10$ & 289 & 119 & 16 & 34 & 195 & 79 & 15 & 146 & 8 & 135 \\
\hline Samoa & 2008 & 63 & 38 & 10 & 6 & 45 & 15 & 3 & 16 & 5 & 42 \\
\hline Senegal & 2006 & 505 & 141 & 20 & 11 & 418 & 66 & 21 & 259 & 3 & 243 \\
\hline Serbia & 2007 & 329 & 227 & 25 & 22 & 110 & 109 & 110 & 123 & 39 & 167 \\
\hline Slovakia & 2007 & 162 & 119 & 13 & 10 & 52 & 56 & 54 & 56 & 23 & 83 \\
\hline Slovenia & 2007 & 242 & 216 & 21 & 19 & 92 & 74 & 76 & 90 & 35 & 117 \\
\hline South Africa & 2006 & 936 & 388 & 40 & 81 & 373 & 371 & 192 & 680 & 15 & 241 \\
\hline Sri Lanka & 2010 & 497 & 135 & 18 & 5 & 272 & 141 & 84 & 275 & 1 & 221 \\
\hline Swaziland & 2005 & 288 & 158 & 14 & 91 & 205 & 54 & 29 & 101 & 31 & 156 \\
\hline Tajikistan & 2007 & 244 & 88 & 19 & 2 & 120 & 83 & 41 & 83 & 39 & 122 \\
\hline Tanzania & 2005 & 407 & 205 & 23 & 27 & 268 & 104 & 35 & 277 & 16 & 114 \\
\hline Timor Leste & 2008 & 103 & 66 & 0 & 16 & 77 & 26 & 0 & 49 & 19 & 35 \\
\hline Togo & 2008 & 109 & 50 & 14 & 26 & 67 & 28 & 14 & 22 & 13 & 74 \\
\hline Tonga & 2008 & 133 & 69 & 21 & 2 & 118 & 15 & 0 & 50 & 1 & 82 \\
\hline $\begin{array}{l}\text { Trinidad and } \\
\text { Tobago }\end{array}$ & 2009 & 294 & 95 & 32 & 9 & 134 & 83 & 77 & 101 & 22 & 171 \\
\hline Turkey & 2007 & 789 & 440 & 27 & 5 & 233 & 302 & 254 & 628 & 6 & 155 \\
\hline Uganda & 2005 & 550 & 221 & 27 & 65 & 373 & 145 & 32 & 334 & 22 & 194 \\
\hline Ukraine & 2007 & 488 & 249 & 30 & 5 & 193 & 179 & 116 & 339 & 20 & 129 \\
\hline Uruguay & 2005/09 & 788 & 479 & 42 & 63 & 314 & 304 & 170 & 465 & 43 & 280 \\
\hline Uzbekistan & 2007 & 336 & 116 & 42 & 6 & 117 & 133 & 86 & 111 & 36 & 189 \\
\hline
\end{tabular}

Continued on next page 
Continued from previous page

\begin{tabular}{|c|c|c|c|c|c|c|c|c|c|c|c|}
\hline Vanuatu & 2008 & 92 & 69 & 11 & 24 & 58 & 34 & 0 & 7 & 19 & 66 \\
\hline Venezuela & 2009 & 137 & 55 & 6 & 14 & 58 & 51 & 28 & 54 & 2 & 81 \\
\hline Vietnam & 2008 & 927 & 631 & 45 & 86 & 221 & 370 & 336 & 693 & 52 & 182 \\
\hline Yemen & 2009 & 276 & 116 & 10 & 0 & 178 & 72 & 26 & 150 & 1 & 125 \\
\hline Zambia & 2006 & 479 & 185 & 38 & 78 & 270 & 146 & 63 & 301 & 4 & 174 \\
\hline Zimbabwe & 2010 & 550 & 193 & 84 & 6 & 215 & 202 & 133 & 301 & 14 & 235 \\
\hline Total & & 45,4 & 23,65 & 2,739 & 3,028 & 21,225 & 515,228 & 89,027 & 27,075 & 52,483 & 15,92 \\
\hline $\begin{array}{l}\text { Small firm } \\
\text { and large } \\
\text { Manufactu } \\
\text { chemicals } \\
\text { Transport } \\
\text { Services in }\end{array}$ & $\begin{array}{l}5-19 \\
00 \text { or } \\
\text { clude } \\
\text { arma } \\
\text { es cor }\end{array}$ & $\begin{array}{l}\text { mane } \\
\text { re pe } \\
\text { ather } \\
\text { icals, } \\
\text { uctior } \\
\text { d wh }\end{array}$ & $\begin{array}{l}\text { emp } \\
\text { zaner } \\
\text { garme } \\
\text { nd ot } \\
\text { ind tr } \\
\text { sale }\end{array}$ & $\begin{array}{l}\text { yees, } \\
\text { emplo } \\
\text { ts, tex } \\
\text { er mar } \\
\text { nsport } \\
\text { ade, ho }\end{array}$ & $\begin{array}{l}\text { nedium } \\
\text { yees. } \\
\text { tiles, fo } \\
\text { iufactu } \\
\text { ation. } \\
\text { otels, } r\end{array}$ & $\begin{array}{l}o d, m \\
\text { ing } i\end{array}$ & $\begin{array}{l}\text { tals an } \\
\text { dustries }\end{array}$ & $\begin{array}{l}d \text { mach } \\
\text { s. } \\
d \text { other }\end{array}$ & inery, & & \\
\hline
\end{tabular}

Table 5.8: Definition of firm-level variables

\begin{tabular}{|c|c|}
\hline $\begin{array}{l}\text { Corresponding } \\
\text { variable }\end{array}$ & Data description \\
\hline Investment & $\begin{array}{l}\text { Total annual expenditure for purchases of equipment and machinery in last } \\
\text { fiscal year } \\
\text { Total annual sales in last fiscal year }\end{array}$ \\
\hline Foreign & $\begin{array}{l}\text { Individuals, companies or organizations that are privately owned and have } \\
10 \% \text { or more foreign equity ownership }\end{array}$ \\
\hline P_Foreign & $\begin{array}{l}\text { Individuals, companies or organizations that are privately owned and are } \\
\text { partially foreign owned }\end{array}$ \\
\hline Foreign 100 & $\begin{array}{l}\text { Individuals, companies or organizations that are privately owned and that are } \\
100 \% \text { foreign owned }\end{array}$ \\
\hline Labour & $\begin{array}{l}\text { Total labor cost (including wages, salaries, bonuses, etc.) in last fiscal year } \\
\text { Total annual sales in last fiscal year }\end{array}$ \\
\hline Age & In what year did this establishment begin operations in this country? \\
\hline Export & $\begin{array}{l}\text { The percentage of the establishment's sales that were: national sales/direct } \\
\text { exports/indirect exports }\end{array}$ \\
\hline Size & $\begin{array}{l}\text { Number of permanent, full-time employees of this firm at the end of last fiscal } \\
\text { year }\end{array}$ \\
\hline Land & How much of an obstacle is access to land to the operations of this firm? \\
\hline Finance & How much of an obstacle is access to finance to the operations of this firm? \\
\hline Competitor & $\begin{array}{l}\text { How much of an obstacle are the informal sector competitors to your } \\
\text { operations? }\end{array}$ \\
\hline Sector & $\begin{array}{l}\text { Industrial sector classification recoded to (1) leather, garments and textiles, } \\
\text { (2) food, (3), metals and machinery, (4) chemicals and pharmaceuticals, (5) } \\
\text { other manufacturing, (6) retail and wholesale trade, ( } 7) \text { hotels, restaurants } \\
\text { and other services, and (8) construction and transportation }\end{array}$ \\
\hline$K$ & Net book value of machinery vehicles, and equipment in last fiscal year \\
\hline
\end{tabular}


Figure 5.3: Histograms of the Distribution of Investment to Sales

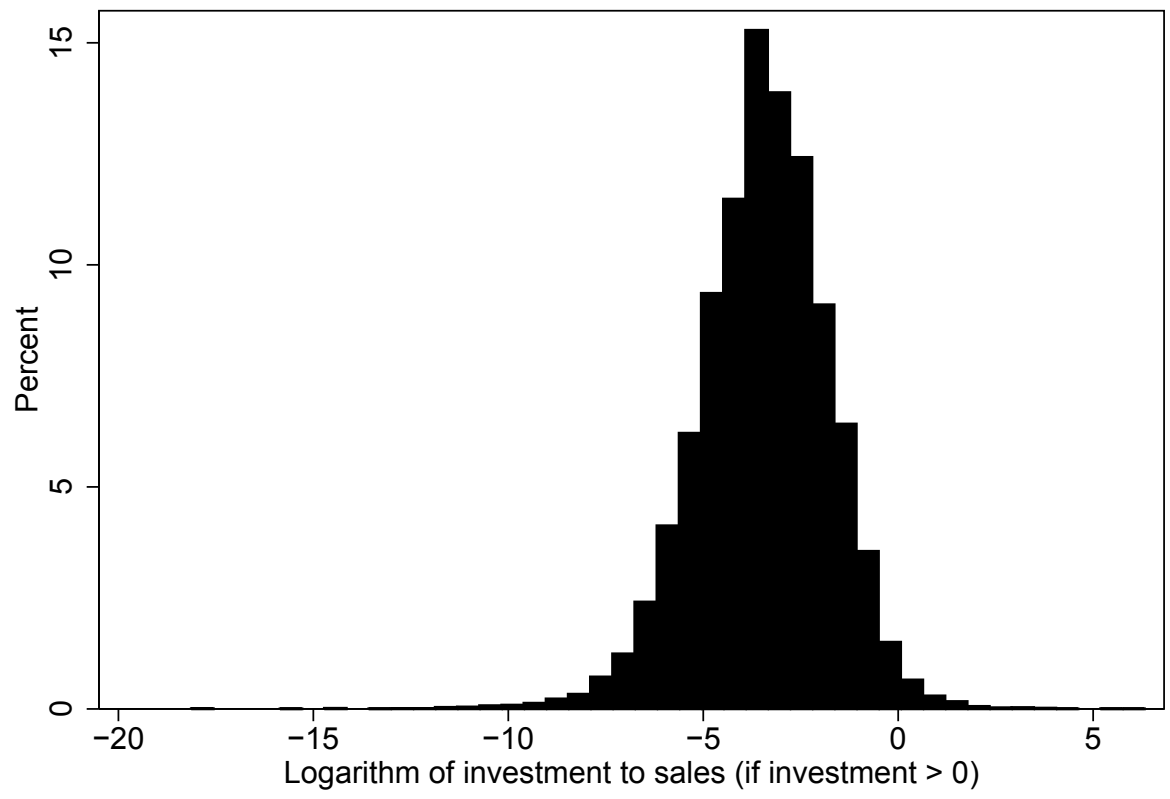

Sources: ES

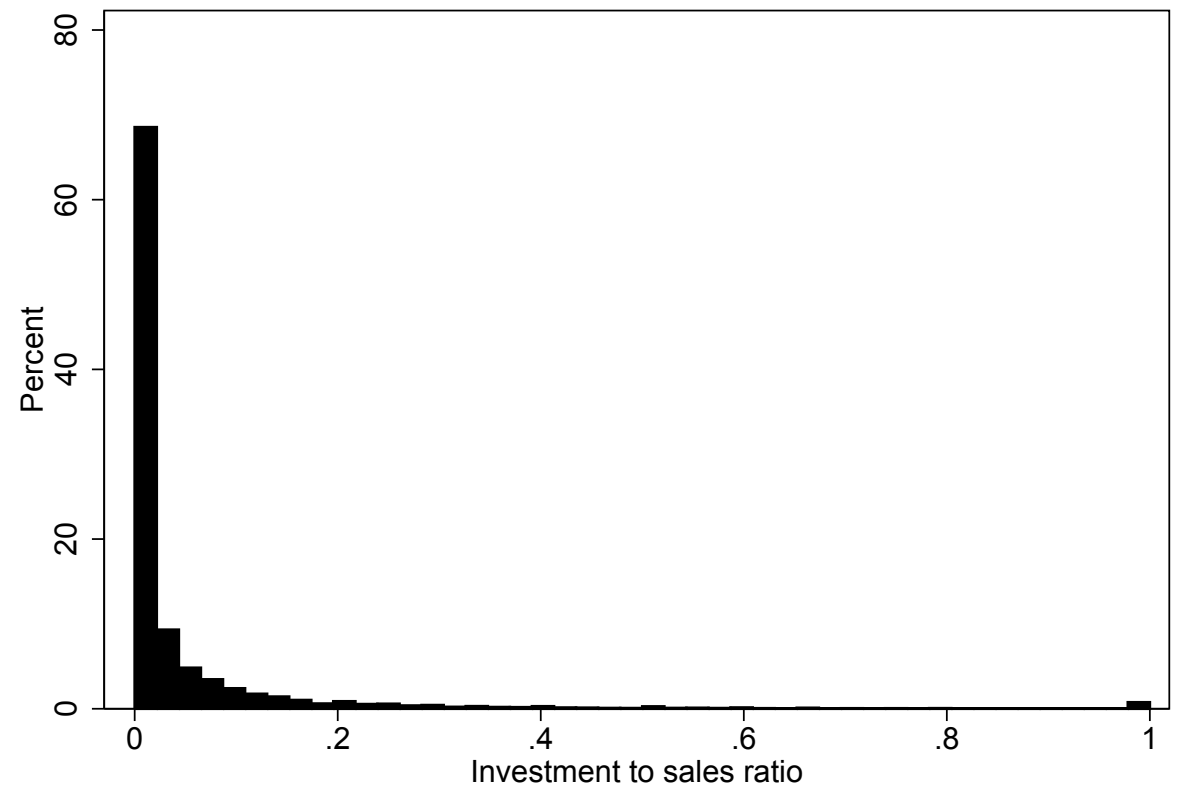

Sources: ES 
Figure 5.4: Histogram of the Distribution of Foreign Ownership

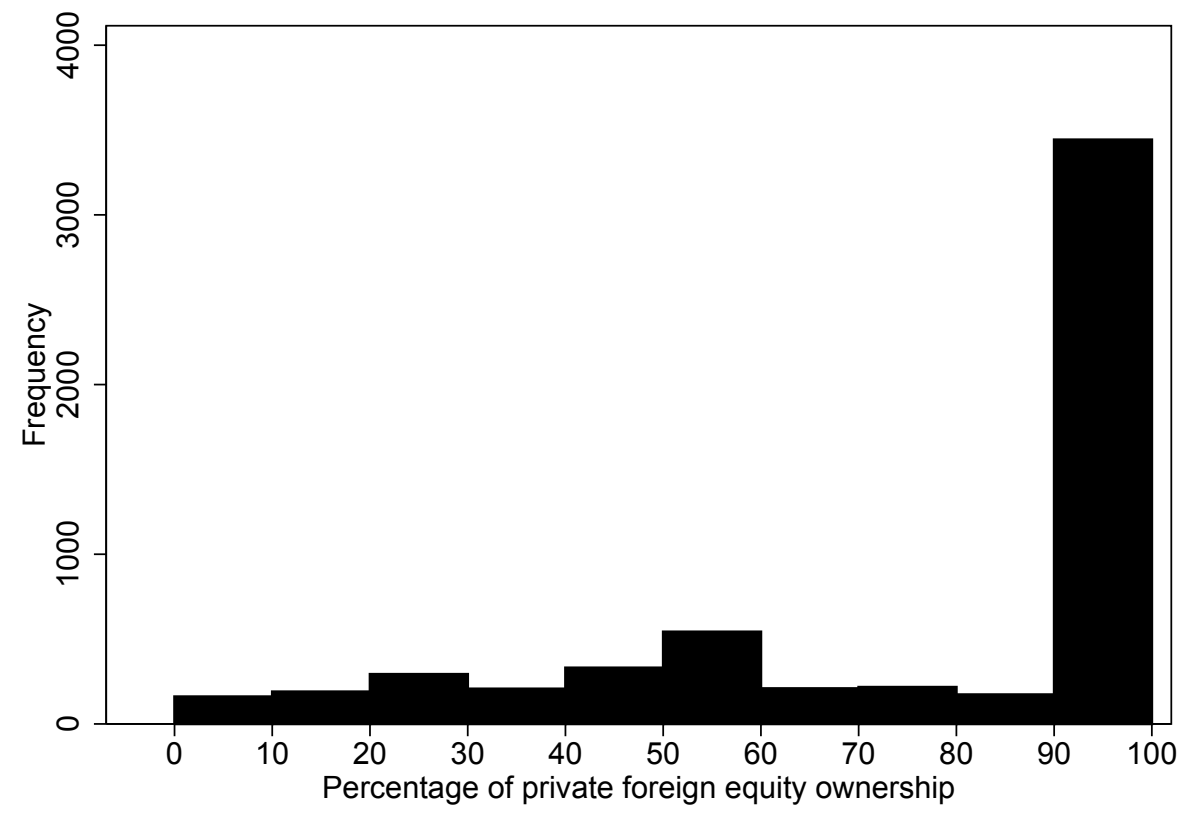

Sources: ES 
Figure 5.5: Histograms of the Distribution of $\widehat{\delta}_{1 j}, \widehat{\delta}_{2 j}$, and $\widehat{v}_{j}$ Random coefficient model: Table 5.9 Model 2
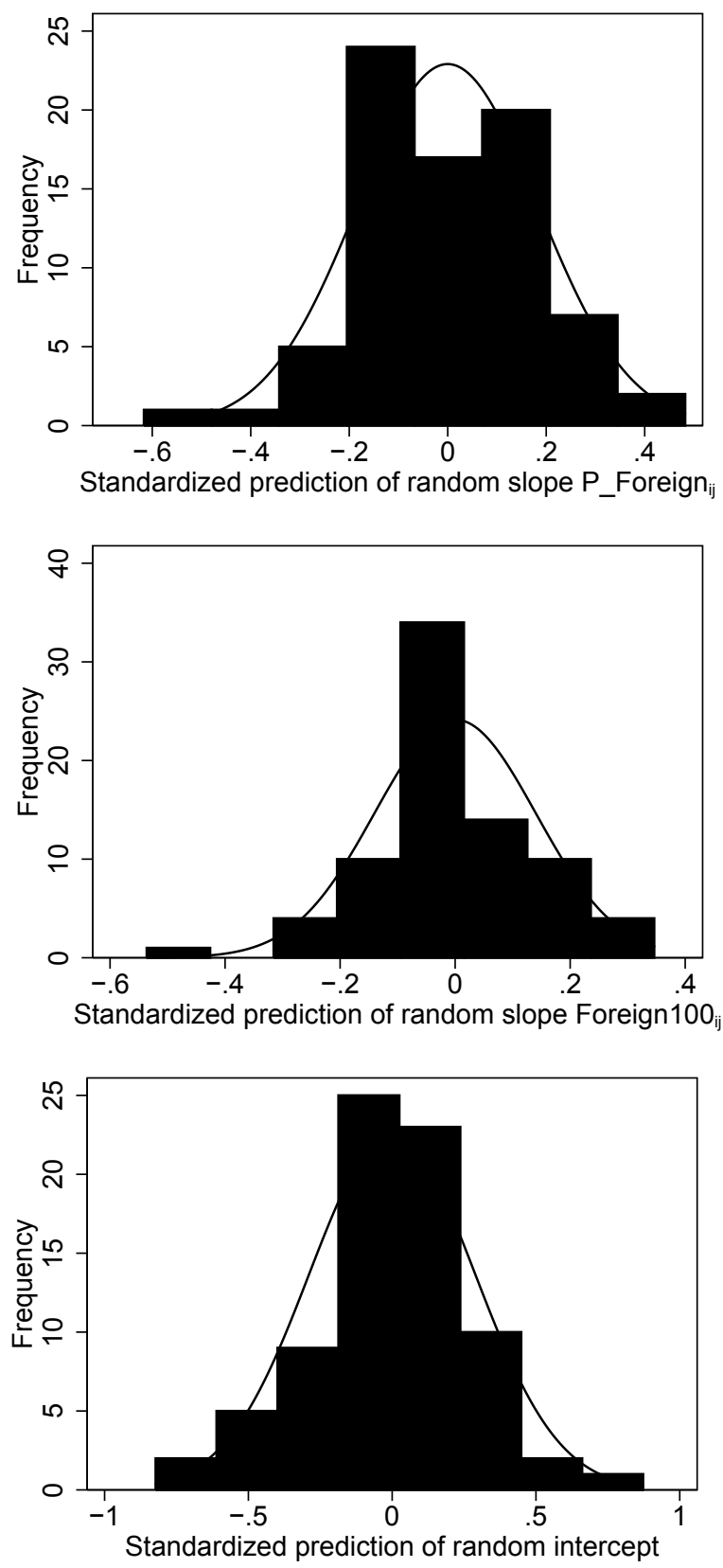


\subsection{Appendix 5B}

\section{Robustness Analysis for the Dependent Variable}

This appendix presents the results of a sensitivity analysis that explores the effect of using alternative dependent variables to capture the determinants of investment behaviour (and/or aspects thereof). These results are comparable to the results of the probit and outcome model that are presented in models 1 and 3 of Table 5.1. First, Model 2 of Table 5.9 presents the results using the natural logarithm of the ratio of investment to labour costs $(\ln (I /$ Labour $))$ as the dependent variable. Both the probit selection model and the outcome model (model 1-2) do not include Labour as an explanatory variable. Second, model 4 uses the natural logarithm of the ratio of investment to capital $(\ln (I / K))$ as the dependent variable. Capital $(K)$ is a measure of firms' net book value of machinery vehicles, and equipment. In terms of definition this dependent variable is a preferred measure of investment. However, as a result of missing observations for $K$, the probit selection model 3 and the outcome model 4 exclude the following countries in the analysis: Benin, Bhutan, Cape Verde, Chad, Eritrea, Fiji, Malawi, Micronesia, Niger, Samoa, Timor Leste, Togo, Tonga, and Vanuatu. Moreover, missing observations reduce the sample used in the outcome model to 11,646 firms. Finally, model 6 uses the natural logarithm of investment $(\ln (I))$ as the dependent variable. The natural logarithm of sales (Sales) is included as an explanatory variable in both the probit selection model 5 and the outcome model 6 . Investment and sales is converted from local currency to US dollar amounts using annual average official exchange rates from the World Bank, WDI. This Heckman selection model excludes observations for the countries Ecuador (for 2009 only), Kosovo, Slovenia, Uzbekistan, and Zimbabwe because of missing data on exchange rates.

We find no systematic differences between the probit selection models 1 and 3 presented in Table 5.9 with respect to the results presented in Table 5.1. In model 5 however, the coefficient of $P_{-}$Foreign is negative but this coefficient remains insignificant. The coefficient of Foreign 100 turns significant and remains negative. And, the coefficient of Labour turns positive and remains significant. These differences in the results are likely to be the effect of including Sales in the model. The coefficient of Sales is significant and positive.

We proceed by examining the differences between models 2, 4, and 6 of Table 5.9 with respect to model 3 of Table 5.1. The results of the outcome models $(2,4$, and 6 ) show that the coefficients of $\lambda$ are not significant; these Heckman selection models are not successful in controlling for selection bias. Because a large number of firms are omitted in model 4 it is not surprising that the coefficient of $\lambda$ (of model 4 ) is not significant. Another difference is that the coefficient of $\lambda$ in model 2 has a negative sign. 
Table 5.9: Probit and outcome random-intercept models models using alternative dependent variables

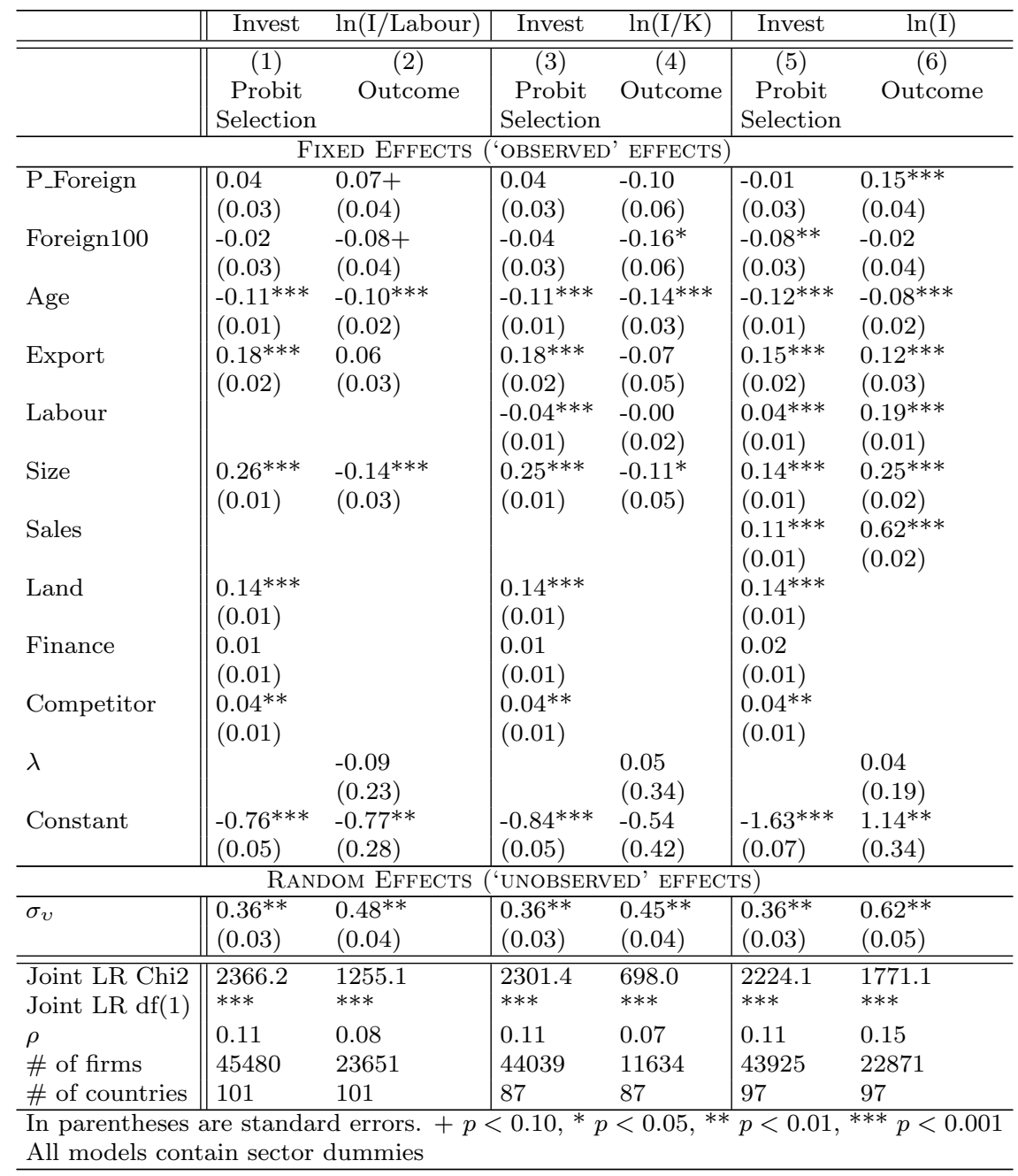

The results displayed in Table 5.9 provide some evidence suggesting a positive effect of acquiring a foreign partner on investment. Following model 2 and 6 the coefficient of Foreign_P is positive and significant; in model 4 this coefficient is negative but insignificant. The coefficient of Foreign 100 is negative in models 2, 4 , and 6 but is only significant in models 2 and 4 . The result presented in model 2 suggests that firms that are completely foreign owned invest more in labour (in terms of wages) relative to fixed capital. Overall, the results support the findings presented in Table 5.1 that suggest that firms that are completely foreign owned invest relatively less in fixed capital formation. Some additional notable differences are that the coefficients of Export and Labour are negative but not significant following model 
4 and the coefficient of Size is positive and significant in model 6 . For the outcome models, the $\rho$ are higher than 0.06 (which is observed in model 3 of Table 5.1). In particular, analysis using the natural logarithm of investment as the dependent variables (model 6 ) yields a $\rho$ of 0.15 . One possibility is that this result is sensitive to the exchange rate conversion.

\section{Robustness Analysis for Partial Foreign Equity Ownership}

In this section we present the results of additional experimentation with the measurement of foreign equity ownership. Specifically, we build on the analysis of Table 5.1 models 1 and 3 and use a set of dummies that identifies firms with different levels of partial foreign ownership using separate categories: firms with less than $50 \%$ foreign ownership (Partial - 50: 1,182 firms) and firms with 50\% or more than 50\% foreign ownership but not 100\% foreign ownership (Partial $+50: 1,557$ firms). We also control for the effect of Foreign 100 on investment. These results are presented in Table 5.10.

When using this set of dummy variables we find no effect of foreign equity ownership on the probability of investment (model 1). Moreover, the coefficients of Partial -50 and Partial +50 are also insignificant following the outcome model (model 2). Albeit insignificant, the coefficient of Partial - 50 is positive and the coefficient of Partial +50 is negative. Still, we find no significant evidence which suggest that there is a non-linear relation between partial foreign equity ownership and investment. In agreement with the results previously discussed, there is a negative relation between Foreign 100 and firms' investment to sales ratio.

Table 5.10: Probit and outcome random-intercept models models using an alternative measure for partial foreign ownership

\begin{tabular}{|c|c|c|}
\hline & $\begin{array}{l}(1) \\
\text { Probit } \\
\text { Selection }\end{array}$ & $\begin{array}{l}(2) \\
\text { Outcome }\end{array}$ \\
\hline \multicolumn{3}{|c|}{ FIXED EFFECTS ('OBSERVED' EFFECTS) } \\
\hline Partial-50 & $\begin{array}{l}0.02 \\
(0.04)\end{array}$ & $\begin{array}{l}0.08 \\
(0.06)\end{array}$ \\
\hline Partial +50 & $\begin{array}{l}0.06 \\
(0.04)\end{array}$ & $\begin{array}{l}-0.03 \\
(0.05)\end{array}$ \\
\hline Foreign 100 & $\begin{array}{l}-0.03 \\
(0.03)\end{array}$ & $\begin{array}{l}-0.21^{* * *} \\
(0.04)\end{array}$ \\
\hline Age & $\begin{array}{l}-0.11^{* * *} \\
(0.01)\end{array}$ & $\begin{array}{l}-0.15^{* * *} \\
(0.02)\end{array}$ \\
\hline Export & $\begin{array}{l}0.17^{* * *} \\
(0.02)\end{array}$ & $\begin{array}{l}0.07^{*} \\
(0.03)\end{array}$ \\
\hline Labour & $\begin{array}{l}-0.04^{* * *} \\
(0.01)\end{array}$ & $\begin{array}{l}0.44^{* * *} \\
(0.01)\end{array}$ \\
\hline Size & $\begin{array}{l}0.25^{* * *} \\
(0.01)\end{array}$ & $\begin{array}{l}-0.10^{* *} \\
(0.03)\end{array}$ \\
\hline Land & $\begin{array}{l}0.14^{* * *} \\
(0.01)\end{array}$ & \\
\hline Finance & $\begin{array}{l}0.01 \\
(0.01)\end{array}$ & \\
\hline Competitor & $0.04^{* *}$ & \\
\hline
\end{tabular}




\begin{tabular}{|c|c|c|}
\hline \multicolumn{3}{|c|}{$(0.01)$} \\
\hline$\lambda$ & & $\begin{array}{l}0.41^{*} \\
(0.21)\end{array}$ \\
\hline Constant & $\begin{array}{l}-0.82^{* * *} \\
(0.05)\end{array}$ & $\begin{array}{l}-2.12^{* * *} \\
(0.26)\end{array}$ \\
\hline \multicolumn{3}{|c|}{ RANDOM EFFECTS ('UNOBSERVED' EFFECTS) } \\
\hline$\sigma_{v}$ & $\begin{array}{l}0.36^{* *} \\
(0.03)\end{array}$ & $\begin{array}{l}0.38^{* *} \\
(0.03)\end{array}$ \\
\hline Joint LR Chi2 & 2388.8 & 916.6 \\
\hline Joint LR df(1) & $* * *$ & $* * *$ \\
\hline$\rho$ & 0.12 & 0.06 \\
\hline \# of firms & 45480 & 23651 \\
\hline countries & 101 & 101 \\
\hline
\end{tabular}

\section{Regression Analysis by Sector}

Variations in investment behaviour are partly attributable to industry and sector specificities. The effect of foreign equity ownership on investment behaviour may also be influenced by these specificities. In this section we control for the robustness of the results of model 1 and 3 of Table 5.1 across sector. First, in models 1 and 2 of Table 5.11 we limit the sample to firms operating in manufacturing industries. Manufacturing industries include leather, garments, textiles, food, metals and machinery, chemicals and pharmaceuticals, and other manufacturing industries. Second, in models 3 and 4 of Table 5.11 we limit the sample to firms operating in service industries which includes retail and wholesale trade, hotels, restaurants, and other service industries. Because we have no data for firms operating in services in Ethiopia this country is excluded from the analysis in models 3 and 4 . The regression models 1-4 do not include sector dummies.

We find no significant relation between foreign equity ownership and the probability of investment. Model 4, which is based on a sample of firms operating in service industries, suggests that firms with partial foreign equity ownership invest relatively more than domestically owned firms. Firms that are completely foreign owned invest less in fixed capital relative to sales. The coefficient of Foreign 100 in model 4 (services) is roughly double the coefficient of Foreign 100 in model 2 (manufacturing). For both models 2 and $4, \lambda$ is not significant. The magnitude of the $\rho$ are comparable in size with the results previously discussed on the basis of Table 5.1 . 
Table 5.11: Probit and outcome random-intercept models models by sector

\begin{tabular}{|c|c|c|c|c|}
\hline & Manufacturing & Manufacturing & Services & Services \\
\hline & $\begin{array}{l}(1) \\
\text { Probit } \\
\text { Selection }\end{array}$ & $\begin{array}{l}(2) \\
\text { Outcome }\end{array}$ & $\begin{array}{l}(3) \\
\text { Probit } \\
\text { Selection }\end{array}$ & $\begin{array}{l}\text { (4) } \\
\text { Outcome }\end{array}$ \\
\hline \multicolumn{5}{|c|}{ FIXED EFFECTS ('OBSERVED' EFFECTS) } \\
\hline P_Foreign & $\begin{array}{l}0.06 \\
(0.04)\end{array}$ & $\begin{array}{l}-0.03 \\
(0.05)\end{array}$ & $\begin{array}{l}0.07 \\
(0.05)\end{array}$ & $\begin{array}{l}0.14+ \\
(0.07)\end{array}$ \\
\hline Foreign 100 & $\begin{array}{l}-0.02 \\
(0.03)\end{array}$ & $\begin{array}{l}-0.15^{* *} \\
(0.05)\end{array}$ & $\begin{array}{l}-0.03 \\
(0.04)\end{array}$ & $\begin{array}{l}-0.31^{* * * *} \\
(0.07)\end{array}$ \\
\hline Age & $\begin{array}{l}-0.11^{* * * *} \\
(0.01)\end{array}$ & $\begin{array}{l}-0.13^{* * *} \\
(0.02)\end{array}$ & $\begin{array}{l}-0.09 * * * \\
(0.02)\end{array}$ & $\begin{array}{l}-0.14^{* * * *} \\
(0.03)\end{array}$ \\
\hline Export & $\begin{array}{l}0.16^{* * *} \\
(0.02)\end{array}$ & $\begin{array}{l}-0.06 \\
(0.04)\end{array}$ & $\begin{array}{l}0.24^{* * *} \\
(0.04)\end{array}$ & $\begin{array}{l}0.10 \\
(0.07)\end{array}$ \\
\hline Labour & $\begin{array}{l}-0.06^{* * * *} \\
(0.01)\end{array}$ & $\begin{array}{l}0.38 * * * \\
(0.01)\end{array}$ & $\begin{array}{l}-0.02^{*} \\
(0.01)\end{array}$ & $\begin{array}{l}0.56 * * * \\
(0.01)\end{array}$ \\
\hline Size & $\begin{array}{l}0.24^{* * *} \\
(0.01)\end{array}$ & $\begin{array}{l}-0.13^{* * *} \\
(0.04)\end{array}$ & $\begin{array}{l}0.28 * * * \\
(0.01)\end{array}$ & $\begin{array}{l}-0.15^{*} \\
(0.06)\end{array}$ \\
\hline Land & $\begin{array}{l}0.17^{* * *} \\
(0.02)\end{array}$ & & $\begin{array}{l}0.12^{* * *} \\
(0.02)\end{array}$ & \\
\hline Finance & $\begin{array}{l}-0.02 \\
(0.02)\end{array}$ & & $\begin{array}{l}0.03 \\
(0.02)\end{array}$ & \\
\hline Competitor & $\begin{array}{l}0.02 \\
(0.02)\end{array}$ & & $\begin{array}{l}0.05^{*} \\
(0.02)\end{array}$ & \\
\hline$\lambda$ & & $\begin{array}{l}0.03 \\
(0.25)\end{array}$ & & $\begin{array}{l}0.30 \\
(0.36)\end{array}$ \\
\hline Constant & $\begin{array}{l}-0.64^{* * *} \\
(0.06)\end{array}$ & $\begin{array}{l}-1.66^{* * *} \\
(0.29)\end{array}$ & $\begin{array}{l}-0.78^{* * *} \\
(0.06)\end{array}$ & $\begin{array}{l}-1.66^{* * * *} \\
(0.45)\end{array}$ \\
\hline \multicolumn{5}{|c|}{ RANDOM EFFECTS ('UNOBSERVED' EFFECTS) } \\
\hline$\sigma_{v}$ & $\begin{array}{l}0.38^{* *} \\
(0.03)\end{array}$ & $\begin{array}{l}0.33^{* *} \\
(0.03)\end{array}$ & $\begin{array}{l}0.38^{* *} \\
(0.03) \\
\end{array}$ & $\begin{array}{l}0.44^{* *} \\
(0.04)\end{array}$ \\
\hline $\begin{array}{l}\text { Joint LR Chi2 } \\
\text { Joint LR df(1) }\end{array}$ & $\begin{array}{l}1550.5 \\
* * *\end{array}$ & $\begin{array}{l}510.4 \\
* * *\end{array}$ & $\begin{array}{l}915.8 \\
* * *\end{array}$ & $\begin{array}{l}347.8 \\
* * *\end{array}$ \\
\hline$\rho$ & 0.13 & 0.05 & 0.13 & 0.07 \\
\hline \# of firms & 27075 & 14420 & 15922 & 7601 \\
\hline \# of countries & 101 & 101 & 100 & 100 \\
\hline
\end{tabular}




\section{Robustness Analysis for Crisis}

Finally we present the results of a robustness analysis that controls for the possible effect of the financial crisis on investment behaviour. As a result of the financial crisis, the economy in many developed countries has slowed down. Arguably, in developing countries the effect of the crisis has been less severe. Yet, it may be possible to observe differences in the determinants of investment behaviour when comparing investment behaviour in pre-crisis years with the investment behaviour since 2008. In this section we seek to establish the degree to which foreign investors behave differently in the years preceding the recent financial crisis with respect to the 'crisis years'.

The sample of observations is divided into a 'pre-crisis' sample (investment in fiscal years 2005, 2006 and 2007) and a 'crisis' sample (investment in fiscal years 2008, 2009 and 2010). Rwanda is excluded from the 'crisis' sample because there are no firms in our sample population that have positive investment in this country in the fiscal year 2010. Because the sample of countries differs across the 'pre-crisis' and the 'crisis' sample we cannot be certain that differences in results are attributable to the effect of the crisis. The results are presented in Table 5.12: models 1 and 2 are based on the 'pre-crisis' sample and models 3 and 4 are based on the 'crisis' sample. These analyses build on the random-intercept models that include only the micro-level covariates.

The analysis based on the 'pre-crisis' sample does not indicate an effect of partial foreign equity ownership on the probability of investment or on the investment to sales ratio. However, the outcome model suggests that completely foreign owned firms invest less than domestically owned firms. The analysis using the 'crisis' sample likewise suggests that the coefficient of Foreign 100 is negatively related to Investment. Model 3 also indicates that P_Foreign is positively related to the probability of investment. 
Table 5.12: Probit and outcome random-intercept models models (pre-crisis \& crisis years)

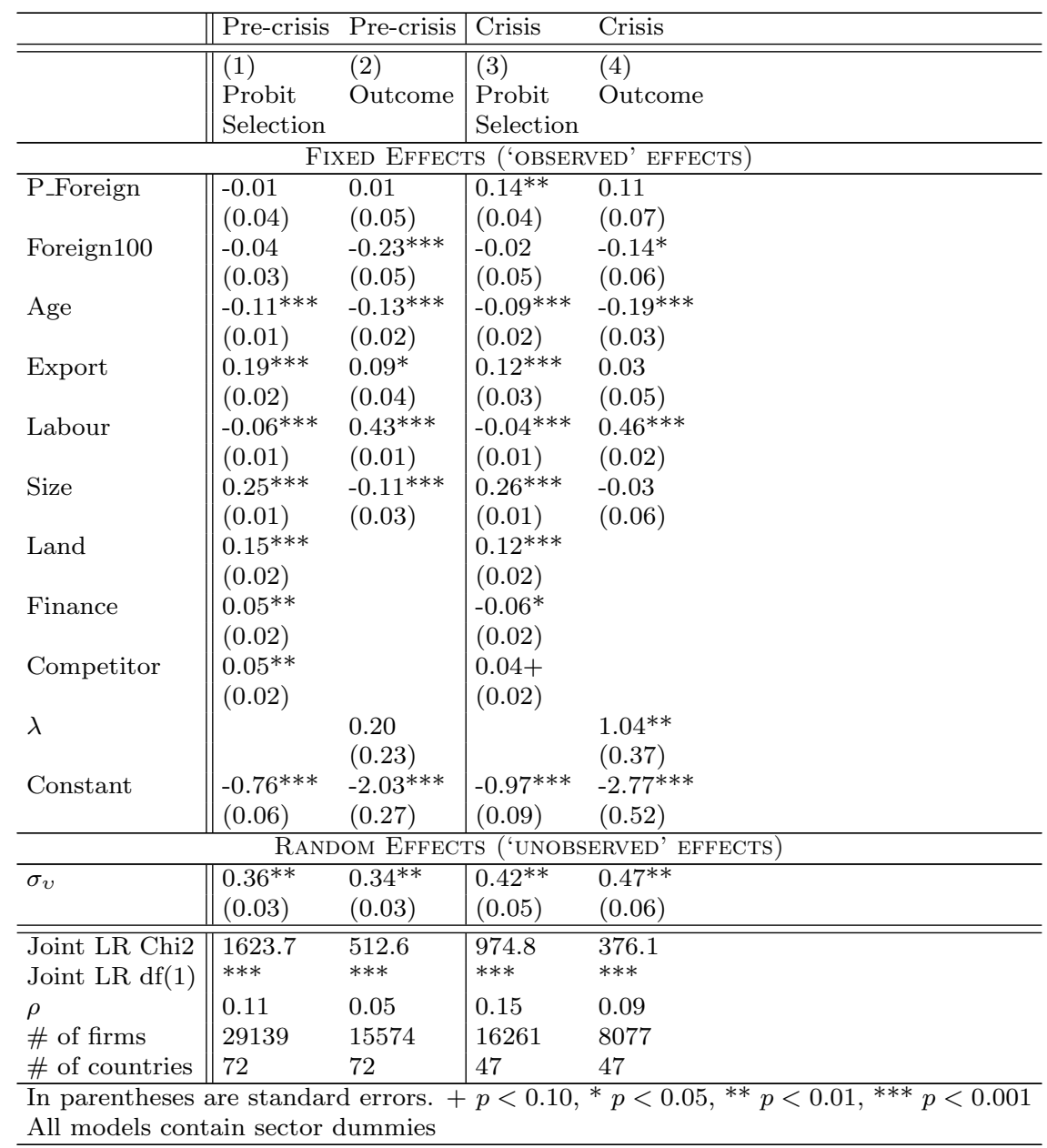


Chapter 6

Conclusion 


\subsection{Main Contributions}

The analysis of institutions and policies as determinants of long-run economic growth is confronted with major challenges in the identification of the relative effect of various growth drivers. This thesis bundles four empirical studies that contribute to the literature in this field. The point of departure of this thesis has been the empirical exploration of the effect of institutions on proximate sources of growth: i.e. financial development and investment. We have also related foreign investment to domestic industry development. Additionally, we have made an effort to analyze the relation between industrial policy and growth. The focus of analysis has been on explaining cross-country variations in development and, whenever possible, the analyses include a time dimension. We have gained a more subtle understanding of the relative importance of different institutional and policy dimensions. We find evidence suggesting that certain institutional developments and policies supporting private sector development are positively related to economic growth. As detailed in the next section, we also find evidence which suggests that other policies and institutional dimensions may have no effect on growth or may have a negative effect on growth.

\section{Summary of Findings}

The empirical analysis started with an investigation of the degree to which institutional characteristics are related to an intermediary factor of economic performance. The study presented in Chapter 2 investigates the relation between institutions and financial development. Based on a literature survey of theories linking institutional foundations and financial development, three categories of institutions are outlined: property rights protection, security of contracts, and competition. Property rights institutions are defined as important because of their role in protecting investments that are financed by loans. The formalization of contracting institutions are important for credit market development because financial arrangements are influenced by respect for contracts. The importance of competition institutions is related to both the demand and supply side of credit extensions. Using data from the institutional profiles database (IPD2009) 15 variables are identified that correspond to the above mentioned institutional characteristics. Next, principal component analysis (PCA) is used to construct three indicators corresponding to the different institutional characteristics. Hence, we showed that PCA allows measuring and separating specific but closely related characteristics of a country's institutional setting. Empirical estimations using the Hausman-Taylor method with AmemiyaMaCurdy specification reveal that the three institutional indicators are positively and significantly related to financial development (i.e. higher level of credit to the private sector). This result remains robust when controlling for the effect of financial policy. These results partially contradict the findings of Acemoglu and Johnson (2005) who, using different institutional indicators, only find a limited effect of contracting institutions on financial development. Regarding the policy indicators, we find some effect of financial policy on credit to the private sector. Specifically, we find that there 
is a (relatively small) positive effect of regulating banking supervision and liberalizing entry barriers in the banking sector on financial deepening. According to the results, there is no effect of privatization in the banking sector on the level of credit to the private sector. Additionally, we estimated the effect of the institutional characteristics on banks' lending capacity and on investment and found mixed results. Overall, we conclude that institutional formalization has a positive impact on credit deepening. The formalization of competition institutions has a positive effect on investment but property right institutions and contracting institutions are not significantly related to investment. This finding probes further inquiry into the extent to which the formalization of institutional formalization leads to the 'right' type of financial deepening; e.g. which stimulates investment in capital formation.

In Chapter 3 we focused on the role of industrial policy in stimulating growth. On the basis of the taxonomy of economic policy developed by Rodrik and Subramanian (2005) we sought to distinguish between 'pro-market' and 'pro-business' policies. 'Promarket' policies are aimed at increasing competition and market access. Rodrik and Subramanian (2005, pp. 215) define pro-business policies as policies that support the development of the existing industry and are "aimed primarily at benefiting incumbents in the formal industrial commercial sector". Using a set of policy variables from the IMD World Competitiveness yearbook and exploratory PCA we are, to some degree, successful in distinguishing between pro-market and pro-business policies. On the basis of this categorization of variables we have constructed a pro-market and a pro-business indicator. The pro-market indicator consists of the average score of pro-market policy variables for each country and year and the probusiness indicator consists of the average score of the pro-market policy variables for each country and year. Pro-market variables measure policy aspects including deregulation, competition, ownership structures, and liberalization and pro-business variables measure policy aspects including environmental and labour regulations and support for innovation and R\&D policy. The two indicators are positively correlated suggesting a positive relation between the levels of countries' implementation of these policy types. We used fixed-effects analysis covering 56 countries for the years 1995 2009 to estimate the effect of industrial policy on growth and income. On the one hand, our results suggest that pro-market policies have no clear effect on growth and income. On the other hand, we find that pro-business policies are positively related to growth. Additionally, we have constructed an indicator that measures innovation and technology policy and estimate the relation between this indicator and economic performance. The innovation indicator is constructed using a sub-set of the pro-business policy variables. Our results suggest that the positive effect of pro-business policy is to a large extent attributable to policy support for innovation and technological advancements.

The study presented in Chapter 4 uses the analysis by Morrissey and Udomkerdmongkol (2012) as a starting point. These authors find a negative effect of FDI on domestic investment, a positive effect of governance on domestic investment, and a negative mediating effect of institutions on the relation between FDI and domestic investment. The negative mediating effect is interpreted as evidence for the hypothesis that domestic investment is discouraged in countries with 'unfriendly 
regimes' unless investors acquire a foreign partner. We view this hypothesis as slightly limited. Using theory on technology spillovers and political elite rentseeking we propose that the sign of the interaction effect is dependent on whether the effect of foreign technological spillovers is more dominant than the effect of rent-seeking behaviour. We tested the robustness of the results of Morrissey and Udomkerdmongkol (2012) using alternative dependent variables, alternative GMM specifications, and also using fixed-effects and pooled-OLS estimations. First, we find evidence that the authors' results suffer from spuriousness as a result of subtracting data on FDI from data on domestic gross fixed capital formation (GFCF) to construct the dependent variable. We used data on investment from PWT and the WDI and (when not seeking to separate domestic and foreign investment by subtracting FDI from GFCF) find evidence suggesting that FDI crowds-in investment. Furthermore, according to the regression results, the coefficients of our variables of interest (FDI, governance, and the interaction term) decrease in significance when using a more appropriate GMM specification. As a result, our analysis suggests only a weak relation between governance and institutions and some evidence of a negative mediating effect of governance on the relation between FDI and domestic investment. We interpret this negative interaction effect as evidence that rent-seeking behaviour favours foreign investors at the expense of domestic investors and find that this effect dominates the effect of foreign technology spillovers on domestic investment.

To some degree, Chapter 5 extends the previous analysis of the impact of FDI on domestic investment; this time we used firm level data on investment and on foreign equity ownership. We deviated the scope of analysis from studying the degree of crowing-in (or crowding-out) and instead we investigated the relative effect of foreign-equity ownership on investment. Our overview of the existing literature suggests that, in contrast to macro-economic evidence, there is a lack of empirical evidence on the determinants of investment in developing countries using firm-level cross-country studies. Our study uses firm-level data on 101 developing and emerging economies to analyze both micro-level and macro-level determinants of investment. We confirm that firms in developing countries have a high level of non-investment. In agreement with previous studies we interpret this phenomena as a result of high irreversibility of investment and proceed to study determinants of both the propensity of investment as well as firms' investment to sales ratio (i.e. in the latter case provided a firm invests more than zero). On the basis of a multi-level Heckman selection model we find that investment behaviour is heterogeneous in nature and that the macro-level impact on investment behaviour is relatively small. We find evidence that firms that are completely foreign owned invest relatively less and less frequently than partially foreign-owned firms or domestically owned firms. One possibility is that foreign firms operate relatively more in extractive industries that require less long-term commitments. In addition, we find some evidence that in countries with better property rights protection and control of corruption firms invest relatively more frequently. Finally, we find some evidence of a positive mediating effect of property rights protection and control of corruption on the relation between foreign ownership and firms' investment to sales ratio. 


\section{Towards an Integrated Policy Framework}

There is a substantial amount of variation in the institutional framework between countries. As a result, opportunities and constraints for private sector development differ. We have argued that in order to compensate for certain ultimate constraints policy makers require more specialized knowledge on the interrelations between growth factors. We have framed our scope of analysis on the objective of establishing whether either the neoliberal policy approach or the structuralist policy approach is most fruitful in terms of stimulating economic development. Additionally, we sought to find empirical evidence that illustrates the feasibility of blending the two policy approaches. In this section we present some of the complementaries and differences of the results of the four empirical studies and reflect upon the extent to which this thesis contributes towards the framing of an integrated policy approach.

What can we conclude about the effectiveness of the structuralist approach and/or the neoliberal approach towards economic development? If we are to summarize the neoliberal approach towards development in terms of property rights protection, 'good governance'/institutions, financial policy, foreign investment policy, and (other) 'pro-market' type policies our findings are ambiguous. We find that FDI positively contributes to a country's overall level of investment. We also find evidence suggesting a positive effect of regulating banking supervision and of liberalizing entry barriers in the banking sector on credit and investment levels. However, the relation between institutions and investment is less strong than expected. Moreover, we find no positive effect of 'pro-market' policy on growth and we find no effect of privatization in the banking sector on credit levels. The results presented in Chapter 5 suggest that foreign owned firms invest relatively less than domestically owned firms. Additionally, we find evidence of a negative effect of 'good governance' on the relation between FDI and domestic investment. This result is interpreted as possible evidence that, as a result of rent-seeking interests, foreign investors benefit at the expense of domestic industry development. Some of these findings are, for example, in line with the theory of Schamis (2002) who argues that, under the pretext of market development, market liberalization and privatization policies have re-distributed large rents to elite. Based on these results we propose that under certain conditions some level of protectionism - e.g. limitations on foreign investment-may be beneficial for the economic development of a country. Following the study on industrial policy, policies that support the development of firms by means of laws and regulation and funding towards technological development have a positive effect on growth. These outcomes provide support to the thesis that structuralist policies can be growth enhancing. Chang (2002) similarly concludes that the industries of todays developed economies initially benefited from protectionist policies.

In Chapter 3 we compared industrial policy that supports pro-market development with industrial policy that supports industrial development. One important result is that our measurements for these two types of industrial policy are positively correlated. We argue that this result suggests that countries have successfully combined both aspects of neoliberal and structuralist policy into the policy framework. Admittedly, we have not been able to study traditional structuralist policies; instead our analysis only captures the more 'soft' type of structuralist policy. Moreover, 
we find that the two policy indicators are positively correlated with indicators of property rights protection and freedom from corruption, which means that countries with stronger property rights protection and less corruption implement relatively more industrial policy/policies.

The possibility of integrating aspects of the neoliberal approach with aspects of the structuralist approach towards development is somewhat in line with the work of Lin and Monga (2010). Lin and Monga propose a new framework, the 'New Structural Economics' (NSE) approach, and use this framework to develop policy recommendations for achieving rapid sustained economic growth. NSE recognizes the importance of the state in addressing market failure and coordination problems which are at the heart of the structuralist approach towards development. Lin (2011) similarly argues that subsidizing new industries and FDI policies can stimulate technological upgrading and yield (endogenous) growth. However, under the framework of NSE, Lin also argues in favour of pursuing a nation's comparative advantage by relying on the market mechanism to allocate resources and by building leadership and governance. Hence, Lin does not dismiss the importance of the free market in stimulating growth. The degree to which a country should follow the current comparative advantage remains debated (see also Lin and Chang, 2009). What seems conclusive is that both aspects of neoliberalism and of structuralist policy should be recognized as important growth drivers.

\subsection{Discussion, Limitations and Future Research Directions}

In this thesis we have experimented with a range of perception-based data and methodology. We find that some of the empirical results are sensitive to the choice of data. Based on different data choices we propose new insights with respect to conclusions previously drawn by reputable scholars. For example, in Chapter 4, we find that empirical results are sensitive to the choice of data on GFCF and its implementation. Johnson et al. (2013) also demonstrate that cross-country growth analysis is sensitive to data selection choices. Using different versions of the PWT GDP estimates, Johnson et al. show that some findings in growth analysis are not robust to the variability of data between versions. For data sources where data updates are not publicly traceable it may be more difficult to independently replicate empirical findings of scholars. As such, we emphasize that transparency in data collection and data treatment are much needed to improve and ascertain evidencebased policy making. Additionally, we find that some empirical results are sensitive to choices in methodology. We warn researchers that PCA (and other types of factor analysis) is sensitive to rotation techniques. Decisions at this level of analysis may have consequences on the results of regression analysis.

Inherently, perception-based indicators will remain limited in several respects. As suggested in the work of De Crombrugghe and Farla (2012), perception-based indicators may suffer from issues related to measurement endogeneity and/or biases. Measurement endogeneity occurs when the object of measurement is influenced by 
the developmental path of a country. "Theories about institutional development may be influenced by the institutional characteristics of generally high performing countries" (De Crombrugghe and Farla, 2012, pp. 20). Bias in the data can stem from misconceptions in perceived changes or cross-country differences of survey respondents. An additional possible shortcoming of perception-based indicators is that changes in a country's score on various variables or even between countries may be a result of changes in data collection and data treatment. Finally, indicators describing characteristics of institutions and policies lack actionability (Oman and Arndt, 2010). Therefore, we also refrain from developing more concrete policy recommendations on the basis of our empirical studies. And, on a similar note, we also see limited value in the practice of ranking countries on institutional indicators.

The formulation of 'good governance' used in association with the WorldWide Governance Indicators of the World Bank is admittedly vague. These governance indicators do not give a clear indication of what institutional factors should be a priority. The notion expressed most clearly is that whatever is so called 'good' is missing in countries that score low on the governance indicators. One possibility would be to replace the term 'good governance' with a more neutral term whereby countries that score low on the good governance indicators are merely seen as countries that have a different institutional system. This approach is, for instance, taken by the Polity IV project which measures a country's political system in terms of democracy versus autocracy.

There is an additional shortcoming that is important to mention at this point. We set out this study with the intention of establishing causal relations between institutions and policy and economic performance. For example, we find that there is a positive effect of formal property rights institutions on the level of credit to the private sector. Hence, in terms of policy conclusions, it is reasonable to argue that countries that have poor protection of property rights would benefit from having more protection of property. However, steering institutional change (and to some extent also policy reform) is challenging and often contested. Moreover, the success of property rights institutions in stimulating growth is dependent on a country's broader institutional framework. The reason is that institutions are deeply rooted within a country's social and economic context. 'Good institutions' should not be understood as a normative model of a global set of institutions that would fit every country's history, society or economic features (see also Meisel and Ould Aoudia, 2008).

Easterly (2008) concludes by posing the question of whether the bottom up view of institutions is hopelessly pessimistic with respect to the alternative 'top down' perspective where institutions can be relatively easily 'corrected' on the basis of a policy programme. We are more comfortable with the 'bottom up' view. Our empirical evidence suggests that the relationship between institutions and growth is more complicated than perhaps was previously thought. It has become unrealistic to assume that changing the 'de-jure' institutional system of a country with poor property rights protection towards the institutional system similar to that of e.g. Switzerland will yield positive growth and development. Institutional change is (usually) a slow step by step process. At this stage we consider it beyond our scope of 
analysis to draw policy recommendations on the degree to which governments should seek to steer institutional change.

Regarding our conclusions on industrial policy we likewise remain humble. One missing element in Chapter 3 is the link between market oriented policy and market competition and therefore our study would benefit from further analysis in this specific direction. One aim of a future research agenda is to empirically explore the effect of competition ans innovation policies on investment at the industry level. Moreover, it would be fascinating to assess the degree to which industrial policy and industrial capabilities are related. On the one hand, industrial policy is intended to create new industrial opportunities. One the other hand, together with market competition, sufficient capabilities are essential to drive industrial development. We find that the dynamics behind these interrelationships remain insufficiently explored from an empirical perspective.

Likewise, we expect that further research on the interaction between institutions and policy will yield valuable insights. In Chapter 2 and Chapter 3 we have distinguished between the effect of institutions and policy on economic performance. Still we find that in terms of measurement the distinction between institutions and policy is sometimes blurred. Certain policy aspects appear institutionalized. Specifically, competition policy is part of and/or related to a country's legal system. It is possible to approach this concept from an institutional perspective whereby the focus is on discussing the functioning of competition regulations. An alternative perspective is that competition policy ought to be tailored to sector development and reformed in accordance to the level of industry maturity.

Finally, it is noteworthy that multi-level modelling has been used rather scarcely in economics, especially with the aim of bridging microeconomic and macroeconomic analyses. Further research in this direction will be fruitful and may provide a better understanding of the micro mechanisms by which policies and institutions influence an organization's behaviour. 


\section{Bibliography}

Abdul-Haque and Shaoping, W. (2008). Uncertainty and investment evidence from a panel of Chinese firms. Structural Change and Economic Dynamics, 19(3):237-248.

Abel, A. B., Dixit, A. K., Eberly, J. C., and Pindyck, R. S. (1996). Options, the value of capital, and investment. The Quarterly Journal of Economics, 111(3):753-777.

Abiad, A., Detragiache, E., and Tressel, T. (2010). A New Database of Financial Reforms. IMF Staff Papers, 57:281-302.

Acemoglu, D., Aghion, P., and Zilibotti, F. (2006). Distance to Frontier, Selection, and Economic Growth. Journal of the European Economic Association, 4(1):37-74.

Acemoglu, D., Akcigit, U., Bloom, N., and Kerr, W. R. (2013). Innovation, reallocation and growth. NBER working paper series 18993.

Acemoglu, D. and Johnson, S. (2005). Unbundling Institutions. Journal of Political Economy, 113(5):949-995.

Acemoglu, D., Johnson, S., and Robinson, J. A. (2001). The Colonial Origins of Comparative Development: An Empirical Investigation. American Economic Review, 91(5):1369-1401.

Adams, S. (2009). Foreign direct investment, domestic investment, and economic growth in Sub-Saharan Africa. Journal of Policy Modeling, 31(6):939-949.

Aghion, P., Bloom, N., Blundell, R., Griffith, R., and Howitt, P. (2005). Competition and Innovation: an Inverted-U Relationship. The Quarterly Journal of Economics, 120(2):701-728.

Aghion, P., Dewatripint, M., Du, L., Harrison, A., and Legros, P. (2012). Industrial policy and competition. NBER working paper No. 18048.

Agosin, M. and Machado, R. (2005). Foreign investment in developing countries: Does it crowd in domestic investment? Oxford Development Studies, 33(2):149-162.

Agosin, M. R. and Mayer, R. (2000). Foreign investment in developing countries, does it crowd in domestic investment? UNCTAD Discussion Papers 146, United Nations Conference on Trade and Development.

Aiginger, K. (2007). Industrial policy: A dying breed or a re-emerging phoenix. Journal of Industry, Competition and Trade, 7(3):297-323.

Aiginger, K. and Sieber, S. (2006). The Matric Approach to Industrial Policy. International Review of Applied Economics, 20(5):573-601. 
Aitken, B. J. and Harrison, A. E. (1999). Do domestic firms benefit from direct foreign investment? evidence from Venezuela. American Economic Review, 89(3):605-618.

Aizenman, J. and Marion, N. (1999). Volatility and investment: Interpreting evidence from developing countries. Economica, 66(262):157-79.

Albouy, Y. D. (2012). The Colonial Origins of Comparative Development: An Empirical Investigation: Comment. American Economic Review, 102(6):3059-3076.

Al-Sadig, A. (2013). The effects of foreign direct investment on private domestic investment: evidence from developing countries. Empirical Economics, 44(4):12671275 .

Alesina, A., Devleeschauwer, A., Easterly, W., Kurlat, S., and Wacziarg, R. (2003). Fractionalization. Journal of Economic Growth, 8:155-194.

Ali, F., Fiess, N., and MacDonald, R. (2010). Do institutions matter for foreign direct investment? Open Economies Review, 21(2):201-219.

Amemiya, T. and MaCurdy, T. E. (1986). Instrumental-Variable Estimation of an Error-Components Model. Econometrica, 54(4):pp. 869-880.

Amsden, A. H. (2007). Nationality of firm ownership in developing countries: Who should "crowd out" whom in imperfect markets? In IDE-Jetro Conference on Economic Development. Momigliano Lecture.

Amsden, A. H. (2008). The Washington Consensus Reconsidered: Towards a New Global Governance, chapter The Wild Ones: Industrial Policies in the Developing World, pages 41-60. Oxford University Press.

Amsden, A. H. (2011). Entepreneurship, Innovation, and Economic Development, chapter Firm Ownership and Entepreneurship, pages 65-77. Oxford University Press.

Andrianova, S., Demetriades, P., and Shortland, A. (2008). Government ownership of banks, institutions, and financial development. Journal of Development Economics, $85(1 / 2): 218-252$.

Apergis, N., Katrakilidis, C. P., and Tabakis, N. M. (2006). Dynamic linkages between FDI inflows and domestic investment: A panel cointegration approach. Atlantic Economic Journal, 34(4):385 - 394.

Arcand, J. L., Berkes, E., and Panizza, U. (2013). Finance and Economic Development in a Model with Credit Rationing? Graduate Institute of International and Development Studies Working Paper, 02/2013.

Arcand, J. L., Berkes, E., and Panizza, U., (2012). Too much Finance? IMF Working Paper, 12(161). 
Arellano, M. and Bond, S. (1991). Some tests of specification for panel data: Monte Carlo evidence and an application to employment equations. Review of Economic Studies, 58(2):277-97.

Arndt, C. (2009). Governance Indicators. PhD thesis, Maastricht Graduate School of Governance, Maastricht University.

Asiedu, E. and Freeman, J. (2009). The effect of corruption on investment growth: Evidence from firms in Latin America, Sub-Saharan Africa, and transition countries. Review of Development Economics, 13:200214.

Asiedu, E., Jin, Y., and Nandwa, B. (2009). Does foreign aid mitigate the adverse effect of expropriation risk on foreign direct investment?. Journal of International Economics, 78(2):268 - 275.

Asiedu, E. and Lien, D. (2011). Democracy, foreign direct investment and natural resources. Journal of International Economics, 84(1):99 - 111.

Atukeren, E. (2010). Politico-economic determinants of the crowding-in effects of public investments in developing countries. Journal of Money, Investment and Banking, 13(13):55 - 73 .

Aw, B. (2003). Competitiveness, FDI and Technological Activity in East Asia., chapter Technology acquisition and development in Taiwan, pages 168-190. Edward Elgar, Cheltenham.

Ayca, T. Cross-border m\&as vs. greenfield investments: Does corruption make a difference? MPRA Paper.

Backer, K. D. and Sleuwaegen, L. (2003). Does foreign direct investment crowd out domestic entrepreneurship? Review of Industrial Organization, 22(1):67-84.

Bae, K. and Goyal, V. K. (2009). Creditor Rights, Enforcement, and Bank Loans. The Journal of Finance, LXIV(2):823-860.

Baltagi, B. H., Demetriades, P. O., and Law, S. H. (2009). Financial development and openness: Evidence from panel data. Journal of Development Economics, 89(2):285 $-296$.

Barro, R. J. (1991). Economic growth in a cross section of countries. The Quarterly Journal of Economics, 106(2):407-43.

Barro, R. J. and Lee, J.-W. (1994). Sources of economic growth. Carnegie-Rochester Conference Series on Public Policy, 40(1):1-46.

Batra, G., Kaufmann, D., and Stone, A. (2003). Investment Climate Around The World: Voices of the Firms from the World Business Environment Survey. The World Bank: Washington, D.C.

Beck, N. and Katz, J. N. (1995). What to do (and not to do) with Time-Series Cross-Section Data. The American Political Science Review, 89(3):634-647. 
Beck, T. and Demirg-Kunt, A. (2009). Financial Institutions and Markets Across Countries and over Time: Data and Analysis. World Bank Policy Research Working Paper No. 4943.

Belloc, M. and Vertova, P. (2006). Public investment and economic performance in highly indebted poor countries: An empirical assessment. International Review of Applied Economics, 20(2):151 - 170.

Benassy-Quere, A., Coupet, M., and Mayer, T. (2007). Institutional determinants of foreign direct investment. World Economy, 30(5):764 - 782.

Bernanke, B. S. (1983). Irreversibility, uncertainty, and cyclical investment. The Quarterly Journal of Economics, 98(1):pp. 85-106.

Besley, T. and Persson, T. (2011). Pillars of Prosperity: the political economies of development clusters. Princeton University Press.

Bianchi, P. and Labory, S. (2006). Empirical evidence on industrial policy using state aid data. International Review of Applied Economics, 20(5):603-621.

Bigsten, A., Collier, P., Dercon, S., Fafchamps, M., Gauthier, B., Gunning, J. W., Oostendorp, R., Pattillo, C., Söderbom, M., and Teal, F. (2005). Adjustment costs and irreversibility as determinants of investment: Evidence from African manufacturing. The B.E. Journal of Economic Analysis \& Policy, 0(1):12.

Bigsten, A., Collier, P., Dercon, S., Gauthier, B., Gunning, J. W., Isaksson, A., Oduro, A., Oostendorp, R., Pattillo, C., Soderbom, M., Sylvain, M., Teal, F., and Zeufack, A. (1999). Investment in Africa's manufacturing sector: A four country panel data analysis. Oxford Bulletin of Economics and Statistics, 61(4):489-512.

Bird, G. and Rowlands, D. (2001). World Bank lending and other financial flows: Is there a connection? Journal of Development Studies, 37(5):83-103.

Blonigen, B. (2005). A review of the empirical literature on FDI determinants. Atlantic Economic Journal, 33(4):383-403.

Blundell, R. and Bond, S. (1998). Initial conditions and moment restrictions in dynamic panel data models. Journal of Econometrics, 87(1):115-143.

Bo, H. and Zhang, Z. (2002). The impact of uncertainty on firm investment: evidence from machinery industry in Liaoning province of China. Economic Systems, $26(4): 335-352$.

Borensztein, E., De Gregorio, J., and Lee, J.-W. (1998). How does foreign direct investment affect economic growth?1. Journal of International Economics, 45(1):115-135.

Bosworth, B. P. and Collins, S. M. (1999). Capital flows to developing economies: Implications for saving and investment. Brookings Papers on Economic Activity, 1999(1):143-180. 
Breschi, S. and Cusmano, L. (2004). Unveiling the texture of a european research area: emergence of oligarchic networks under EU framework programmes. Int. J. Technology Management, 27(8):747-772.

Breusch, T., Ward, W. M. B., Hoa, N., and Kompas, T. (2011). FEVD: Just IV or Just Mistaken? Political Analysis, 19:123134.

Buchanan, B. G., Le, Q. V., and Rishi, M. (2012). Foreign direct investment and institutional quality: Some empirical evidence. International Review of Financial Analysis, 21:81-89.

Buigues, P.-A. and Sekkat, K. (2011). Public subsidies to business: An international comparison. Journal of Industry, Competition and Trade, 11(1):1-24.

Burstein Goldszmidt, R. G., Ledur Brito, L. A., and Carvalho de Vasconcelos, F. (2011). Country effect on firm performance: A multilevel approach. Journal of Business Research, 64(3):273 - 279.

Busse, M. and Hefeker, C. (2007). Political risk, institutions and foreign direct investment. European Journal of Political Economy, 23(2):397 - 415.

Busse, M. and Königer, J. and Nunnenkamp, P. (2010). FDI promotion through bilateral investment treaties: More than a bit? Review of World Economics, 146(1):147-177.

Büthe, T. and Milner, H. V. (2008). The politics of foreign direct investment into developing countries: Increasing FDI through international trade agreements? American Journal of Political Science, 52(4):741-762.

Butkiewicz, J. L. and Yanikkaya, H. (2005). The effects of IMF and World Bank lending on long-run economic growth: An empirical analysis. World Development, $33(3): 371-391$.

Buts, C. and Jegers, M. (2013). The effect of 'state aid' on market shares: An empirical investigation in an EU member state. Journal of Industry, Competition and Trade, 13(1):89-100.

Cameron, A. C., Gelbach, J. B., and Miller, D. L. (2011). Robust inference with multiway clustering. Journal of Business 85 Economic Statistics, 29(2):238-249.

Carruth, A., Dickerson, A., and Henley, A. (2000). What do we know about investment under uncertainty? Journal of Economic Surveys, 14(2):119-53.

Cavallo, E. and Daude, C. (2011). Public investment in developing countries: A blessing or a curse?. Journal of Comparative Economics, 39(1):65 - 81.

Chatelain, J. and Ralf, K. (2010). Inference on Time-Invariant Variables using Panel Data: A Pre-Test Estimator with an Application to the Returns to Schooling. hal-00492039, HAL. 
Chinn, M. D. and Ito, H. (2008). A new measure of financial openness. Journal of Comparative Policy Analysis, 10(3):309-322.

Cimoli, M., Dosi, G., and Stiglitz, J. E. (2009a). Industrial Policy and Development, chapter The Future of Industrial Policies in the New Millenium: Toward a Knowledge-Contered Development Agenda. Oxford University Press.

Cimoli, M., Dosi, G., and Stiglitz, J. E. (2009b). Industrial Policy and Development, chapter The Political Economy of Capabilities Accumulation: The Past and Future of Policies for Industrial Development. Oxford University Press.

Claessens, S. and Laeven, L. (2003). Financial development, property rights, and growth. Journal of Finance, 58(6):2401 - 2436.

Coase, R. H. (1937). The nature of the firm. Economica, 4(16):386-405.

Coase, R. H. (1960). The Problem of Social Cost. Journal of Law and Economics, $3: 1-44$.

Cohen, E. (2007). Industrial Policies in France: The Old and the New. Journal of Industry, Competition and Trade, 7(3):213-227.

Crespo, N. and Fontoura, M. P. (2007). Determinant factors of FDI spillovers - what do we really know? World Development, 35(3):410-425.

Criscualo, C., Martin, R., Overman, H. G., and van Reenen, J. (2012). The causal effects of an industrial policy. Center for Economic Policy.

Dalmazzo, A. and Marini, G. (2000). Foreign debt, sanctions and investment: A model with politically unstable less developed countries. International Journal of Finance and Economics, 5(2):141 - 153.

Darku, A. B. (2000). Private investment, uncertainty, and irreversibility in Uganda.

Daude, C. and Fratzscher, M. (2008). The pecking order of cross-border investment. Journal of International Economics, 74(1):94 - 119.

Daude, C. and Stein, E. (2007). The quality of institutions and foreign direct investment. Economics \& Politics, 19(3):317 - 344.

de Crombrugghe, D. (2010). Unity in Diversity: Studies on Micro and Macro Panel Data Sets. PhD thesis, Maastricht Univeristy. Chapter 6.

De Crombrugghe, D. and Farla, K. (2012). Preliminary Conclusions on Institutions and Economic Performance. UNU-MERIT Working Paper Series 035, UNUMERIT.

De la Torre, A., Gozzi, J. C., and Schmukler, S. L. (2007). Innovative Experiences in Access to Finance: Market Friendly Roles for the Invisible Hand? World Bank Policy Research Policy Paper 4326. 
de Mello, Luiz R, J. (1999). Foreign direct investment-led growth: Evidence from time series and panel data. Oxford Economic Papers, 51(1):133-51.

Del Rosal, I. (2011). The empirical measurement of rent-seeking costs. Journal of Economic Surveys, 25(2):298 - 325.

Di Maio, M. (2009). Industrial Policy and Development, chapter Industrial Policies in Developing Countries: History and Perspectives. Oxford University Press.

Diaz-Cayeros, A. (2013). In the Shadow of Violence: Politics, Economics, and the Problems of Development, chapter Entrenched Insiders: Limited Access Order in Mexico, pages 233-260. Cambridge University Press.

Dixit, A. (2009). Governance Institutions and Economic Activity. American Economic Review, 99:5-24.

Djankov, S., McLiesh, C., and Shleifer, A. (2007). Private Credit in 129 Countries. Journal of Financial Economics, 48:299-329.

Easterly, W. (2008). Institutions: Top Down or Bottom Up? American Economic Review, 98(2):9599.

Easterly, W. and Levine, R. (2003). Tropics, germs, and crops: how endowments influence economic development. Journal of Monetary Economics, 50(1):3-39.

Engerman, S. L. and Sokoloff, K. L. (1997). Factor Endowments, Institutions and Differential Paths of Growth among New World Economies. In Stanford, C., editor, How America Fell Behind, pages 260-304. Stanford Univeristy press.

Erden, L. and Holcombe, R. G. (2006). The linkage between public and private investment: A co-integration analysis of a panel of developing countries. Eastern Economic Journal, 32(3):479 - 492.

Everhart, S., Martinez-Vazquez, J., and McNab, R. (2009). Corruption, governance, investment and growth in emerging markets. Applied Economics, 41(13):1579-1594.

Everhart, S. and Sumlinski, M. (2001). Trends in private investment in developing countries, statistics for 1970-200 and the impact on private investment of corruption and the quality of public investment. Papers 44, World Bank - International Finance Corporation.

Fagerberg, J. and Srholec, M. (2008). National innovation systems, capabilities and economic development. Research Policy, 37(9):1417-1435.

Faria, A. and Mauro, P. (2009). Institutions and the external capital structure of countries. Journal of International Money and Finance, 28(3):367 - 391.

Fu, X., Pietrobelli, C., and Soete, L. (2011). The role of foreign technology and indigenous innovation in the emerging economies: Technological change and catching-up. World Development, 39(7):1204-1212. 
Furman, J. L., Porter, M. E., and Stern, S. (2002). The determinants of national innovative capacity. Research Policy, 31(6):899-933.

Fuss, C. and Vermeulen, P. (2008). Firms' investment decisions in response to demand and price uncertainty. Applied Economics, 40(18):2337-2351.

Gaviria, A. (2002). Assessing the effects of corruption and crime on firm performance: Evidence from Latin America. Emerging Markets Review, 3(3):245-268.

Gebreeyesus, M. (2009). Inactions and spikes of investment in ethiopian manufacturing firms: Empirical evidence on irreversibility and non-convexities. UNU-MERIT Working Paper Series 061, United Nations University, Maastricht Economic and social Research and training centre on Innovation and Technology.

Gerschenkron, A. (1962). Economic Backwardness in Historical Perspectives. Harvard University Press.

Gilchrist, S., Sim, J. M., and Zakrajšek, E., (2013). Missallocation and financial market frictions: some direct evidence from the dispersion in borrowing costs. Review of Economic Dynamics, 16:159-176.

Glaeser, E., LaPorta, R., Lopez-de-Silanes, F., and Shliefer, A. (2004). Do Institutions Cause Growth? Journal of Economic Growth, 9:271-303.

Glen, J. and Sumlinski, M. (1994). Trends in private investment in developing countries 1995, statistics for 1980-93. Papers 25, World Bank - International Finance Corporation.

Goedhuys, M. and Srholec, M. (2010). Understanding multilevel interactions in economic development. UNU-Merit Working Paper Series 2010-003.

Goto, A. and Odagiri, H. (2003). Competitiveness, FDI and technological Activity in East Asia, chapter Building technological capabilities with or without inward direct investment: The case of Japan, pages 83-102. Edward Elgar, Cheltenham.

Green, C. J., Lensink, R., and Murinde, V. (2001). Demand uncertainty and the capital-labour ratio in Poland. Emerging Markets Review, 2(2):184-197.

Greene, W. (2011). Fixed Effects Vector Decomposition: A Magical Solution to the Problem of Time Invariant Variables in Fixed Effects Models? Political Analysis, 19:135406.

Greenland, S. (2000). Principles of multilevel modelling. International Journla of Epidemiology, 29:158-167.

Greenwald, B. and Stiglitz, J. E. (2006). Helping infant economies growth: Foundations of trade policies for developing countries. The American Economic Revew, 96(2):141-146. 
Greenwood, J., Sanchez, J.M., and Wang, C., (2013). Quantifying the impact of financial development on economic development Review of Economic Analysis, 16: $194-215$.

Greenwood, J., Sanchez, J.M., and Wang, C., (2010). Financing Development: the role of information costs American Economic Review, 100:1975-1891.

Greif, A. and Tabellini, G. (2010). Cultural and Institutional Bifurcation: China and Europe compared. American Economic Review, 100(2):135-140.

Grindle, M. S. (2004). Good Enough Governance: Poverty Reduction and Reform in Developing Countries. Governance, 17(4):525-548.

Guiso, L. and Parigi, G. (1999). Investment and demand uncertainty. The Quarterly Journal of Economics, 114(1):185-227.

Chang, H.-J. (2002). Kicking Away the Ladder: Development Strategy in Historical Perspective. Anthem Press.

Hartman, R. (1972). The effects of price and cost uncertainty on investment. Journal of Economic Theory, 5(2):258-266.

Hasan, I., Wachtel, P., and Zhou, M., (2009). Institutional development, financial deepening and economic growth: Evidence from China. Journal of Banking $\&$ Finance, 33:157-170.

Hausman, J. A. and Taylor, W. E. (1981). Panel data and unobservable individual effects. Econometrica, 49(6):1377 - 1398.

Hausmann, R., rodrik, D., and Velasco, A. (2008). The Washington Consensus Reconsidered: Towards a New Global Governance, chapter Growth Diagnostics, pages 41-60. Oxford University Press.

Hawawini, G., Subramanian, V., and Verdin, P. (2004). The home country in the age of globalization: how much does it matter for firm performance? Journal of World Business, 39(2):121-135.

Henisz, W. (2000). The institutional environment for multinational investment. Journal of Law, Economics, and Organization, 16(2):334-364.

Heritage Foundation (2013). Index of economic freedom.

Heston, A., Summers, R., and Aten, B. (2009). Penn World Table 6.3 . Technical report, Center for International Comparisons of Production, Income and Prices at the University of Pennsylvania.

Heston, A., Summers, R., and Aten, B. (2011). Penn World Table Version 7.0 .

Heston, A., Summers, R., and Aten, B. (2012). Penn World Table Version 7.1 .

Hiley, M. (2000). Lessons for Sub-Sahraran Africa from the experience of Easia Asia: $S A D C$ and $A S E A N$ compared. Edward Elgar. 
Hofman, A. A. (1992). Capital accumulation in Latin America: A six country comparison for 1950-89. Review of Income and Wealth, 38(4):365-401.

Huang, R. D. and Shiu, C.-Y. (2009). Local effects of foreign ownership in an emerging financial market: Evidence from qualified foreign institutional investors in Taiwan. Financial Management, 38(3):567-602.

Huang, Y. (2010). Political Institutions and Financial Development: An Empirical Study. World Development, 38(12):1667 - 1677.

IMD (2011). World Competitiveness Yearbook (WCY).

Institute for Health Metrics and Evaluation (IHME) (2013). Educational Attainment and Child Mortality Estimates by Country 1970-2009.

IPD (2009). Institutional Profiles Database.

J. L. Gallup, and A. D. Mellinger, and J. D. Sachs (2001). Geography Datasets, Center for International Development.

James R. Hines, J. (1995). Forbidden payment: Foreign bribery and American business after 1977. Working Paper 5266, National Bureau of Economic Research.

Javorcik, B. S. and Wei, S. (2009). Corruption and cross-border investment in emerging markets: Firm-level evidence. Journal of International Money and Finance, 28(4):605 - 624 .

Jeong, H., and Townsend, R. M. (2007). Sources of TFP Growth: occupational choice and financial deepening. Economic Theory, 32179-221.

Johnson, S. (2009). The Quiet Coup.

Johnson, S., La Porta, R., Lopez-de-Silanes, F., and Schliefer, A. (2000). Tunneling. American Economic Review, 90(2):22 - 27.

Johnson, S., Larson, W., Papageorgiou, C., and Subramanian, A. (2013). Is newer better? penn world table revisions and their impact on growth estimates. Journal of Monetary Economics, 60(2):255-274.

Jones, C. I. and Romer, P. M. (2010). The New Kaldor Facts: Ideas, Institutions, Population, and Human Capital. American Economic Journal: Macroeconomics, 2(1):224-45.

Kaufmann, D., Kraay, A., and Mastruzzi, M. (2005). Measuring governance using cross-country perceptions data. MPRA Paper 8219, University Library of Munich, Germany.

Kaufmann, D., Kraay, A., and Mastruzzi, M. (2009). Governance matters viii: Aggregate and individual governance indicators 1996-2008. Technical report, World Bank Institute, Washington, DC. 
Keefer, P. and Knack, S. (2007). Boondoggles, rent-seeking, and political checks and balances: Public investment under unaccountable governments. Review of Economics and Statistics, 89(3):566 - 572 .

Kesternich, I. and Schnitzer, M. (2010). Who is afraid of political risk? multinational firms and their choice of capital structure. Journal of International Economics, 82(2):208-218.

Khan, M. H. (2008). Vulnerabilities in Market-led Growth Strategies and Challenges for Governance. Project Report DFID.

Khan, M. H. and Blankenburg, S. (2009). Industrial Policy and Development, chapter The Political Economy of Industrial Policy in Asia and Latin America. Oxford University Press.

Kim, L. . (1997). Imitation to Innovation: The Dynamics of Korea's Technological Learning. Harvard Business School Press, Harvard.

Kim, L. (2003). Competitiveness, FDI and Technological Activity in East Asia., chapter The dynamics of technology development: Lessons from the Korean experience, pages 143-167. Edward Elgar, Cheltenham.

Kinda, T. (2010). Investment climate and FDI in developing countries: Firm-level evidence. World Development, 38(4):498-513.

Kindleberger, C. and Aliber, R. (2005). Manias, Panics, and Crashes: A History of Financial Crises. Wiley, 5th edition.

Koetse, M. J., de Groot, H. L., and Florax, R. J. (2009). A meta-analysis of the investment-uncertainty relationship. Southern Economic Journal, 76(1):283-306.

Koo, J. and Maeng, K. (2006). Foreign ownership and investment: evidence from Korea. Applied Economics, 38(20):2405-2414.

Kosovà, R. (2010). Do foreign firms crowd out domestic firms? evidence from the Czech Republic. The Review of Economics and Statistics, 92(4):861-881.

Kumo, W. 1. (2006). Macroeconomic uncertainty and aggregate private investment in South Africa. South African Journal of Economics, 74(2):190-204.

La Porta, R., Lopez-De-Silanes, F., and Shleifer, A. (1999). Corporate ownership around the world. Journal of Finance, 54:265-301.

La Porta, R., Lopez-de Silanes, F., Shleifer, A., and Vishny, R. (2000). Investor Protection: Origins, Consequences, Reform. The World Bank. Financial Sector Discussion Paper No.1.

La Porta, R., Lopez-De-Silanes, F., and Shleifer, A. (2002). Government Ownership of Banks. The Journal of Finance, LVII(1):265-301. 
Lee, J. (2011). The performance of industrial policy: Evidence from Korea. International Economic Journal, 25(1):1-27.

Leefmans, N. (2011). Investment and uncertainty in Tanzanian manufacturing. University of Amsterdam.

Lensink, R., Steen, P., and Sterken, E. (2005). Uncertainty and growth of the firm. Small Business Economics, 24(4):381-391.

Levine, R. (2005). Law, Endowments and Property Rights. Journal of Economic Perspectives, 19(3):61-88.

Lin, J. Y. (2011). New structural economics: A framework for rethinking development. World Bank Research Observer, 26(2):193-221.

Lin, J. Y. and Chang, H.-J. (2009). Should industrial policy in developing countries conform to comparative advantage or defy it? a debate between Justin Lin and Ha-joon Chang. Development Policy Review, 27(5):483-502.

Lin, J. Y. and Monga, C. (2010). The growth report and new structural economics. Policy Research Working Paper Series 5336, The World Bank.

Lipsey, R. E. (2000). Interpreting developed countries' foreign direct investment. NBER Working Papers 7810, National Bureau of Economic Research, Inc.

Liu, Z. (2008). Foreign direct investment and technology spillovers: Theory and evidence. Journal of Development Economics, 85(1-2):176-193.

Livesey, F. (2012). Rationales for industrial policy based on industry maturity. Journal of Industry, Competition and Trade, 12(3):349-363.

Lucas, R. E. (1990). Why doesn't capital flow from rich to poor countries? The American Economic Review, 80(2):92-96.

Marshall, M. G. and Jaggers, K. (2009). Polity IV Project. Center for Global Policy and School of Public Policy and George Mason University and Center for Systemic Peace. Dataset Users' Manual.

Mathur, A. and Singh, K. (2013). Foreign direct investment, corruption and democracy. Applied Economics, 45(8):991-1002.

Mauro, P. (1995). Corruption and growth. Quarterly Journal of Economics, 110(3):681 - 712 .

Meisel, N. and Ould Aoudia, J. (2008). Is "Good Governance" a Good Development Strategy? Working Paper, Agence Française de Développement.

Melo, A. (2001). Industrial Policy in Latin America and the Caribbean at the Turn of the Century. Research Department Publications 4281, Inter-American Development Bank, Research Department. 
Minsky, H. (1986). Stabilizing an Unstable Economy. Yale University Press.

Mishkin, F. S. (1996). Understanding Financial Crises: A Developing Country Perspective. NBER Working Paper Series 5600.

Misun, J. and Tomsik, V. (2002). Does foreign direct investment crowd in or crowd out domestic investment?. Eastern European Economics, 40(2):38.

Morck, R., Deniz, Y. M., and Yeung, B. (2011). Banking system control, capital allocation, and economy performance. Journal of Financial Economics, 100(2):264 $-283$.

Morrissey, O. and Udomkerdmongkol, M. (2012). Governance, private investment and foreign direct investment in developing countries. World Development, 40(3):437 445 .

Mundlak, Y. (1978). On the Pooling of Time Series and Cross Section Data. Econometrica, 46(1):69-85.

Mutenyo, J., Asmah, E., and Kalio, A. (2010). Does foreign direct investment crowdout domestic private investment in Sub-Saharan Africa? The African Finance Journal, 12(1):27-52.

Ndikumana, L. and Verick, S. (2008). The linkages between FDI and domestic investment: Unravelling the developmental impact of foreign investment in SubSaharan Africa. Development Policy Review, 26(6):713-726.

Nickell, S. (1978). The Investment Decisions of Firms. Cambridge University Press.

Ninh, L. K., Hermes, N., and Lanjouw, G. (2004). Investment, uncertainty and irreversibility. The Economics of Transition, 12(2):307-332.

North, D. (1990). Institutions, Institutional Change and Economic Performance. Cambridge University Press, New York.

North, D. C. (1994). Economic Performance through Time. American Economic Review, 84(3):359-368.

North, D. C., Wallis, J. J., and Weingast, B. R. (2009). Violence and Social Orders: a conceptual framework for interpreting human history. Cambridge University Press.

Ocampo, J. A. (2004). Beyond the Washington consensus: what do we mean? Journal of Post Keynesian Economics, 27(2):293-314.

Ocampo, J. A. and Stiglitz, J. E., editors (2008). Capital Market Liberalization and Development. Oxford University Press.

Oman, C. P. and Arndt, C. (2010). Measuring governance. Technical report, OECD.

Pack, H. and Saggi, K. (2006). The case for industrial policy : a critical survey. Policy Research Working Paper Series 3839, The World Bank. 
Pattillo, C. (1998). Investment, uncertainty, and irreversibility in Ghana. IMF Staff Papers, 45(3):522-553.

Peneder, M. (2012). Competition and Innovation: Revisiting the Inverted-U Relationship. Journal of Industry, Competition and Trade, 12(1):1-5.

Peres, W. (2009). Industrial Policy and Development, chapter The (Slow) Return of Industrial Policies. Oxford University Press.

Pindyck, R. S. (1991). Irreversibility, uncertainty, and investment. Journal of Economic Literature, 29(3):1110-48.

Plumper, T. and Troeger, V. E. (2011). Fixed-Effects Vector Decomposition: Properties, Reliability, and Instruments. Political Analysis, 19:147-164.

Possas, M. L. and Borges, H. (2009). Industrial Policy and Development, chapter Competition Policy and Industrial Development. Oxford University Press.

Quintyn, M. and Verdier, G. (2010). "Mother, Can I Trust the Government?" Sustained Financial Deepening - A Political Institutions View. IMF Working Paper 210.

Rabe-Hesketh, S. and Skrondal, A. (2008). Multilevel and Longitudinal Modeling Using Stata. Stata Press.

Ramirez, M. (2011). Is foreign direct investment productive in the Latin American case? a panel co-integration analysis, 1980-2002. The International Trade Journal, $25(1): 35-73$.

Reinhart, C. M. and Rogoff, K. S. (2009). This Time Is Different: Eight Centuries of Financial Folly. Princeton University Press.

Rencher, A. C. (1992). Interpretation of canonical discriminant functions, canonical variates, and principal components. The American Statistician, 46(3):pp. 217-225.

Rodrik, D. (2006). Goodbye Washington Consensus, Hello Washington Confusion? A Review of the World Banks Economic Growth in the 1990s: Learning from a Decade of Reform. Journal of Economic Literature, XLIV:969-983.

Rodrik, D. (2008). One Economics, Many Recipes: globalization, institutions and economic growth. Princeton University Press.

Rodrik, D. (2009). Industrial policy: Don't ask why, ask how. Middle East Development Journal (MEDJ), 01(01):1-29.

Rodrik, D., Subramanian, A., and Trebbi, F. (2004). Institutions Rule: The Primacy of Institutions over Geography and Integration in Economic Development. Journal of Economic Growth, 9:131-165.

Rodrik, D. and Subramanian, S. (2005). From "Hindu Growt" to Productivity Surge: the mystery of the Indian growth transition. IMF Staff Papers, 52(2). 
Roodman, D. (2009a). How to do xtabond2: An introduction to difference and system GMM in stata. Stata Journal, 9(1):86-136.

Roodman, D. (2009b). A note on the theme of too many instruments. Oxford Bulletin of Economics and Statistics, 71(1):135-158.

Safavian, M. and Sharma, S. (2007). When do creditor rights work? Journal of Comparative Economics, 35:484-508.

Schamis, H. E. (2002). Re-forming the state: the politics of privatization in Latin America and Europe. University of Michigan Press.

Serven, L. (1998). Macroeconomic uncertainty and private investment in developing countries - an empirical investigation. Policy Research Working Paper Series 2035, The World Bank.

Serven, L. and Solimano, A. (1993). Debt crisis, adjustment policies and capital formation in developing countries: Where do we stand? World Development, 21(1):127-140.

Shiferaw, A. (2009). Which firms invest less under uncertainty? evidence from Ethiopian manufacturing. Courant Research Centre: Poverty, Equity and Growth - Discussion Papers 2, Courant Research Centre PEG.

Soete, L. (2007). From industrial to innovation policy. Journal of Industry, Competition and Trade, 7(3):273-284.

Spolaore, E., and Wacziarg, R. (2013). How Deep are the Roots of Economic Decelopment?. Journal of Economic Literature, 52(2):325-369.

Srholec, M. (2010). A multilevel approach to geography of innovation. Regional Studies, 44(9):1207-1220.

Stiglitz, J. E. (2008). The Washington Consensus Reconsidered: Towards a New Global Governance, chapter Is there a Post-Washinton Cosensus Consensus?, pages 41-60. Oxford University Press.

Svensson, J. (2000). Foreign aid and rent-seeking. Journal of International Economics, $51(2): 437-461$.

Szirmai, A. (2012). Proximate, intermediate and ultimate causality: Theories and experiences of growth and development. UNU-MERIT Working Paper 2012-032.

Tang, S., Selvanathan, E. A., and Selvanathan, S. (2008). Foreign direct investment, domestic investment and economic growth in China: A time series analysis. World Economy, 31(10):1292-1309.

Tchakoute-Tchuigoa, H. (2012). Active risk management and loan contract terms: Evidence from rated microfinance institutions.. The Quarterly Review of Economics and Finance, 52427-437. 
Teorell, J., Charron, N., Dahlberg, S., Holmberg, S., Rothstein, B., Sundin, P., and Svensson, R. (2013). The quality of government dataset. Technical report, University of Gothenburg: The Quality of Government Institute. version 15May13.

The World Bank Group. CPIA 2011 Criteria.

Titarenko, D. (2005). The influence of foreign direct investment on domestic investment processes in Latvia. MPRA Paper 18192, University Library of Munich, Germany.

Transparency International (2011). Corruption Perception Index. Technical report, (TI).

Tressel, T. and Detragiache, D. (2008). Do Financial Sector Reforms Lead to Financial Development? Evidence from a new dataset. IMF Working Paper 265.

Tribe, M. (2000). Industrial Development and Policy in Africa. Edward Elgar.

UNCTAD (2007). Model Law on Competition. Technical report, United Nations.

UNCTAD (2011). World Investment Report.

UNICEF (1987). Annual Report 1987.

Valila, T. (2006). No policy is an island - on the interaction between industrial and other policies. EIB Papers 7/2006, European Investment Bank, Economics Department.

Wade, R. H. (2009). Rethinking industrial policy for low income countries. African Development Review, 21(2):352-366.

Wade, R. H. (2012). Return of industrial policy? International Review of Applied Economics, 26(2):223-239.

Wei, S. (2001). Domestic crony capitalism and international fickle capital: Is there a connection? International Finance, 4(1):15-45.

Wei, S. and Wu, Y. (2002). Negative Alchemy? Corruption, Composition of Capital Flows, and Currency Crises., pages 461 - 501. NBER Conference Report series., IMF and Center for International Development, Harvard U.

Williamson, J. (2004). Practitioners of development. In The Washington Consensus as Policy Prescription for Development. World Bank.

Williamson, O. E. (1979). Transaction-Cost Econometrics: The Governance of Contractual Relations. Journal of Law and Economics, 22(2):233-261.

Williamson, O. E. (2000). The New Institutional Economics: Taking Stock, Looking Ahead. Journal of Economic Literature, XXXVIII:595-613.

Windmeijer, F. (2005). A finite sample correction for the variance of linear efficient two-step GMM estimators. Journal of Econometrics, 126(1):25-51. 
Wong, P. (2003). Competitiveness, FDI and technological Activity in East Asia, chapter From using to creating technology: The evolution of Singapore's national innovation system and the changing role of public policy, pages 191-238. Edward Elgar, Cheltenham.

Wooster, R. and Diebel, D. (2006). Productivity spillovers from foreign direct investment in developing countries: A metaregression analysis. Working paper available at SSRN.

World Bank (2011). World Development Indicators.

World Bank (2012). World Development Indicators.

World Economic Forum (2010). The Global Competitiveness Report 2010-2011. Switzerland.

Zhu T (2007) Institutional Change and Economic Development, chapter Rethinking import-substituting industrialization: Development strategies and institutions in Taiwan and China. UNU Press.

Zourek, H. (2007). The European Commissions new industrial policy in an integrating and globalizing world. Journal of Industry, Competition and Trade, 7(3):285-295. 


\section{Samenvatting}

In de empirische analyse van instituties en beleid als determinanten van langetermijn groei wordt men geconfronteerd met methodologische uitdagingen bij het schatten van het relatieve effect van verschillende groeifactoren. Dit proefschrift bundelt vier empirische studies die bijdragen aan de literatuur op dit gebied. In de essays onderzoeken wij het spanningsveld tussen enerzijds het ogenschijnlijk succes van neo-liberaal beleid en anderzijds het ogenschijnlijk succes van structuralistisch industrieel beleid in het stimuleren van economische ontwikkeling. De resultaten suggereren dat landen aspecten van neo-liberaal beleid en structuralistisch beleid hebben gecombineerd in hun groei politiek. In overeenstemming met het werk van Lin and Monga (2010) wordt voorgesteld dat beide aspecten van neo-liberaal beleid en structuralistisch beleid worden erkend als belangrijke groeifactoren.

Het eerste essay onderzoekt de relatie tussen instituties en financiële ontwikkeling. Op basis van een literatuurstudie van theorieën over de relatie tussen instituties en financiële ontwikkeling worden drie institutionele factoren geïdentificeerd: eigendomsrecht instituties, contractuele instituties, en concurrentie instituties. Met behulp van data van de Institutional Profiles Database worden 15 variabelen geïdentificeerd die overeenkomen met de bovengenoemde institutionele factoren. Vervolgens wordt principale componentenanalyse (PCA) toegepast om drie indicatoren te construeren die overeenkomen met de verschillende institutionele kenmerken. Volgens Hausman-Taylor schattingen met AmemiyaMaCurdy specificatie blijkt dat de drie institutionele indicatoren positief en significant gerelateerd zijn aan financiële ontwikkeling. In deze essay wordt financiële ontwikkeling gemeten als het niveau van de kredietverlening aan de particuliere sector. Het hierboven beschreven resultaat blijft significant wanneer wordt gecontroleerd voor het effect van financieel beleid.

De doelstelling van het tweede essay is het analyseren van de rol van industriebeleid in het stimuleren van groei. Indicatoren voor enerzijds 'pro-market' en anderzijds 'probusiness' beleid worden geconstrueerd met behulp van de taxonomie van economisch beleid ontwikkeld door Rodrik and Subramanian (2005) gebruik makende van een reeks variabelen van het IMD World Competitiveness Yearbook. Pro-market beleid is gericht op het vergroten van de concurrentie en markttoegang. Rodrik and Subramanian (2005) definiëren pro-business beleid als beleid dat de ontwikkeling van de bestaande industrie in de formele industriële commerciële sector ondersteunt. De twee indicatoren zijn positief gecorreleerd hetgeen suggereert dat er een positieve relatie is tussen het niveau van implementatie van deze twee verschillende typen beleid. Fixed effect schattingen suggereren dat 'pro-market' beleid geen duidelijk effect heeft op economische groei en het niveau van inkomen. Anderzijds geven de resultaten aan dat pro-business beleid positief gerelateerd is aan economische groei. Daarnaast wordt een derde indicator geconstrueerd die de intensiteit van innovatiebeleid en 
technologiebeleid meet. Deze indicator wordt geconstrueerd door middel van het aggregeren van een deel van de pro-business variabelen. Aanvullende schattingen suggereren dat het positieve effect van pro-business beleid op economische groei voor een groot deel kan worden toegeschreven aan innovatiebeleid en technologiebeleid.

Het derde essay onderzoekt het verdringingseffect van buitenlandse investeringen op het niveau van binnenlandse investeringen, het effect van instituties op het niveau van binnenlandse investeringen, en het interactie-effect van instituties op de relatie tussen buitenlandse en binnenlandse investeringen. Deze studie bouwt voort op de studie van Morrissey and Udomkerdmongkol (2012). Deze auteurs vinden een negatief effect van buitenlandse investeringen op binnenlandse investeringen, een positief effect van instituties op binnenlandse investeringen en een negatief effect van instituties op de relatie tussen buitenlandse investeringen en binnenlandse investeringen. Het negatieve bemiddelende effect wordt geïnterpreteerd als een bewijs voor de hypothese dat binnenlandse investeringen worden ontmoedigd in landen met een 'onvriendelijke overheid' tenzij investeerders een buitenlandse partner hebben. Wij zien deze hypothese als enigszins beperkt. Wij interpreteren het interactie-effect met behulp van theorie over technologie-overdrachten ('spillovers') en rentezoekend gedrag door de politieke elite. Het netto-effect hangt af van het relatieve belang van buitenlandse technologische overdrachten en van rentezoekend gedrag. De resultaten Morrissey and Udomkerdmongkol (2012) zijn erg gevoelig voor een verfijnde definitie van de afhankelijke variabele en alternatieve GMM specificaties. Wanneer, in tegenstelling tot de methode gebruikt door de auteurs, het niveau van buitenlandse investeringen niet wordt afgetrokken van het niveau van binnenlandse investeringen suggereren GMM schattingen dat de instroom van buitenlandse investeringen binnenlandse investeringen niet verdringen maar integendeel opdrijven. Bovendien worden de coëfficiënten van de variabelen minder significant met alternatieve GMM specificaties. GMM analyse toont aan dat er slechts een zwakke relatie bestaat tussen instituties en investeringen en dat er een negatief interactie-effect is van instituties op de relatie tussen de instroom van buitenlandse investeringen en binnenlandse investeringen. Dit negatieve effect wordt geinterpreteerd als een bewijs dat rentzoekend gedrag gunstig is voor buitenlandse investeerders maar ten koste gaat van binnenlandse investeringen. Dit resultaat suggereert ook dat dit effect groter is dan het effect van buitenlandse technologie-overdrachten op binnenlandse investeringen.

Het laatste empirische essay maakt gebruik van micro en macro data uit 101 ontwikkelingslanden en opkomende economieën om het effect van determinanten op zowel microniveau als macroniveau op investeringen te analyseren. Het onderzoek bevestigt dat bedrijven in ontwikkelingslanden in hoge mate niet investeren. In overeenstemming met voorgaand onderzoek interpreteren we dit fenomeen als een gevolg van de hoge onomkeerbaarheid van investeringen. Deze studie onderzoekt de determinanten van zowel de kans dat een bedrijf investeert als de grootte van gedane investeringen, gemeten in verhouding tot de totale omzet in het eerst voorafgaande fiscale jaar. De resultaten van een multi-level selectiemodel van het Heckmantype suggereren dat investeringsgedrag heterogeen is en dat macroniveau effecten op investeringsgedrag relatief beperkt zijn. Bedrijven die volledig in buitenlands bezit zijn investeren relatief minder vaak dan bedrijven die gedeeltelijk in buitenlands 
bezit zijn en dan bedrijven die volledig in binnenlands bezit zijn. Een mogelijke verklaring is dat buitenlandse ondernemingen actiever zijn in industrieën waar er op lange termijn minder wordt geïnvesteerd. Deze studie toont tevens aan dat bedrijven relatief vaker investeren in landen met een betere bescherming van eigendomsrechten en tegen corruptie. Ten slotte suggereren de resultaten dat er een positief interactieeffect is van een goede bescherming van eigendomsrechten en tegen corruptie op de relatie tussen buitenlands bezit en investeringen in verhouding tot omzet. 


\section{Biography}

Kristine Farla studied economics, international business, and public policy completing two master programmes at Maastricht University in 2008. She complemented her studies in Maastricht with course work and/or research at La Sapienza, Universidad IberoAmericana, and the Université Libre de Bruxelles. Since 2009 Kristine worked on a project launched by the French ministry and the Agence Française de Développement which funded her doctoral research at Maastricht University. As part of this collaboration she worked with the Institutional Profiles Database and wrote several technical and academic papers most of which have been collected in this dissertation. In 2012 she was a visiting fellow at the Australia National University for several months. Additionally, before and parallel to her doctoral research, Kristine worked on research projects for the Dutch government and the Asian Development Bank. 


\section{MGSoG Dissertation Series}

Marina Petrovic

Social Assistance and Activation in the Pursuit of Happiness: Shedding New Light on Old Policy Solutions to Social Exclusion

MGSoG Dissertation Series, nr 37 (2013)

Laura Torvinen

Assessing Governance Assessments; The Case of Mozambique: Governance Assessments in the Context of Aid Effectiveness Discourse

MGSoG Dissertation Series, nr 36 (2013)

Biniam Egu Bedasso

Institutional Change in the Long Shadow of Elites: Essays on Institutions, Human Capital and Ethnicity in Developing Countries

MGSoG Dissertation Series, nr 35 (2013)

Sepideh Yousefzadeh Faal Deghati

Childhoods Embargoed: Constructing and Reconstructing Multidimensional Child Poverty in Iran 1984-2009

MGSoG Dissertation Series, nr 34 (2013)

Robert Bauchmüller

Investing in Early Childhood Care and Education: The Impact of Quality on Inequality

MGSoG Dissertation Series, nr 33 (2013)

Martin Rehm

Unified Yet Separated: Empirical Study on the Impact of Hierarchical Positions within Communities of Learning

MGSoG Dissertation Series, nr 32 (2013)

Dorcas Mbuvi

Utility Reforms and Performance of the Urban Water Sector in Africa

MGSoG Dissertation Series, nr 31 (2012)

Lina Salanauskaite

Distributional Impacts of Public Policies: Essays in Ex-Ante and Ex-Post Evaluation

MGSoG Dissertation Series, nr 30 (2012) 
Esther Schüring

To Condition or not - is that the Question? An Analysis of the Effectiveness of Ex-Ante and Ex-Post Conditionality in Social Cash Transfer Programs

MGSoG Dissertation Series, nr 29 (2012)

Joe Abah

Strong Organisations in Weak States: Atypical Public Sector Performance in Dysfunctional Environments

MGSoG Dissertation Series, nr 28 (2012)

Zina Samih Nimeh

Social Citizenship Rights: Inequality and Exclusion

MGSoG Dissertation Series, nr 27 (2012)

Lenka Eisenhamerová

Legitimacy of Humanitarian Military Intervention

MGSoG Dissertation Series, nr 26 (2011)

Sonila Tomini

Informal Payments for Health Care Services in Albania

MGSoG Dissertation Series, nr 25 (2011)

Jinjing Li

Dynamic Microsimulation in Public Policy Evaluation

MGSoG Dissertation Series, nr 24 (2011)

Aziz Atamanov

Rural Nonfarm Employment and International Migration as Alternatives to Agricultural Employment: The Case of Kyrgyztan

MGSoG Dissertation Series, nr 23 (2011)

Frieda Vandeninden

Poverty Alleviation: Aid and Social Pensions

MGSoG Dissertation Series, nr 22 (2011)

Juliana Nyasha Tirivayi

The Welfare Effects of Integrating AIDS Treatment with Food Transfers: Evidence from Zambia

MGSoG Dissertation Series, nr 21 (2011)

Agnieska Ewa Sowa

Who's Left Behind? Social Dimensions of Health Transition and Utilization of Medical Care in Poland

MGSoG Dissertation Series, nr 20 (2011) 
Emmanaouil Sfakianakis

The Role of Private Actors in the Provision of Public Goods with Applications to Infrastructure and Financial Stability

MGSoG Dissertation Series, nr 19 (2011)

Siu Hing Lo

White Collars Green Sleeves: An Interonganizational Comparison of Deteminants of Energy-Related Behaviors among Office Workers

MGSoG Dissertation Series, nr 18 (2011)

Treena $\mathrm{Wu}$

Constraints to Human Capital Investment in Developing Countries: Using the Asian Financial Crisis in Indonesia as a Natural Experiment

MGSoG Dissertation Series, nr 17 (2011)

Henry Espinoza Peña

Impact Evaluation of a Job-Training Programme for Disadvantaged Youths: The Case of Projoven

MGSoG Dissertation Series, nr 16 (2011)

Florian Tomini

Between Family and Friends: Understanding the Interdependency of Private Transfers

MGSoG Dissertation Series, nr 15 (2010)

Michał Polalowski

The Institutional Transformation of Social Policy in East Central Europe: Poland and Hungary in comparative and historical perspective

MGSoG Dissertation Series, nr 14 (2010)

Maha Ahmed

Defining, Measuring and Adressing Vulnerability: The Case of Post Conflict Environments

MGSoG Dissertation Series, nr 13 (2010)

Pascal Beckers

Local Space and Economic Success: The role of spatial segregation of migrants in the Netherlands

MGSoG Dissertation Series, nr 12 (2010)

Victor Cebotari

Complicting Demands in Ethnically Diverse Societies Ethnopolitical Contention and Identity Values in Europe

MGSoG Dissertation Series, nr 11 (2010) 
Dennis Gyllensporre

Competing and Complementary Perspectives on the EU as a Crisis Management Actor: An Examination of the Common Security and Defence Policy through the Lenses of Idealism and Realism

MGSoG Dissertation Series, nr 10 (2010)

Judit Vall Castello

Business Cycle and Policy Effects on Labour Market Transitions of Older and Disabled Workers in Spain

MGSoG Dissertation Series, nr 9 (2010)

Keetie Roelen

False Positives or Hidden Dimentions: the definition and measurement of child poverty

MGSoG Dissertation Series, nr 8 (2010)

Denisa Maria Sologon

Earning Dynamics in Europe

MGSoG Dissertation Series, nr 7 (2010)

Melissa Siegel

Money and Mobility: Migration and Remittances

MGSoG Dissertation Series, nr 6 (2010)

Jessica S. Hagen-Zanker

Modest Expectations: Causes and effects of migration on migrant households in source countries

MGSoG Dissertation Series, nr 5 (2010)

Mirtha R. Muniz Castillo

Human Development and Autonomy in Project Aid: Experiences from four bilateral projects in Nigaragua and El Salvador

MGSoG Dissertation Series, nr 4 (2009)

Christiane Arndt

Governance Indicators

MGSoG Dissertation Series, nr 3 (2009)

Britta Augsburg

Microfinance - Greater Good or Lesser Evil?

MGSoG Dissertation Series, nr 2 (2009)

Geranda Notten

Measuring and Managing Poverty Risks

MGSoG Dissertation Series, nr 1 (2008) 